\title{
Instrument Installation and Preliminary Data in a Full-Scale Anaerobic Bioreactor Landfill, Sainte-Sophie, Quebec, Canada
}

\author{
by

\section{Emily Vingerhoeds} \\ B.Eng, Environmental Engineering, Carleton University, 2009
}

A thesis submitted to the Faculty of Graduate Studies and Postdoctoral Affairs in partial fulfillment of requirements for the degree of

Master of Applied Science

in

Environmental Engineering

The Ottawa-Carleton Institute for Environmental Engineering (OCIENE)

Carleton University

Ottawa, Ontario, Canada

CEmily Vingerhoeds, 2011 
Library and Archives

Canada

Published Heritage
Branch

395 Wellington Street

Ottawa ON K1A ON4

Canada
Bibliothèque et

Archives Canada

Direction du

Patrimoine de l'édition

395 , rue Wellington

Ottawa ON K1A ON4

Canada
Your file Votre référence
ISBN: 978-0-494-83206-6
Our file Notre référence
ISBN: $978-0-494-83206-6$
NOTICE:

The author has granted a nonexclusive license allowing Library and Archives Canada to reproduce, publish, archive, preserve, conserve, communicate to the public by telecommunication or on the Internet, loan, distribute and sell theses worldwide, for commercial or noncommercial purposes, in microform, paper, electronic and/or any other formats.

The author retains copyright ownership and moral rights in this thesis. Neither the thesis nor substantial extracts from it may be printed or otherwise reproduced without the author's permission.
AVIS:

L'auteur a accordé une licence non exclusive permettant à la Bibliothèque et Archives Canada de reproduire, publier, archiver, sauvegarder, conserver, transmettre au public par télécommunication ou par l'Internet, prêter, distribuer et vendre des thèses partout dans le monde, à des fins commerciales ou autres, sur support microforme, papier, électronique et/ou autres formats.

L'auteur conserve la propriété du droit d'auteur et des droits moraux qui protège cette thèse. $\mathrm{Ni}$ la thèse ni des extraits substantiels de celle-ci ne doivent être imprimés ou autrement reproduits sans son autorisation.
In compliance with the Canadian Privacy Act some supporting forms may have been removed from this thesis.

While these forms may be included in the document page count, their removal does not represent any loss of content from the thesis.
Conformément à la loi canadienne sur la protection de la vie privée, quelques formulaires secondaires ont été enlevés de cette thèse.

Bien que ces formulaires aient inclus dans la pagination, il n'y aura aucun contenu manquant.

\section{Canadä}




\begin{abstract}
The bioreactor landfill promotes rapid waste stabilization through optimizing microbiological processes. In turn, the enhanced biodegradation increases the production of landfill gas that can be used in energy applications and promotes waste settlement maximizing usable air space. However, cold temperatures constrain the optimization of waste stabilization in bioreactor landfills in northern climates.
\end{abstract}

The objective of this thesis was to monitor various in-situ parameters, climatic conditions, and operating practices to develop a clearer understanding of the waste stabilization process in a full-scale bioreactor landfill in northern climates. In-situ temperatures, total load, settlement, moisture content, electrical conductivity, and oxygen content were measured every 30 minutes, over 1.3 years. Multiple factors were found to affect the feasibility of the bioreactor landfill thus far. Waste temperature and waste placement practices were responsible for delaying the onset of biodegradation. Observed settlement was mainly attributed to compaction rather than biodegradation due to the frozen waste temperature. 


\section{Acknowledgements}

Thank you to Waste Management of Canada for their interest and support which contributed to the success of this project. Special thanks to Simon Mercier and Benoit Marsolais of the Sainte-Sophie landfill site for their continuous support.

Thank you to Ontario Centres of Excellence (OCE) who provided financial support for this research, and showed interest in the results.

I would like to thank my supervisors, Paul Van Geel and Claire Samson, for their advice, support, and help in field work throughout this project.

Thank you to our consulting group partners for their interest and feedback on the project, including Golder Associates, WESA, AECOM, Jagger Hims, Genivar, and Alston \& Associates. Thanks also to Hoskin Scientific, RST Instruments, Decagon, and Apogee, who not only supplied instruments but provided valuable technical support throughout the duration of the project.

Thank you to all the students who enjoyed a hard work day at the landfill during multiple instrument installations, specifically Jamie Bonany.

To Timothy Hopkins, Elizabeth and Michael Vingerhoeds, Agatha Schrama, and the rest of my family, a big thank you goes out to you all for your continuous care and unconditional love throughout this process. 


\section{Table of Contents}

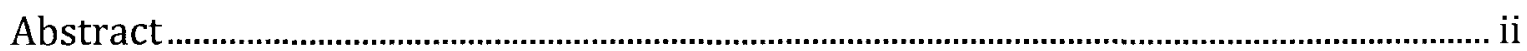

Acknowledgements …….................................................................................................... ii

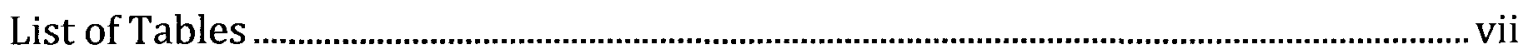

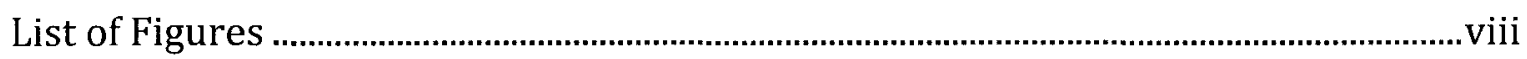

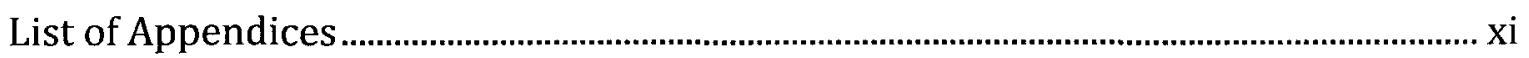

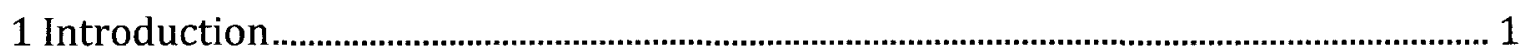

1.1 Problem Statement.................................................................................................... 1

1.2 Research Objectives ................................................................................................... 4

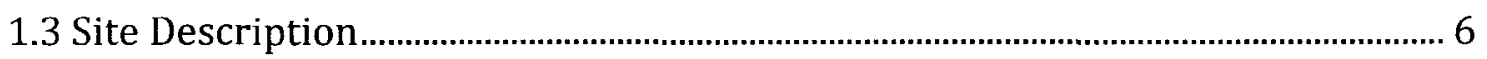

2 Literature Review and Background Theory …………………………………………...

2.1 Advantages of Bioreactor Landfills …….......................................................................10

2.2 Design of Bioreactor Landfills .......................................................................................11

2.2.1 Liner and Leachate Collection Systems.............................................................13

2.2.2 Leachate Recirculation ......................................................................................13

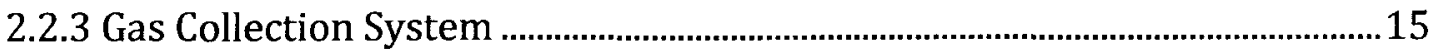

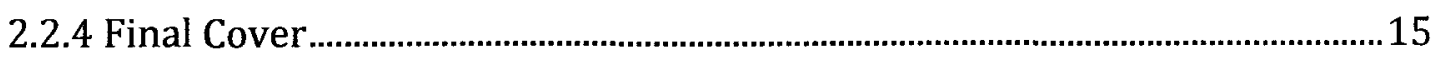

2.3 Operation of Bioreactor Landfills ..........................................................................16

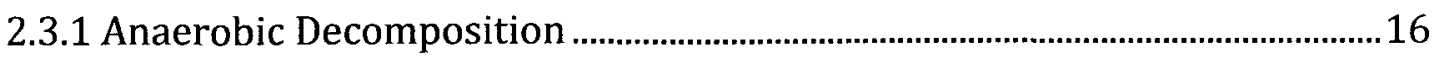


2.3.4 Settlement

2.4.1 Florida Bioreactor Demonstration Project, Union County, Florida.

2.4.2 Anchorage Regional Landfill, Anchorage, Alaska 25

2.4.3 Northern Oaks Recycling and Disposal Facility, Harrison, Michigan ...........25

2.4.4 Yolo County Bioreactor Landfill Project, Davis, California ................................26

2.5 Global Positioning System (GPS) ................................................................................2

2.5.1 Real-Time Kinematic with Differential GPS (RTK-DGPS) …….........................27

2.5.2 Use of GPS in Bioreactor Landfills ......................................................................29

3 Initial Testing in Lab-Scale Bioreactor Landfill..................................................................

4 Instrument Bundle Installation in Full-Scale Bioreactor Landfill...................................33

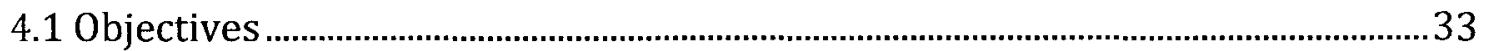

4.2 Instrument Bundle Equipment.....................................................................................

4.2.1 Settlement System ................................................................................................34

4.2.2 Total Earth Pressure Cell ...........................................................................................36

4.2.3 Piezometer................................................................................................................

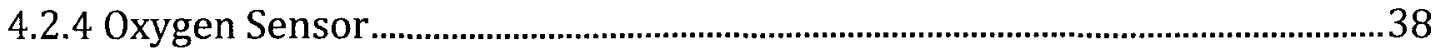

4.2.5 Moisture and Electrical Conductivity Sensor.......................................................39 
4.3 Data Acquisition System and Data Collection Software

4.4 Installation Methodology

4.4.1 Layer 1 - Instrument Bundles 1 and 2 Installation

4.4.2 Layer 2 - Instrument Bundles 3 and 4 Installation. 45

4.4.3 Layer 3 - Instrument Bundles 5 and 6 Installation 46

4.4.4 Layer 4 - Instrument Bundles 7 and 8 Installation 47

4.5 Instrument Bundle Results 49

4.5.1 Temperature Probes. 50

4.5.2 Total Earth Pressure Cell .66

4.5.3 Liquid Settlement System. .82

4.5.4 Moisture and Electrical Conductivity Sensor .98

4.5.5 Oxygen Sensor. 118

4.5.6 Vibrating Wire Piezometer 129

5 Conclusions and Recommendations 132

References... 135

Appendices. 


\section{List of Tables}

Table 1: Advantages and disadvantages of horizontal and vertical leachate recirculation systems (modified from Reinhart \& Townsend 1998)...............................14 Table 2: Influencing factors of MSW settlement (modified from Warith et al. 2005).

Table 3: Schedule of Instrument Bundle Installation in Field and Connection to Datalogger 49

Table 4: Accuracy of Settlement System for Bundles 1-8 .83

Table 5: Percentage of settlement for waste layer between each bundle over study period. 97 


\section{List of Figures}

Figure 1: View of the Sainte-Sophie Zone 4 bioreactor landfill (modified from Genivar 2008).

Figure 2: Typical configuration of an anaerobic bioreactor (With permission from

Waste Management 2004). 12

Figure 3: Schematic of RTK-DGPS surveying.................................................................28

Figure 4: Use of a repeater station in RTK-DGPS.

Figure 5: Vibrating wire pressure sensor mounted on steel plate....................................35

Figure 6: 10psi accumulator, with liquid-filled tubes from Bundles 1 and 2 attached via quick-connect ports. 36

Figure 7: Weighted accumulator, with liquid-filled tubes from Bundles 7 and 8 attached via quick-connect ports. 36

Figure 8: Total earth pressure cell mounted on steel plate. 37

Figure 9: Vibrating wire piezometer with external housing filter. 38

Figure 10: 0xygen sensor (on right) with diffusion mesh head (on left). .39

Figure 11: Moisture and electrical conductivity sensor. 40

Figure 12: Cross-section of bioreactor landfill with instrument bundle placement and elevations (not to scale). 43

Figure 13: Temperature from 4 Instruments in Bundle 1................................................51

Figure 14: Temperature from 4 Instruments in Bundle 2 ...................................................52

Figure 15: Temperature from 4 Instruments in Bundle 3.................................................52

Figure 16: Temperature from 4 Instruments in Bundle 4…………………………….....53

Figure 17: Temperature from 3 Instruments in Bundle 5 .................................................53 
Figure 18: Temperature from 3 Instruments in Bundle 6................................................54

Figure 19: Temperature from 3 Instruments in Bundle 7 ................................................54

Figure 20: Temperature from 3 Instruments in Bundle 8...............................................55

Figure 21: Average Temperature of Bundles 1-8............................................................57

Figure 22: Temperature profile of waste in bioreactor landfill from Column 1..........61

Figure 23: Temperature profile of waste in bioreactor landfill from Column 2..........63

Figure 24: General time frame of waste placement in the bioreactor landfill..............64

Figure 25: TEPC pressure versus time for Bundles 1-8. ……………..................................67

Figure 26: TEPC pressure versus time for Bundles 1-2 ....................................................71

Figure 27: TEPC pressures versus time for Bundles 3-4. ....................................................

Figure 28: TEPC pressures versus time for Bundles 5-6....................................................75

Figure 29: TEPC pressures versus time for Bundles 7-8 .....................................................77

Figure 30: TEPC pressure for Bundles 1-6 during loading test 1 on July 22, 2010...79

Figure 31: Instrument bundle elevation versus time........................................................... 84

Figure 32: Instrument bundle settlement versus time........................................................85

Figure 33: Settlement of Bundles 1 and 2 compared with pressures from TEPC.......88

Figure 34: Settlement of Bundles 3 and 4 compared with pressures from TEPC.......91

Figure 35: Settlement of Bundles 5 and 6 compared with pressures from TEPC.......94

Figure 36: Settlement of Bundles 7 and 8 compared with pressures from TEPC.......96

Figure 37: VWC for Bundles 1-8 in relation to precipitation. ......................................... 100

Figure 38: VWC of Bundles 1-2 in relation to temperature............................................ 103

Figure 39: VWC of Bundles 1-2 in relation to EC. …….................................................... 104

Figure 40: VWC of Bundles 3-4 in relation to temperature............................................. 107 
Figure 41: VWC of Bundles 3-4 in relation to EC ........................................................... 108

Figure 42: VWC of Bundles 5-6 in relation to temperature.......................................... 111

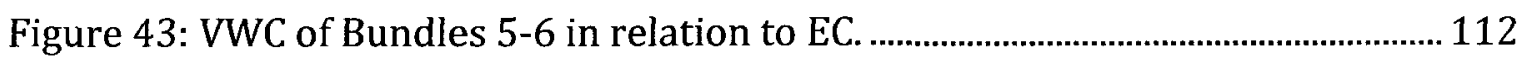

Figure 44: VWC for Bundles 5-6 comparison of lab and field data................................ 113

Figure 45: VWC of Bundles 7-8 in relation to temperature........................................... 115

Figure 46: VWC of Bundles 7-8 in relation to EC. ……..................................................... 116

Figure 47: Oxygen Content for Bundles 1-8............................................................... 120

Figure 48: Oxygen Content for Bundles 1-2 in Relation to Temperature. ...................122

Figure 49: Oxygen Content for Bundles 3-4 in Relation to Temperature.................... 124

Figure 50: Oxygen Content for Bundles 5-6 in Relation to Temperature.................... 126

Figure 51: Oxygen Content for Bundles 7-8 in Relation to Temperature. ................... 128

Figure 52: Piezometer pressures for Bundles 1-4......................................................... 131 


\section{List of Appendices}

Appendix A - Instrument Specifications ............................................................................. 139

Appendix B - Data Acquisition System Specifications and Sample Datalogger

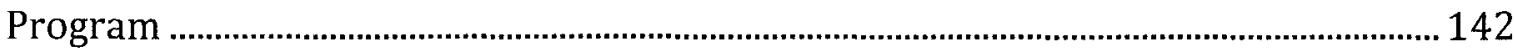

Appendix C - Supplemental Figures from Installation...................................................... 155

Appendix D - Calibration Details and Example Calculation for Total Earth Pressure

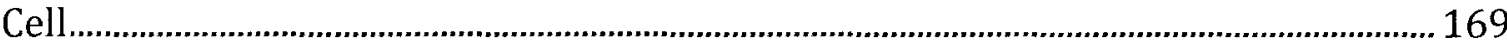

Appendix E - Calibration Details and Example Calculation for Liquid Settlement

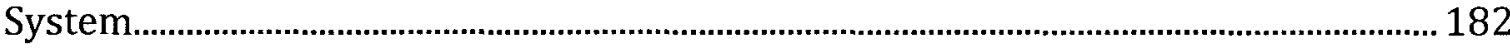

Appendix F - Conversion of Raw Counts to Final Values for VWC ................................ 204

Appendix G - Moisture Content and Sensor Tests ............................................................. 207

Appendix H - Calibration Details and Example Calculation for Oxygen Sensor......... 211

Appendix I - Calibration Details and Example Calculation for Vibrating Wire

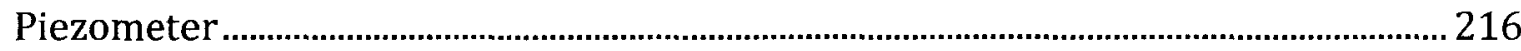




\section{Introduction}

\subsection{Problem Statement}

The generation of municipal solid waste (MSW) has increased globally due to population growth and escalating consumerism. An integrated waste management approach, including source reduction, recycling, composting, incineration, and landfilling, has been promoted in North America to cope with the increasing volume of MSW (Pichtel 2005). Despite large volumes of MSW being diverted from landfills through the integrated waste management approach, landfilling remains the predominant MSW disposal option (Warith et al. 2005). Conventional landfills tend to follow either the low-infiltration approach or the moderate-infiltration approach. The low-infiltration approach limits leachate generation to reduce groundwater contamination risk. The moderate-infiltration approach promotes accelerated waste biodegradation to reach a biologically stable state such that the contaminating lifespan of the landfill is reduced (Rowe et al. 1995, Benson et al. 2007). The lowinfiltration approach is supported through United States Subtitle D landfill principles, while the moderate-infiltration approach is supported by the Ontario Regulation 232/98 landfill standards guideline (Rowe et al. 1995, MOE 2010).

Restricted moisture in conventional landfills limits MSW biodegradation and results in poorly stabilized waste. The poorly stabilized waste can continue to be a source of contaminating leachate and gas generation for well past the life of the engineered components of the landfill (Benson et al. 2007, Reinhart et al. 2002). Alternatively, 
the bioreactor landfill is capable of shortening the contaminating lifespan of a landfill due to enhanced methods for waste stabilization. As such, the bioreactor landfill is a more sustainable method of managing MSW over conventional landfilling.

The design and controlled operation of a bioreactor landfill promotes optimal microbiological processes so the organic portion of MSW can rapidly degrade and stabilize (Sharma \& Reddy 2004). The bioreactor landfill minimizes environmental impacts associated with waste disposal, as it stabilizes waste within five to ten years following closure, as opposed to many decades to a century for conventional landfills (Reinhart \& Townsend 1998, Pichtel 2005). Biodegradation is promoted in a bioreactor landfill with microbiological activity stimulated by moisture addition, usually through leachate recirculation. As the organic constituents of the waste biodegrade in the process of becoming stable, the enhanced biodegradation process provides advantages such as increased landfill gas production (which can be recovered and transformed to energy), enhanced waste settlement (which maximizes usable air space and limits the creation of additional landfill footprint), and lower leachate costs (due to leachate treatment via recirculation through the landfill) (Benson et al. 2007).

Various conditions and operating practices affect the optimization of the physical, chemical, and biological processes of the bioreactor landfill. Bioreactor landfills can be operated either anaerobically, aerobically, or as a combination of both approaches. Anaerobic bioreactor landfills promote methane generation as a result 
of minimizing oxygen infiltration to the system such that anaerobic biodegradation can take place. Aerobic bioreactor landfills involve injecting air into the waste to promote stabilization through aerobic activity, while limiting methane generation (Sharma \& Reddy 2004, Lefebvre et al. 2000). Apart from adding moisture to the waste, biosolids addition, temperature control, nutrient supplementation, buffers, and leachate pre-treatment are further control and process optimization methods for an anaerobic bioreactor landfill (Warith 2005, Reinhart 2002, Valencia et al. 2009).

Site-specific environmental stresses, such as cold temperatures, add additional constraints to optimal process control of the bioreactor landfill. Yet, despite the advantages of bioreactor landfills and ongoing research in the past several decades, knowledge of optimal process control for the full-scale bioreactor landfill is still limited (Komilis et al. 1999). Lab-scale and pilot-scale research has proven the viability of bioreactor landfills based on leachate recirculation (Reinhart et al. 2002). More specifically, the lab-scale and pilot-scale research has shown that waste degradation, in-situ treatment of leachate, enhanced gas production, and rapid settlement can occur in bioreactor landfills (Reinhart \& Townsend, 1998). However, conclusions drawn from lab-scale and pilot-scale experimentation have not been directly applicable to full-scale bioreactor landfills, due to varying conditions experienced in the field. Several case studies have determined that waste settlement is larger and occurs faster in bioreactor landfills rather than conventional landfills, due to the enhanced moisture content (Benson et al. 2007). Most of the research involving full-scale bioreactor landfills has therefore focused on monitoring and 
optimizing moisture levels; however, due to the heterogeneity of the waste, even moisture distribution is difficult to achieve (Gawande et al. 2003). Methods of monitoring moisture content in-situ have been researched for full-scale bioreactor landfills, yet many methods are far from practical or accurate (Catley et al. 2008, Imhoff et al. 2007, Gawande et al. 2003). Elagroudy et al. (2008) has suggested that the overall settlement observed in landfills can be defined by three stages of settlement; initial compression, primary compression, and secondary compression. However, in-situ settlement measurements, which would aid in differentiating the amount of settlement attributed to each settlement stage, have not been the focus of bioreactor landfill case studies (Benson et al. 2007).

\subsection{Research Objectives}

This thesis covers the first two years of a projected three-year research project. The overall objective of the three-year research project is to develop a better understanding of how operating practices and environmental conditions at a northern climate bioreactor landfill impact waste stabilization, in order to optimize landfill gas production and usable air space. The overall research project involves the installation of various instruments to monitor in-situ waste parameters within a bioreactor landfill cell as it is progressively filled with waste, a weather station to monitor climatic conditions around the site, and a global positioning system (GPS) mounted to sheepsfoot compactors to monitor waste placement and compaction practices in the landfill. The on-site weather station will record various 
environmental conditions at the landfill including temperature, humidity, precipitation, wind speed and direction, and barometric pressure. The GPS system will be used to evaluate the operating practices at the site, with lift thickness, number of passes per lift, and compaction for each pass being determined. The onsite weather station and GPS system were not fully operational during the study period; therefore, the anticipated information from these could not be linked to the in-situ instrument data at the time of writing this thesis. In place of the on-site weather station data, barometric pressure and precipitation were obtained from the closest Environment Canada weather station at the Pierre Elliot Trudeau International Airport, Montreal, Quebec (45.46692N, 73.75020W).

This thesis, which covers the first two years of the overall research project, describes the installation of the instruments within the bioreactor landfill and provides as analysis of the preliminary data collected by those instruments. The preliminary data provided an initial understanding of the feasibility of operating a bioreactor landfill in northern climates. Collectively, the instruments used to monitor in-situ parameters within the bioreactor landfill were termed an instrument bundle, and included a range of sensors to measure in-situ temperatures, total load, settlement, moisture content, electrical conductivity, oxygen content of the air space, and mounding of leachate. A central data acquisition system, located outside of the landfill, stored data collected from each instrument bundle, and was remotely accessed to retrieve data in real-time. 
Therefore, the research objectives of this project included installing instrument bundles in different waste layers as the bioreactor landfill was filled with waste, monitoring in-situ waste parameters which indicated the degree of waste biodegradation, and analyzing the preliminary data to develop an understanding of the feasibility of the bioreactor in northern climates, in order to develop methods how to enhance waste biodegradation and optimized waste stabilization in the future. The future work required to continue the overall project is outlined in the conclusions.

\subsection{Site Description}

The Sainte-Sophie gas-to-energy facility $(45.7794 \mathrm{~N}, 73.9061 \mathrm{~W})$ is located approximately $50 \mathrm{~km}$ northwest of Montreal, Quebec near the village of SainteSophie. It is operated by Waste Management of Canada Corporation (WM). Three landfills on-site contribute methane gas to the energy facility. Older conventional landfills were retrofitted with gas collection pipes for the collection of methane gas. A landfill was designed and built specifically as an anaerobic bioreactor and was filled between 2000 and 2005. This was the first large-scale bioreactor landfill in Canada.

The newest bioreactor landfill, known as Zone 4, is capable of receiving close to one million tonnes of waste per year, over a footprint of approximately $475 \mathrm{~m}$ wide by $650 \mathrm{~m}$ long by $25 \mathrm{~m}$ deep. Figure 1 displays an elevated view of the Zone 4 bioreactor landfill with delineation of the three filling phases. Phase 1 was already full at the beginning of the study and final cover was placed during the study. Phase 2 was 
close to being full at the beginning of the study and continued to be filled intermittently over the first eight months of the study. Phase 3 started empty and was progressively being filled with waste in coordination with the study. Further expansion to the immediate south-east of the bioreactor landfill was under development during the time of the study.

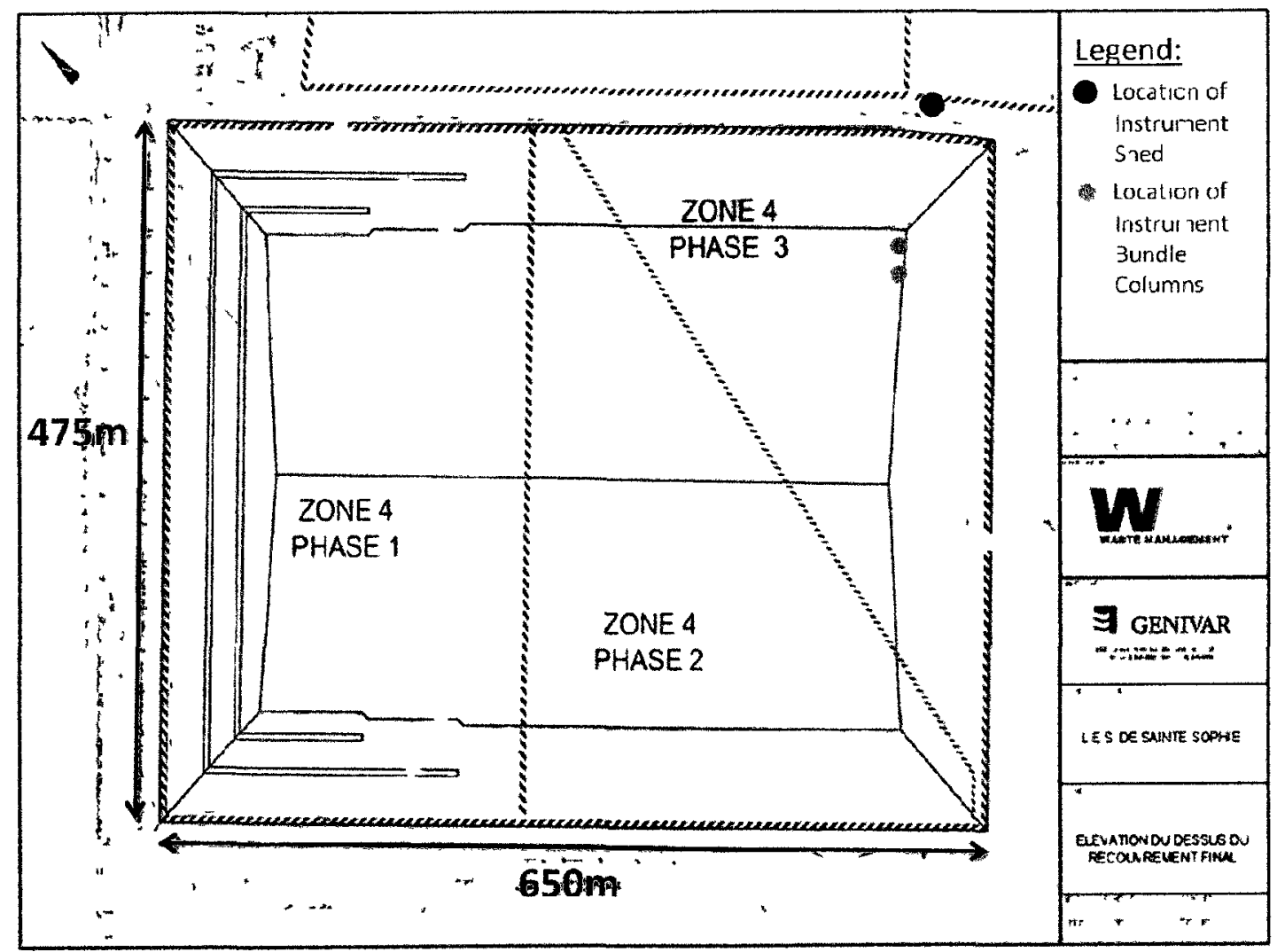

Figure 1: View of the Sainte-Sophie Zone 4 bioreactor landfill (modified from Genivar 2008).

In the Zone 4 bioreactor landfill, waste is contained by a double-composite engineered liner system. The upper drainage layer consists of a leachate collection system, while the lower drainage layer is the leak detection system. The primary header leachate collection pipe in the upper layer was constructed from perforated 
dr-11 high-density polyethylene (HDPE) of diameter $200 \mathrm{~mm}$. Both the secondary header leachate collection pipe in the upper layer and the primary header leak detection pipe in the lower layer were constructed from perforated dr-11 HDPE of diameter $150 \mathrm{~mm}$. The bioreactor was designed to accommodate four levels of horizontally-placed biogas collection pipes, which are being added as the landfill is filled with waste. Both the older landfills and the Zone 4 bioreactor landfill contribute to the production of over 70 million cubic metres of landfill gas annually ( $9000 \mathrm{~m}^{3}$ hourly). A $13 \mathrm{~km}$-long Gaz Métro pipeline delivers landfill gas from the Sainte-Sophie facility to the Cascades Inc. pulp and paper mill in Saint-Jérôme, Quebec, covering the entire energy needs of the mill. Additional landfill gas is flared on-site.

The instrumentation for this study was installed in Phase 3 of the Zone 4 bioreactor landfill. An instrument shed was erected on the north-east side of the landfill to house the data cable connections to the data acquisition system, as well as to provide power to the instruments. The locations of the instrument shed and the two columns of instrument bundles are shown in Figure 1.

Filling of the empty cell of Phase 3 in the Zone 4 bioreactor began in October 2009 with a $1 \mathrm{~m}$ waste "fluff" layer. The fluff layer was placed with minimal compaction, to act as a protective layer above the gravel layer making up the leachate collection system. Subsequent waste placement occurred in layers, known as waste "lifts", with average thickness of $3-4 \mathrm{~m}$. These lifts were constructed as a series of waste layers 0.3-0.5m in thickness each compacted via sheepsfoot compactors. Waste placement 
occurred continuously throughout the year, resulting in frozen waste lifts being placed during winter and warmer waste lifts being placed in summer. 


\section{Literature Review and Background Theory}

\subsection{Advantages of Bioreactor Landfills}

The bioreactor landfill is emerging as a viable approach to managing MSW in comparison to conventional landfilling, as the optimization of microbiological processes results in rapid stabilization (Warith 2002, Sharma \& Reddy 2004). Advantages of bioreactor landfills over conventional landfills include increased gas production, enhanced waste settlement, the possibility of reduced leachate treatment costs, and reduced long-term environmental risk.

Increased landfill gas production is the result of rapid decomposition of MSW over a shorter than usual length of time (Benson et al. 2007, Reinhart \& Townsend 1998). As methane generation rates are generally $200-250 \%$ greater than in conventional landfills, the quantity of gas produced makes gas-to-energy options economically feasible (Pichtel 2005, Benson et al. 2007). The gas collection system captures landfill gas in a controlled manner, reducing the release of greenhouse gases to the atmosphere (Warith 2002, Sharma \& Reddy 2004).

Enhanced waste settlement is also the result of rapid decomposition of MSW and contributes to maximizing landfill airspace. By freeing up landfill airspace, more waste can be placed in the prescribed landfill volume before closure (Benson et al. 2007, Pichtel 2005). Optimizing the use of landfill airspace extends the lifetime of landfills, diminishing the need for construction of additional landfills and ultimately

reducing the land footprint of waste disposal (Sharma \& Reddy 2004). 
Correspondingly, landfilling costs are reduced, as landfills are capable of receiving more waste per unit volume (Warith 2002).

Bioreactor landfills can provide the possibility of reduced leachate treatment costs, if leachate is recirculated through the waste. Leachate recirculation is beneficial not only as it raises moisture content leading to improved waste biodegradation, but also as it provides treatment and storage of the leachate during bioreactor landfill operation. As the recirculated leachate slowly filters through the waste, costs previously associated with treating and storing leachate outside of the landfill are reduced (Sharma \& Reddy 2004, Pichtel 2005).

Reduced long-term environmental risk is also an advantage of a bioreactor landfill. Due to the rapid stabilization of the MSW, contaminant concentrations decrease significantly during the operating lifetime of the bioreactor landfill (Warith 2002). The contaminating lifespan of the bioreactor landfill declines as contaminant concentrations decrease, thereby minimizing any long-term environmental dangers linked with the failure of the engineered components of the landfill (Reinhart \& AlYousfi 1996). Post-closure maintenance costs are also reduced as MSW stabilization occurs mainly during the operating lifetime of the bioreactor landfill, providing a more stable landfill at closure (Sharma \& Reddy 2004).

\subsection{Design of Bioreactor Landfills}

Similar components, viz. liner, leachate collection system, gas collection system, and final cover, of conventional landfills are found in the design of the bioreactor landfill, as both waste disposal systems are governed by similar regulations in North 
America (Reinhart \& Townsend 1998). However, these same components function differently in bioreactor landfills as more leachate and gas must be handled, and leachate recirculation may be incorporated (Sharma \& Reddy 2004). A schematic of a typical configuration of an anaerobic bioreactor is presented in Figure 2 (Waste Management 2004). This schematic shows the use of vertical leachate recirculation pipes to distribute moisture to the MSW in the bioreactor landfill. In addition, gas collection pipes withdraw landfill gas which is then converted to energy and placed on the energy grid for use. Although the figure shows vertical gas collection and leachate/liquids addition pipes, both pipe systems can be installed vertically in the landfill as the waste is placed.

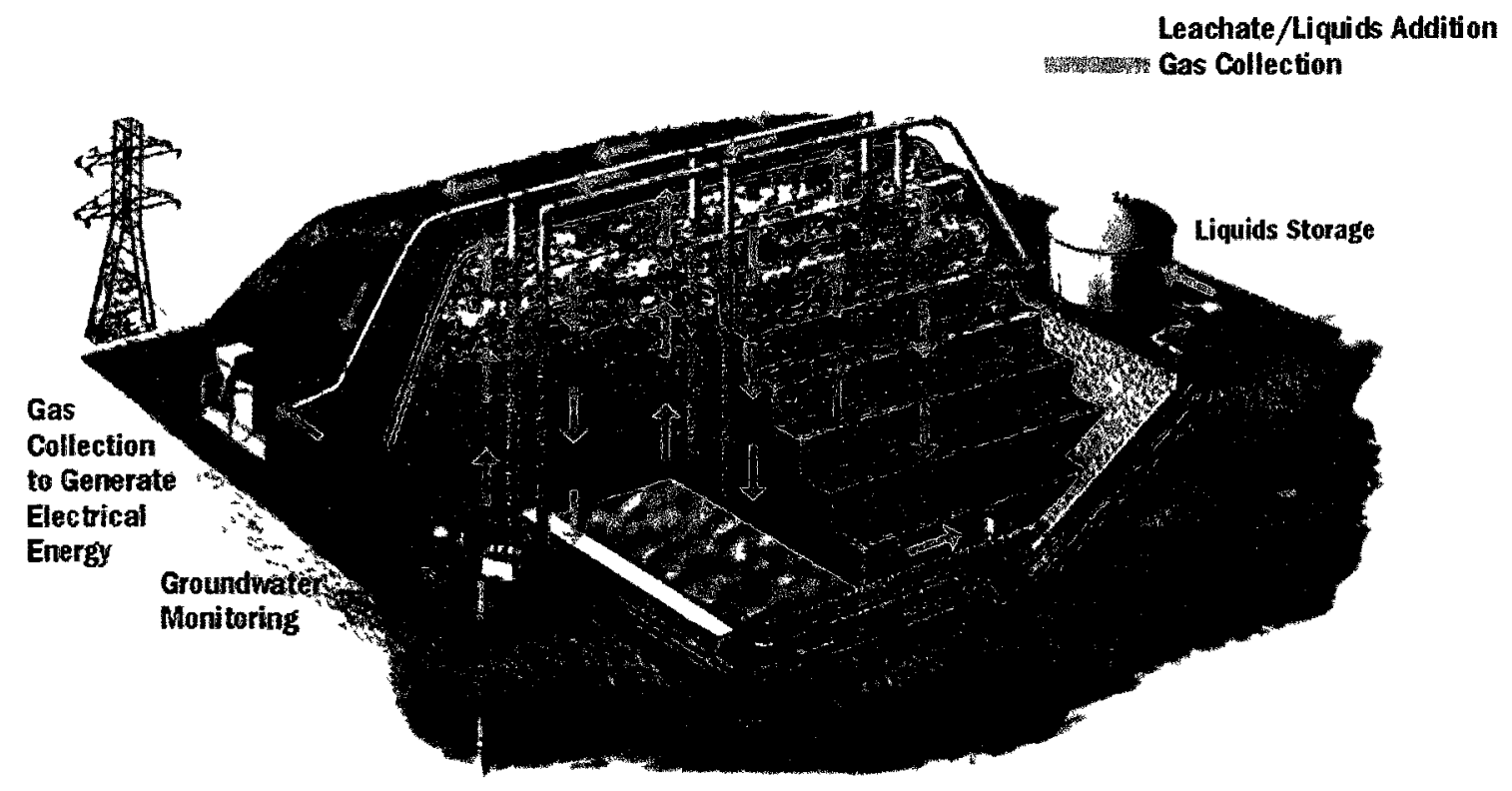

Figure 2: Typical configuration of an anaerobic bioreactor (With permission from Waste Management 2004). 


\subsubsection{Liner and Leachate Collection Systems}

As a bioreactor landfill reacts to the addition of moisture, waste density increases causing greater loading on the liner and leachate collection systems (Sharma \& Reddy 2004). Although waste density increases, the shear strength of the waste decreases with moisture addition. Both slope stability and waste mass stability are important design features for bioreactor landfills keeping in mind lower waste shear strengths (Pichtel 2005). Reinhart and Townsend (1998) delivered contradictory results regarding potential clogging of the leachate collection system under bioreactor landfill conditions; however, a conservative approach suggests that the leachate collection system should be designed with filters to minimize the risk of clogging.

\subsubsection{Leachate Recirculation}

Leachate recirculation is often the defining component in the design of bioreactor landfills as opposed to conventional landfills. Appropriate leachate recirculation systems address the provision of sufficient moisture to the waste as well as leachate storage (Sharma \& Reddy 2004). Leachate recirculation also promotes the distribution of nutrients and enzymes, $\mathrm{pH}$ buffering, dilution of inhibitory compounds, redistribution of methanogenic microorganisms, and liquid storage (Reinhart 1996). If the volume of leachate generated from the landfill is not sufficient to increase moisture to a desired level, additional liquids (i.e. water) can be added to the recirculation system. Several leachate recirculation systems have 
been employed in full-scale bioreactor landfills, including spraying, surface ponds, vertical injection wells, and horizontal injection devices (Reinhart \& Townsend 1998, Reinhart \& Al-Yousfi 1996). Horizontal and vertical injection systems were deemed the most practical and efficient based on full-scale studies; the advantages and disadvantages of these systems are presented in Table 1 (modified from Reinhart \& Townsend 1998).

Table 1: Advantages and disadvantages of horizontal and vertical leachate recirculation systems (modified from Reinhart \& Townsend 1998).

\begin{tabular}{|c|c|c|}
\hline $\begin{array}{l}\text { Recirculation } \\
\text { Method }\end{array}$ & Disadvantages & Advantages \\
\hline $\begin{array}{c}\text { Vertical Injection } \\
\text { Wells }\end{array}$ & $\begin{array}{l}\text { - Subsidence problems } \\
\text { - Limited Recharge Area } \\
\text { - Interference with waste } \\
\text { placement operations }\end{array}$ & $\begin{array}{l}\text { - Relatively large volumes of } \\
\text { leachate can be recirculated } \\
\text { - Low cost materials } \\
\text { - Easy to construct during and } \\
\text { following waste placement } \\
\text { - Compatible with closure }\end{array}$ \\
\hline $\begin{array}{c}\text { Horizontal } \\
\text { Injection (Trench) } \\
\text { System }\end{array}$ & $\begin{array}{l}\text { - Potential subsidence } \\
\text { impact on trench integrity } \\
\text { - Potential biofouling may } \\
\text { limit volume } \\
\text { - Inaccessible for } \\
\text { remediation }\end{array}$ & $\begin{array}{l}\text { - Low cost materials } \\
\text { - Large volumes of leachate can } \\
\text { be recirculated } \\
\text { - Compatible with closure } \\
\text { - Unobtrusive during landfill } \\
\text { operation }\end{array}$ \\
\hline
\end{tabular}

However, optimal designs of leachate recirculation systems are not well understood; pipe placement within a bioreactor landfill typically involves previous experience with a system rather than being based on optimal performance (Reinhart \& Townsend 1998). Attention should be paid to the volume of leachate being injected into the waste mass, as excessive moisture reduces the waste strength which may cause slope failure and reduces gas production (Sharma \& Reddy 2004). 
Additionally, even distribution of moisture throughout the waste is difficult in fullscale bioreactor landfills due to the heterogeneity of waste. Low permeability layers of waste may block the infiltration of leachate throughout the waste, and cause leachate to seep from the sides of the landfill (Rowe et al. 2004). These leachate seeps should be limited as the leachate may contaminate groundwater sources or storm water runoff (Sharma \& Reddy 2004).

\subsubsection{Gas Collection System}

The gas collection system of an anaerobic bioreactor landfill must deal with gas production on the order of $200-250 \%$ greater than that experienced in conventional landfills; design usually employs larger pipe diameter gas transportation to handle the increased gas volume (Pichtel 2005, Sharma \& Reddy 2004). Landfill gas is also produced at a much faster rate than in conventional landfills, so gas collection systems should be implemented early on in the operating life of the landfill (Sharma \& Reddy 2004). Transformation of landfill gas to energy is viable for bioreactor landfills based on the enhanced gas production (Benson et al. 2007).

\subsubsection{Final Cover}

Final cover designs fall under regulations, such as the United States Subtitle D landfill principle which promotes low-infiltration, and the Ontario Regulation 232/98 landfill standards guideline which promotes moderate-infiltration (Rowe et al. 1995, MOE 2010). According to the regulations, cover designs should not allow moisture to penetrate through the cover to the waste. Hence, in order to allow precipitation to aid in increasing moisture content, the installation of the final cover 
should be delayed until stabilization of the waste is complete (Sharma \& Reddy 2004, Reinhart \& Townsend 1998).

\subsection{Operation of Bioreactor Landfills}

\subsubsection{Anaerobic Decomposition}

Anaerobic bioreactor landfills involve moisture addition, usually through leachate recirculation, to enhance microbial activity which in turn promotes biodegradation. Biodegradation is allowed to occur anaerobically, so no additional oxygen is delivered to the system. An important product of anaerobic biodegradation is the production of landfill gas, comprising largely carbon dioxide and methane. Approximately $50 \%$ of landfill gas is methane, which can be transformed into energy. Research about characterizing the stabilization of MSW over time suggests that five distinct stabilization phases occur, in which leachate and biogas qualities and quantities change (Warith et al. 2005). The five phases indicate microbial processes are changing over time in the landfill; the anaerobic stage of the bioreactor landfill occurs after the first phase when all the available oxygen in the waste is depleted. However, clear changes in these phases are difficult to determine in full-scale bioreactor landfills as microbial processes vary across the landfill depending on organic contents of the waste, nutrient accessibility, moisture content, and initial compaction (Pichtel 2005).

\subsubsection{Phase 1 - Initial Adjustment Phase}

Phase 1 represents the aerobic phase of the landfill, which occurs mainly during the initial placement of waste (Warith et al. 2005). Oxygen is still sufficiently available 
in the voids of the waste, at around $20 \%$ by volume (Pichtel 2005). Moisture levels are rising during this phase (Reinhart \& Townsend 1998).

\subsubsection{Phase 2 - Transition Phase}

Moisture levels increase such that the field capacity of the waste is exceeded, and leachate is formed. Phase 2 represents the first anaerobic phase, as available oxygen from the void space is depleted (Reinhart \& Townsend 1998). Hence, aerobic degradation processes begin to transition to anaerobic degradation processes. The limited amount of oxygen results in reducing conditions as nitrates and sulphates reduce to nitrogen gas $\left(\mathrm{N}_{2}\right)$ and hydrogen sulphide $\left(\mathrm{H}_{2} \mathrm{~S}\right)$. As a result, carbon dioxide $\left(\mathrm{CO}_{2}\right)$ forms, and displaces oxygen. Organic acid formation and the rise in carbon dioxide begin to decrease the $\mathrm{pH}$ of the system (Pichtel 2005). Hydrolysis of carbohydrates, proteins and lipids occurs in this phase, creating more soluble compounds such as sugars, amino acids, and long-chain fatty acids (Warith et al. 2005).

\subsubsection{Phase 3 - Acid Formation Phase}

Phase 3 represents the second anaerobic phase in which acetogenic fermentation transforms the products from Phase 2 into intermediate volatile fatty acids (VFAs), and final carbon dioxide, hydrogen, and acetate (Warith et al. 2005). The intermediate VFAs can be oxidized to form carbon dioxide, hydrogen, and acetate. However, VFAs can accumulate in this phase, contributing to high chemical oxygen demand (COD). Acidic conditions form, with a $\mathrm{pH}$ of approximately 5, as organic acids and carbon dioxide accumulate (Pichtel 2005). 


\subsubsection{Phase 4 - Methane Fermentation Phase}

Phase 4 represents the third anaerobic phase where methanogenic microorganisms work to transform hydrogen, carbon dioxide, and acetate into methane and additional carbon dioxide (Warith 2005). The pH increases during Phase 4 to a neutral level which sustains methanogenic microorganism growth (Pitchel 2005, Reinhart \& Al-Yousfi 1996). This stage is identifiable in a bioreactor landfill through the production of landfill gas.

\subsubsection{Phase 5 - Maturation Phase}

Phase 5 represents the final phase of stabilization as the easily biodegradable organic content of the waste has been transformed to methane and carbon dioxide, and stabilization of the waste results (Warith 2005). As biological processes slow down due to limited nutrients and substrate, landfill gas production declines (Pichtel 2005). Eventually, natural environment conditions return to the landfill.

\subsubsection{Moisture}

The addition of moisture is the main parameter which affects biodegradation rates and waste decomposition (Imhoff et al. 2007). The addition of moisture to the bioreactor landfill is generally completed through controlled leachate recycle, and can result in reduced stabilization times of $10-15$ years in anaerobic bioreactor landfills as opposed to 30-100 years in conventional landfills (Reinhart 1996, Sharma \& Reddy 2004). Most MSW deposited in landfills generally retains gravimetric moisture contents of $15 \%$ to $40 \%$ (wet-weight basis) (Pichtel 2005). The wet-weight basis for gravimetric moisture content is the mass of water per 
mass of wet soil. Reinhart and Townsend (1998) suggest a minimum gravimetric moisture content of $25 \%$ (wet-weight basis) for operation of a bioreactor landfill, with gravimetric moisture contents between $40 \%$ and $70 \%$ (wet-weight basis) for optimal waste degradation. In comparison, Rowe et al. (2004) states that optimal anaerobic decomposition occurs at gravimetric moisture contents of $45 \%$ to $65 \%$ (dry-weight basis). The dry-weight basis for gravimetric moisture content is the mass of water per mass of dry soil. Understanding the moisture distribution throughout the landfill is an important step for appropriate leachate recirculation to achieve uniform waste degradation. Several techniques and sensors for measuring volumetric moisture content in-situ have been developed and used in field studies (Kumar et al. 2009). These techniques involve measuring a soil property which is affected by moisture, such as electrical resistance. Gawande et al. (2003) developed a new sensor, the Moisture, Temperature and Gas (MTG) sensor, based on electrical resistivity. Measuring the electrical resistivity of the leachate present in the waste gives an indication of the moisture content: the lower the electrical resistivity, the higher the moisture content (Grellier et al. 2006). After significant field testing, Kumar et al. (2009) suggested that the newly developed MTG sensors provided reasonable estimates of moisture content, if they are calibrated properly. Although moisture sensors can be utilized to measure point moisture content within a landfill, they may not represent the overall moisture content due to preferential flow paths and heterogeneity of the waste (Kumar et al. 2009). 


\subsubsection{Temperature}

Decomposition of waste, through aerobic and anaerobic processes, is the main generator of heat in a landfill (Yesiller et al. 2005). In addition, rising waste temperatures promote microbial activity which, in turn, increases the decomposition of the waste (Yesiller et al. 2005). Various aspects, such as type of waste, moisture content of waste, biomass content, rate of waste placement, thickness of waste lifts, and climatic environment of site, can affect the temperature in a landfill (Rowe \& Islam 2009). As such, the overall temperature of the landfill is influenced by heat gain through waste decomposition and heat loss through dissipation to the surrounding soil and atmosphere (Reinhart \& Townsend 1998). The organic content of MSW is degraded by mesophilic microorganisms, working at optimal temperatures of $35^{\circ} \mathrm{C}$ to $40^{\circ} \mathrm{C}$, and thermophilic microorganisms, working at optimal temperatures of $50^{\circ} \mathrm{C}$ to $60^{\circ} \mathrm{C}$ (Rowe \& Islam 2009). However, lab-scale studies have shown that gas production is optimized when waste temperatures are between $34^{\circ} \mathrm{C}$ to $45^{\circ} \mathrm{C}$, with higher temperatures limiting the rate of gas production (Reinhart \& Townsend 1998, Rees 1980).

Rees (1980) indicated that optimum temperatures are difficult to achieve and maintain in a landfill, and suggests various techniques that can be incorporated in landfill operations to achieve the desired temperature. These techniques include the addition of moisture to enhance biodegradation, the addition of methanogenic organisms to initiate methane production, and the placement of an insulating waste layer over the reactive waste for protection in winter. Further techniques have been studied to control temperature at landfills including the injection of air to promote 
aerobic decomposition and recirculating heated leachate (Reinhart \& Townsend 1998). However, Reinhart \& Townsend (1998) concluded that these attempts to increase temperature are impractical and costly at full-scale bioreactor landfills.

\subsubsection{Settlement}

Settlement of waste occurs as the volume of waste as initially placed is reduced over time. Several case studies have determined that waste settlement is larger and occurs faster in bioreactor landfills rather than conventional landfills, due to the enhanced moisture content (Benson et al. 2007). Several mechanisms affect the rate of settlement including physical compression, ravelling, physical and chemical changes, and biological processes, shown in Table 2 (modified from Warith et al. 2005).

Table 2: Influencing factors of MSW settlement (modified from Warith et al. 2005).

\begin{tabular}{|c|l|}
\hline $\begin{array}{c}\text { Influencing Factor on } \\
\text { Settlement }\end{array}$ & \multicolumn{1}{|c|}{ Description } \\
\hline Physical Compression & $\begin{array}{l}\text { Distortion, bending, crushing and reorientation of the } \\
\text { materials; it is similar to the compression of non- } \\
\text { organic soils }\end{array}$ \\
\hline Ravelling & $\begin{array}{l}\text { Shifting of fine materials into the voids between } \\
\text { larger soil particles }\end{array}$ \\
\hline $\begin{array}{c}\text { Physical and chemical } \\
\text { processes }\end{array}$ & $\begin{array}{l}\text { Corrosion, oxidation, and/or combustion of the waste } \\
\text { material }\end{array}$ \\
\hline $\begin{array}{c}\text { Biological processes } \\
\text { Aerobic/anaerobic biodegradation of the waste } \\
\text { material }\end{array}$ \\
\hline Interaction & $\begin{array}{l}\text { Above factors could interact to cause additional } \\
\text { settlement }\end{array}$ \\
\hline
\end{tabular}


Settlement data can be used to infer which phase of stabilization the waste has reached; however, it is difficult to determine the amount of settlement caused by each mechanism (Benson et al. 2007).

Elagroudy et al. (2008) proposed a model for settlement behaviour which included three key stages: initial compression, primary compression, and secondary compression. Biodegradation induced settlement is assumed to generally fall within the timeframe of secondary compression (Elagroudy et al. 2008). However, in-situ settlement measurements, which would aid in differentiating the amount of settlement attributed to each stage, have not been the focus of case studies (Benson et al. 2007). Direct measurements of settlement in various pilot and full-scale bioreactor landfills have been found to reach high levels of $20-25 \%$, whereas settlement in conventional landfills only reaches as high as $8 \%$ (Benson et al. 2007, Reinhart \& Townsend 1998). If the proposed gain in airspace is not obtained by adequate settlement during the operational lifetime of the landfill, Sharma and Reddy (2004) suggest that filling above the design grade is acceptable, as settlement post-closure will eventually bring the height of the waste back to within the design criteria. Rapid settlement is not always beneficial for bioreactor landfills as large stresses can be induced on leachate collection and recirculation systems and gas collection systems (Reinhart \& Townsend 1998, Warith et al. 2005). In addition, differential settlement can affect placement and effectiveness of covers (Sharma \& Reddy 2004). 


\subsection{In-Situ Instruments in Full-Scale Landfill Studies}

\subsubsection{Florida Bioreactor Demonstration Project, Union County, Florida}

The Florida bioreactor demonstration project was managed by the Hinkley Center for Solid and Hazardous Waste Management, the University of Florida, and the University of Central Florida. The purpose of the project was to "design, construct, operate, and monitor a full-scale landfill bioreactor in Florida in a manner that permits a complete and fair evaluation of this technology as a method of solid waste management in Florida, with appropriate consideration of science, engineering, environmental, and economic issues" (Hinkley et al. 2008). Five landfill sites were selected to participate in the project: New River Regional Landfill (NRRL), Tomoka Farms Road Landfill, Polk County North Central Landfill, Alachua County Southwest Landfill, and Highlands County Landfill. In-situ instruments were installed into the research-built full-scale bioreactor landfill at NRRL.

\subsubsection{New River Regional Landfill (NRRL)}

The NNRL is located in Union County, Florida and was selected for implementation of a full-scale bioreactor landfill to compare aerobic and anaerobic waste decomposition processes (Hinkley et al. 2008). The bioreactor landfill operated for seven years, from 2001 to 2008 . Leachate recirculation, air injection, and gas collection were featured at the site. Instrumentation installed within the waste allowed for monitoring of in-situ parameters. The instrumentation installed included pressure transducers (to measure head on the liner), total earth pressure cells (to measure applied load forces), moisture sensors (to measure moisture 
content), thermocouples (to measure temperature), and vibrating wire piezometers (to measure pore water pressure) (Hinkley et al. 2008).

No reliable data were reported from the pressure transducers as the instrument failed during testing. The total earth pressure cells showed increases in pressure in relation to waste lift placement; however, pressure values were underestimated by $50 \%$ when compared to calculated values based on waste height and density (Hinkley et al. 2008). It was suggested that arching, point load susceptibility, and pressure cell malfunction could affect the pressure readings. Two types of moisture sensors were tested based on electrical resistance and time domain reflectometry methods. The sensors indicated gravimetric moisture levels of $34 \%$ to $40 \%$ prior to leachate recirculation, and $68 \%$ after leachate recirculation. However, a water balance calculation indicated an expected moisture content of only 34.6\% (Hinkley et al. 2008). The high sensor readings were attributed to a higher leachate conductivity experienced in the field than used to produce calibration curves and proximity to preferential leachate paths through the waste. Thermocouples found average temperatures of $35^{\circ} \mathrm{C}$ to $65^{\circ} \mathrm{C}$ after two years of operation (Hinkley et al. 2008). Leachate recirculation facilitated rising temperature. Settlement was surveyed via a GPS system, at approximately every 45 days, by measuring points along the surface of the landfill and at the top of vertical wells placed at varying depths in the landfill (Hinkley et al. 2008). An average settlement of $10 \%$ occurred over the landfill by the project end (Hinkley et al. 2008). 


\subsubsection{Anchorage Regional Landfill, Anchorage, Alaska}

The success of a bioreactor landfill operation in Alaska was uncertain due to cold temperatures limiting the production of landfill gas. Waste placement, under the influence of a cold climate, was studied at the Anchorage Regional Landfill to evaluate the corresponding decomposition (Hanson 2006). Thermocouples and sampling ports were installed throughout the landfill to measure temperature and gas, respectively. The waste placed during winter months formed a $7 \mathrm{~m}$ thick layer of frozen material, which remained frozen for more than two years after placement, as it was insulated by surrounding waste (Hanson 2006). Steady temperatures, of approximately $25-30^{\circ} \mathrm{C}$, were reached for waste in the middle of the landfill if placement was originally done in the summer (Hanson 2006). Temperatures varied near the top and bottom on the landfill, as seasonal air temperature and ground temperature influenced waste temperatures. Due to the overall low temperatures, which are unfavourable for microbial activity, gas generation only started three to four years after waste was placed in the landfill (Hanson 2006).

\subsubsection{Northern Oaks Recycling and Disposal Facility, Harrison, Michigan}

The Northern Oaks Recycling and Disposal Facility (NORDF) created a 0.49 ha fullscale bioreactor landfill for research purposes (Zhao et al. 2008). Filling of the cell spanned from July to March of the following year, such that waste was placed both in summer and winter months. Forty-eight sites within the research cell were instrumented with a moisture sensor, a temperature probe, a leachate collection basin, and a gas sampling port (Zhao et al. 2008). The moisture sensor utilized the time domain reflectometry technique, and measured a steady increase in moisture 
content as leachate was added. The first waste lift was placed in the summer and showed elevated temperatures conducive to microbial activity; however, the remaining waste lifts were mainly placed during winter months, and froze due to cool ambient temperatures. Zhao et al. (2008) stated that the upper waste lifts maintained temperatures of below $0^{\circ} \mathrm{C}$ for more than 6 months after closure of the cell. Differential settlement was measured from settling of conduits installed within the waste. The highest amount of settlement was observed in the middle lifts, and was attributed to degradation of the waste lifts below.

\subsubsection{Yolo County Bioreactor Landfill Project, Davis, California}

The Yolo County bioreactor landfill project compared a bioreactor landfill to a conventional landfill, using two research cells, which demonstrated the advantages of a bioreactor landfill using leachate recirculation (Reinhart \& Townsend 1998). Sensors installed throughout the waste included pressure transducers (to measure hydraulic head), thermistors (to measure temperature), and moisture probes (to measure moisture content), and survey monuments (to measure surface settlement). In addition, a communication system allowed remote access to the moisture and temperature sensors data (Sharma \& Reddy 2004). After approximately a ten year study period, leachate recirculation proved to greatly improve the landfill gas production and waste settlement. Landfill gas measurements indicated that $75 \%$ more landfill gas was produced in the bioreactor landfill over the conventional landfill (Sharma \& Reddy 2004). Approximately 16\% settlement was observed in the bioreactor landfill, while the conventional landfill exhibited only $2 \%$ settlement (Sharma \& Reddy 2004). 


\subsection{Global Positioning System (GPS)}

\subsubsection{Real-Time Kinematic with Differential GPS (RTK-DGPS)}

The global positioning system (GPS) allows users to assign coordinates (latitude, longitude, elevation) to a point on the surface of the Earth, using information from several satellites. Differential GPS (DGPS) improves the accuracy of GPS coordinates. It requires that a stationary ground control, known as a base station receiver, be set up at a precisely known location. The base station receiver communicates with satellites to calculate its location, compares this value to its known coordinates, and determines the difference between the two. At the same time a second receiver, known as a roving receiver or rover, can roam in the vicinity of the base station receiver. The rover communicates with identical satellites to the base station receiver to calculate its coordinates. The difference calculated by the base station receiver can then be applied to correct the GPS coordinates recorded by the rover.

The application of real-time kinematic (RTK) to DGPS allows the difference calculated by the base station receiver to be applied to the coordinates of the rover in real-time. The base station receiver communicates with the rover via a radio communication link. Figure 3 illustrates the method of RTK-DGPS surveying with the base station installed on a building and the roving receiver being held by a surveyor. 


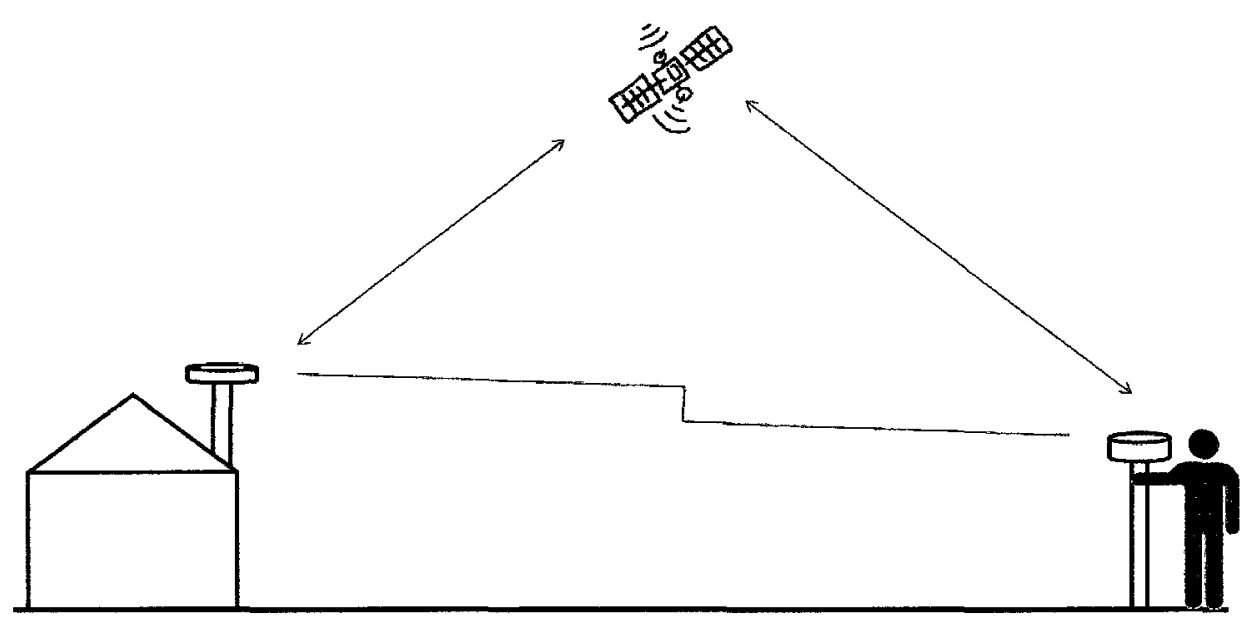

Figure 3: Schematic of RTK-DGPS surveying.

Additional information can be passed between the base station receiver and the rover through the radio communication link, including corrections to the clock and estimated accuracy of the coordinate corrections (Kaplan \& Hegarty 2006). Accurate coordinates can only be provided if both the base station receiver and the rover communicate with a minimum number of satellites, typically eight. While standard single point GPS only delivers accuracy levels of approximately $10-15 \mathrm{~m}$, the RTKDGPS used during the study via the Altus Positioning System achieved accuracy levels of $1 \mathrm{~cm}$ (NRC 2007).

RTK-DGPS requires a clear line of sight between the base station receiver and the rover to function successfully. The radio communication link can fail if a clear line of sight is blocked by topography or other large-scale obstacles, such as a landfill (ElRabbany 2006). A clearer line of sight may be achieved by extending the height of the base station or rover radio antenna, to allow the signal to relay over the obstructions (El-Rabbany 2006). Alternatively, a repeater station can be installed on 
site to improve the radio communication link by bypassing the obstruction. This is shown in Figure 4 with a landfill obstructing the line of sight between the base station and the rover. A repeater station is installed at the top of the landfill to relay the signal between the two receivers.

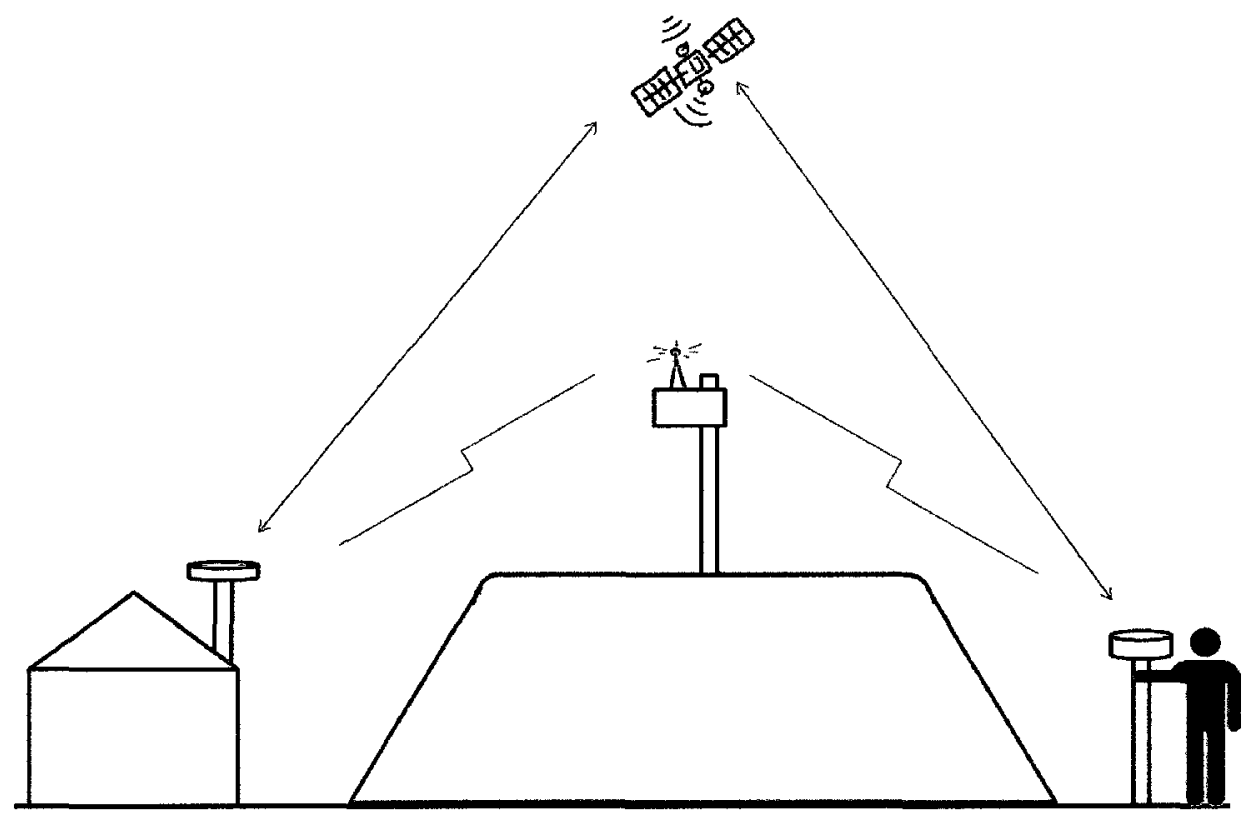

Figure 4: Use of a repeater station in RTK-DGPS.

\subsubsection{Use of GPS in Bioreactor Landfills}

Typical methods of analyzing waste density and compaction at landfills involves ground surveying or aerial topography (Jackson 2008). However, the time, labour, and cost required for these methods make them unattractive. Additionally, the information provided from these methods generally becomes available after a timelag of several months. Instead, RTK-GPS technology has been recently introduced to landfill operations and management as a cost-effective alternative to provide 
extremely accurate positioning coordinates in real-time (Griesbach 2010). The rover is generally mounted to landfill machinery, such as the sheepsfoot compactors, to determine the exact location of the machines in the landfill. In-cab computers display the location of the machines in relation to an uploaded engineered landfill drawing, allowing the user to have greater control for lift placement, compaction, and grading (Fickes 2004). This technology generates multiple benefits including improved airspace utilization, enhanced compaction, and achievement of ideal densities. The life of the landfill can be extended as these benefits maximize the utilization of the landfill volume for waste placement. 


\section{Initial Testing in Lab-Scale Bioreactor Landfill}

To increase the chances of survival for the instrument bundles in the bioreactor landfill, a proof-of-concept study was completed a few months before the initiation of this project (Van Geel 2010). The study tested a prototype instrument bundle using a lab-scale representation of a bioreactor landfill in order to expose the sensors to the rigour of vertical loading and to the harsh chemical environment generated by the leachate. To recreate the conditions expected in the field, waste from the landfill face and fresh leachate were obtained from Waste Management of Canada's Carp Road Landfill in Ottawa, Ontario. A large rectangular steel bin, $2.5 \mathrm{~m}$ long by $1.5 \mathrm{~m}$ wide, was filled with a $1 \mathrm{~m}$ thick layer of waste to represent a lab-scale bioreactor landfill. The instrument bundle was tested in the lab-scale bioreactor landfill for nearly four months in the fall of 2008 as part of a $4^{\text {th }}$ year engineering project.

The instruments in the prototype instrument bundle were similar to those used in instrument bundles installed in the full-scale bioreactor landfill research project (see Chapter 4 for description of instruments). The oxygen sensor, moisture and electrical conductivity sensor, and piezometer were placed in a geotextile bag filled with sand and then placed over the instrument bundle. The prototype instrument bundle was placed between several layers of waste within the lab-scale bioreactor landfill, with approximately $0.5 \mathrm{~m}$ of waste above and below. Following the placement of the instrument bundle in the waste, vertical loading was applied to the waste to simulate the weight of additional layers of waste. Approximately $135 \mathrm{kPa}$ 
(representing $16-19 \mathrm{~m}$ of waste dependent on waste density) was applied to the instrument bundle. Raw leachate was also added to the waste to simulate the toxic environment caused by leachate. Approximately 417L (110 gallons) of leachate was added to the waste.

The stainless steel casing of the oxygen sensor showed some deterioration after the laboratory testing; however, it continued to accurately record the oxygen content. An improved, plastic-body oxygen sensor was suggested for use in the field instrument bundles to withstand contact with the leachate. The moisture and electrical conductivity sensor measured a sharp rise in volumetric water content after the leachate addition, eventually decreasing to a constant $30 \%$ moisture content reading. The sensor then failed near the end of the four month experiment, and hence for the field instrument bundles, a more robust epoxy-coated moisture and electrical conductivity sensor was proposed. Further testing of the improved moisture and electrical conductivity sensor placed directly in raw leachate showed that the sensor could withstand the chemical environment. The liquid settlement system, piezometer, and total earth pressure cell all proved to be capable of withstanding the environment of the lab-scale bioreactor landfill. 


\section{Instrument Bundle Installation in Full-Scale Bioreactor}

\section{Landfill}

\subsection{Objectives}

Several instruments, including thermistors, a total earth pressure cell, a settlement system, a moisture and electrical conductivity sensor, an oxygen sensor, and a piezometer were bundled together for placement within the Sainte-Sophie bioreactor landfill. Twelve instrument bundles were planned for installation in the bioreactor landfill while it is progressively filled with waste, in order to monitor various in-situ parameters of the waste which impact waste degradation and stabilization. These instrument bundles specifically monitor in-situ temperatures, total load, settlement, total load, moisture content, electrical conductivity, oxygen content of air space, and mounding of leachate. At the time of writing this thesis, eight instrument bundles were installed in the Sainte-Sophie bioreactor landfill as described in Chapter 4.4. The data presented in this thesis, in Chapter 4.5, corresponds with the eight instruments bundles from their time of installation in the landfill up to April 2011.

\subsection{Instrument Bundle Equipment}

Instrument bundles 1-4 contained thermistors, a total earth pressure cell, a settlement system, a moisture and electrical conductivity sensor, an oxygen sensor, and a piezometer. Bundles 5-12 contained the same instruments minus the piezometer, as mounding of leachate was not expected in the landfill at the higher 
installation heights. The total earth pressure cell, settlement system, and piezometer (if applicable) were mounted to a steel plate approximately $70 \mathrm{~cm}$ long by $70 \mathrm{~cm}$ wide by $2.54 \mathrm{~cm}$ thick. The instruments of each instrument bundle were wired individually to a connection box on the steel plate. The connection box was sealed with epoxy to prevent potential damage from infiltrating leachate or waste. From the connection box, a single data cable with 24-paired wires connected the instrument bundle to an RST Flexi-Mux multiplexer and Model CR1000FlexDAQ Datalogger located in the instrument shed situated north-east of the Zone 4 bioreactor landfill. In addition to the single data wire, two liquid-filled flexible tubes connected each settlement system in an instrument bundle to a reservoir in the instrument shed. Two empty flexible tubes also spanned the distance between each instrument bundle and the instrument shed, allowing oxygen to be pumped to an instrument bundle or gas/liquid samples to be withdrawn from the instrument bundle. The following sections describe in detail the individual sensors which made up the instrument bundles. A summary of the instrument specifications are included in Appendix A.

\subsubsection{Settlement System}

The following section is summarized from RST Instruments' Vibrating Wire Liquid Settlement System instruction manual provided with the instrument bundles (RST Settlement Manual 2008). The settlement system was designed by RST Instruments and commercialized under the name "Vibrating Wire Liquid Settlement System". The vibrating wire pressure sensor, as shown in Figure 5, was mounted to the steel plate of the instrument bundle and installed within the landfill. Two liquid-filled 
flexible tubes connected the sensor to a pressurized reservoir, also known as an accumulator, located in the instrument shed. The sensor measured the hydraulic head of liquid at the instrument bundle (the liquid being $50 \%$ water and $50 \%$ glycol to prevent freezing). A second pressure sensor measured the pressure at the accumulator in the shed. As the instrument bundle settled within the waste, the pressure differential between the pressure measured at the instrument bundle and the pressure measured at the accumulator, increased. The pressure differential was converted to a height based on the density of the liquid. The accumulator was mounted at a fixed location on a wall inside the instrument shed and was pressurized to ensure a positive pressure reading at the instrument bundle. The resulting settlement of the instrument bundle was measured relative to the initial readings taken by the sensor immediately after installation.

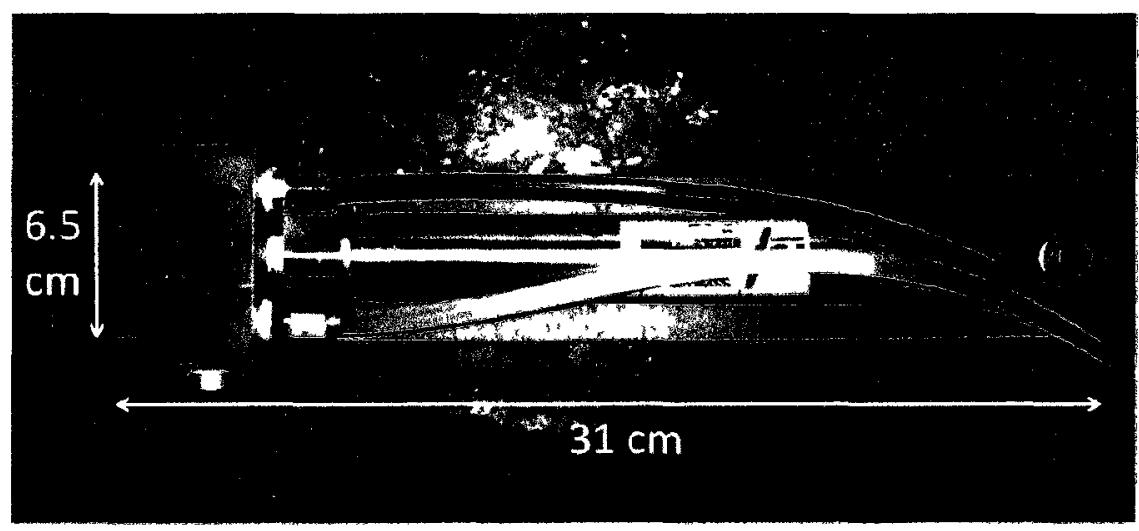

Figure 5: Vibrating wire pressure sensor mounted on steel plate.

Two different types of accumulators were used for the project as per availability from RST Instruments. The first three instrument bundles were connected to a 10 psi $(70 \mathrm{kPa})$ accumulator, as shown in Figure 6 . The next three instrument 
bundles were connected to an identical 10 psi accumulator. The last two instrument bundles installed were connected to a weighted accumulator, as shown in Figure 7. The weighted accumulator is capable of accommodating eight liquid-filled flexible tubes with quick connect ports, thereby handling up to four instrument bundles. The remaining four bundles (of the planned 12 instrument bundles) are to be installed on the current weighted accumulator and a second identical weighted accumulator.

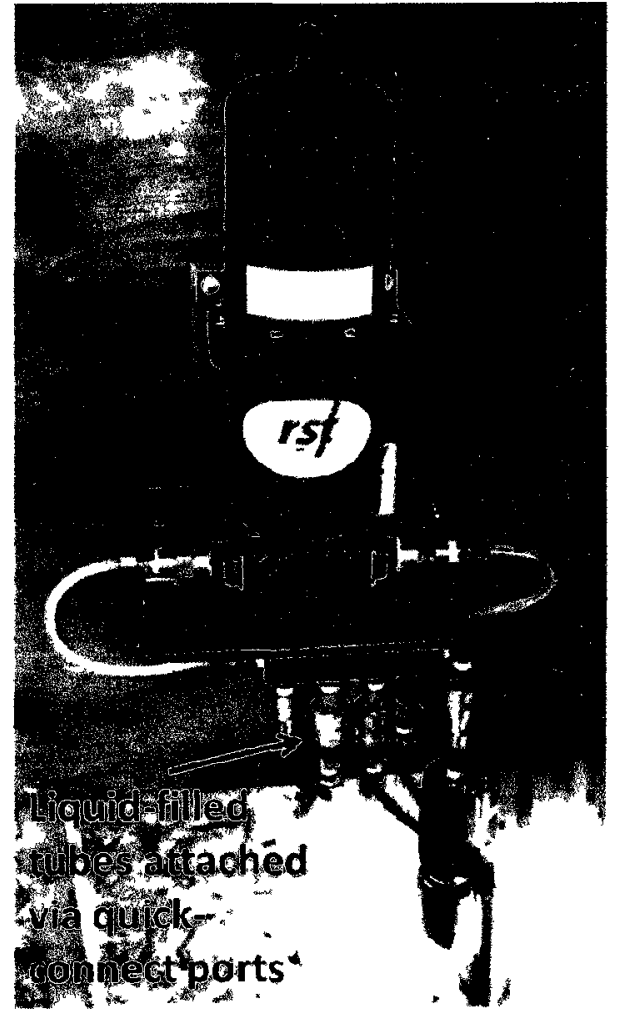

Figure 6: 10psi accumulator, with liquid-filled tubes from Bundles 1 and 2 attached via quick-connect ports.

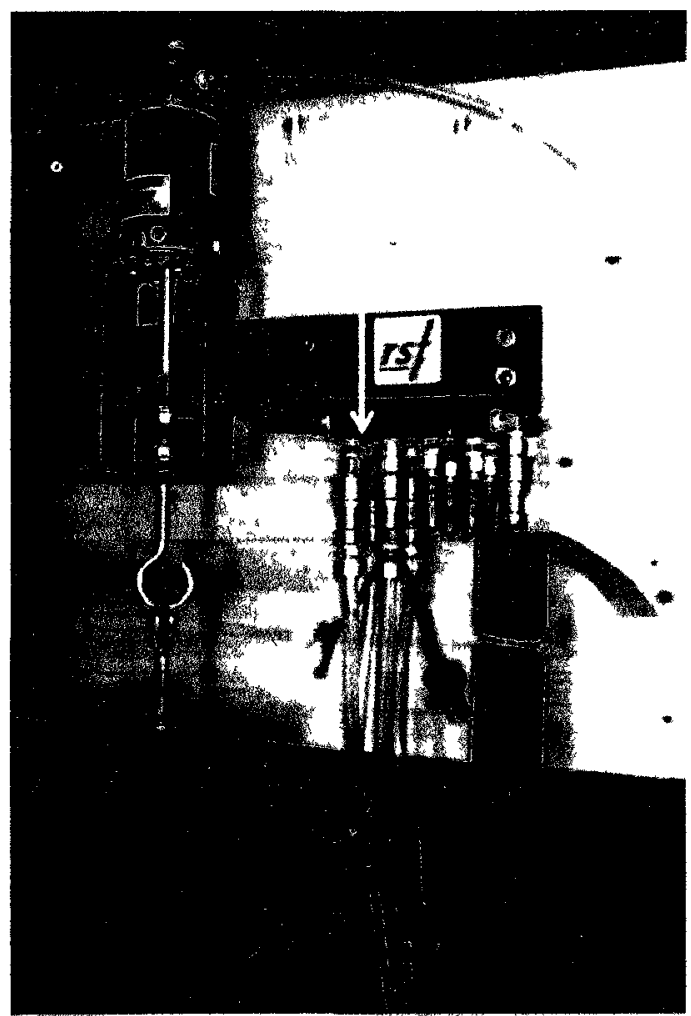

Figure 7: Weighted accumulator, with liquidfilled tubes from Bundles 7 and 8 attached via quick-connect ports.

\subsubsection{Total Earth Pressure Cell}

The following section is summarized from RST Instruments' Total Earth Pressure Cell instruction manual provided with the instrument bundles (RST Pressure 
Manual 2004). The total earth pressure cell (TEPC) was designed by RST Instruments to measure the stress acting on plane surfaces. The instrument, shown in Figure 8, was mounted to the steel plate of the instrument bundle and installed within the landfill. It consisted of a glycol-filled cell connected to a vibrating wire pressure transducer forming a closed hydraulic system. The vibrating wire pressure transducer measured any change in pressure of the glycol, which would be caused by stress exerted on the surface of the cell. By loading the cell with waste layers as the landfill is filled, the pressure within the cell increased.

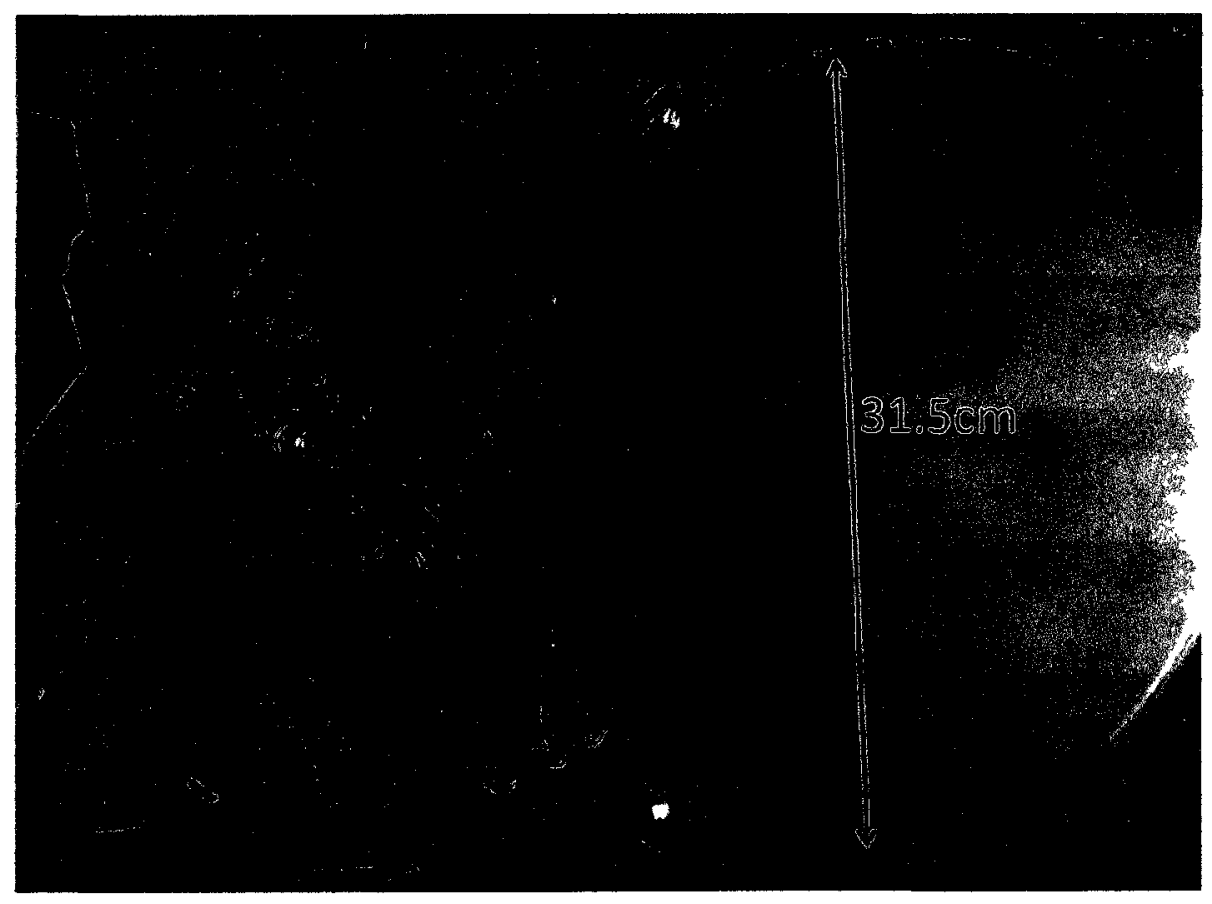

Figure 8: Total earth pressure cell mounted on steel plate. 


\subsubsection{Piezometer}

The following section is summarized from RST Instruments' Vibrating Wire Piezometer Model VW2100 instruction manual provided with the instrument bundles (RST Piezometer Manual 2006). The piezometer was designed by RST Instruments and commercialized under the name "Vibrating Wire Piezometer". The piezometer, shown in Figure 9, was mounted on the steel plate of the instrument bundle and installed within the landfill. A vibrating wire pressure sensor within the piezometer determined the pore water pressure within the waste. The pore water pressure would have increased if leachate accumulated over the instrument bundle and filled the void space of the waste. An external housing filter protected the vibrating wire sensor from soil particles.

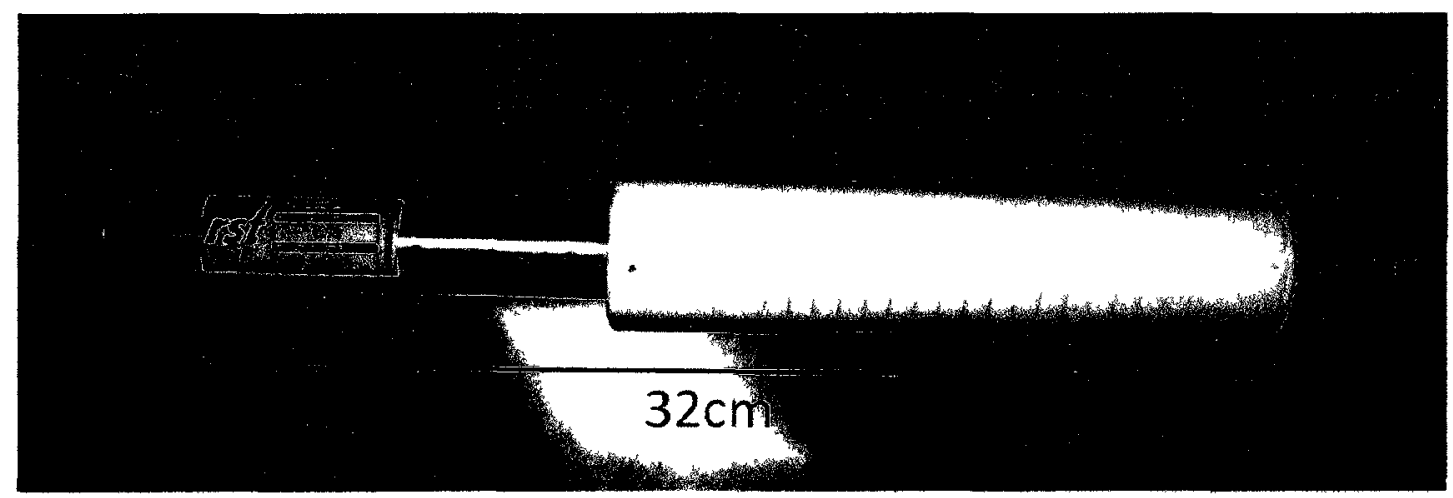

Figure 9: Vibrating wire piezometer with external housing filter.

\subsubsection{Oxygen Sensor}

The following section is summarized from Apogee Instruments' Oxygen Sensor SO$100 \& 200$ Series owner's manual provided with the instrument bundles (Apogee Manual 2010). The oxygen sensor, shown in Figure 10, was designed by Apogee 
Instruments Inc. and measured the percentage of oxygen gas in the air space of the waste. The oxygen sensor was placed vertically within a protective layer of sand directly above the instrument bundle. The current flowing between the electrodes in the oxygen sensor was proportional to the oxygen concentration being measured. An internal resistor provided an output in millivolts corresponding to the partial pressure of oxygen in the air space, which was then converted to a percentage of oxygen. A diffusion mesh head was attached to the oxygen sensor to allow air flow through the air space of the waste to the sensor.

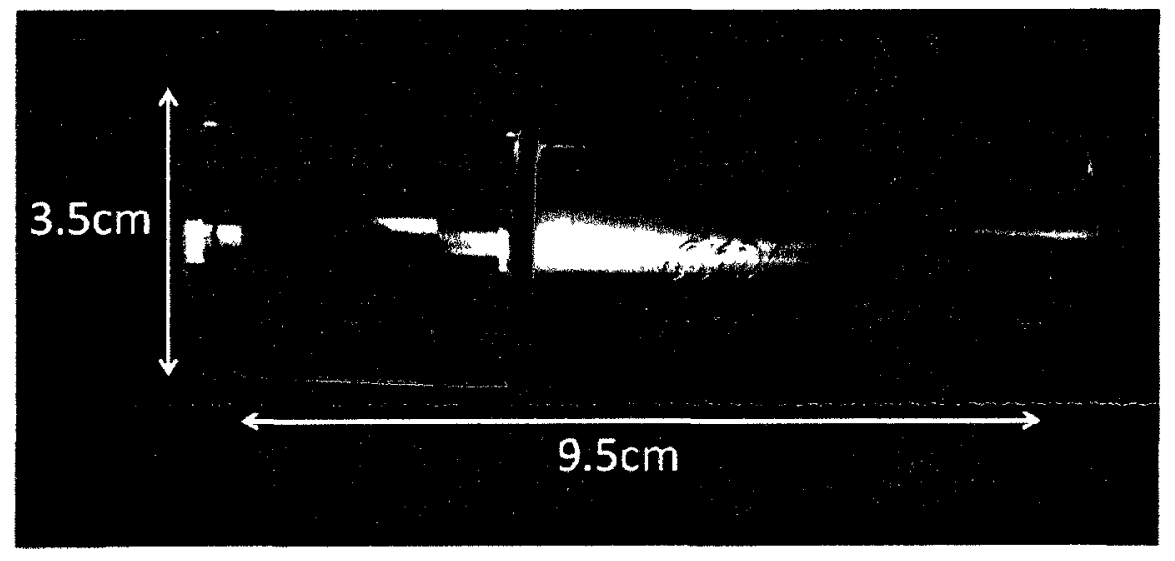

Figure 10: Oxygen sensor (on right) with diffusion mesh head (on left).

\subsubsection{Moisture and Electrical Conductivity Sensor}

The following section is summarized from Decagon Devices' 5TE Water Content, EC and Temperatures Sensors Version 5 operator's manual provided with the instrument bundles (Decagon Manual 2010). The moisture and electrical conductivity sensor was designed by Decagon Devices and commercialized under the name "5TE soil moisture, temperature, and electrical conductivity probe". It was 
capable of independently measuring volumetric water content, bulk electrical conductivity, and temperature of soil. The sensor was inserted into the protective layer of sand overlying the instrument bundle. It was assumed that the parameters measured by the sensor in the sand would reflect values of the surrounding waste. The instrument, shown in Figure 11, determined the volumetric water content of the waste by measuring the dielectric permittivity of the waste through an electromagnetic field supplied to the prongs. Waste temperature was determined by a thermistor which measured the prong surface temperature. Bulk electrical conductivity was determined by a two-probe electrical array with the screws on the prongs of the instrument. Pore electrical conductivity could then be calculated from the measured bulk electrical conductivity.

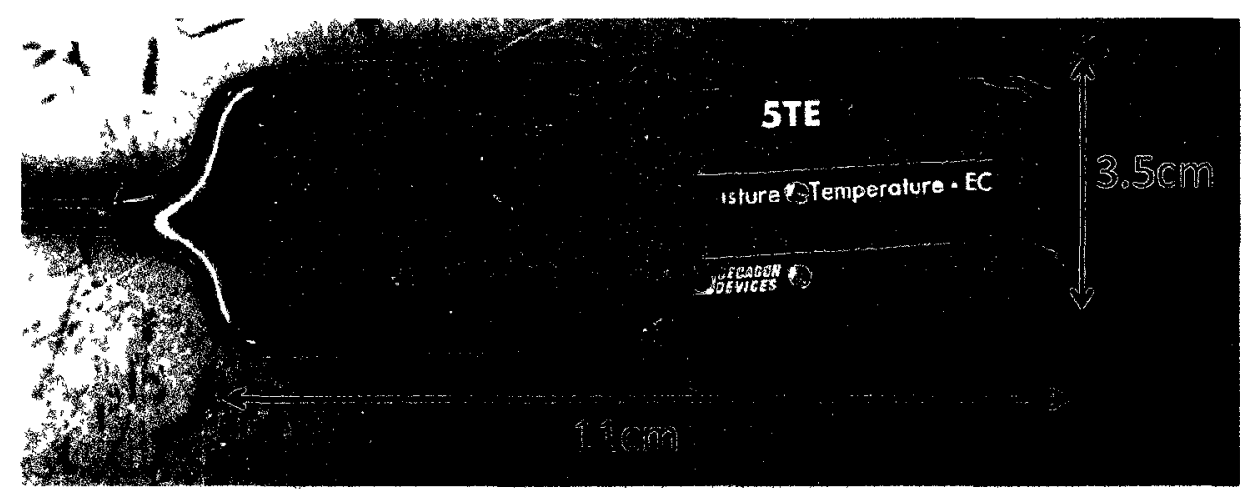

Figure 11: Moisture and electrical conductivity sensor.

\subsubsection{Temperature Thermistors}

The total earth pressure cell, settlement system, moisture and electrical conductivity sensor, and the oxygen sensor each contained a thermistor capable of temperature measurement. Many of the thermistor temperature measurements 
were required for corrections to reduce temperature effects on the raw instrument readings. Due to limited ports for thermistors on the datalogger in the instrument shed, the total earth pressure cell thermistors were not accessed by the datalogger for temperature readings. The remaining instruments provided multiple temperature readings for each instrument bundle.

\subsection{Data Acquisition System and Data Collection Software}

The following section is summarized from Campbell Scientific's CR1000 Measurement and Control System manual and RST Instruments' Flexi-Mux instruction manual provided with the instrument bundles (Campbell Manual 2006, RST Flexi-Mux Manual 2004). From the connection box on the instrument bundle plate, a single data cable with 24-paired wires connected the instrument bundle to a data acquisition system in the instrument shed. The system was encased in a weather-proof steel enclosure mounted within the instrument shed. The data acquisition system involved twelve Flexi-Mux multiplexers and a Model CR1000 FlexDAQ datalogger as designed by RST Instruments. The twelve multiplexers provided supplementary ports such that data from the multiple instruments of the proposed twelve instrument bundles could be recorded by this single datalogger. The system was powered by a $12 \mathrm{~V}$ power supply with charging regulator, and required a constant power source for recording data. In the event of the main power failing, a back-up battery is able to maintain power to the memory and clock of the system. The datalogger stored all data from the instrument bundles with a time 
stamp in real-time. A modem connected to the datalogger provided an internet IP address so that data was accessed and collected remotely. On-site data collection was achieved through a USB connection from the datalogger to a PC. Data collection was completed through LoggerNet 3.4.1, a Campbell Scientific user interface program for the datalogger. Details for the data acquisition system and data collection software are included in Appendix B. A sample program for recording data from twelve instrument bundles currently being used with the datalogger is included in Appendix B. Sampling frequency varied over the course of the project, with a preferred sampling frequency of 30 minute intervals. During specific tests, the sampling frequency was increased to 1-3 minute intervals to allow for proficient data analysis.

\subsection{Installation Methodology}

Twelve instrument bundles were designed to be installed in the landfill as the landfill progressively filled with waste. Figure 12 illustrates the proposed placement of the instrument bundles within the landfill, as two vertical columns of six layers of instrument bundles each. Instrument bundle placement was shown in Figure 1, with Column 1 placed approximately $80 \mathrm{~m}$ into the landfill from the north-east edge (5070937.52 N, $273056.9 \mathrm{E}$ ). Column 2 was placed $15 \mathrm{~m}$ further into the landfill past

Column 1 ( $5070925 \mathrm{~N}, 273045.1 \mathrm{E}$ ). The landfill was designed to accommodate $25 \mathrm{~m}$ height of waste. Therefore, the instrument bundles in each column were designed to be separated by four metres of waste. Final installation heights were dependent on 
waste placement during landfill operation, and are shown in Figure 12 for the layers placed during the study period.

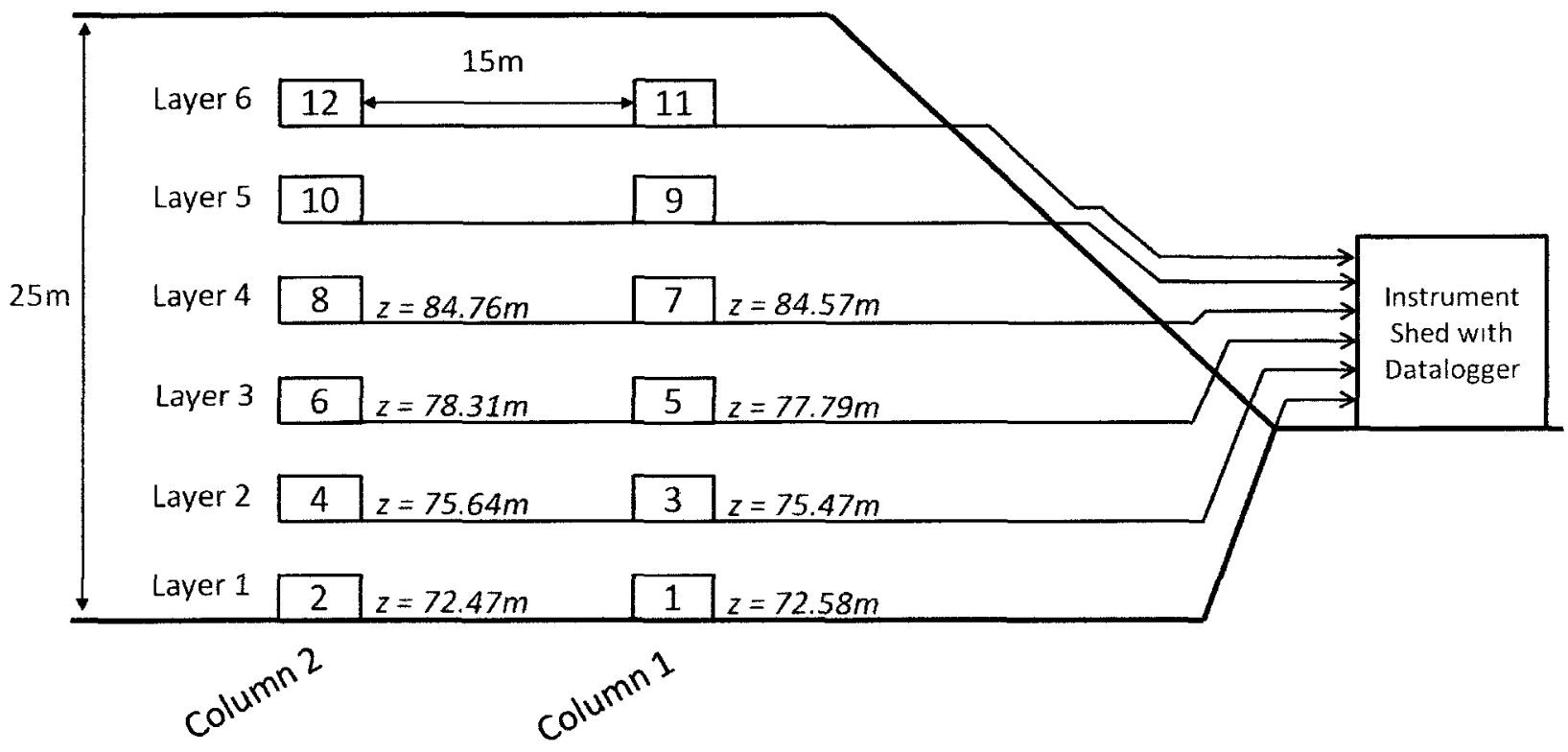

Figure 12: Cross-section of bioreactor landfill with instrument bundle placement and elevations (not to scale).

At the time of writing this thesis, four layers of instrument bundles were installed in the waste of the Sainte-Sophie bioreactor landfill. The first layer, which contained Bundles 1 and 2, was installed in October and November 2009. The second layer, which contained Bundles 3 and 4, was installed in January 2010. The third layer, which contained Bundles 5 and 6, was installed in June 2010 and was the only summer installation. The fourth layer, which contained Bundles 7 and 8 , was installed in February 2011. These installations are discussed in more detail in the following sections. Appendix C contains supplemental figures of the installation process for the eight bundles. 


\subsubsection{Layer 1 - Instrument Bundles 1 and 2 Installation}

The first layer of instrument bundles was installed in the landfill on October 20-23, 2009. The cell was void of waste at the onset of the study, so the first layer of instrument bundles was placed directly on the gravel layer of the leachate collection system at elevations of $72.58 \mathrm{~m}$ for Bundle 1 and $72.47 \mathrm{~m}$ for Bundle 2. The northing, easting, and elevation of the instrument bundle steel plate were determined and recorded using differential GPS. The cable and tubing were snaked to provide slack to deter damage in the case of differential settlement, as the cable lengths for all bundles were increased by $20 \%$ to allow for the potential differential settlement. Some cracking of the protective orange casing around the cable and tubing arose during installation. The jagged edges of the casing were wrapped with geotextile and duct tape to limit damage to the cable and tubing inside. Sand and geotextile were placed around the cable and tubes for protection. Approximately $0.5 \mathrm{~m}$ of sand was deposited over the steel plate of the instrument bundle. In this sand, the oxygen probe and moisture probe were inserted vertically. Due to a road crossing between the landfill and the instrument shed, twelve HDPE pipes were installed under the road crossing to allow access for the cables and tubes of all 12 proposed instrument bundles to connect the instrument bundles to the datalogger in the instrument shed.

Power was brought to the instrument shed for the datalogger to function continuously. A 10psi accumulator (VW11887) was installed for use by the settlement system for Bundles 1 and 2. It was pumped to 10psi via a bike pump, while monitoring of the pressure rise through the LoggerNet software program for the datalogger. The liquid-filled flexible tubes extending out of the landfill from each 
instrument bundle were connected via quick-connect ports to the accumulator. The final wiring of the data cable to the datalogger and the tubing to the accumulator was completed on November 12, 2009.

With the instrument bundles installed in the north-east corner of the empty cell, waste began being placed in the southern corner of the empty cell with the waste front moving towards the north-east. With the waste front slowly progressing in the direction of the instrument bundles, the instrument bundles remained uncovered for a couple months. The instrument bundles were finally covered by the approximately $5 \mathrm{~m}$ thick first waste lift on January 3-8, 2010.

\subsubsection{Layer 2 - Instrument Bundles 3 and 4 Installation}

The second layer of instrument bundles was installed on January 8-9, 2010. The Layer 2 installation proceeded similar to the Layer 1 installation, but the bundles were installed near the middle of the first waste lift. Bundle 3 was installed at an elevation of $75.47 \mathrm{~m}$ (with $2.89 \mathrm{~m}$ of waste between Bundle 3 and Bundle 1 ) and Bundle 2 was installed at an elevation of $75.64 \mathrm{~m}$ (with $3.17 \mathrm{~m}$ of waste between Bundle 4 and Bundle 2). Four metres of waste between instrument bundle layers was the initial goal, but due to the operating practices on-site, a smaller thickness of waste between layers was achieved. At the top of the waste lift, a $0.5 \mathrm{~m}$ trench was excavated along the waste lift for placement of the instrument bundles, data cables and liquid-filled and empty flexible tubes. Approximately $5 \mathrm{~cm}$ of sand was used to line the trench providing some protection of the data cables and tubes from the waste. After the instrument bundles, data cables, and tubes were placed in the 
trench, a $0.5 \mathrm{~m}$ layer of sand was placed as a protective cover. The trench was then backfilled with waste. After this, the remaining waste from the first waste lift was rolled out over the instrument bundles, with $2.82 \mathrm{~m}$ covering Bundle 3 and $3.17 \mathrm{~m}$ covering Bundle 4.

Just before the road crossing, the gaps between the cables and tubes and the orange protective casing of Bundles 1-4 were filled with expanding foam sealant to limit movement of landfill gas from the landfill to the instrument shed. Likewise, the holes in the side of the instrument shed, which were created for the cables and tubes to enter the instrument shed, were filled with expanding foam sealant.

On January 9, 2010, Bundle 3 was wired to the datalogger, and the settlement gauge was attached to the previously installed 10psi accumulator (VW11887). The second 10psi accumulator (VW11886) was installed on January 16, 2010 and pumped up to required the pressure on January 16,2010 . Bundle 4 was then wired to the datalogger, and the settlement gauge attached via quick-connects to the accumulator.

\subsubsection{Layer 3 - Instrument Bundles 5 and 6 Installation}

The third layer of instrument bundles was installed in the landfill on June 22-24, 2010 near the top of the first waste lift. This installation was the only summer installation to date. The Layer 3 installation proceeded similar to the Layer 2 installation. Bundle 5 was installed at an elevation of $77.79 \mathrm{~m}$ (with $5.21 \mathrm{~m}$ of waste between Bundle 5 and Bundle 1) and Bundle 6 was installed at an elevation of $78.31 \mathrm{~m}$ (with $5.84 \mathrm{~m}$ of waste between Bundle 6 and Bundle 2). The instrument 
bundles in Layer 3 were immediately covered with approximately $0.5 \mathrm{~m}$ of waste, as the trench was re-filled.

Due to extensive snaking of the cables and tubes, the liquid-filled flexible tubes for the settlement system of Bundle 6 ended up being too short (by approximately 30 $\mathrm{cm}$ ) to reach the designated accumulator (VW11886), but could reach the first accumulator (VW11887). Therefore, Bundle 6 was connected to first accumulator (VW11887) by switching locations with Bundle 1. In return, Bundle 1 was removed from its original location on first accumulator (VW11887), and re-attached to second accumulator (VW11886).

\subsubsection{Layer 4 - Instrument Bundles 7 and 8 Installation}

The fourth layer of instrument bundles was installed in the landfill on February 1516, 2011, approximately eight months after the installation of Layer 3 . The fourth layer of instrument bundles was installed after the placement of the second and third waste lifts in the study area; the second waste lift was placed in December 2010 and the third waste lift was placed within January and February of 2011. The Layer 4 installation proceeded similar to the Layer 3 installation, but near the top of the third waste lift. Bundle 7 was installed at an elevation of $84.57 \mathrm{~m}$ (with $11.99 \mathrm{~m}$ of waste between Bundle 7 and Bundle 1) and Bundle 8 was installed at an elevation of $84.76 \mathrm{~m}$ (with $12.29 \mathrm{~m}$ of waste between Bundle 8 and Bundle 2). The wiring of the data cable to the datalogger was completed on February 16, 2011. The instrument bundles in Layer 4 were then immediately covered with $0.5 \mathrm{~m}$ of waste, as the trench was re-filled. 
A weighted accumulator (VW16732) was installed for use by the settlement system for Bundles 7 and 8 . The liquid-filled flexible tubes were connected via quick connect ports to the accumulator on March 4, 2011. A barometer was also installed in the instrument shed on March 4, 2011. The barometer provides accurate measurements of barometric pressure which is required for corrections to several instrument readings.

Issues that arose during installation of Layer 4 included incorrect placement of the oxygen sensor and the moisture probe for both Bundles 7 and 8 . The oxygen sensor was placed vertically in the sand over the instrument bundle steel plate, however it was placed up-side down. The moisture sensor was installed with the plastic protection on the prongs which requires removal prior to installation. An attempt to expose these instruments by excavating them occurred on March 4, 2011. However, damage to both the oxygen sensor and moisture probe occurred while excavating these instruments from Bundle 8. Luckily, the readings from both instruments appear unharmed as the oxygen sensor only experienced losing the diffusive mesh cover, and the moisture sensor lost one prong which was required only for measuring the electrical conductivity. However, it is noted that long term results may not be accurate. The mesh cover for the oxygen probe was reattached to the probe with electrical tape, and both instruments were placed back in the sand correctly. Due to the damage experienced with Bundle 8, the excavation and attempt at fixing the placement of the oxygen probe and moisture sensor for Bundle 7 was stopped. Appendix C contains pictures of the damaged instruments. 


\subsection{Instrument Bundle Results}

At the time of writing this thesis, eight instrument bundles were installed in the Sainte-Sophie bioreactor landfill over the span of 16 months. A complete schedule of the instrument installation and subsequent connection to a datalogger is provided in Table 3. The sampling frequency was set to 15 minute intervals after the installation of Bundles 1 and 2. Over time, as the data showed minimal changes, the datalogger program was updated to a 30 minute interval sampling frequency. During the installation of Bundles 3 to 8 , the datalogger program was altered to a 1 minute interval sampling frequency to allow for better observation of the data throughout the installations. After the installations were complete, the datalogger program reverted to a 30 minute interval sampling frequency.

Table 3: Schedule of Instrument Bundle Installation in Field and Connection to Datalogger

\begin{tabular}{|c|c|c|}
\hline Instrument Bundle & Installation Date in Field & Connection to Datalogger \\
\hline 1 & October 20-23, 2009 & November 12, 2009 \\
\hline 2 & October 20-23, 2009 & November 12, 2009 \\
\hline 3 & January 8-9, 2010 & January 9, 2010 \\
\hline 4 & January 8-9, 2010 & January 16, 2010 \\
\hline 5 & June 22-24, 2010 & June 23, 2010 \\
\hline 6 & June 22-24, 2010 & June 23, 2010 \\
\hline 7 & February 15-16, 2011 & March 4, 2011 \\
\hline 8 & February 15-16, 2011 & March 4, 2011 \\
\hline
\end{tabular}

The quick sampling frequency allowed a large quantity of data to be recorded. Data analysis for this thesis was completed on a condensed version of the recorded data, with four daily values at times of 06:00, 12:00, 18:00, and 24:00. Sensor reading 
error, which returned a "-100" or "NAN" value to the datalogger program, was removed from the data. A gap in the data represents an area of sensor reading error where the true values are unknown. The following chapters present the data collected from each sensor from their time of installation to April 2011. The condensed data used for this thesis is included on an accompanying CD, within the "Data" folder. The complete data set, as downloaded directly from the datalogger, is also included on the CD in the same folder.

\subsubsection{Temperature Probes}

The in-situ waste temperatures recorded at each instrument bundle provided insight on the operation of bioreactor landfills in northern climates. The settlement sensor, piezometer, moisture sensor, and oxygen sensor all contained thermistors measuring temperature in degrees Celsius. The instruments each measured temperature due to the requirement of temperature corrections for the observed parameter. The temperature corrections for the observed parameter of each instrument were completed using the individually measured temperature, and are presented in the following sections for each instrument.

Figures 13 to 20 illustrate the temperatures measured by the thermistors from each instrument in the eight bundles. In general, the temperatures measured by the settlement sensor, piezometer, and moisture and electrical conductivity sensor were all very similar being on average within $1^{\circ} \mathrm{C}$ of each other. However, at various times the oxygen sensor measured temperature values approximately $2^{\circ} \mathrm{C}$ higher than the other instrument thermistors, due to an internal heater in the oxygen sensor which 
would operate at various times to prevent condensation. The oxygen sensors were likely insulated well enough in the protective sand layer such that the heat generated from the internal heater was trapped causing the oxygen sensor thermistor to measure temperatures higher than the actual surrounding waste temperature. The difference between the oxygen sensor temperature and the remaining instrument temperatures is clearly seen for Bundles 1-4 in Figures 13 through 16. Overall, the thermistors from the settlement sensors, piezometers, moisture and electrical conductivity sensors, and oxygen sensors have correlated well for each instrument bundle, indicating the durability of the thermistors and the accuracy they continue to achieve while being buried in the bioreactor landfill.

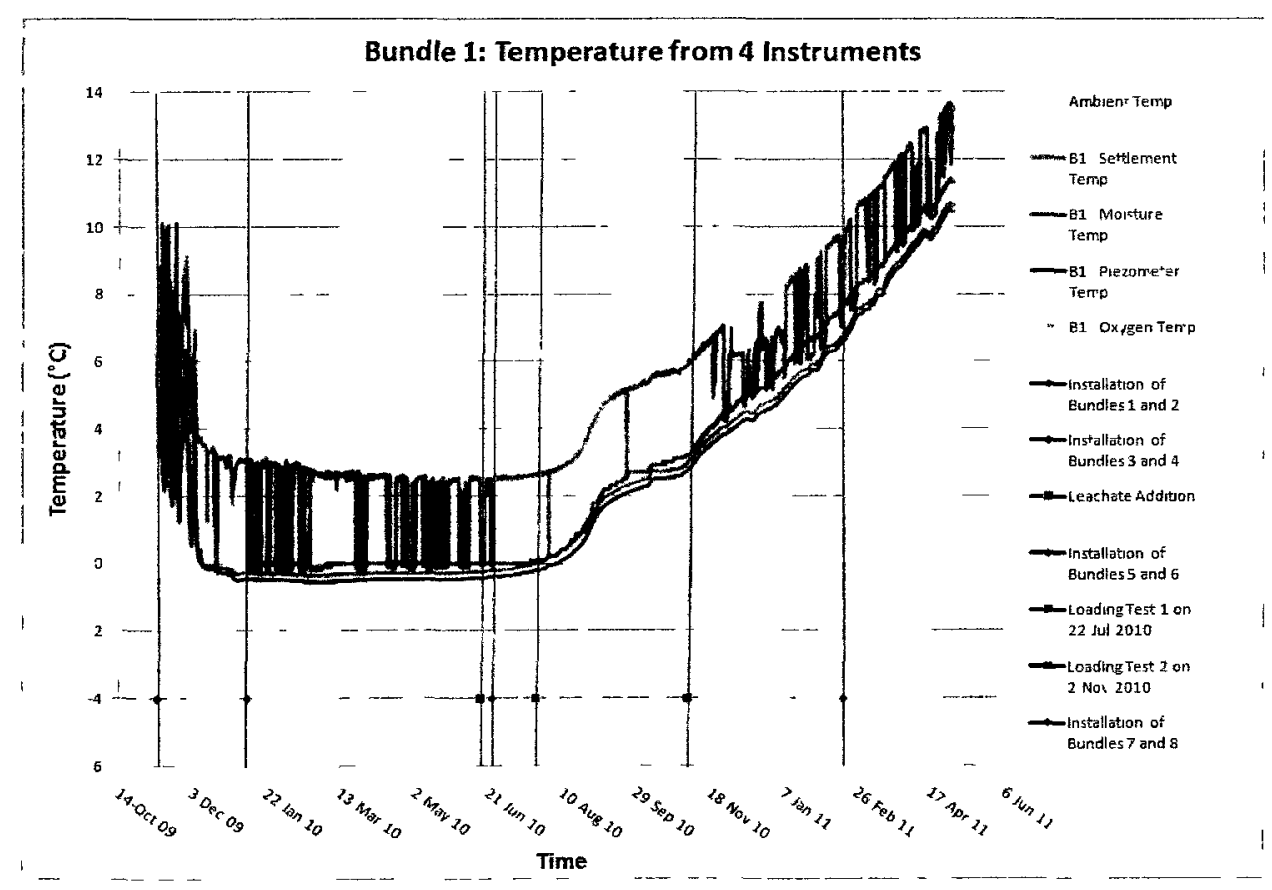

Figure 13: Temperature from 4 Instruments in Bundle 1. 


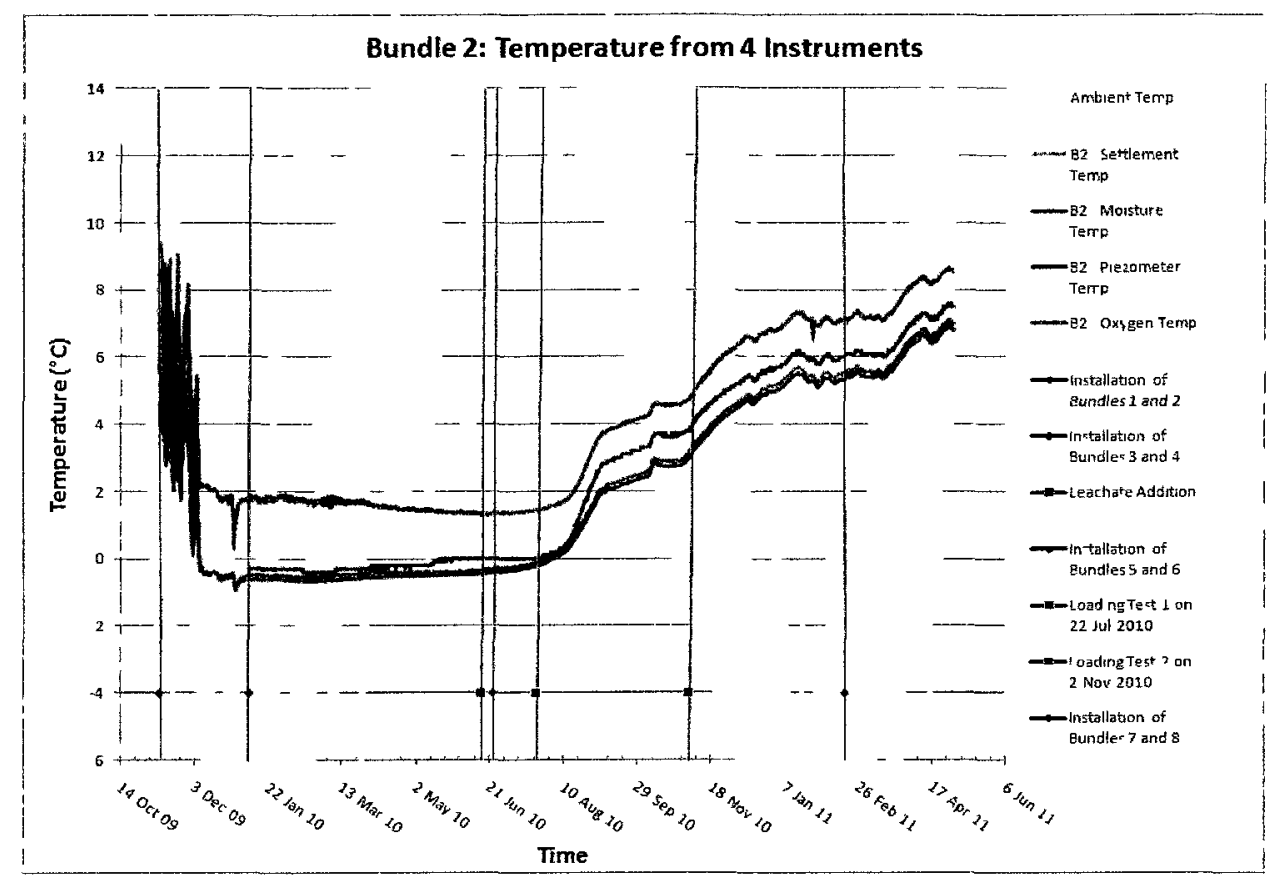

Figure 14: Temperature from 4 Instruments in Bundle 2.

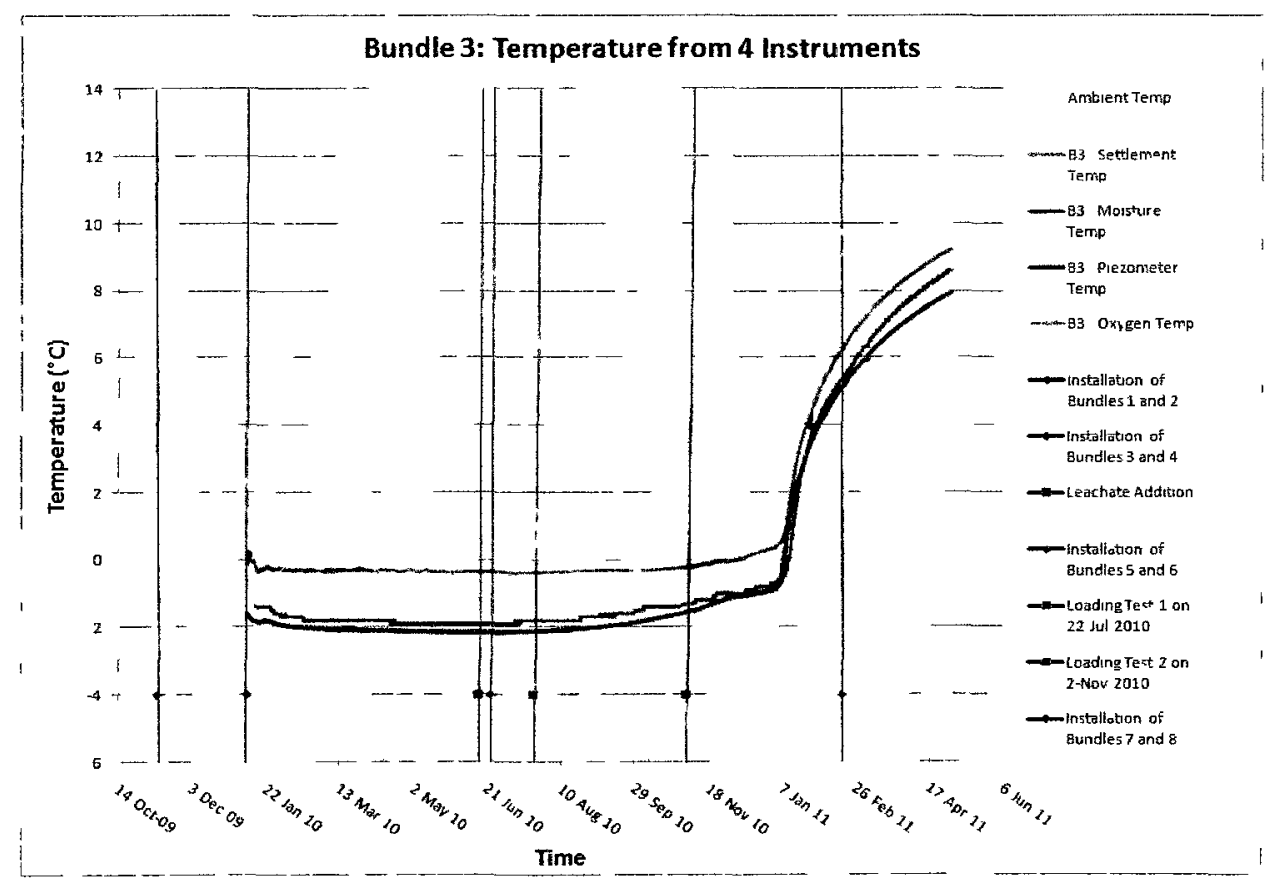

Figure 15: Temperature from 4 Instruments in Bundle 3. 


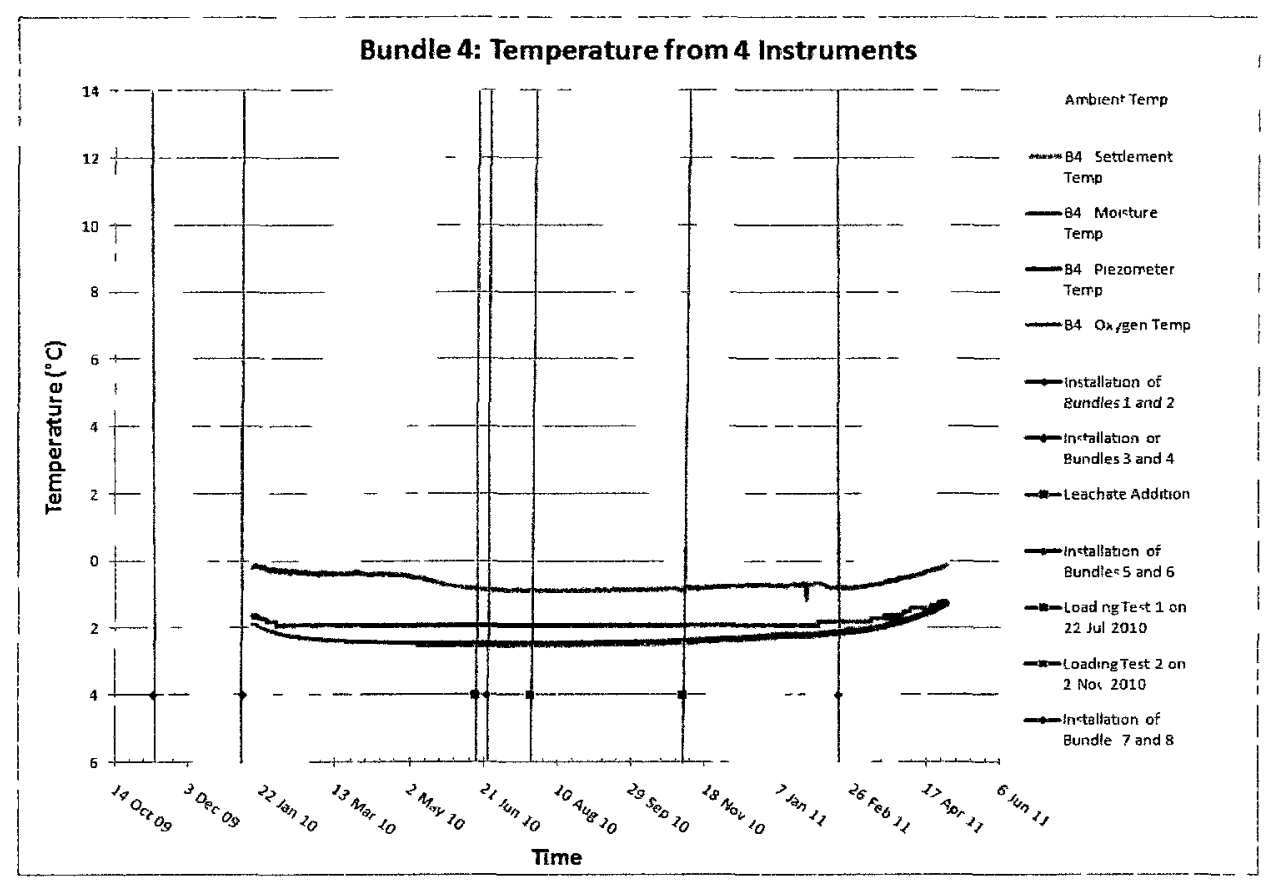

Figure 16: Temperature from 4 Instruments in Bundle 4.

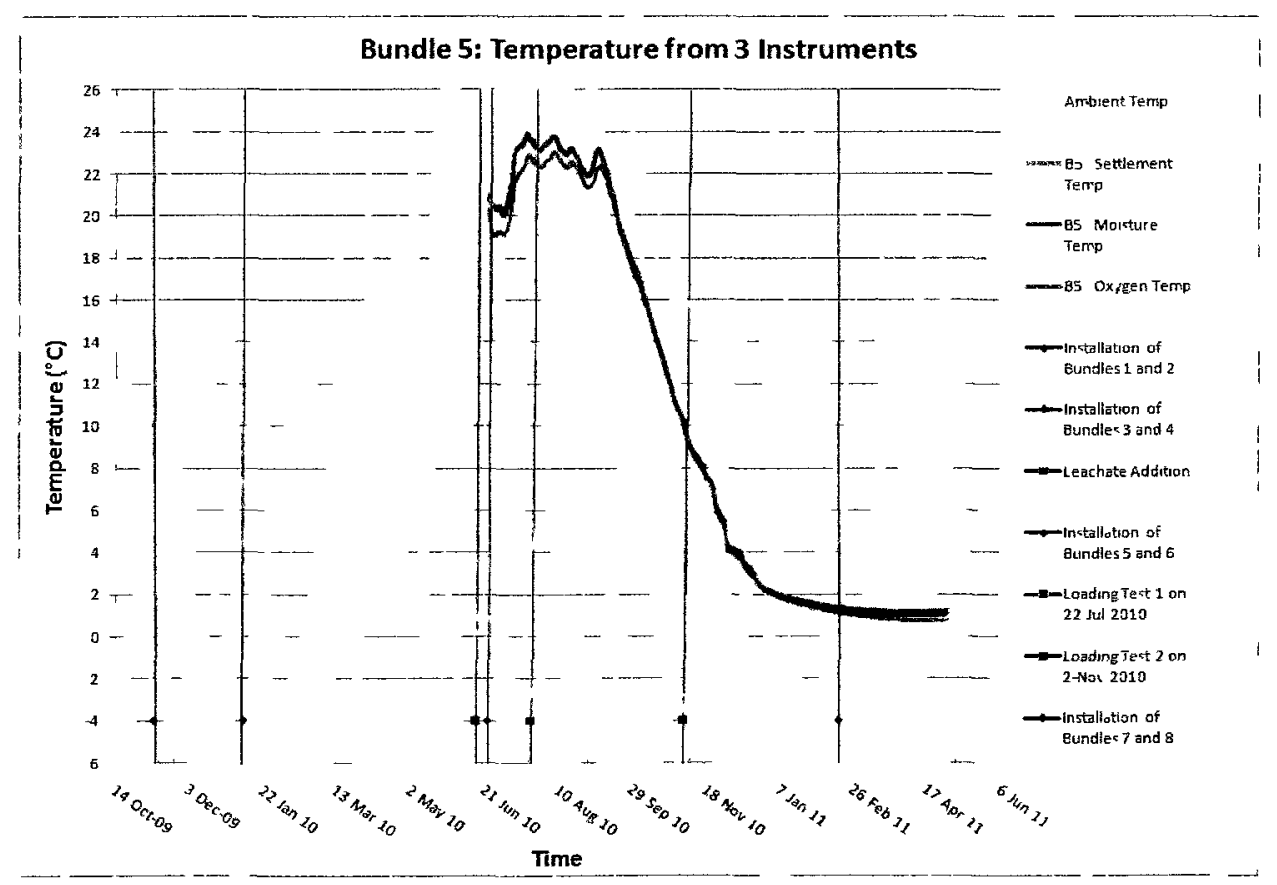

Figure 17: Temperature from 3 Instruments in Bundle 5. 


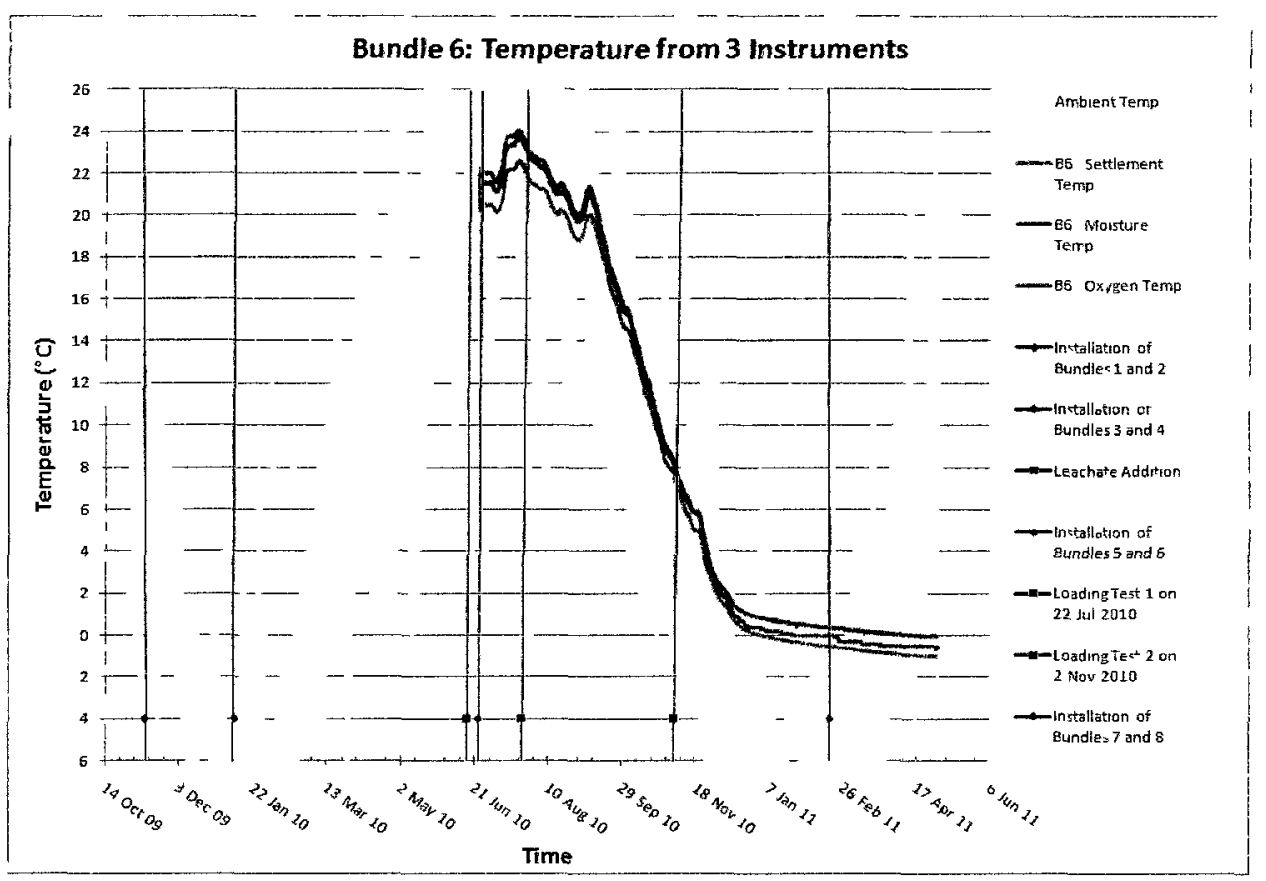

Figure 18: Temperature from 3 Instruments in Bundle 6.

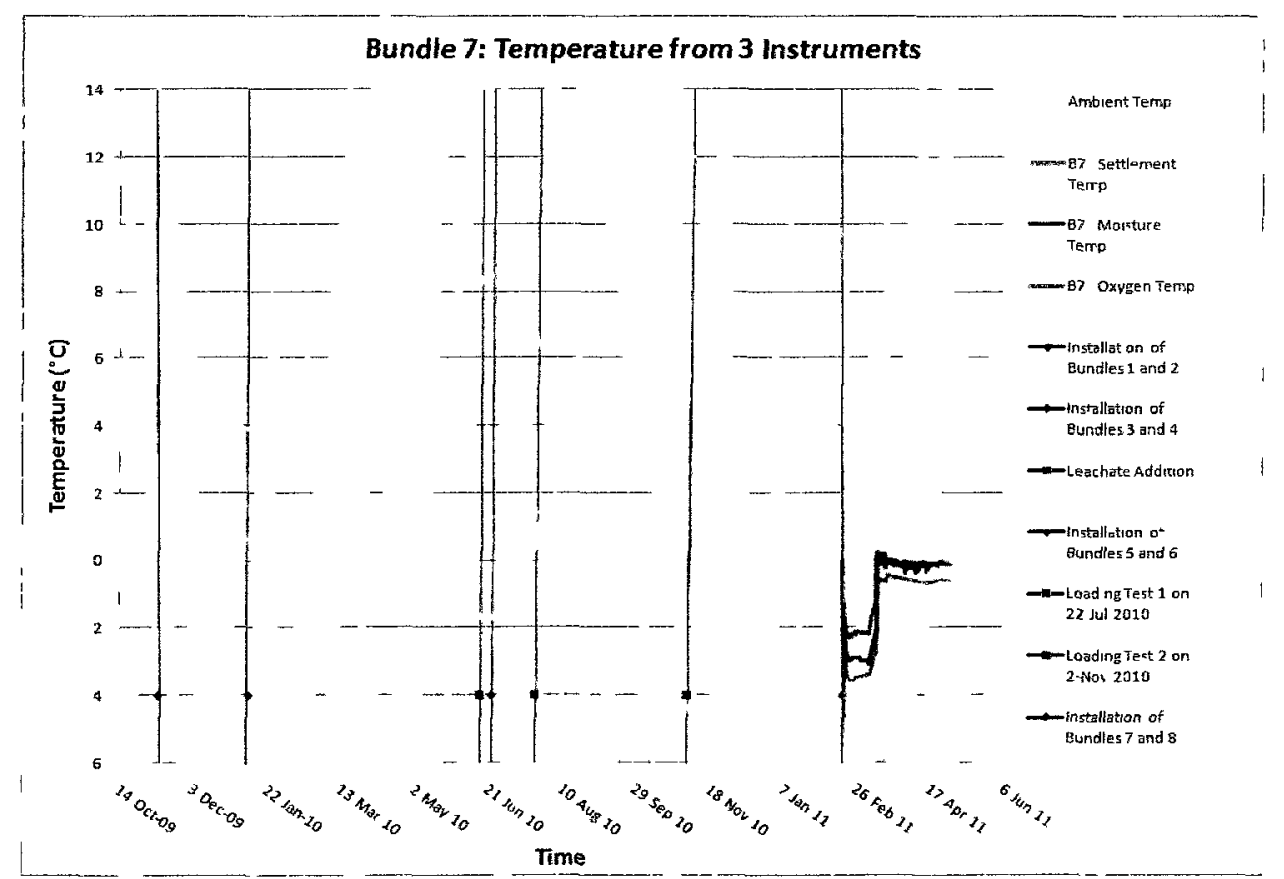

Figure 19: Temperature from 3 Instruments in Bundle 7. 


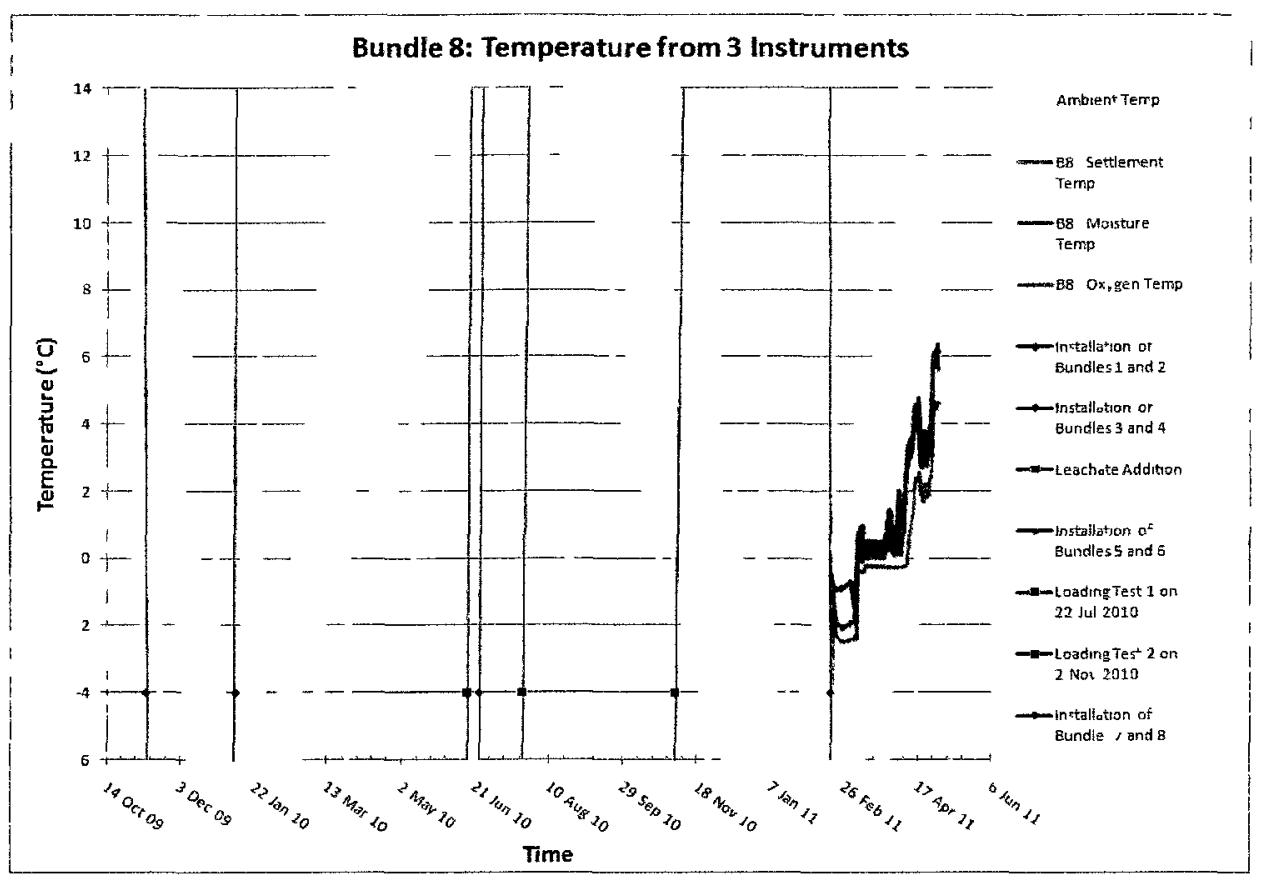

Figure 20: Temperature from 3 Instruments in Bundle 8.

Due to the approximate $2^{\circ} \mathrm{C}$ difference sometimes observed between the oxygen sensor and the remaining instrument temperatures, an average waste temperature was calculated based on only the temperatures measured by the settlement sensor, the piezometer, and the moisture and electrical conductivity sensor for each bundle.

While the thermistor of the settlement sensor in Bundle 4 malfunctioned from the time of installation in January 2010 to the beginning of May 2010; the average waste temperature was calculated by averaging only the piezometer and the moisture and electrical conductivity temperatures for that timeframe. After May 2010, the average waste temperature calculation included the temperature measured by the settlement sensor thermistor of Bundle 4. 
Figure 21 shows the average waste temperature at each bundle location from the settlement sensor (for Bundles 1-8), piezometer (for Bundles 1-4), and the moisture and electrical conductivity sensor (for Bundles 1-8).

As shown in Figure 21, the average temperatures recorded for Bundles 1 and 2 initially followed the positive ambient temperature as the bundles lay uncovered by waste for the first month, yet covered by a $0.5 \mathrm{~m}$ high protective sand layer. By December 2009, the ambient temperatures had dropped to below $0^{\circ} \mathrm{C}$ and the protective sand layer over the bundles froze. After that point, the temperatures measured by the instruments no longer followed the ambient temperature, but stabilized at a temperature of approximately $-0.5^{\circ} \mathrm{C}$. Soon after, from January $3-13$ 2010, the first layer of waste was placed over Bundles 1 and 2. The bundles maintained a stable temperature of approximately $-0.5^{\circ} \mathrm{C}$ even as the ambient temperature rose above $20^{\circ} \mathrm{C}$ in the summer of 2010 . This trend indicates even a frozen waste layer of $5 \mathrm{~m}$ high acts as an excellent insulator and implies that the thermal conductivity of waste is very low. Eventually, around August 2010, the temperatures of first two bundles reached $0^{\circ} \mathrm{C}$ indicating that the waste was beginning to thaw. The increased temperature measured at the bundles is largely attributed to heat from the ground reaching the bundles, as the bundles were placed on the cell floor immediately above the leachate collection system. Some temperature rise may also be due to heat given off from the warm leachate, generated in an older section of the bioreactor landfill, which travels through the underlying leachate collection system. 


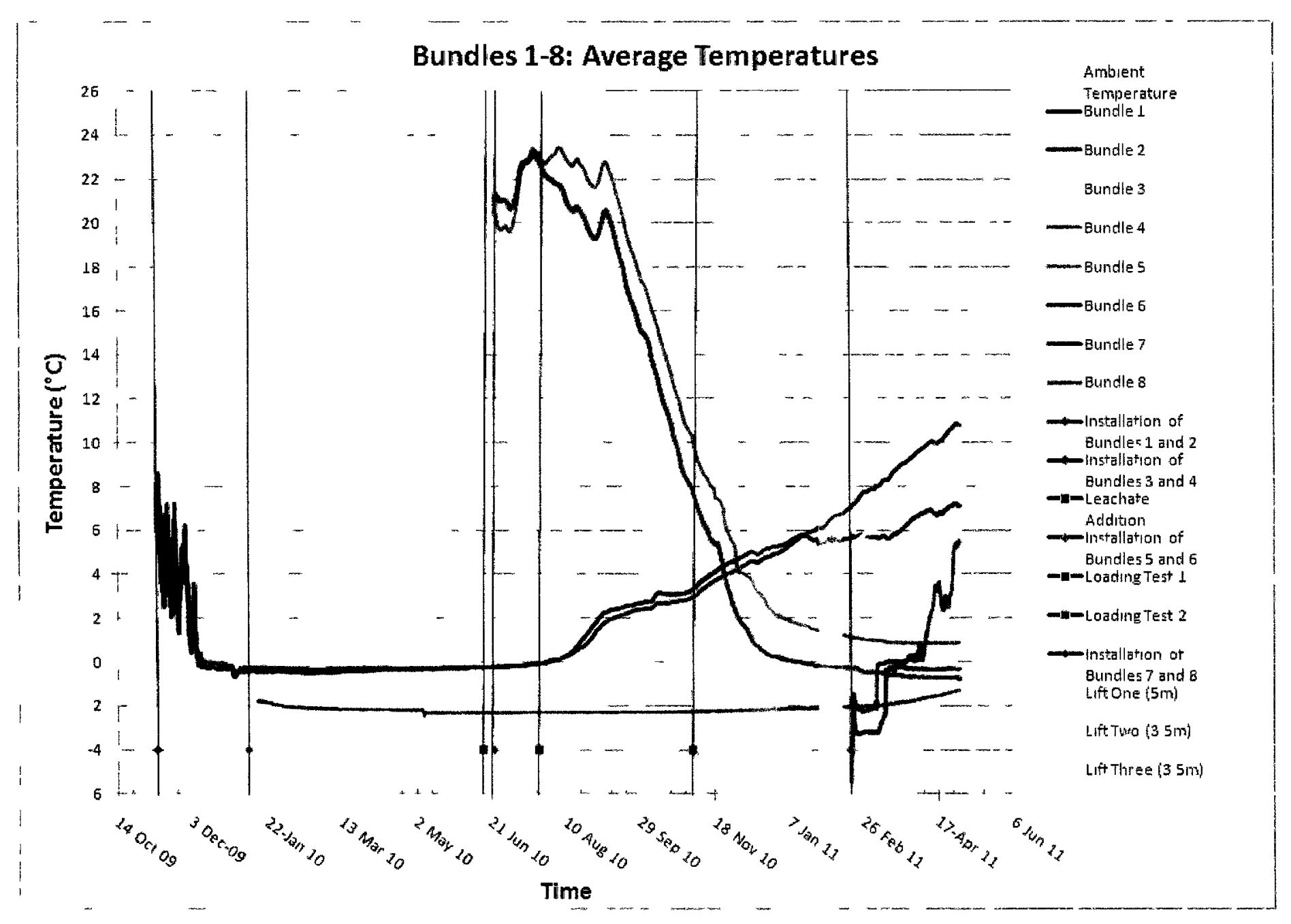

Figure 21: Average Temperature of Bundles 1-8. 
Bundles 3 and 4 were installed in January 2010 during the rolling out of the first waste lift. After approximately $2.5 \mathrm{~m}$ of waste was placed, the bundles were installed and were immediately covered with the remaining $2.5 \mathrm{~m}$ of waste for the $5 \mathrm{~m}$ lift. The ambient temperature during installation was below $0^{\circ} \mathrm{C}$, causing the waste around Bundles 3 and 4 to freeze as shown in Figure 21. Initial waste temperatures around Bundles 3 and 4 were measured at close to $-2^{\circ} \mathrm{C}$. Despite the ambient temperature rising to above $20^{\circ} \mathrm{C}$ in the summer of 2010 , limited heat could be transferred from the ambient air through the waste to promote any thawing of the waste. Once again, this trend indicates that the frozen waste has a low thermal conductivity thereby acting as a good insulator. Interestingly, the waste surrounding Bundle 3 began to thaw, with temperatures above $0^{\circ} \mathrm{C}$ being measured, starting in January 2011. Fifteen metres further into the landfill, Bundle 4 remained frozen while Bundle 3 thawed. The rapid rise in temperature at Bundle 3 is unexpected at this time, especially in comparison to the frozen state of Bundle 4 . However, it may be due to some generation of heat from an initiation of biological activity within the organic matter of the waste. Bundle 4 remained frozen from the time of installation to the end of the study period in April 2011, a length of 16 months; however, the temperature was rising near the end of the study period. As such, it may be possible that the frozen layer of waste surrounding Bundle 4 may thaw in the near future.

Bundles 5 and 6 were installed in the June 2010, and were covered immediately with $0.5 \mathrm{~m}$ of waste. Figure 21 shows that the temperatures measured at the bundles did not follow the daily fluctuation of ambient temperature, indicative of the insulating trend of the $0.5 \mathrm{~m}$ of material above the waste. However, the waste 
temperatures did decrease as the ambient temperature decreased and followed the average ambient temperatures lagged by several days. In December 2010, a second layer of waste was placed over the area of the instrument bundles providing an additional layer of insulation for the bundles. Soon after, a third waste lift was added to the landfill, in January and February 2011. By that time, the waste around Bundle 5 had retained just enough heat to remain above freezing, at approximately $1^{\circ} \mathrm{C}$. However, Bundle 6 had already lost sufficient heat such that the waste froze. The additional waste lifts have ensured that the waste around Bundle 5 was maintained at approximately $0.8^{\circ} \mathrm{C}$, and the waste around Bundle 6 was maintained at approximately $-0.4^{\circ} \mathrm{C}$ until the end of the study period.

Bundles 7 and 8 were installed in February 2011, with frozen waste below and $0.5 \mathrm{~m}$ frozen waste above. Over a span of two weeks, from the time of installation to early March 2011, both bundles measured stable negative temperatures of approximately $-3^{\circ} \mathrm{C}$ and $-2^{\circ} \mathrm{C}$ for Bundles 7 and 8 as shown in Figure 21. However, after an attempted excavation of Bundle 7 and an actual excavation of Bundle 8 on March 4, 2011 , the temperatures rose to $0^{\circ} \mathrm{C}$. From that point, the waste temperature measured at Bundle 7 has been maintained at $0^{\circ} \mathrm{C}$. Bundle 8 was excavated and left uncovered by waste until the end of the study period, although some sand and precipitation did flow into the excavation.

As discussed and presented in Figure 21, the waste temperature varied greatly at different points within the landfill, as measured at each instrument bundle, over the 16-month waste placement period from January 2010 to April 2011. The variations 
in waste temperature were dependent on the heat flux from surrounding soil and ambient temperature as well as potential heat generation from biological activity. Figure 22 and Figure 23 show the vertical temperature profiles observed in the waste lifts over the span of the study period, with arrows indicating the direction of the thermal gradient or heat flux.

The waste temperatures measured by the first column of instrument bundles, consisting of Bundles 1, 3, 5, and 7, are presented in Figure 22. A consistent transfer of heat from the underlying ground into the waste was observed through the increasing temperatures seen at Bundle 1 over the span of the study period. At the top of the $5 \mathrm{~m}$ first waste lift, the transfer of heat between the waste and the ambient temperature changed directions due to the fluctuating ambient temperatures according to the season. Initially, heat was leaving the waste as the ambient temperature was cooler. As the ambient temperatures increased in the summer months, the direction of heat transfer was reversed allowing heat to penetrate the waste. However, as seen by the temperature profile, the middle of the $5 \mathrm{~m}$ first waste lift remained frozen despite the high ambient temperatures during the summer of 2010 as it was inhibited by the poor conductance of heat by the waste. Instead, the transfer of heat from the underlying ground to the waste seems to have played a larger role in increasing the temperature in the middle of the $5 \mathrm{~m}$ first waste lift as measured at Bundle 3, due to the heat flux having been constant over the entire 16month period. By the end of the study period, there remained a frozen section of waste within the landfill due to the placement of the $3.5 \mathrm{~m}$ second waste lift and 3.5m third waste lift during the winter months of December 2010 to February 2011. 
Bundle 7 indicated that the top of $3.5 \mathrm{~m}$ third waste lift remained frozen through to the end of the study period, although the ambient temperature rose above $0^{\circ} \mathrm{C}$.

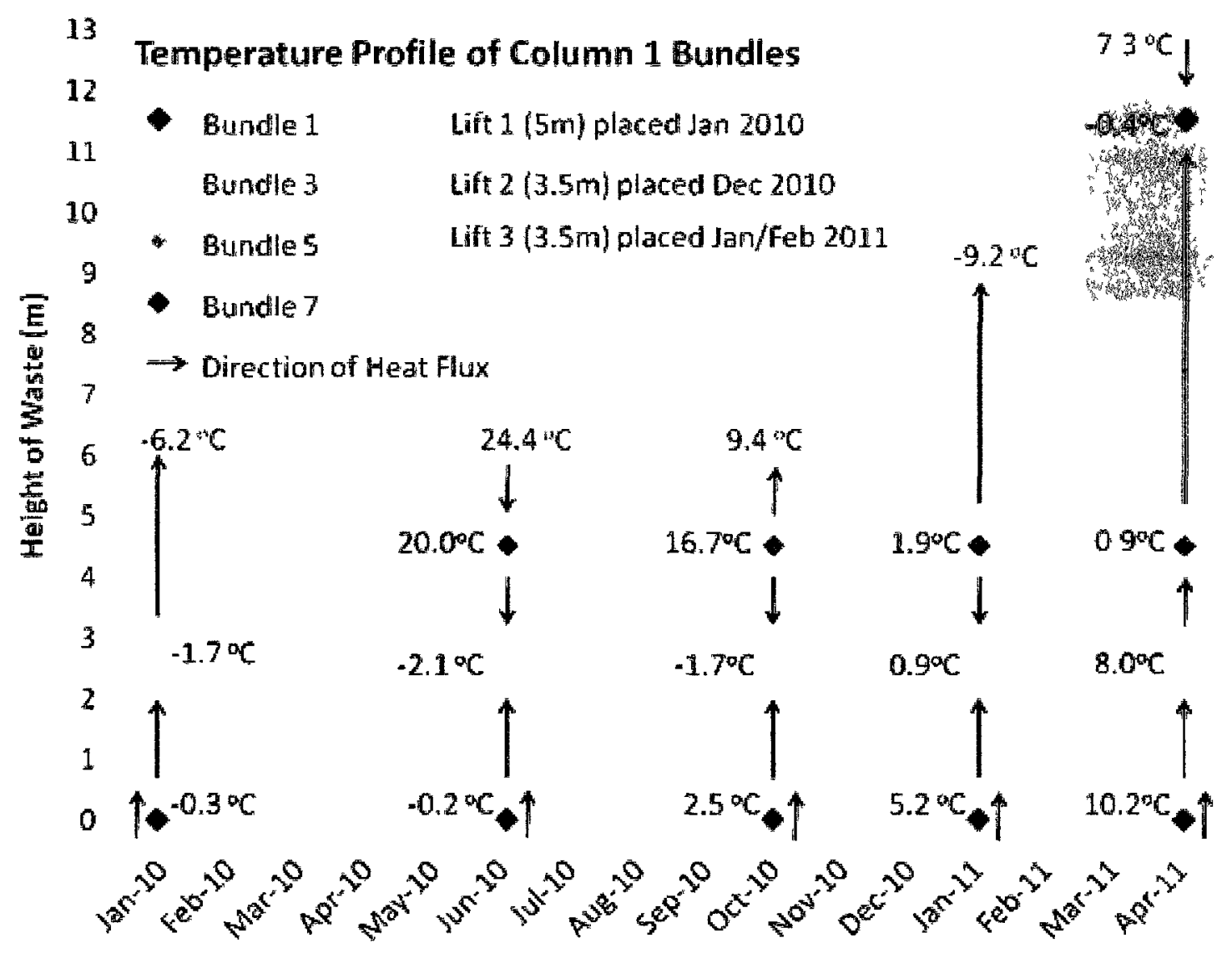

Figure 22: Temperature profile of waste in bioreactor landfill from Column 1.

Figure 23 presents the waste temperatures measured by the second column of instrument bundles consisting of Bundles 2, 4, 6, and 8. Bundle 2 shows increasing temperatures over the span of the study period due to a consistent transfer of heat from the underlying ground into the waste, which is a similar trend as discussed for Bundle 1 above. Again, the direction of heat transfer between the waste and the 
ambient temperature is reversing based on the season, as seen by the temperatures at Bundle 6 and the ambient temperatures. The heat transfer from the top of the $5 \mathrm{~m}$ first waste lift was so great, that the waste eventually froze as indicated by the Bundle 6 temperature in April 2011. The middle of the $5 \mathrm{~m}$ first waste lift also remained frozen throughout the study period. Positive temperatures were observed at Bundle 8 at the top of the $3.5 \mathrm{~m}$ third waste lift by the end of the study period; however, the positive temperature is a poor representation of the actual waste temperature due to the excavation exposing the bundle to the positive ambient temperature. Therefore, in Figure 23, a dashed line represents the unknown direction of heat flux as the actual temperature of the waste at Bundle 8 is unknown. 


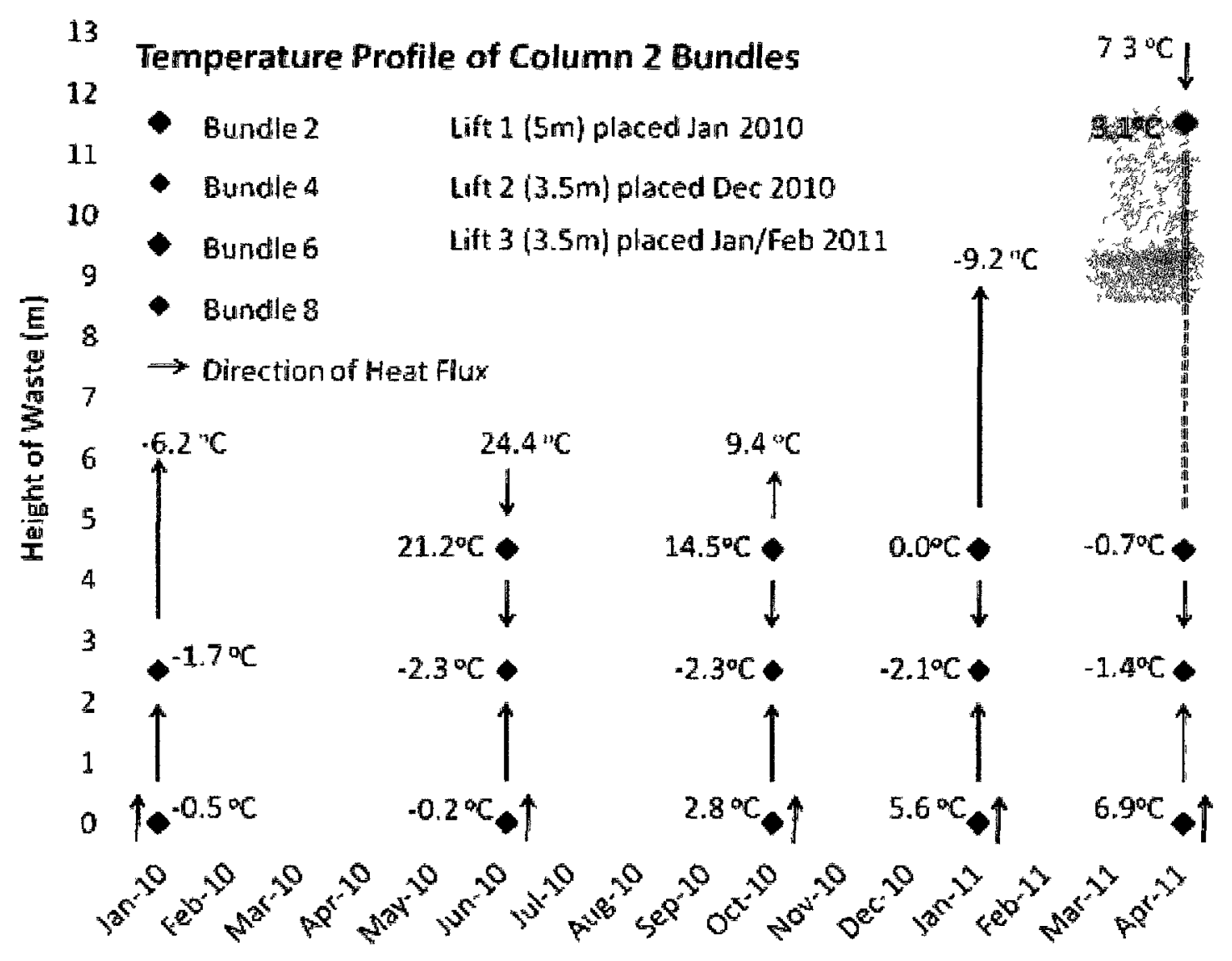

Figure 23: Temperature profile of waste in bioreactor landfill from Column 2.

The three waste lifts placed in the vicinity of the instrument bundles were rolled out during winter months. The low thermal conductivity observed for the waste is indicative of a good insulating material; as such, it proved extremely difficult for the waste lifts to thaw by means of high ambient temperatures during the short timeframe of subsequent summer months. Figure 24 shows the basic timeframe of waste placement in the empty cell of Zone 4 , with the location of the instrument bundle columns marked. The placement practices were such that the area of the landfill with the instrument bundles was filled with waste placed during winter 
months, while the opposite end of the landfill was filled with waste placed during late summer months.

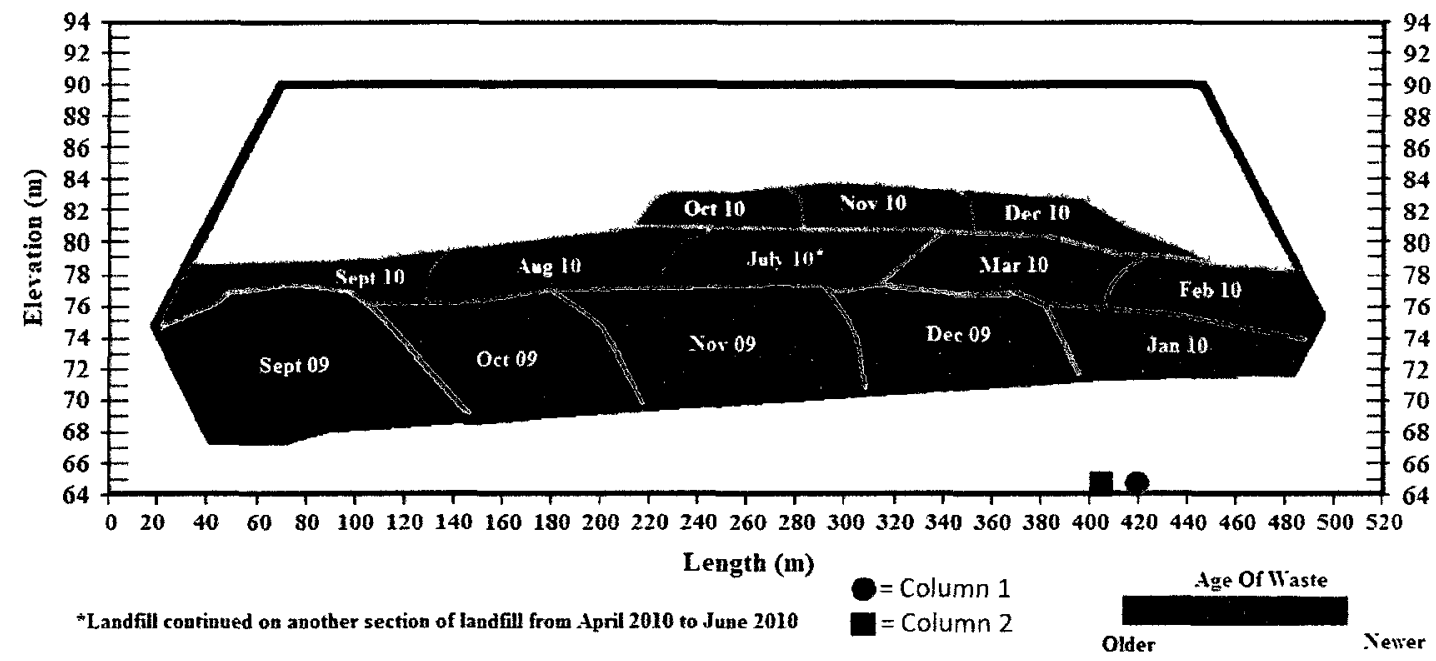

Figure 24: General time frame of waste placement in the bioreactor landfill.

In general, Figures 22 and 23 indicate that the sequence of waste placement in the vicinity of the instrument bundles has resulted in vertical temperature profiles with temperatures well below those expected in a bioreactor landfill and well below temperatures needed to support microbial activity.

Not only does the aforementioned waste placement practice inhibit microbial activity in the vicinity of the instrument bundles due to placement during winter months, but it also causes differential settlement to occur across the bioreactor landfill due to differing rates of settlement as a result of differing temperatures. Similar results were found during full-scale landfill studies at both the Northern Oaks Recycling and Disposal Facility (NORDF) and the Anchorage Regional Landfill 
(ARL). At both sites, waste placed during winter months remained frozen for periods of times after placement, from 6 months to 2 years. At the NORDF, differential settlement occurred within the landfill, with most settlement occurring within waste lifts placed in summer months due to the warmer temperature of the waste. At the ARL, a $7 \mathrm{~m}$ layer of waste remained frozen for a lengthy period, such that gas generation only began three to four years after waste placement.

Therefore, the sequencing of waste placement is an important issue for bioreactor landfills in northern climates, as microbial activity and waste stabilization are a function of temperature. In addition, revenue generated through gas-to-energy projects may be reduced if favourable temperatures for microbial activity can not be reached quickly. The delay in the biodegradation process caused by low waste temperatures will extend the contaminating lifespan of a landfill as it will take longer for the waste to stabilize. Designing a waste placement sequence that avoids several consecutive waste lifts placed under freezing conditions will help ensure that certain waste layers do not remain frozen for extended periods of time. If waste placement can be sequenced such that waste lifts placed in January are covered with waste lifts placed in July, the heat initially contained in the waste and the biodegradation that will occur in the warm waste layer will help to increase the temperature in the adjacent frozen waste layer. This will eventually lead to a more uniform temperature and more uniform waste stabilization within the bioreactor landfill. 


\subsubsection{Total Earth Pressure Cell}

The total earth pressure cell (TEPC) produced vibrating wire outputs in B units $\left(\mathrm{Hz}^{2} \times 10^{-3}\right)$. The raw outputs from the TEPC required corrections for initial installation readings and barometric pressure, in order calculate an actual pressure reading in $\mathrm{kPa}$. Appendix $\mathrm{D}$ contains all calibration equations, a sample calculation, and calibration records, for the TEPC.

During installation, the sensors read large pressures without any application of load. Therefore, the pressure readings were zeroed post-process to indicate that, at installation, there was no waste over the instrument bundle - and hence no pressure on the TEPC. The zeroing was calculated by subtracting the initial installation pressure reading from the current pressure reading.

Figure 25 shows a plot of the final TEPC values representing the pressure exerted by the waste above each instrument bundle on the TEPC versus time. Overall, the expected pressures resulting from the three waste lifts placed in the landfill cell during the study period are indicated by coloured rows on this figure. The expected pressures based on the initial waste lift height were estimated assuming a constant waste density of $1000 \mathrm{~kg} / \mathrm{m}^{3}$, which reflected the placement densities determined by Waste Management based on quarterly surveys of the Sainte-Sophie site. 


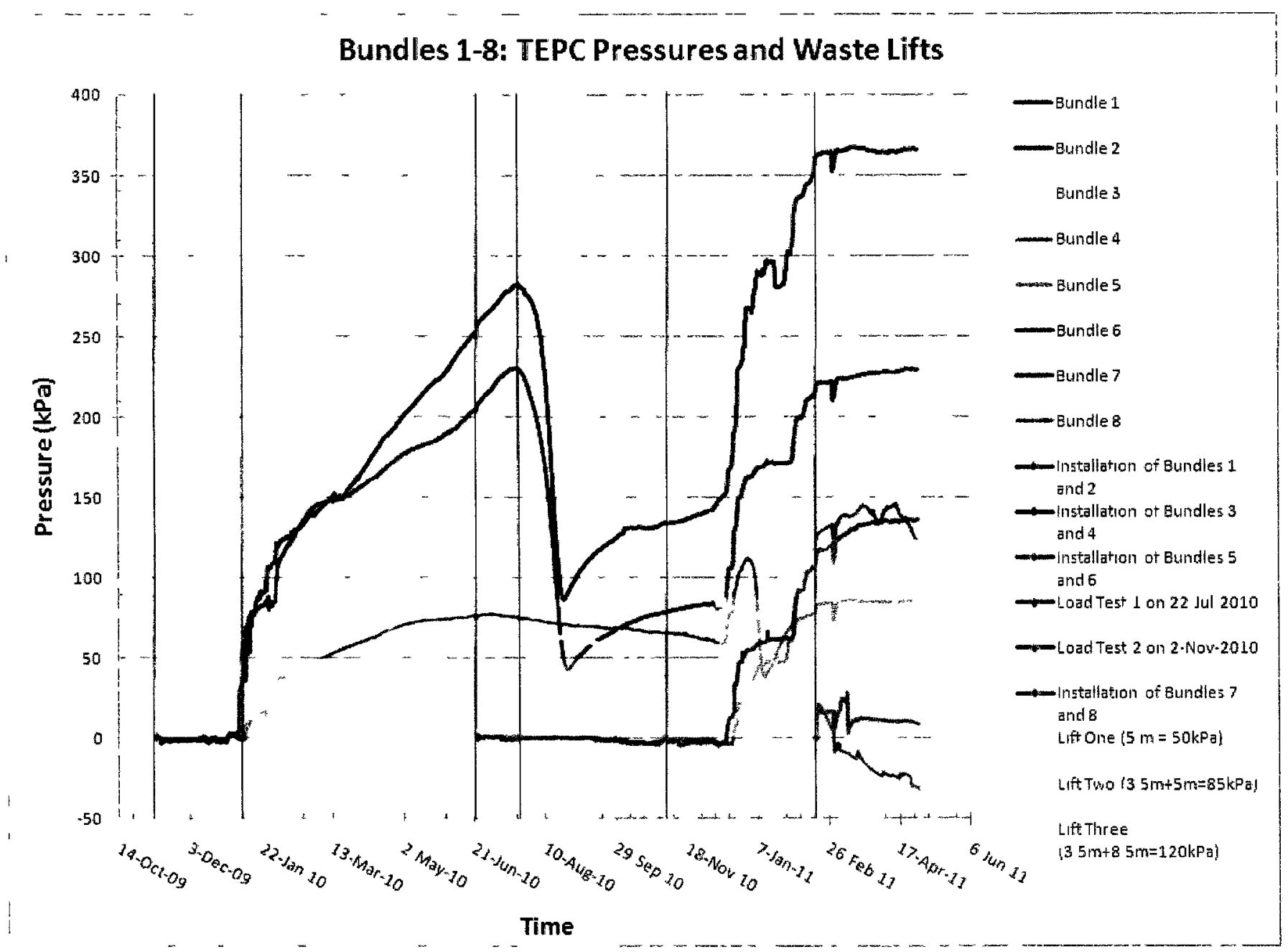

Figure 25: TEPC pressure versus time for Bundles 1-8. 
The pressures measured by the TEPCs as shown in Figure 25 are split into four plots, as shown in Figures 26-30, to compare the measured pressures to the estimated expected pressures for each instrument bundle.

Figure 26 shows the pressures exerted on the TEPCs due to waste accumulated above Bundles 1 and 2 from the placement of the first, second, and third waste lifts. Bundles 1 and 2 were installed with a protective layer of sand of approximate height of $0.5 \mathrm{~m}$. The pressures recorded by Bundles 1 and 2 followed the expected trend corresponding with the $0.5 \mathrm{~m}$ sand layer. In January 2010 , the first waste lift was placed over Bundles 1 and 2 with a constant expected pressure trend of $50 \mathrm{kPa}$. The pressures recorded by Bundles 1 and 2 indicated a sharp pressure increase at the time of the first waste lift placement. However, the pressure continued to increase with time although no additional waste was placed, which is counterintuitive.

When the first waste lift was placed, the waste surrounding both bundles was frozen. Originally, two scenarios related to freezing temperatures were hypothesized to explain the puzzling pressure readings. The first scenario suggested a bridging of pressure occurring within the waste because the waste was frozen. Rather than the initial assumption of pressure reflecting the height of a vertical column of waste above instrument bundle, the TEPC would be measuring greater pressures due to a frozen volume of waste above the instrument bundle that is wider that the just the vertical column of waste. This scenario showed merit after the first load test. The first load test, completed on July 22, 2010, involved placing an additional load (via a filled dump truck) over the instrument bundles to observe 
pressure changes. Pressures recorded by Bundles 1 and 2 decreased after the first load test, suggesting that the bridging within the frozen waste may have shifted or changed. The pressure at Bundle 2 dropped to the expected pressure trend of $50 \mathrm{kPa}$. Yet, while the pressure at Bundle 1 did decrease, the TEPC still recorded a higher pressure than expected. After the sharp declines, the TEPC indicated rising pressures once again although the expected pressure remained constant. Therefore, it was unlikely that a bridging of pressure within frozen waste could completely explain the higher than expected pressure readings.

The TEPCs responded sharply to the second and third waste lifts which were placed in December 2010 and January 2011. However, higher pressures than expected were still recorded. The pressure readings varied between Bundles 1 and 2, although both bundles had similar amounts of waste placed over them. The second scenario, which was hypothesized to explain the puzzling pressure readings related to freezing temperatures, is more comprehensive than the first scenario as it also explains the continued high pressure recordings. According to the second scenario, it is believed that water may have seeped between the bottom side of the TEPC and the steel plate to which it is mounted. Because the temperatures were below zero, this water would have frozen and created an ice lens. The ice lens would expand in the area between the base of the TEPC and the steel plate, pushing on the base of the TEPC, deflecting it upwards. The deflection of the TEPC would increase the recorded pressure, resulting in higher than expected pressures. If this scenario were true, as the temperatures at Bundles 1 and 2 increased above zero, the pressures from the ice lens should dissipate and TEPCs should record pressures that once again reflect 
the height of waste in a vertical column above the TEPCs. This did not occur. However, it is possible that the deflection of the base of the TEPC was permanent, and added residual pressure. 
Bundles 1-2: TEPC Pressure

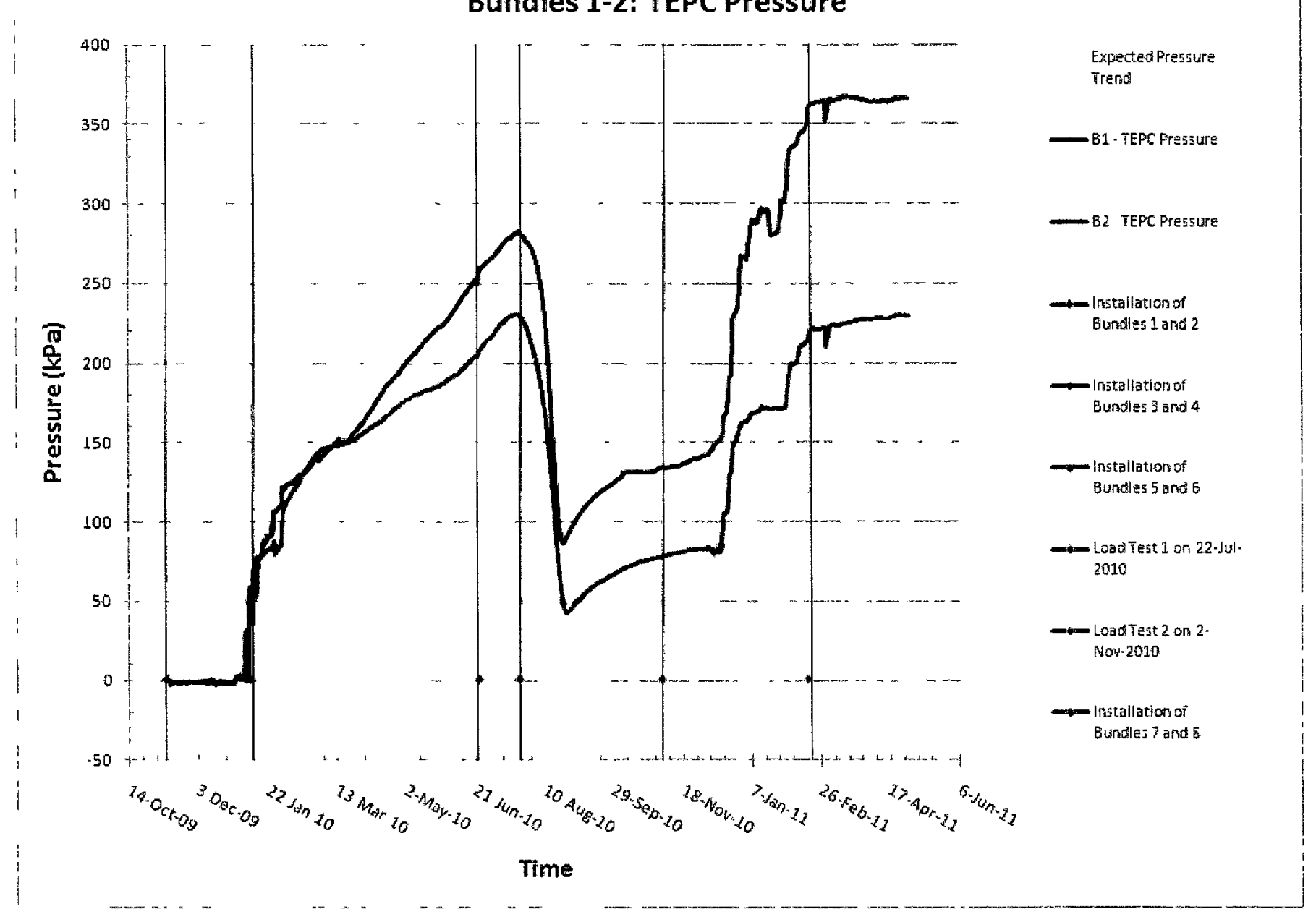

Figure 26: TEPC pressure versus time for Bundles 1-2.

71 
Figure 27 shows the pressures measured by the TEPCs in Bundles 3 and 4 . Bundles 3 and 4 were installed half-way into the first waste lift, with approximately $3 \mathrm{~m}$ of waste below and $2 \mathrm{~m}$ of waste above the bundles. The pressures recorded by Bundles 3 and 4 responded to the addition of the $2 \mathrm{~m}$ of waste above the bundles. However, pressures continued to rise above the expected pressure trend of approximately $33 \mathrm{kPa}$. A slow decrease in pressure was noticed for both bundles after the first and second load tests, with only Bundle 3 dropping to the initial expected pressure. Both bundles responded to the addition of the second waste lift of $3.5 \mathrm{~m}$ in December 2010, but continued to show higher than expected pressures. Bundle 4 showed a sharp decrease in pressure followed by a sharp increase in pressure. This response was similar to the sharp fall and rise in pressures recorded at Bundles 1 and 2; however, this trend was not related to any change in expected pressures or temperature. With the addition of the third waste lift of $3.5 \mathrm{~m}$ in January 2011, both bundles again responded but with higher than expected pressures. 


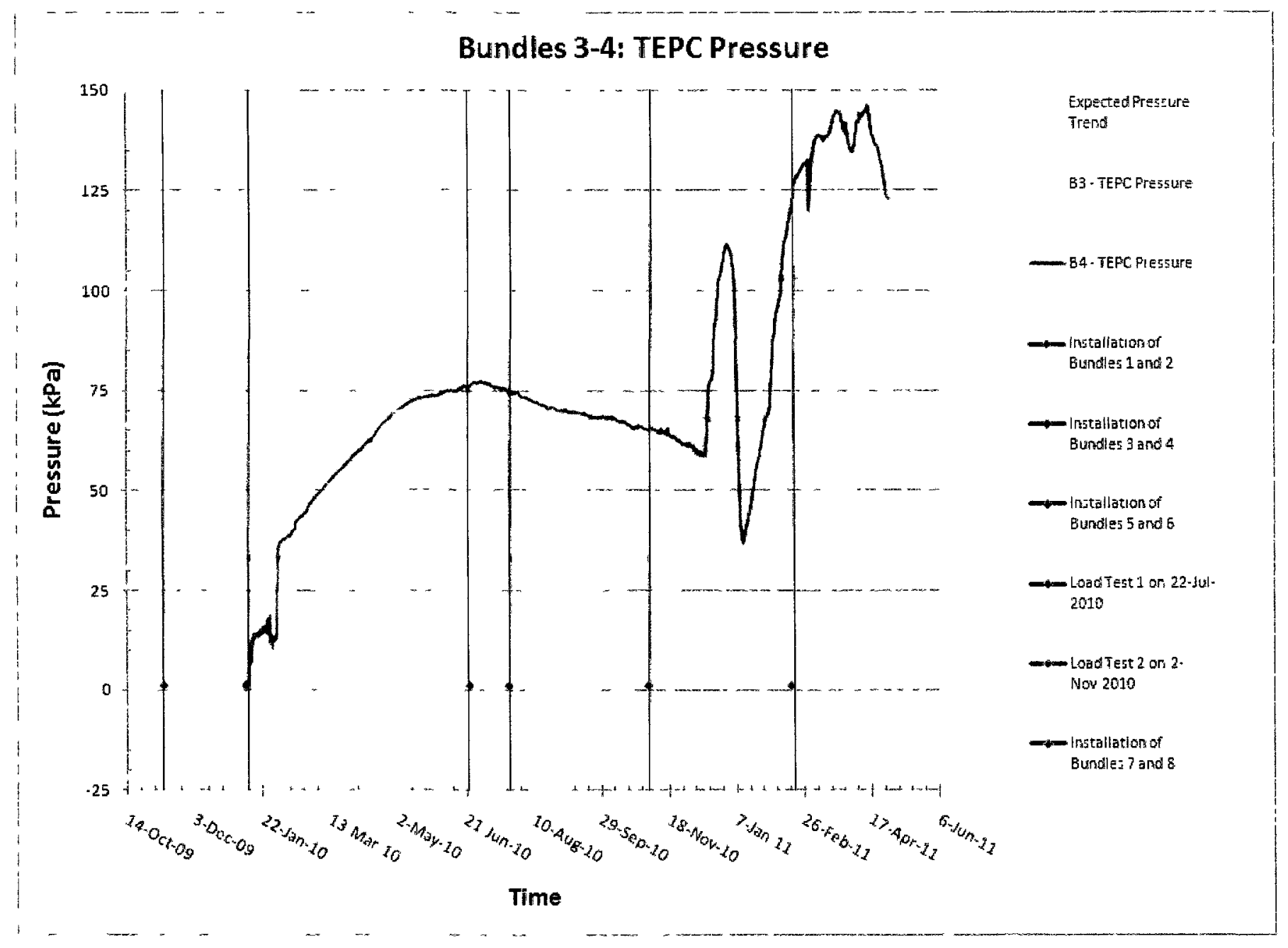

Figure 27: TEPC pressures versus time for Bundles 3-4.

73 
Figure 28 shows the pressures measured by the TEPCs at Bundles 5 and 6 . Bundles 5 and 6 were installed at the top of the first waste lift, with $0.5 \mathrm{~m}$ of waste above the bundles. The waste surrounding Bundle 5 was the only instrument bundle location which never froze throughout the study period. As such, Bundle 5 represented the only data in which the scenario of the ice lens is not applicable. Not coincidentally, the pressures recorded at Bundle 5 corresponded well with the expected pressure trend. This indicates that the pressure readings at Bundle 5 relate well to the amount of waste accumulated above the bundle. Both Bundles 5 and 6 showed incremental pressure step increases which corresponded with the addition of the second and third waste lift. However, the TEPC at Bundle 6 continued to measure increasing pressures after the placement of the third waste. 


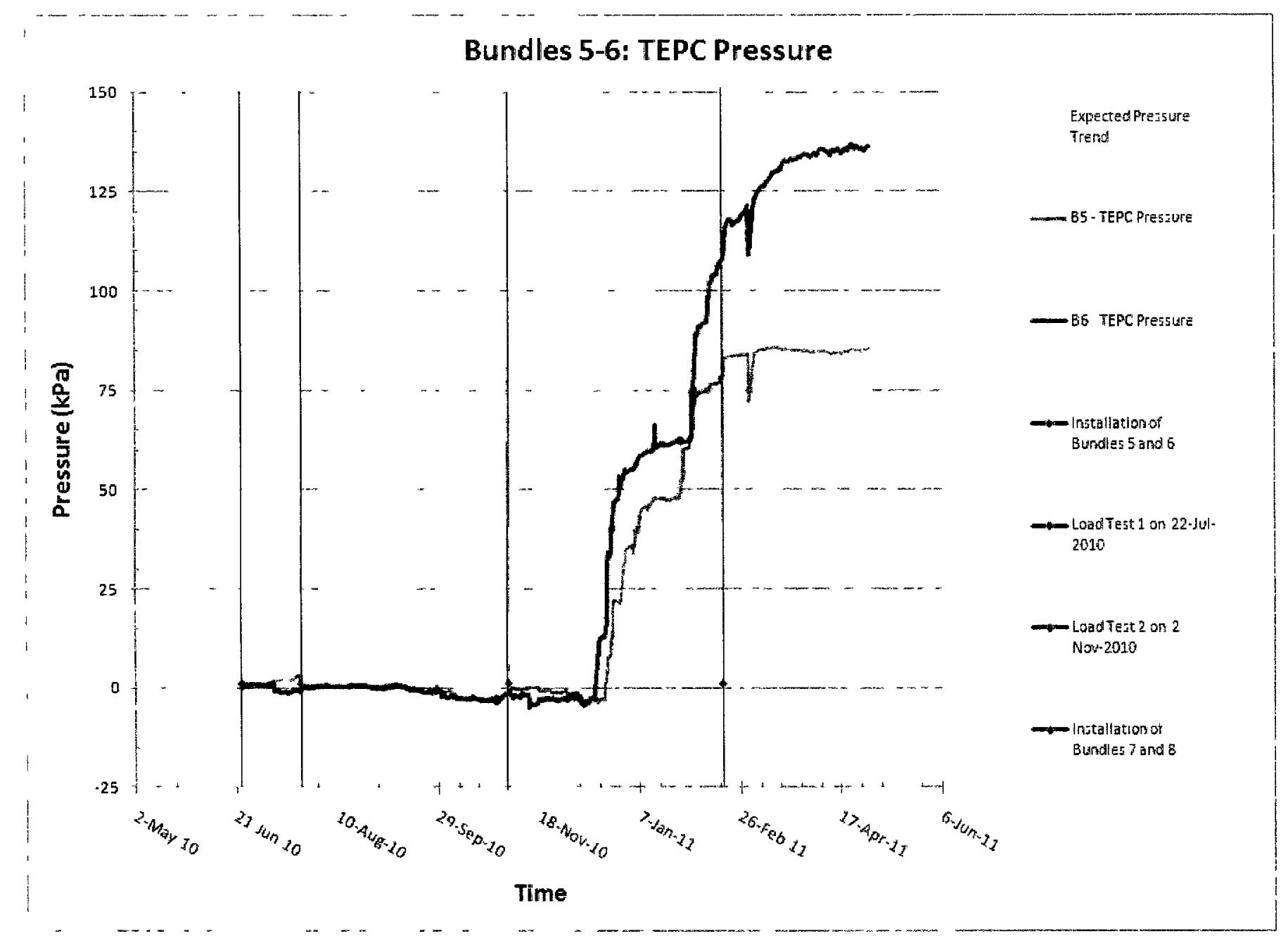

Figure 28: TEPC pressures versus time for Bundles 5-6. 
Figure 29 shows the pressure measured by the TEPC in Bundles 7 and 8 . Bundles 7 and 8 were installed at the top of the third waste lift, with approximately $0.5 \mathrm{~m}$ of waste above the bundles. The waste was frozen upon placement of the instrument bundles, and the scenario of the ice lens would be applicable for both bundles. Initially, both bundles showed pressures which corresponded fairly well with the expected pressure trend. However, around the time of the excavation of Bundle 8 on March 4 2011, both bundles experienced a sharp decrease in pressure. Over time, the pressure readings from Bundle 7 stabilized and continued to follow the expected pressure trend. Although the waste was frozen, the consistent pressure readings indicated that it was unlikely that an ice lens has deformed the TEPC. Bundle 8 was excavated and remained exposed to the elements to the end of the study period. Negative pressure readings were recorded starting at the time of excavation and continuing to the end of the study period. During the excavation, the TEPC at Bundle 8 may have been punctured or impacted and no longer provides reliable pressure readings. 


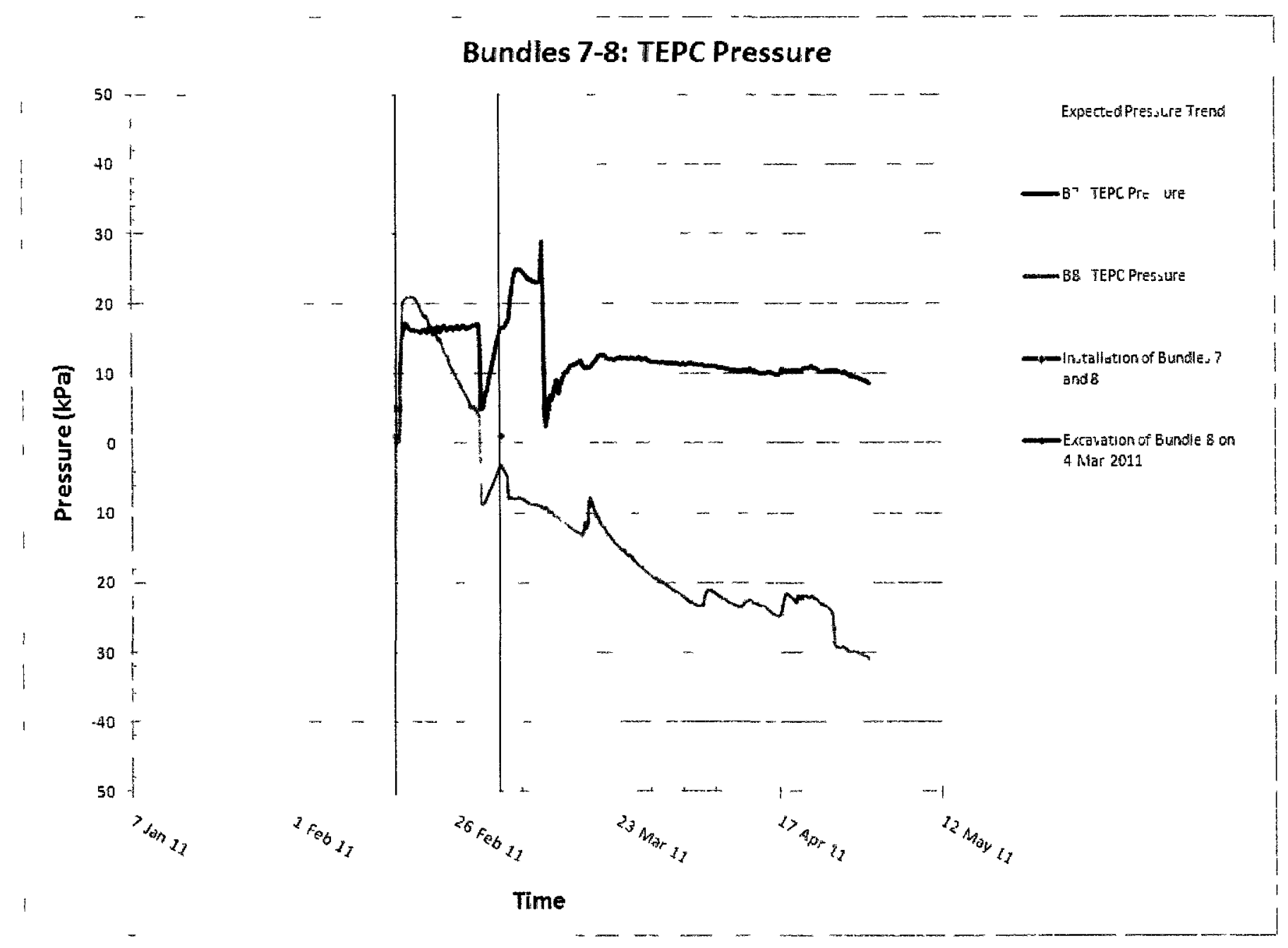

Figure 29: TEPC pressures versus time for Bundles 7-8. 
Some error should be associated with the calculation of the expected pressure due to the assumption that the waste density would remain constant over the course of the study period at $1000 \mathrm{~kg} / \mathrm{m}^{3}$. The density of the waste would in reality increase over time as a result of consolidation or settlement of the waste. Increased density is especially likely as moisture content increases aiding in waste settlement. However, conservative estimates of the possible increase in waste density due to settlement and additional moisture are not sufficient to account for the large differences seen in the TEPC data; especially for Bundles 1 and 2 where the TEPC data indicates pressures 2 to 3 times the expected values.

To trouble shoot the larger than expected readings from the TEPCs, two loading tests were conducted. On July 22,2010 , a dump truck filled with waste was placed over the instrument bundles to act as a load source. The dump truck was initially placed over Bundles 1, 3, and 5 for a time period of 10 minutes, with the wheels of the dump truck straddling the location of the instrument bundles; i.e. the centre of the truck was placed directly above the bundles which resulted in the wheels of the dump truck applying load approximately $2 \mathrm{~m}$ from the instrument bundles (see Figure D-9). The dump truck generated an estimated average load of $25 \mathrm{kPa}$ over an area equal to the wheel base of the dump truck. The dump truck was then moved over Bundles 2, 4, and 6 for a 10 minute period, again with the wheels of the dump truck straddling the location of the instrument bundles. Figure 30 shows the response of the TEPC pressures to the loading tests. 
TEPC : Load Test 1 on July 22, 2010: Bundles 1-6

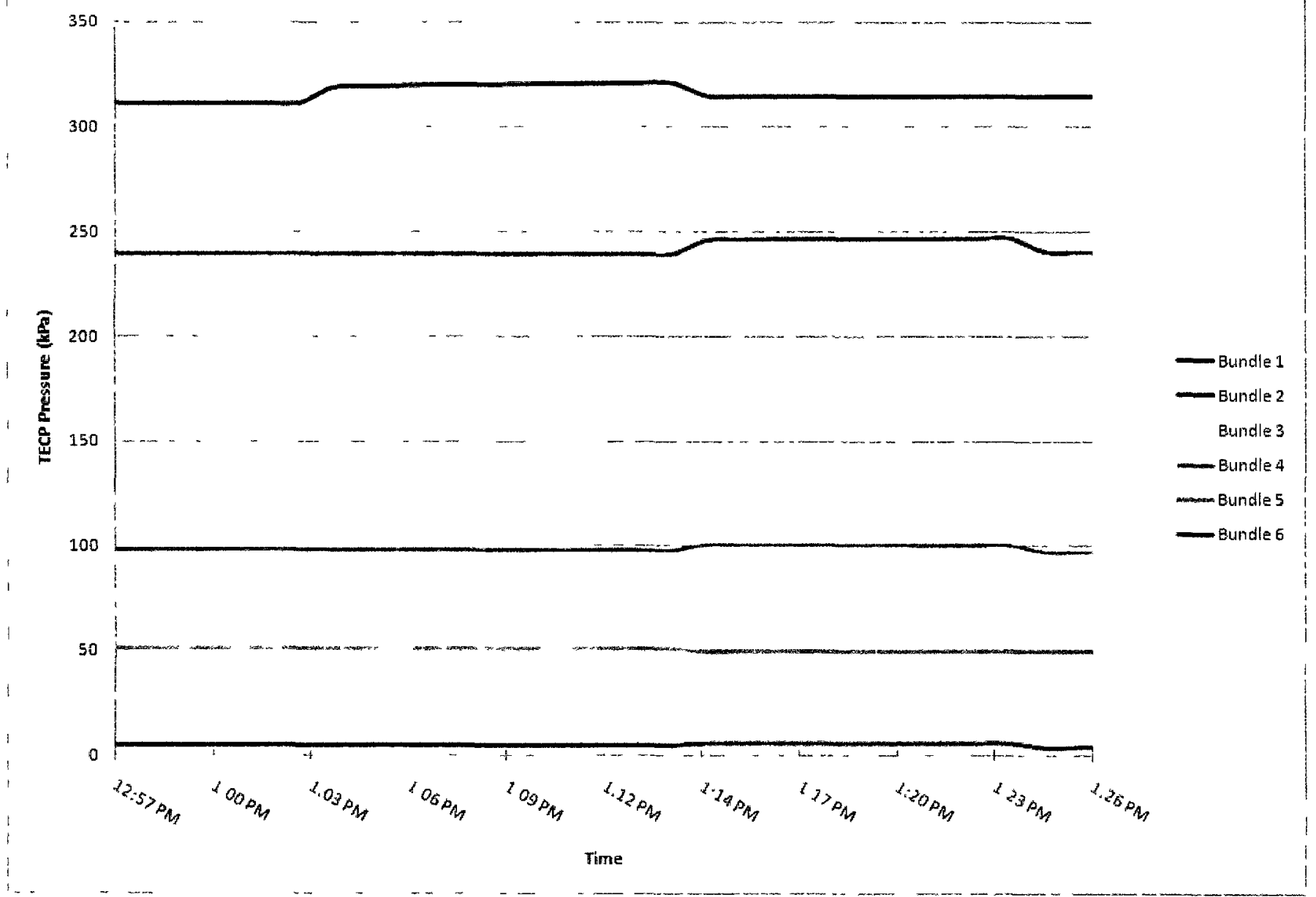

Figure 30: TEPC pressure for Bundles 1-6 during loading test 1 on July 22, 2010. 
The expected trend for the loading test was that the instrument bundles closest to the load source would experience the largest increase in pressures. The observed trend during the first loading test was opposite of the expected trend. Five metres of waste separated Bundles 1 and 2 from the load source, and the bundles showed an increase in pressure of approximately $10 \mathrm{kPa}$ and $7.5 \mathrm{kPa}$ during loading. Two metres of waste separated Bundles 3 and 4 from the load source. These bundles showed an increase in pressure of approximately $4.7 \mathrm{kPa}$ and $2.5 \mathrm{kPa}$ during loading, which is smaller than the observed pressure at Bundles 1 and 2. Half a metre of waste separated Bundles 5 and 6 from the load source. Bundle 6 showed an increase in pressure of about $1 \mathrm{kPa}$ during loading. Bundle 5 however showed no increase during loading, but did experience a decrease in pressure of approximately $0.2 \mathrm{kPa}$ after loading. The limited response at Bundles 5 and 6 may be attributed to the fact that the dump truck wheels straddled the bundle locations. For typical soils, one would expect the pressures to be greatest immediately below the source load and decrease with depth. From this test, the opposite was recorded in that the instrument bundles furthest from the load source experienced higher pressures than the closer instrument bundles. As discussed earlier in this section, the pressures at Bundles 1 and 2 may be higher than expected due to the frozen waste mass above the bundles. The placement of the additional load just added to the total mass. Bundles 3 and 4 are contained within the frozen waste mass and as a result did not take as much load. It may be that the frozen waste mass acted as a bridge to direct the pressure from the load source directly to Bundles 1 and 2. 
On November 2, 2010, the second load test was performed with an excavator placed over the instrument bundles to act as a load source (see Figure D-10). The excavator was placed over Bundles 2, 4, and 6 for about 20 minutes. The data collected by the datalogger was accidently deleted by the datalogger program, and hence is not presented here. However, field notes of the pressures recorded during the second loading test showed a similar trend to that which was experienced during the first loading test. That is to say, the instrument bundle furthest from the load source experienced higher pressures than the instrument bundle closest to the load source. During the second load test, the waste surrounding Bundles 1 and 2 had thawed with temperatures reaching approximately $3^{\circ} \mathrm{C}$. However, a frozen layer of waste surrounding Bundles 3 and 4 still existed, which may have continued to act as a bridge to direct the pressure from the load source directly to Bundles 1 and 2 .

Studies completed at the New River Regional Landfill (NRRL) have involved testing similar pressure cells in the base of a bioreactor landfill. Data showed that the pressure cells responded with pressure step increases corresponding with the placement of a waste lifts. However, the pressure values were underestimated (by nearly half of the value) when compared to expected values. The opposite of this issue is experienced in the current study. In several instrument bundles, there is an overestimation of pressure by the TEPC. The NRRL suggested that arching (or bridging) of pressures within the waste may have distributed the pressures over the pressure cells resulting in lower pressure readings. The same idea has been presented in the first scenario for this study which suggests that bridging of pressures has distributed additional pressure directly onto the TEPC, causing the 
TEPC to read higher pressures. Bundle 8 measured increasingly negative pressures after being excavated; it may be that the TEPC was punctured during the bundle excavation and is therefore producing impossible values.

\subsubsection{Liquid Settlement System}

The liquid settlement sensors and accumulators produced outputs in B units $\left(\mathrm{Hz}^{2} \times 10^{-3}\right)$ and temperature readings in degrees Celsius. The raw outputs from the transducers at the settlement sensors and accumulators required corrections for initial installation readings and temperature, in order to determine settlement. Appendix E contains all calibration equations, a sample calculation, and calibration records for the liquid settlement system.

The change in sensor depth was calculated by subtracting the pressure readings between the settlement sensor at the instrument bundles and the accumulator in the instrument shed. Barometric pressure corrections were negligible in the calculations, as the same pressure acts on both the settlement sensor and the accumulator. The difference in pressure between the settlement sensor and the accumulator was converted to an equivalent height, in metres, based on the assumed density of the water/glycol mixture which hydraulically connects the two units. The initial elevation difference or height between the settlement sensor and the accumulators is known and the settlement is equal to the difference between the initial and the heights estimated by the difference in the pressure transducers. The final elevation of the instrument bundle was calculated by subtracting the settlement from the initial placement elevation of the instrument bundle. 
Figure 31 shows a plot of the elevations of the eight bundles within the waste over time. This plot visually indicates the elevation of each bundle in relation to the other bundles within the waste. A decrease in elevation of an instrument bundle corresponds to the amount of settlement it has experienced. Figure 32 shows the amount of settlement experienced by each instrument bundle. Each instrument bundle has experienced some settlement. The largest settlement has occurred at Bundles 3, 4, 5, and 6 with values reaching between $0.96 \mathrm{~m}-1.32 \mathrm{~m}$.

The accuracy of the settlement systems were provided in the individual calibration sheets in Appendix E. A summary of these values are provided in the following table.

Table 4: Accuracy of Settlement System for Bundles 1-8.

\begin{tabular}{|l|l|l|l|l|l|l|l|l|}
\cline { 2 - 7 } \multicolumn{1}{c|}{} & $\begin{array}{l}\text { Bundle } \\
1\end{array}$ & $\begin{array}{l}\text { Bundle } \\
2\end{array}$ & $\begin{array}{l}\text { Bundle } \\
3\end{array}$ & $\begin{array}{l}\text { Bundle } \\
4\end{array}$ & $\begin{array}{l}\text { Bundle } \\
5\end{array}$ & $\begin{array}{l}\text { Bundle } \\
6\end{array}$ & $\begin{array}{l}\text { Bundle } \\
7\end{array}$ & $\begin{array}{l}\text { Bundle } \\
8\end{array}$ \\
\hline $\begin{array}{l}\text { Accuracy } \\
\pm \mathrm{cm})\end{array}$ & 6.63 & 6.29 & 7.14 & 7.14 & 6.12 & 6.80 & 8.16 & 8.16 \\
\hline
\end{tabular}




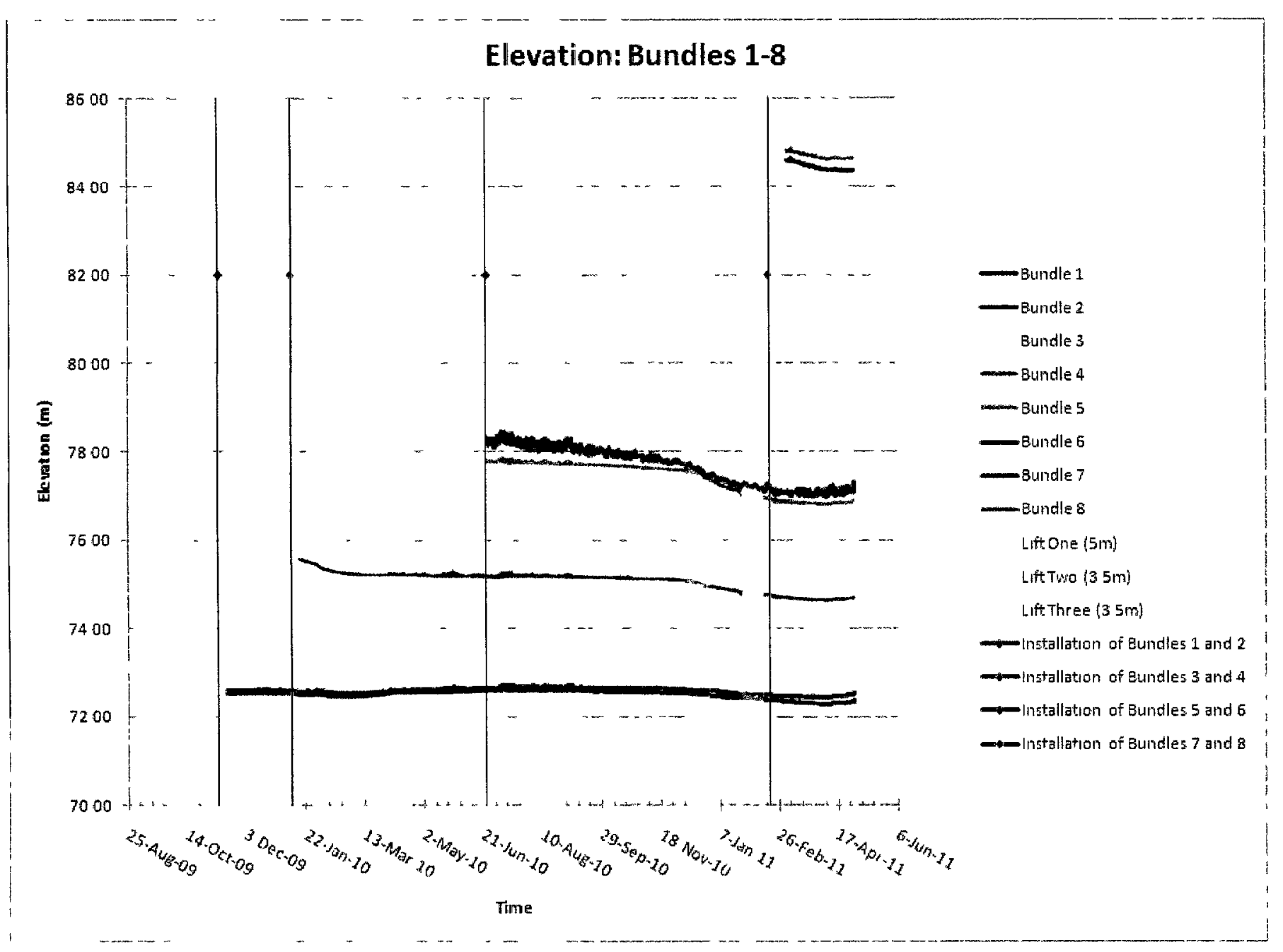

Figure 31: Instrument bundle elevation versus time. 


$$
\mathscr{L}
$$


The settlement measured by the settlement sensors as shown in Figure 32 were split into four plots, as shown in the following Figures 33-36, to compare the measured settlement to the measured pressures by the TEPC and the estimated expected pressures for each instrument bundle.

Bundles 1 and 2 were installed in late October 2009 and began recording settlement data in early November 2009. The bundles were installed directly on the cell floor over the gravel layer of the leachate collection system. The GPS rover was used to survey the initial elevations which were found to be at elevations of $72.58 \mathrm{~m}$ and $72.47 \mathrm{~m}$. A $0.5 \mathrm{~m}$ thick protective layer of sand was placed over the instrument bundles. Figure 33 shows the settlement experienced by Bundles 1 and 2 over the study period compared to the measured pressures from the TEPC and the estimated expected pressure. Initially, while the bundles were covered by only the $0.5 \mathrm{~m}$ layer of sand, there is negligible settlement due to the limited load.

In January 2010, the first waste lift of approximately $5 \mathrm{~m}$ (corresponding with a pressure of approximately $50 \mathrm{kPa}$ ) was placed over the instrument bundles. Despite the TEPC indicating rising pressures, the expected pressure trend shown in Figure 33 is more realistic as there was no change in load between the placement of the first waste lift and second waste lift. The accuracy of the settlement systems for Bundles 1 and 2 are $\pm 6.63 \mathrm{~cm}$ and $\pm 6.29 \mathrm{~cm}$, respectively, which accounts for a large portion of the variation seen in the settlement measurements after placement of the first waste lift. The second and third pressure step increases seen in the expected pressure trend in Figure 33 indicates the time at which the second waste lift and 
third waste lift were placed over the instrument bundles. In December 2010, the $3.5 \mathrm{~m}$ thick second waste lift was placed over the instrument bundles, and promoted an increased rate of settlement. After one month of the second waste lift being placed, Bundles 1 and 2 settled approximately $10 \mathrm{~cm}$. After the one month period, the $3.5 \mathrm{~m}$ thick third waste lift was placed over the instrument bundles in January and February 2011. The rate of settlement for Bundle 1 decreased shortly after the placement of the third waste lift. The rate of settlement for Bundle 2 continued at the same pace for a slightly longer period of time before it too decreased. In the first week of April 2011, a maximum settlement of approximately $0.16 \mathrm{~m}$ was reached for Bundle 1, and approximately $0.24 \mathrm{~m}$ for Bundle 2 . Near the end of April 2011, there appears to be a rebound of the instrument bundles within a short span of time after the bundles achieved their maximum settlement. There is no physical explanation for this and future monitoring of the settlement of these bundles will determine whether the rebound is actually occurring and to what extent or whether the values are a function of unaccounted instrument error. 


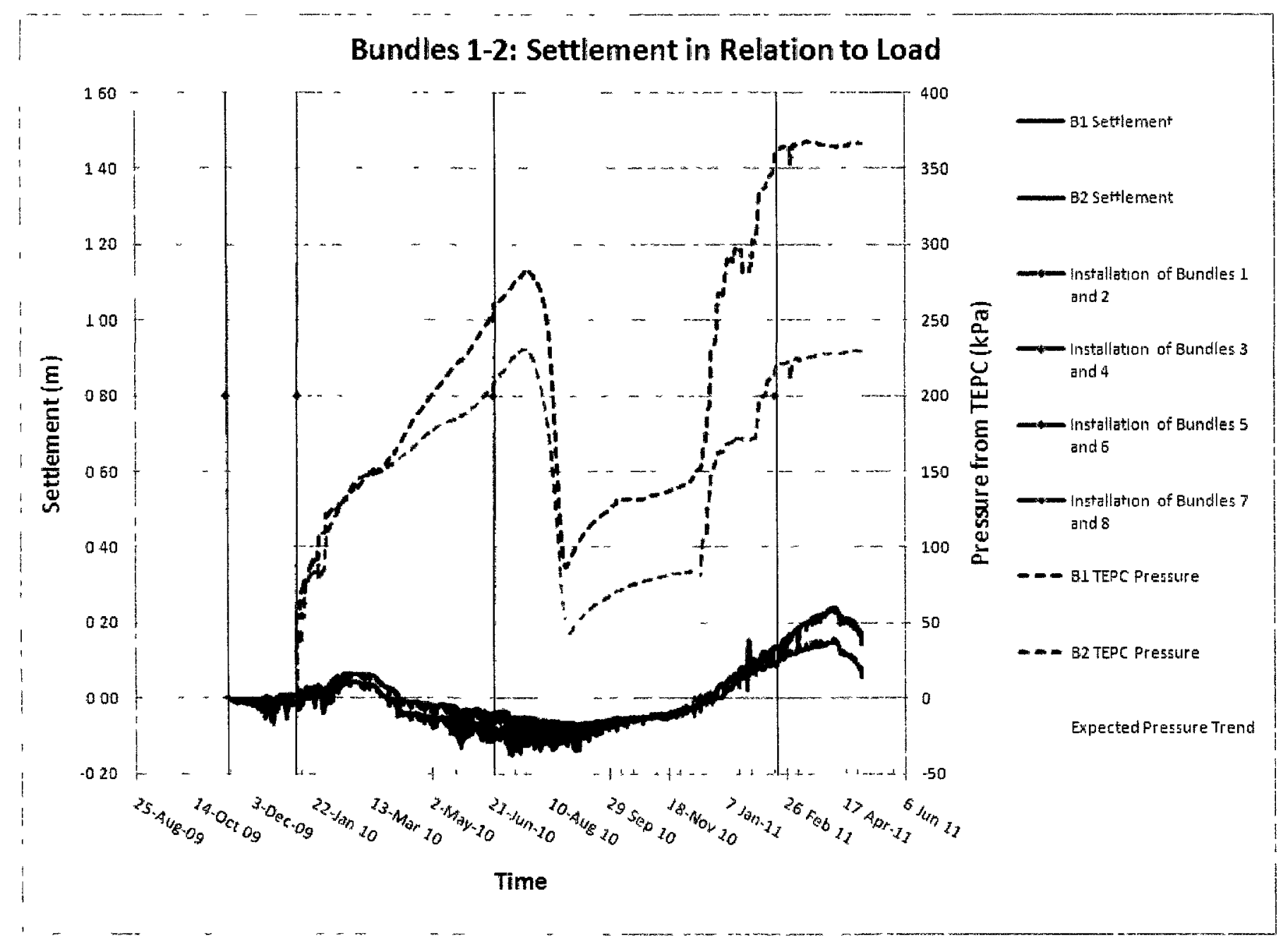

Figure 33: Settlement of Bundles 1 and 2 compared with pressures from TEPC. 
Bundles 3 and 4 were installed and began recording settlement data in January 2010. The bundles were installed at elevations of $75.47 \mathrm{~m}$ and $75.64 \mathrm{~m}$, half-way within the first lift of waste. The bundles were installed over approximately $3.3 \mathrm{~m}$ of waste and were immediately covered by the remaining $1.7 \mathrm{~m}$ of waste from the first waste lift (corresponding with a pressure of approximately $17 \mathrm{kPa}$ ). Figure 34 shows the settlement experienced by Bundles 3 and 4 over the study period compared to the measured pressures from the TEPC and the estimated expected pressure.

In response to the placement of the $1.7 \mathrm{~m}$ of waste above the bundles, the bundles settled approximately $0.36 \mathrm{~m}$ over the initial 2 month period after which the settlement rate decreases to a steady value and the bundles settlement an additional $0.14 \mathrm{~m}$ prior to the placement of the second waste lift. This initial amount of settlement was attributed to compaction of the underlying $3.3 \mathrm{~m}$-thick waste lift, as the lift was constructed starting with a $1 \mathrm{~m}$ "fluff" layer of waste. The fluff layer consisted of a non-compacted layer of waste, which was placed in the empty cell as protection for the underlying leachate collection system from the heavy machinery and sheepsfoot compactors.

In response to the placement of the second and third lifts, the rate of settlement increased until mid-April 2011. At this point the maximum settlement of approximately $0.95 \mathrm{~m}$ was reached. Similar to Bundles 1 and 2, a small rebound appears near the end of April and future monitoring of the settlement of these bundles will determine whether the rebound is actually occurring and to what extent or whether the values are a function of unaccounted instrument error. 
Waste temperature was also compared to the settlement values, to determine if the observed settlement was the result of biodegradation generated by positive temperatures. Reinhart and Townsend (1998) stated that temperature plays a role in encouraging microbial activity which in turn promotes settlement. However, there was very little chance for microbial activity to take place within the 18-month study period due to the waste generally being frozen. The rate of settlement rose simultaneously for Bundles 3 and 4 , regardless of the diverging trend in temperature for these bundles. As the small temperature differences observed in the bioreactor during the study did not appear impact the rate of settlement, the observed settlement was not considered to be due to biodegradation. Rather, the insitu settlement of Bundles 3 and 4 was a function of consolidation caused by the load placed over the bundles with overlying waste layers and the settlement of the ground below Bundles 1 and 2 . 


\section{Bundles 3-4: Settlement in Relation to Load}

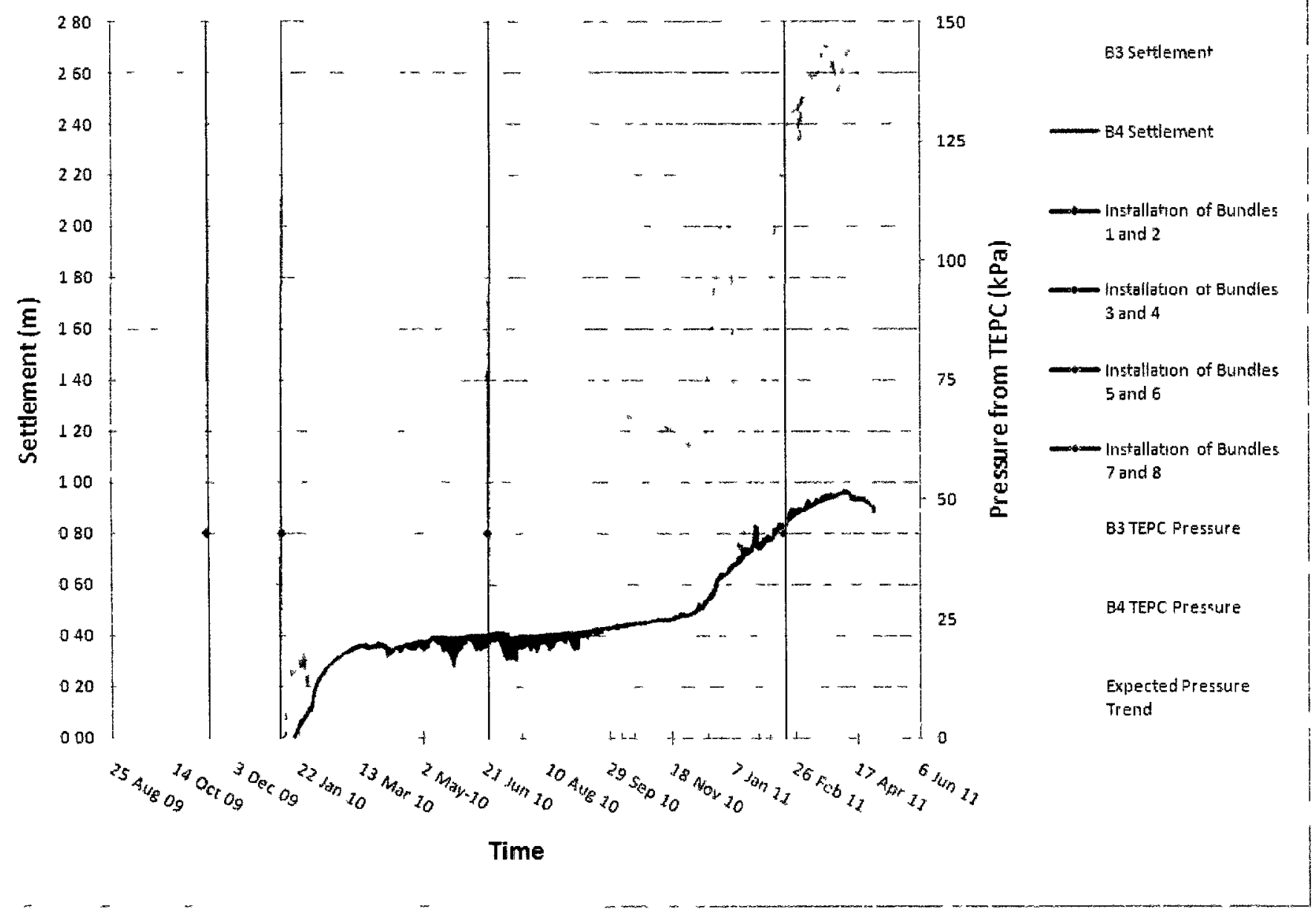

Figure 34: Settlement of Bundles 3 and 4 compared with pressures from TEPC. 
Bundles 5 and 6 were installed and began recording settlement data in June 2010 . These bundles were installed at elevations of $77.79 \mathrm{~m}$ and $78.31 \mathrm{~m}$ respectively. They were installed in an excavated trench at the top of the first waste lift. Therefore, the bundles were installed over approximately $4.5 \mathrm{~m}$ of waste and were immediately covered by $0.5 \mathrm{~m}$ of previously excavated waste from the trench. Figure 35 shows the settlement experienced by Bundles 5 and 6 over the study period compared to the measured pressures from the TEPC and the estimated expected pressure.

Although only $0.5 \mathrm{~m}$ covered the instrument bundles (corresponding with a pressure of approximately $5 \mathrm{kPa}$ ), both instrument bundles experienced large amounts of settlement prior to the placement of the second waste lift. As discussed previously, the in-situ settlement is a function of the consolidation of the underlying waste due to load placed over the bundles as well as the settlement of the waste and ground below Bundles 1-4. Therefore, much of the observed settlement for Bundles 5 and 6 prior to the placement of waste lifts is mainly due to settlement occurring by the ground and waste below Bundles 1-4.

Bundle 5 settled approximately $0.24 \mathrm{~m}$ while Bundle 6 settled approximately $0.6 \mathrm{~m}$ prior to the second waste lift. The rate and total amount of settlement at Bundles 5 and 6 should be equal to or greater than the settlement of Bundles 3 and 4 . Bundles 3 and 4 settled approximately $0.10 \mathrm{~m}$ during this same period indicating that the waste layer between Bundles 3 and 4 and Bundles 5 and 6 underwent additional compaction during this time period. After the placement of the $3.5 \mathrm{~m}$-high second waste lift, as shown by the second pressure step increase seen in the expected 
pressure trend in Figure 35, the rate of settlement increased. Bundle 5 exhibited a higher rate of settlement after the addition of load via the second waste lift than Bundle 6. However, after the placement of the third waste lift, the rate of settlement for both instrument bundles slowed. In the first week of April 2011, the settlement reached $1 \mathrm{~m}$ for Bundle 5, and 1.28m for Bundle 6 . Much of the initial settlement may be the result of waste consolidation, as there was little indication of waste stabilization due to biodegradation due to the low temperatures of the initial waste layer.

Large variability of the settlement data is observed in Bundle 6 in comparison to Bundle 5. The accuracy of the settlement system is $\pm 6.8 \mathrm{~cm}$ for Bundle 6 , but variability in the date is larger than the assumed accuracy of the settlement system. It was initially assumed that the variability may have been caused by the proximity of Bundle 6 to an access road where dump trucks would carry daily cover to the top of the bioreactor landfill. However, this alone was is not capable of explaining the variability of the data, as the settlement data for Bundle 6 was observed for variability during the load tests. No large variability occurred in the settlement data while the dump truck drove around and parked over the instrument bundles during the load test. The issue is currently being resolved through discussions of the data with the instrument supplier. 


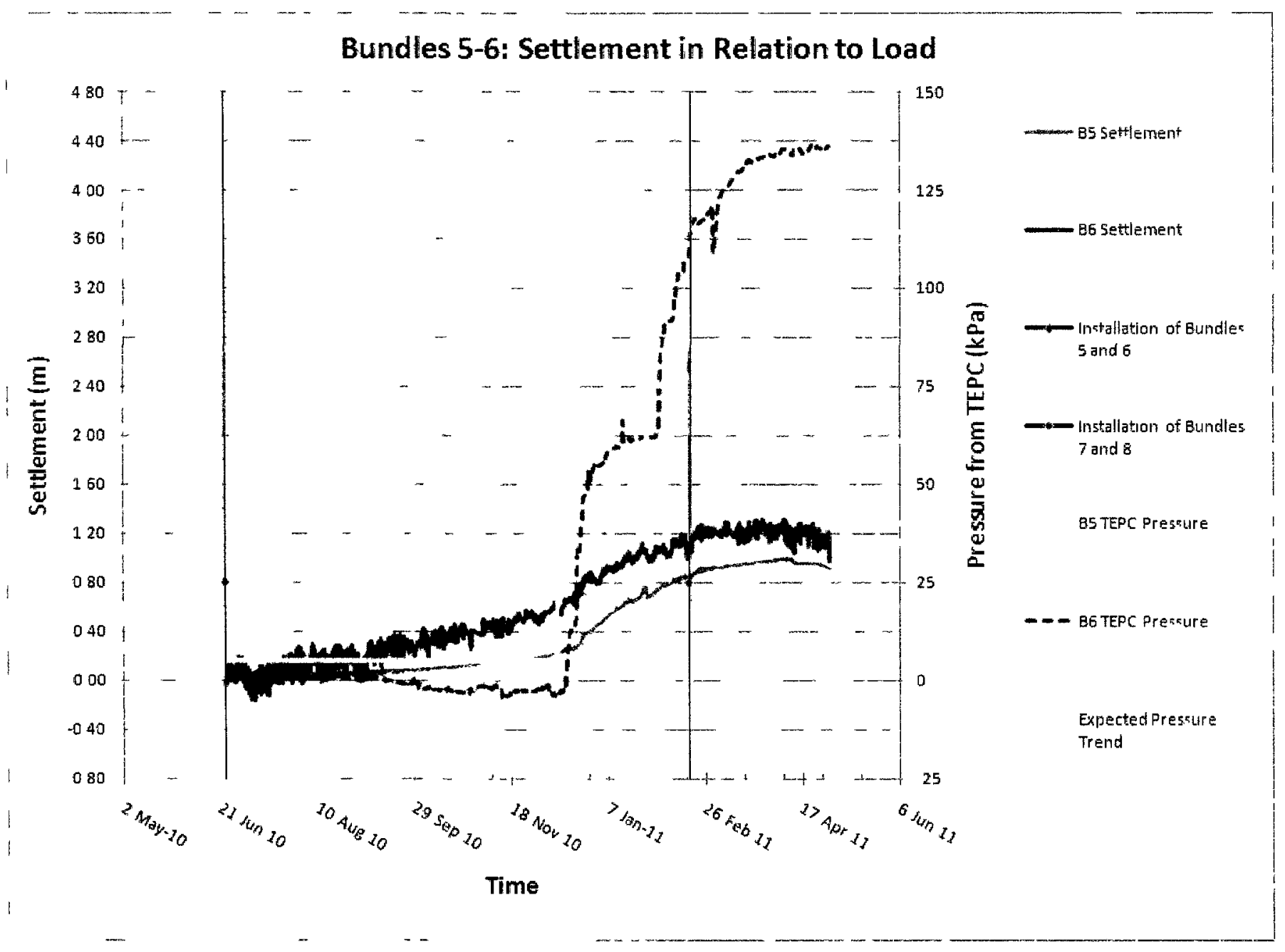

Figure 35: Settlement of Bundles 5 and 6 compared with pressures from TEPC. 
Bundles 7 and 8 were installed in February 2011; however, the accumulator required for the settlement system was only delivered and installed in March 2011. As such, Bundles 7 and 8 only began recording settlement data starting on March 4, 2011. The bundles were installed at elevations of $84.57 \mathrm{~m}$ and $84.76 \mathrm{~m}$ in an excavated trench at the top of the third waste lift. Therefore, the bundles were installed over approximately $11.5 \mathrm{~m}$ of waste and were immediately covered by the $0.5 \mathrm{~m}$ of waste (corresponding with a pressure of approximately $5 \mathrm{kPa}$ ). Figure 36 shows the settlement experienced by Bundles 7 and 8 over the study period compared to the measured pressures from the TEPC and the estimated expected pressure. As expected, magnitude of the settlement recorded at Bundles 7 and 8 of approximately $0.2 \mathrm{~m}$ was greater than the settlement recorded for Bundles 3-6 of approximately $0.1 \mathrm{~m}$ over the same period. This is due to the in-situ settlement being a function of consolidation through load applied by overlying waste layers as well as the settlement occurring in the ground and waste below Bundles 1-6. 


\section{Bundles 7-8: Settlement in Relation to Load}

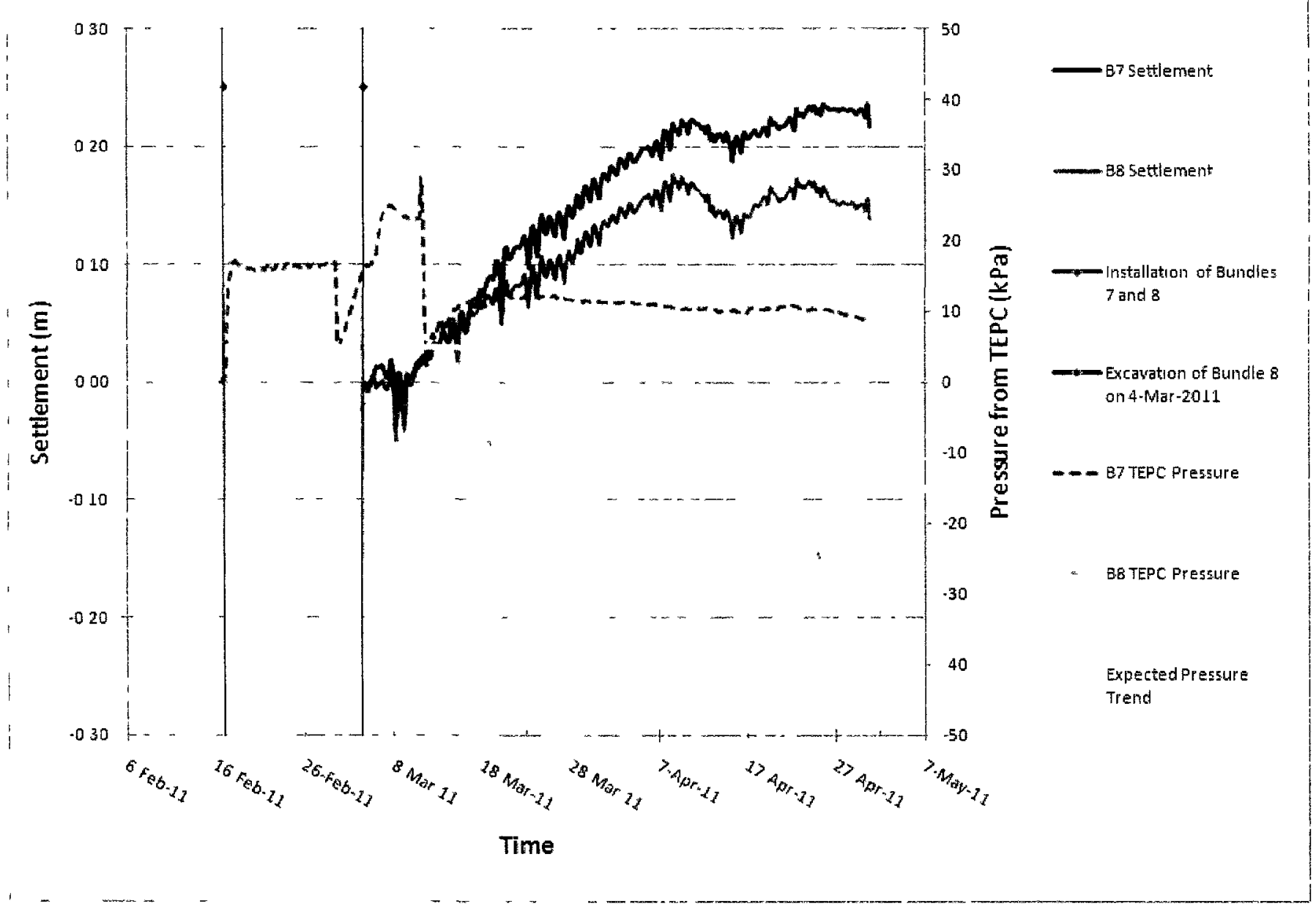

Figure 36: Settlement of Bundles 7 and 8 compared with pressures from TEPC. 
To better understand the level of compaction of each waste layer, the differential settlements between two bundle layers were used to estimate the degree of compaction of each waste layer. The results are presented in Table 5 as the percent settlement achieved by each waste lift. For instance, Bundle 3 was installed over $2.89 \mathrm{~m}$ of waste. Taking into account the settlement of Bundle 3 and Bundle 1 occurring simultaneously, the layer of waste between the two bundles consolidated to $2.09 \mathrm{~m}$ by the end of the study period. Therefore, the difference between the initial height and the final height provided a settlement of $28 \%$. This was the largest percentage settlement observed in the layers of waste in the landfill. On average, the layer of waste between Bundles 3 and 4 and Bundles 1 and 2 achieved a settlement above $26 \%$, over a time period of 1 year and 4 months. Taking into account the settlement which occurred for Bundles 1-4, the layer of waste between Bundles 5 and 6 and Bundles 3 and 4 originally was approximately $2.89 \mathrm{~m}$ thick. The waste layer then achieved an average settlement of over $15 \%$, over a time period of 10 months. The layer of waste between Bundles 7 and 8 and Bundles 5 and 6 originally was $7.67 \mathrm{~m}$ thick. Taking into account the simultaneous settlement of Bundles 5 and 6 , the layer of waste between the layers of bundles achieved an average settlement of over $3 \%$, during time period of 4 months.

Table 5: Percentage of settlement for waste layer between each bundle over study period.

\begin{tabular}{|c|c|c|c|c|c|}
\hline Bundles & \% Settlement & Bundles & \% Settlement & \multicolumn{2}{|c|}{ Average \% Settlement } \\
\hline B7- B5 & 2.52 & B8- B6 & 4.05 & Average: & 3.29 \\
\hline B5-B3 & 15.14 & B6-B4 & 15.73 & Average: & 15.44 \\
\hline B3-B1 & 27.99 & B4-B2 & 24.76 & Average: & 26.37 \\
\hline
\end{tabular}


The percentage of settlement values presented in Table 5 shows that higher loads over a longer period of time aid in the initial settlement of the waste via consolidation. However, the amount of initial settlement which can be achieved is dependent on the waste composition. The heterogeneous nature of waste is a contributing factor to differential settlement within a landfill. Comparing the differences in percent settlement between the two columns of instrument bundles, which are spaced only $18 \mathrm{~m}$ apart, shows that a small amount of differential settlement has occurred.

Waste settlement within a bioreactor landfill was observed at both the New River Regional Landfill (NRRL) and the Yolo County Bioreactor Landfill Project. At the NRRL, an average settlement of $10 \%$ was measured after a 7 year period. At Yolo, an average settlement of $16 \%$ was measured after a 10 year period. In comparison, over the 18 month period as observed in this study, in-situ settlement measurements have shown that the layers of waste have achieved extensive amounts of settlement corresponding solely with consolidation at this point. As waste temperatures increase such that biodegradation of waste is promoted, additional settlement is expected for each of the waste layers.

\subsubsection{Moisture and Electrical Conductivity Sensor}

The moisture and electrical conductivity sensor produced outputs for raw volumetric water content (VWC) which was related to the dielectric permittivity of the sand surrounding the sensor. The sensor also produced outputs for raw electrical conductivity (EC) and temperature in degrees Celsius. Appendix F 
contains the equations for converting the raw outputs to the corresponding final values. The equations were incorporated directly into the datalogger program, thereby eliminating the need for post-processing of the VWC data. The raw VWC was converted to dielectric permittivity and in turn related to the estimated VWC. The raw EC was converted to bulk EC of the surrounding soil and then related to pore water EC using the equations provided by the supplier and presented in Appendix F.

It is assumed that the VWC in the sand increases and decreases in response to increases and decreases in the VWC of the waste as the two media are in direct contact and hydraulically connected. Figure 37 shows the VWC for Bundles 1-8 throughout the study period compared to precipitation. Precipitation was obtained from the closest Environment Canada weather station at the Pierre Elliot Trudeau International Airport, Montreal, Quebec (45.46692N, 73.75020W). 


\section{Bundles 1-8: VWC in Relation to Precipitation}

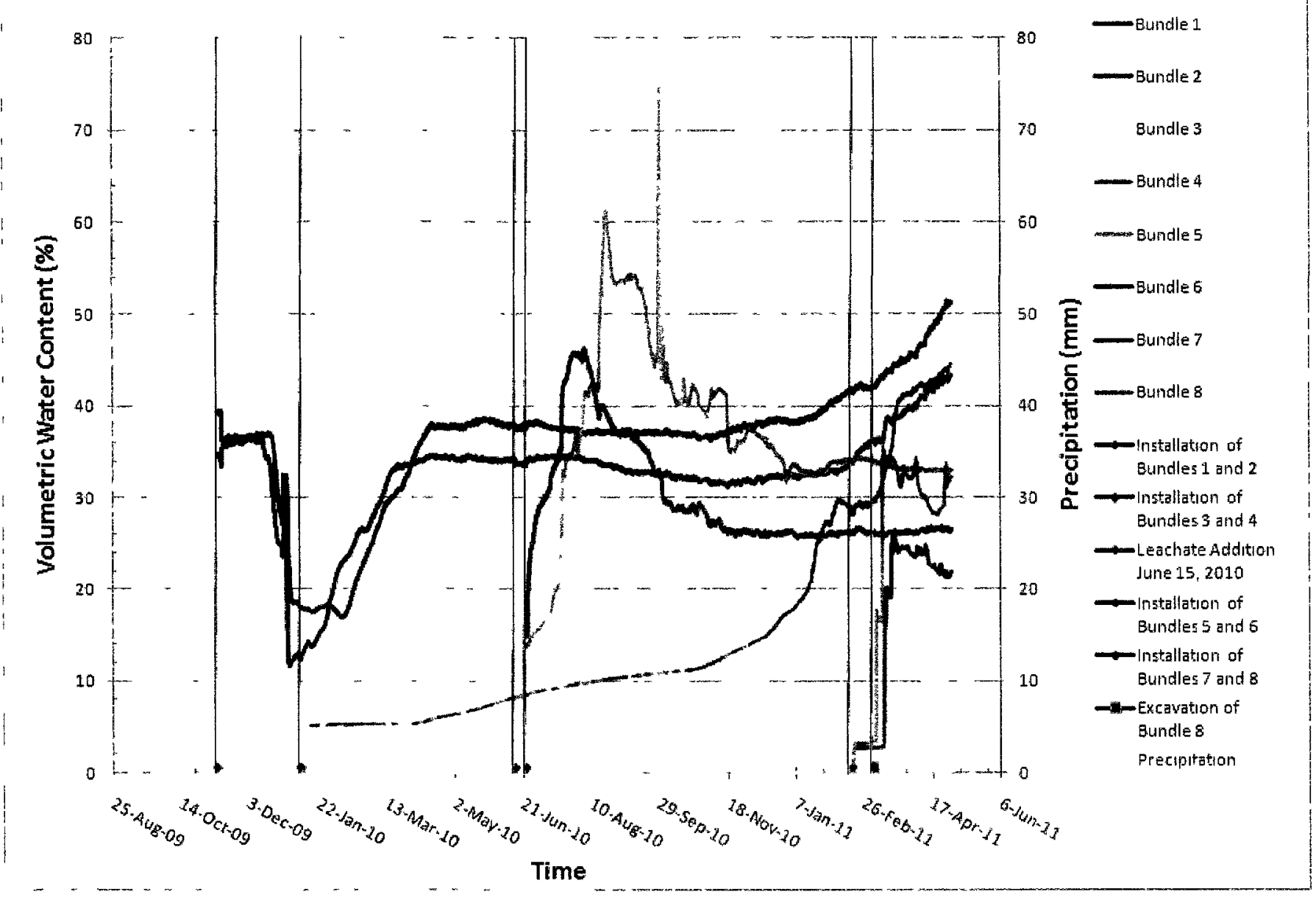

Figure 37: VWC for Bundles 1-8 in relation to precipitation. 
The volumetric water content (VWC) values estimated by the moisture and electrical conductivity sensor were affected by temperature and electrical conductivity (EC). Figure 38 shows the VWC measured at Bundles 1 and 2 in relation to temperature. Initially, the bundles were covered with only $0.5 \mathrm{~m}$ of sand which became saturated with rain water, as indicated by the high moisture content of approximately $36 \%$. As the temperature dropped below $0^{\circ} \mathrm{C}$ for both bundles, the water initially present in the pore spaces of the waste froze. The sensor estimates VWC based on the dielectric constant of water, which is approximately 80 . As the water in the pore spaces froze, the actual dielectric constant would drop to approximately 3 which represents that of ice, and is similar to that of solids and soil grains. As the actual dielectric constant decreased, the estimated VWC also decreased as shown in Figure 38 starting in December 2009.

Despite the waste remaining frozen until nearly August 2010, the estimated VWC of Bundles 1 and 2 had already returned to indicate saturated conditions. The dielectric constant would have remained around 3 representing ice based on the temperature, but another parameter was discovered to impact the estimated VWC. This parameter is the EC of the liquid within the pore space of the waste. Figure 39 shows the VWC of Bundles 1-2 in relation to the EC. Salts leaching from the waste into the water within the pore space of the waste, cause leachate to be produced. Higher salt contents equate to higher $\mathrm{EC}$, which causes the instrument to estimate a higher VWC than what the system actually contains. Beginning in February 2010, the EC of Bundles 1 and 2 rose which may have contributed to the rebound of VWC seen at that time. The increase in EC may have also lowered the freezing point of 
the water, causing the water to thaw and the estimated VWC to rebound back to its original values.

At the time of placement of the second and third waste lifts in December 2010 and January and February 2011, many changes were observed in the waste surrounding Bundles 1 and 2. Temperatures had increased allowing the waste to thaw and allow water movement. The placement of the second and third lift increased the level of compaction of the lower lift, as seen by the settlement data presented in the previous section, which in turn reduced the void space and increased the VWC of the waste and may have caused leachate to migrate vertically downwards. The sharp increases in EC values seen in Figure 39 coincide with the placement of the second and third lift supporting the argument that leachate is migrating to Bundles 1 and 2 . As the EC values increased, the estimated VWC increased to values greater than the assumed porosity of the sand, which is not possible. Hence, the calibration equations used to estimate VWCs in the presence of high EC values are no longer valid and the estimated VWCs are incorrect.

The moisture and electrical conductivity sensors were calibrated by the instrument providers to be accurate between an EC range of $1-8 \mathrm{dS} / \mathrm{m}$. Although the EC levels remain mainly within this calibrated EC range, there still appears to be a relation between high EC and VWC, which may be caused by the extreme sensitivity of the sensors to leachate. The calibration process for the sensor should be repeated with leachate in the laboratory for future analysis. 


\section{Bundles 1-2: VWC in Relation to Temperature}

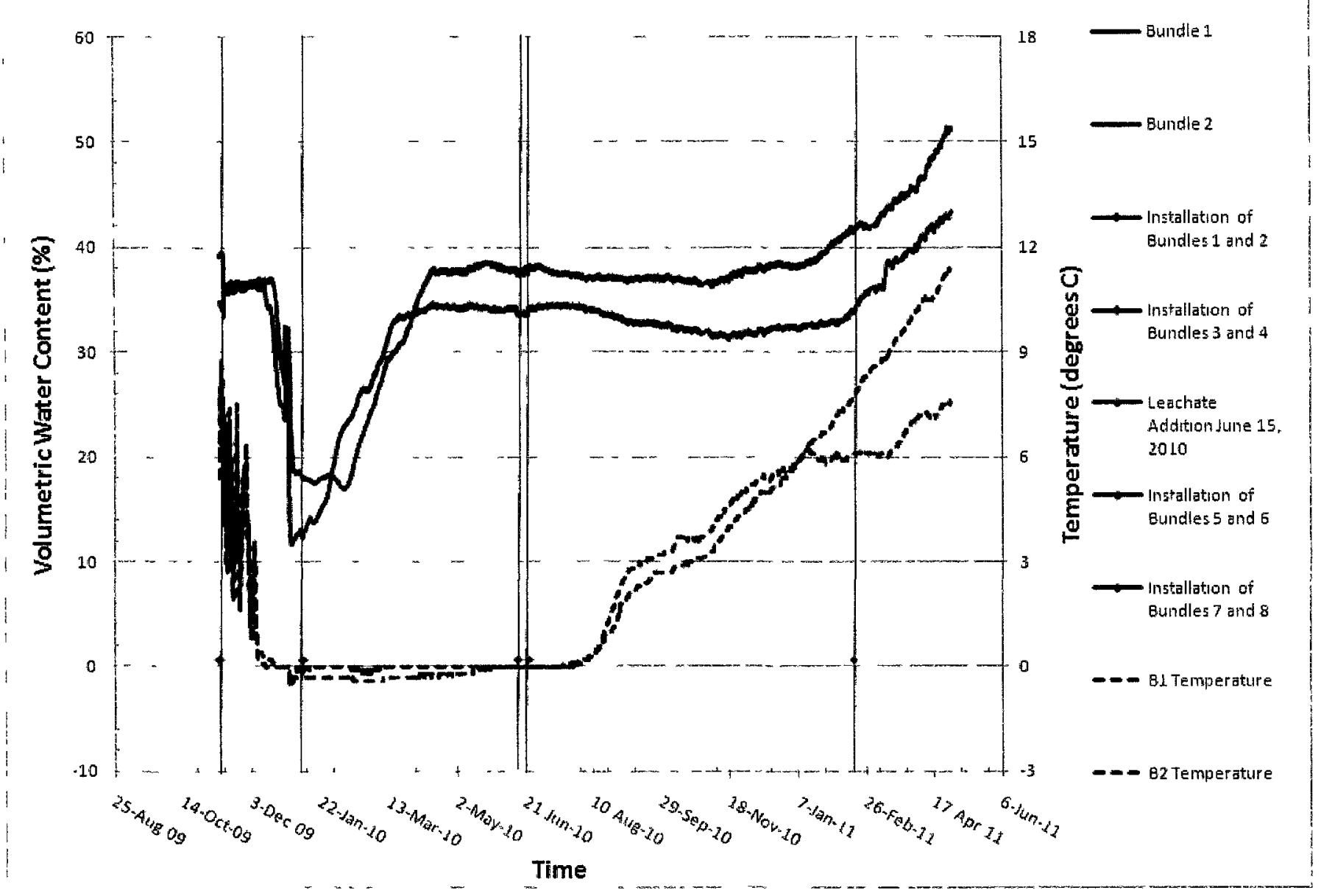

Figure 38: VWC of Bundles 1-2 in relation to temperature. 


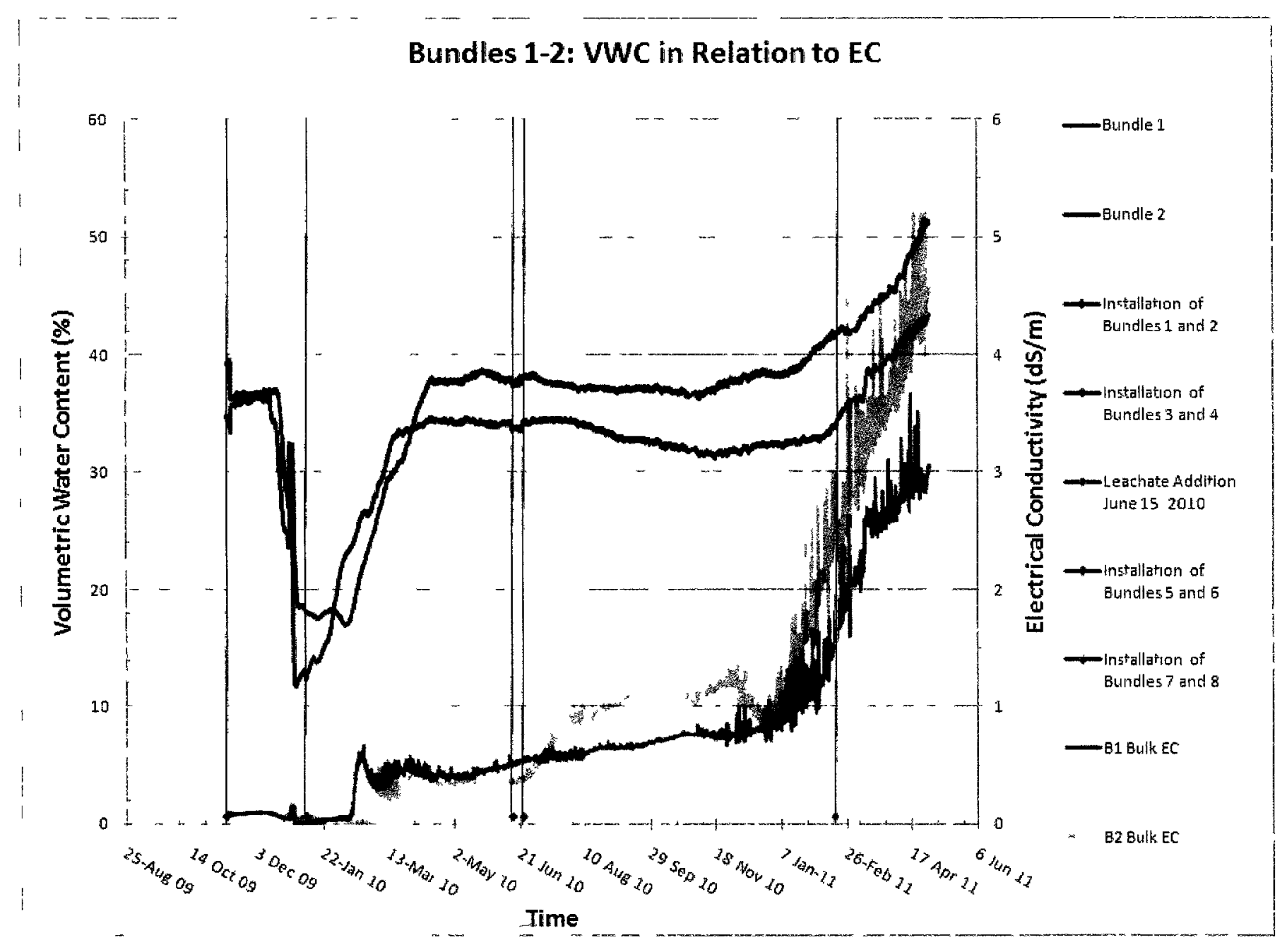

Figure 39: VWC of Bundles 1-2 in relation to EC. 
Figure 40 shows the VWC measured at Bundles 3 and 4 in relation to temperature. Unlike Bundles 1 and 2, which were placed when temperatures were above freezing and were left uncovered for over a month, Bundles 3 and 4 were immediately covered with sand and installed in frozen waste in January 2010 (with the ambient temperature during installation approximately at $-18^{\circ} \mathrm{C}$ ). Hence, there was no opportunity for precipitation to increase the VWC of the sand. In addition, any water present within the pore space of the sand or the surrounding waste would have been frozen. A low dielectric constant corresponding with the frozen water within the pore space may have affected the estimate of VWC causing the instrument to record a low VWC of approximately $5 \%$ as seen in Figure 40 . The VWC gradually increased, although no aforementioned parameter appears to be acting to change the VWC.

Similar to Bundles 1 and 2, several changes were observed in the waste surrounding Bundles 3 and 4 at the time of placement of the second and third waste lifts in December 2010 and January and February 2011. The waste temperature around Bundle 3 increased allowing the waste to thaw and allowing the dielectric constant to increase. However, the temperature of the waste around Bundle 4 remained constant, indicating the waste remained frozen throughout the study period. The VWC of Bundle 4 was measured to be higher than that of Bundle 3 which is counterintuitive given the waste temperatures and corresponding dielectric constants. Therefore, another parameter has influenced the VWC measurement. Figure 41 shows the VWC of Bundles 3-4 in relation to EC, and it is evident that VWC has followed the trend of the EC. The changes in waste temperature and EC 
developed only after the placement of the additional load from the second and third waste lifts. As mentioned before, the pore space of the waste may have been reduced sufficiently that leachate was generated. This leachate may have migrated to the location of Bundles 3 and 4 by January 2011, corresponding with higher VWC values. 


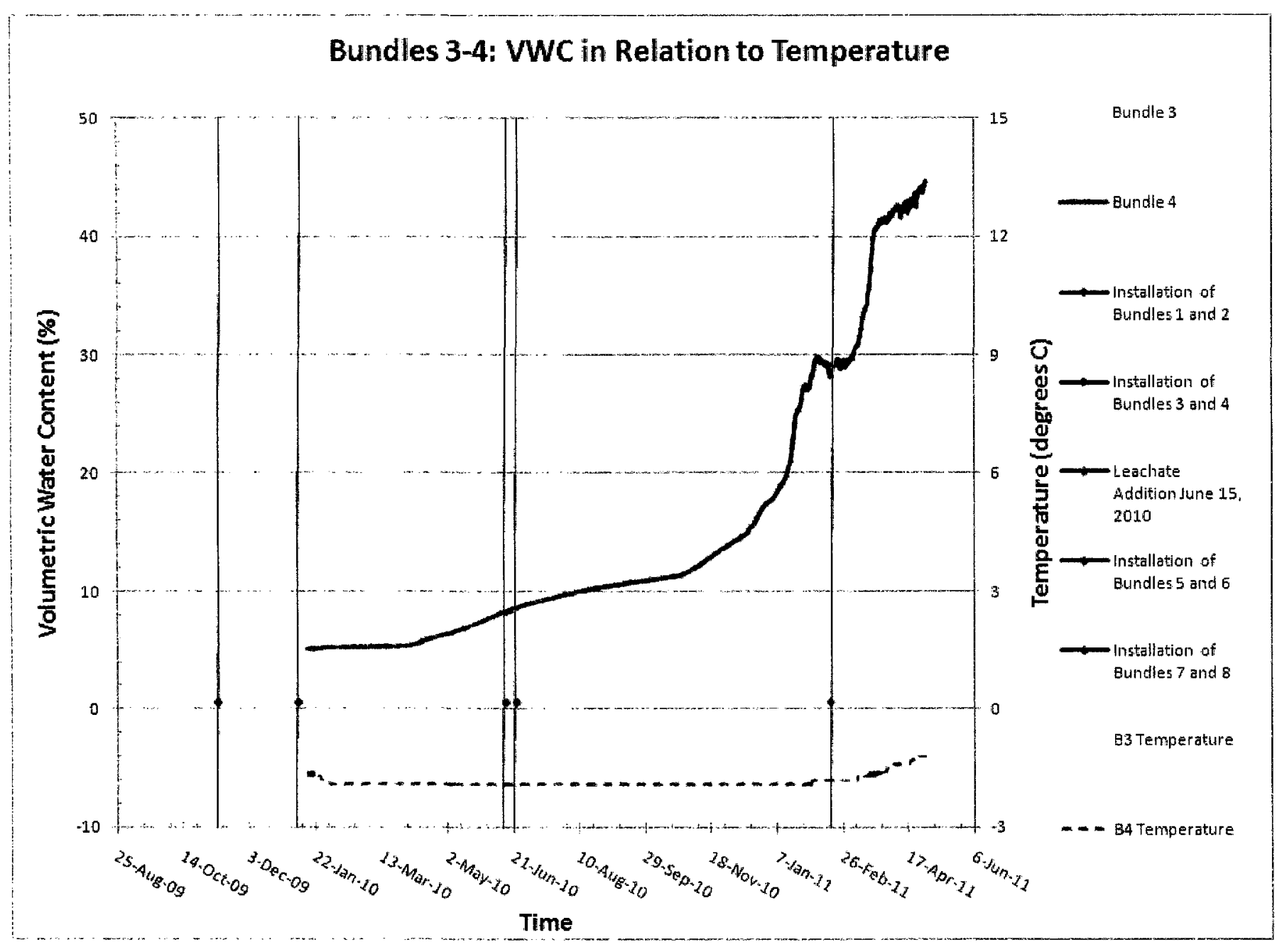

Figure 40: VWC of Bundles 3-4 in relation to temperature. 


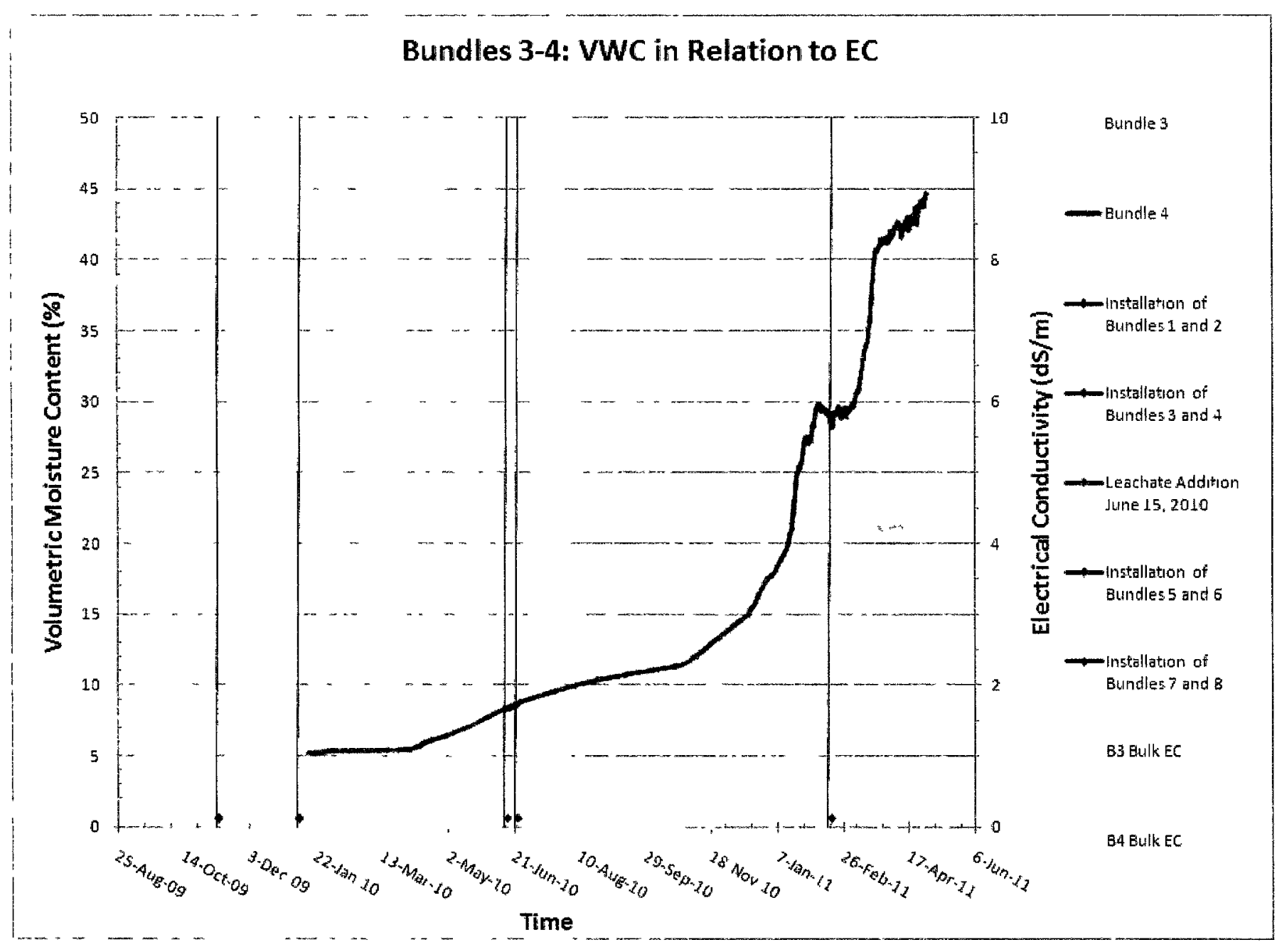

Figure 41: VWC of Bundles 3-4 in relation to EC. 
Figure 42 shows the VWC measured at Bundles 5 and 6 in relation to temperature. Initially, the bundles were covered by $0.5 \mathrm{~m}$ of waste after the installation process in June 2010. As Bundles 5 and 6 were the only instrument bundles to be installed during the summer, the temperature of the waste was quite warm. Hence, the dielectric constant of the water would remain at 80 and temperature should not influence the estimated VWC. The EC is clearly the prominent parameter affecting the VWC measurements as VWC measurements have followed the same trend observed for the EC, as shown in Figure 43. Due to the proximity of the Bundles 5 and 6 to the surface of the waste lift, large rainfall events coincided with sharp increases in VWC as the precipitation contributed to leaching of salts from the waste, causing the EC to increase. The influence of precipitation diminished as additional waste lifts were placed over the bundles, as the moisture migrates through the waste. Much of the VWC measurements were above the saturation of the sand (approximated to be between 35-40\%) surrounding the instrument bundles. The VWC measurements are unreliable at this time, as the actual VWC of the sand can not rise above saturation. Samples of the sand were taken from Bundles 5 and 6 just after the unreliable VWC measurements, on November 2, 2010.

The waste above Bundles 5 and 6 was excavated on November 2,2010 to expose the sand covering the instrument bundles. From the sand directly above the instrument bundles, two samples were taken. These samples were analyzed in the lab to determine the moisture content. Additional details of the analysis are included in Appendix G. The sand samples collected at Bundles 5 and 6 had VWCs of approximately $27 \%$ and $26 \%$. 
Figure 44 shows the comparison between the VWC estimated by the moisture and electrical conductivity sensor in the field and the lab analyzed sand samples. There is a large discrepancy between the VWC measured at Bundle 5, which may be caused by the high EC which results in unreliable high VWC. In comparison, the VWC measured at Bundle 6 by the moisture and electrical conductivity sensor corresponds with the lab analyzed sand sample. This may be because the EC is shown to be less at Bundle 6 than at Bundle 5, therefore there was less impact by the EC on the VWC. Further laboratory tests of the moisture and electrical conductivity sensor were completed to generate a better understanding of the influence that high EC has on VWC, the results of which are discussed at the end of this section.

The EC decreases after November 2010 for both bundles. This may be due to a displacement or flushing out of the initial release of salts from the waste above and from the sand surrounding Bundles 5 and 6 . By the end of the study period, the instrument was recording VWC of approximately $30 \%$ for Bundle 5 and approximately $28 \%$ for Bundle 6 , suggesting that the waste layer is not saturated. 


\section{Bundles 5-6: VWC in Relation to Temperature}

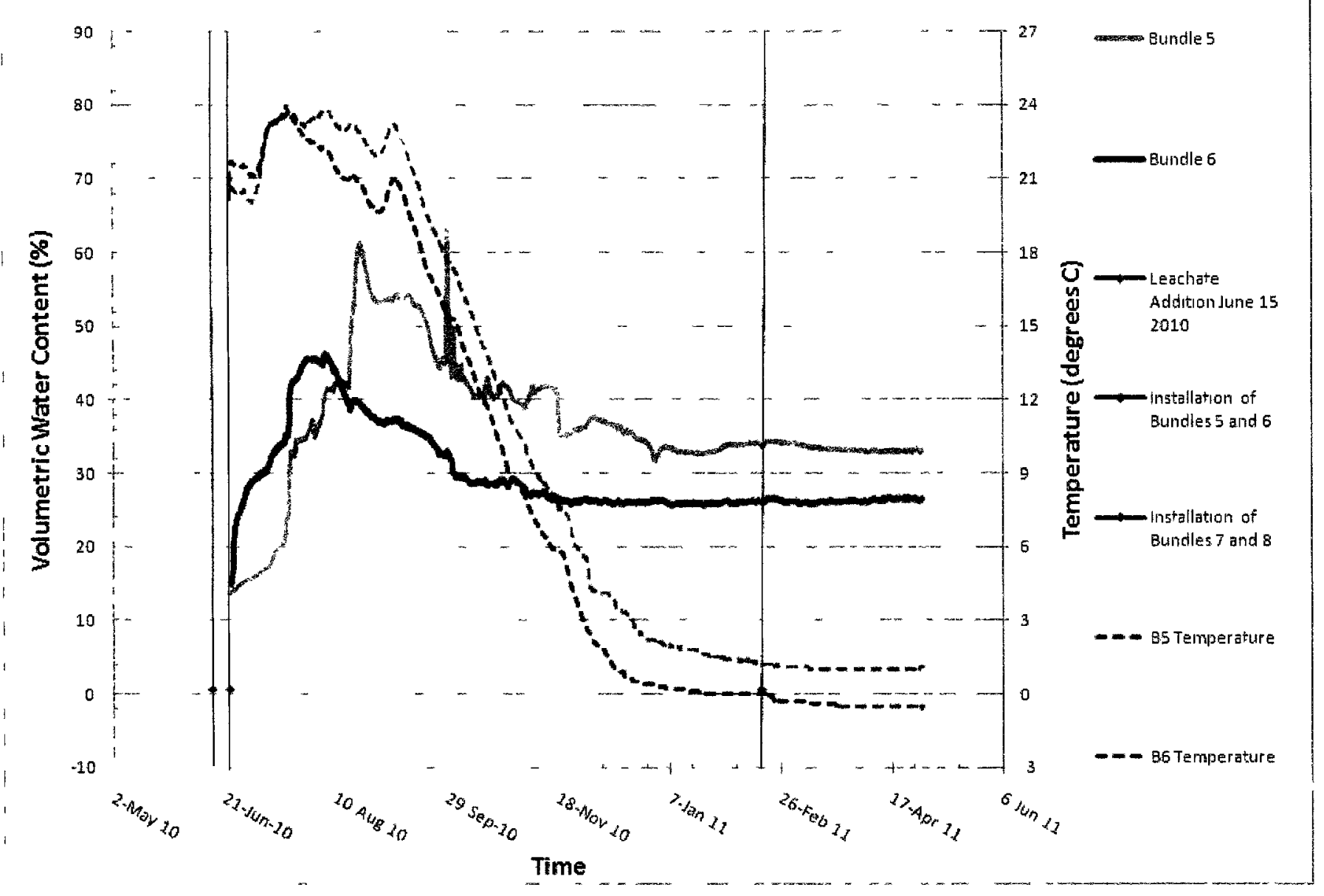

Figure 42: VWC of Bundles 5-6 in relation to temperature. 


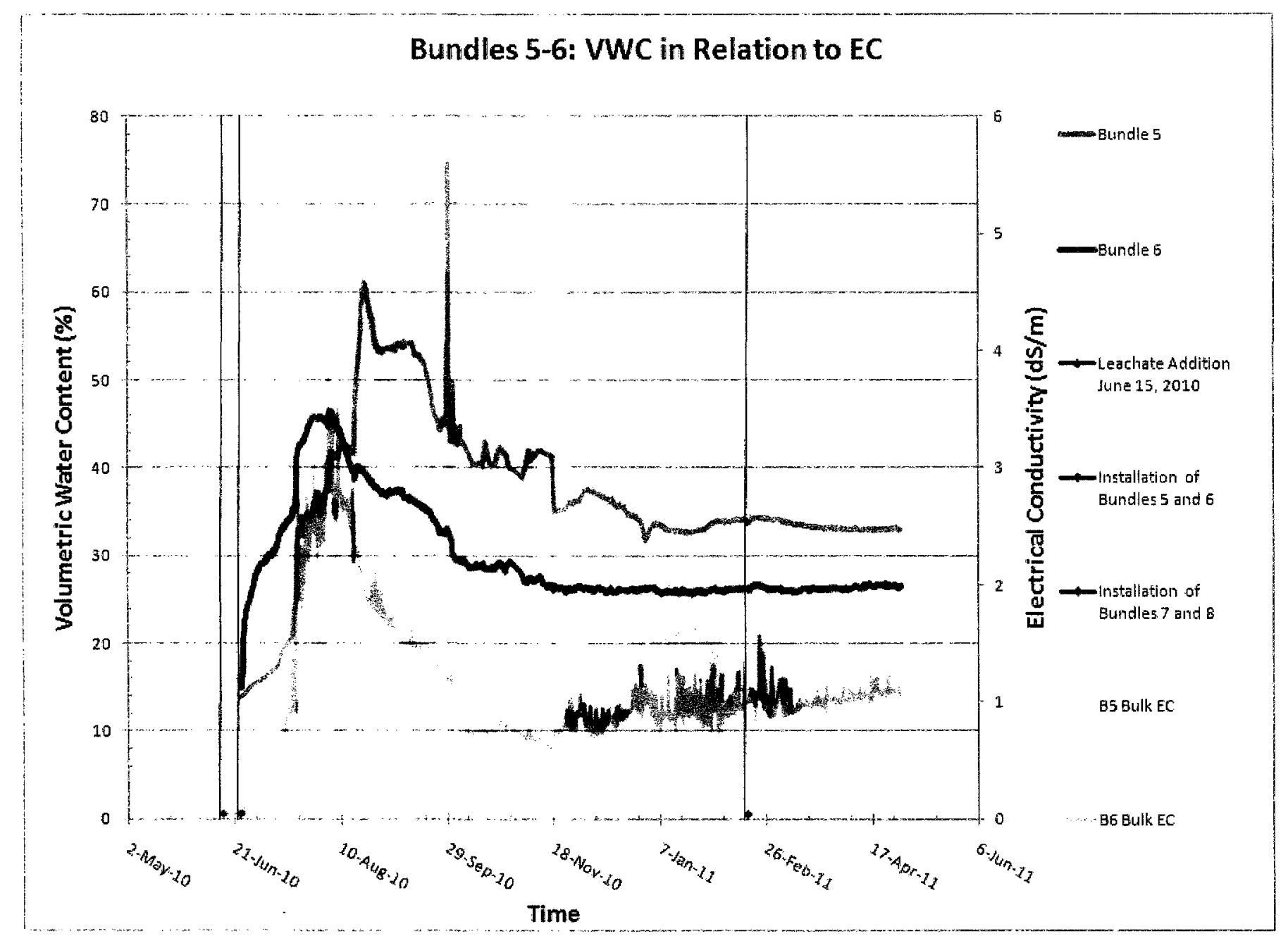

Figure 43: VWC of Bundles 5-6 in relation to EC. 


\section{Bundles 5-6: VWC Comparison through Lab Data and Field Sensor}

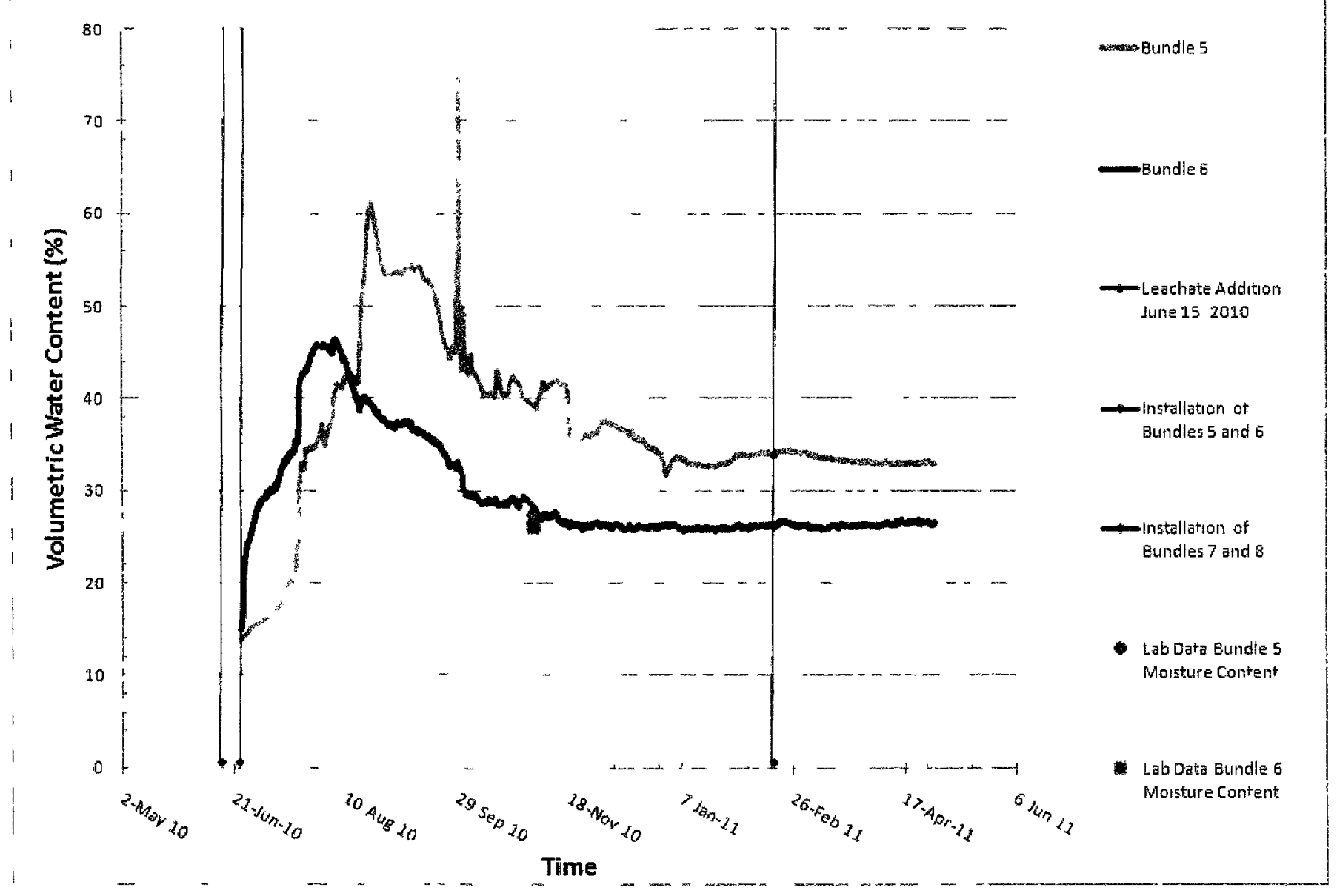

Figure 44: VWC for Bundles 5-6 comparison of lab and field data. 
Figure 45 shows the VWC measured at Bundles 7 and 8 in relation to temperature. Initially, the bundles were covered with $0.5 \mathrm{~m}$ of waste after a winter installation in February 2011. Low VWCs of approximately 3\% were measured initially for Bundles 7 and 8; these may have been affected by a low dielectric constant of approximately 3 representing ice due to the frozen state of the sand and surrounding waste. After the excavation of Bundle 8, and an attempted excavation at Bundle 7 , the waste temperature increases to approximately $0^{\circ} \mathrm{C}$. This small increase in waste temperature seemed to be enough to cause the water to thaw and increase the dielectric constant of the sand. This change in dielectric constant was the main parameter which influenced the VWC to increase to approximately $25 \%$ for Bundle 7 and approximately $35 \%$ for Bundle 8 .

There is negligible influence on VWC measurements from the EC at Bundles 7 and 8. As shown in Figure 46, the EC remained extremely low for Bundles 7 and 8 as there may have been very limited salt content leaching from the waste. 


\section{Bundles 7-8: VWC in Relation to Temperature}

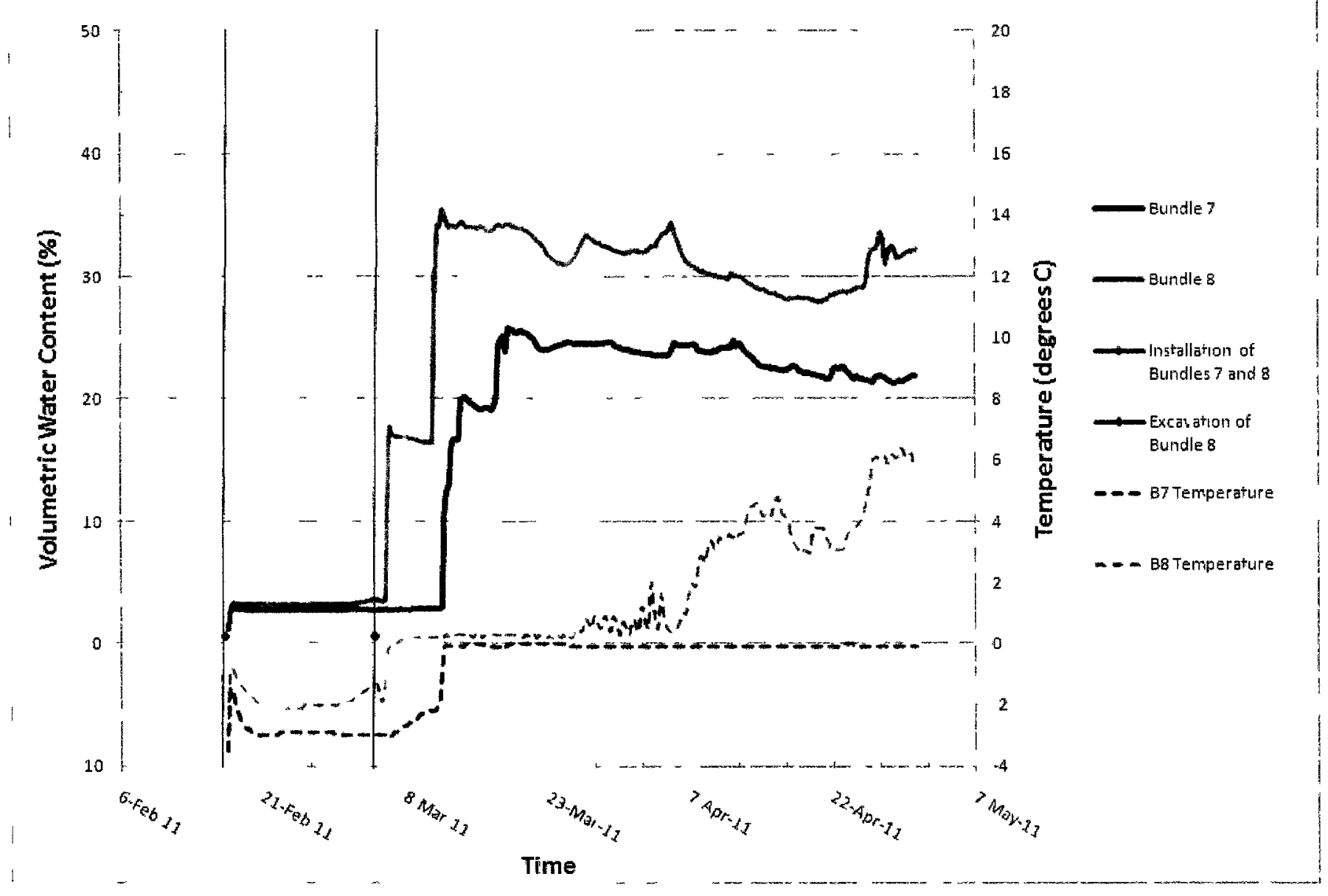

Figure 45: VWC of Bundles 7-8 in relation to temperature. 


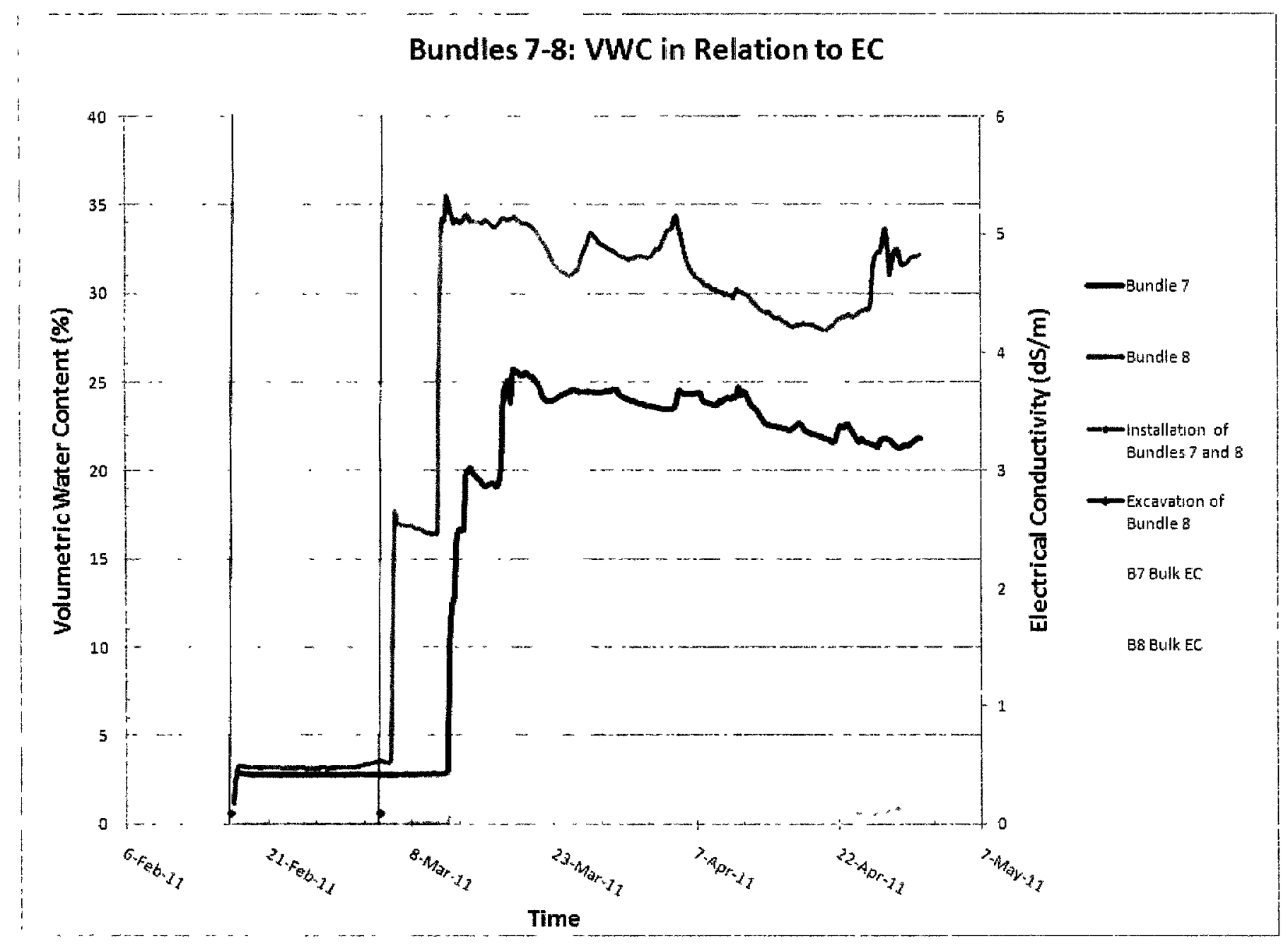

Figure 46: VWC of Bundles 7-8 in relation to EC. 
Two moisture and electrical conductivity sensors was tested in the laboratory to generate a better understanding of the influence that high EC has on VWC. Initially, the sensors were tested in $1500 \mathrm{~mL}$ of sand, with varying levels of moisture introduced through the addition of water to the sand. Appendix G includes a summary of the moisture sensor testing and photos from the testing. VWC was recorded by the sensors for each moisture level. The test showed that at the highest moisture level obtained in the lab, the moisture and electrical conductivity sensor recorded a VWC of just less than $30 \%$. This may be due to water pooling at the top of the sand despite adequate mixing; as such, the sensor could not read higher VWC values.

The sensors were also tested in $600 \mathrm{~mL}$ of saturated sand, with varying levels of salt addition in order to observe increases in VWC as the result of increased EC. The test assumed a theoretical moisture content of $35 \%$ to represent saturated sand, despite the sensor previously reading a maximum $30 \% \mathrm{VWC}$. The addition of salt to the pore water of the saturated sand caused a rapid increase in the EC as measured by the moisture and electrical conductivity sensor. The sensor also measured higher VWC values corresponding with higher EC values. Therefore, the laboratory test demonstrated that sensor measurements of VWC are affected by high EC levels, causing VWC measurements to be higher than what the system actually contains.

One leachate addition test was also completed to verify instrument response from the moisture sensors and thermistors, and in an attempt to raise the waste temperature (see Figure G-4). On June 15, 2010, a hole with approximate 
dimensions of $2 \mathrm{~m}$ long, $1.5 \mathrm{~m}$ wide, and $0.5 \mathrm{~m}$ deep was excavated within the waste directly over Bundles 2 and 4. At the time of leachate addition, all temperature readings indicated frozen waste around each instrument bundle. A truck carrying leachate at a temperature of $21^{\circ}$ began pumping leachate into the excavated hole. The leachate slowly penetrated the waste, causing the excavated hole to fill quickly. As the leachate level in the excavated hole dropped after several hours, additional leachate was pumped into the excavated hole. Within the one day of leachate addition, approximately 2700 litres were added to the waste over Bundles 2 and 4 . Despite the addition of the leachate, there was no significant change in moisture content for Bundles 2 and 4, which were directly below the added leachate. The temperature of the waste was also not impacted by the addition of the warm leachate. It is likely that the frozen waste directly below the excavation cooled the leachate and prohibited it from migrating downwards to reach the instrument bundles. The leachate pumped into the excavation may have pooled on the top of the frozen waste layer. The waste around Bundle 4 remained frozen throughout the study period, which may have prevented the migration of the added leachate downwards past the instrument bundle.

\subsubsection{Oxygen Sensor}

The oxygen sensor produced a resistance output in $\mathrm{mV}$ and temperature readings in degrees Celsius. The raw $\mathrm{mV}$ outputs from the oxygen sensor required corrections for temperature in order to determine percent oxygen. Appendix $\mathrm{H}$ contains all calibration equations, and a sample calculation for the oxygen sensor. 
The corrected oxygen sensor values are presented in Figure 47. As seen, by the end of the study period the oxygen has been depleted from the pore space of the waste for Bundles 1-8. Two peaks in Bundle 5 and one peak in Bundle 6 are the result of oxygen being added by pumping air through the empty flexible tubes back to the instrument bundle in order to verify the response of the oxygen sensor. The oxygen addition tests are discussed in more detail later in this section. 
Bundles 1-8: Oxygen Content

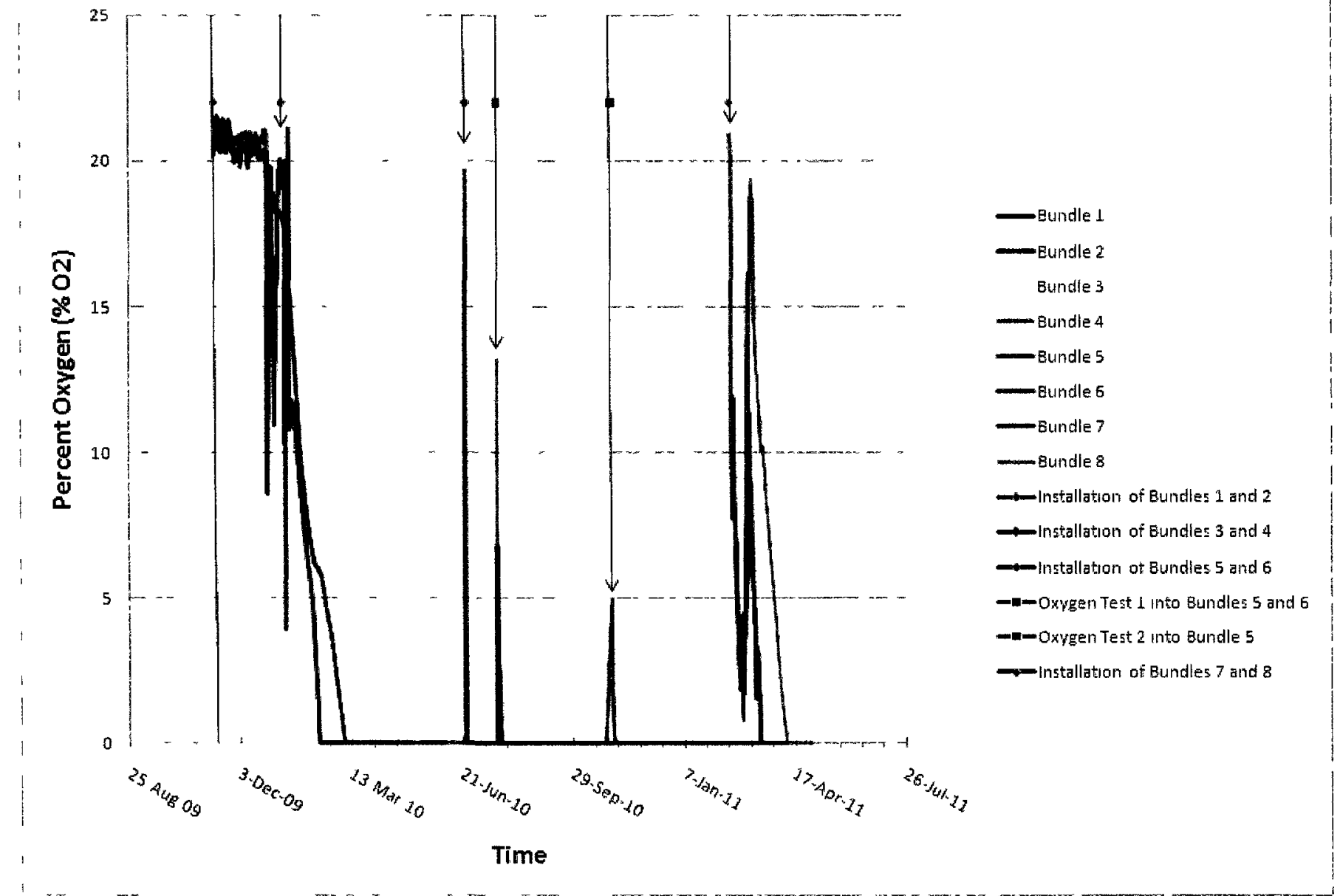

Figure 47: Oxygen Content for Bundles 1-8. 
The oxygen contents measured by the oxygen sensors as shown in Figure 47 were split into four plots, as shown in the following Figures 48-51, to compare the measured oxygen content to the average temperature of the corresponding bundle.

Figure 48 shows the oxygen content recorded at Bundles 1 and 2 over the study period compared to the average temperature of the waste. The oxygen levels remained at approximately $21 \%$ until the bundles were covered by the first waste lift in January 2010. After the bundles were covered with waste, the oxygen content slowly declined to zero over a two-month period. A miniscule amount of oxygen was consumed by the current flow required for the oxygen sensor measurement. In discussion with the instrument supplier, the small consumption of oxygen by the sensor would not explain the slow decline in oxygen content unless zero amount of oxygen could diffuse or migrate through the surrounding sand and waste to the diffusion head of the sensor. The temperature of the waste remained below $0^{\circ} \mathrm{C}$ indicating limited microbial activity would occur, yet the oxygen still declined to zero. The decline in oxygen content may be due to isolated pockets where a high concentration of organic waste exists within the waste and biodegradation may be occurring which in turn is slowing depleting the oxygen.

To ensure that the oxygen sensor was working, tests were conducted to pump air back to the instrument bundle via the tubing; however, this could not be done for Bundles 1 and 2 because the air was blocked from reaching the bundles. It is anticipated that water seeped into the tubing and froze with the negative temperatures, thus the ice would be preventing the addition of air. 


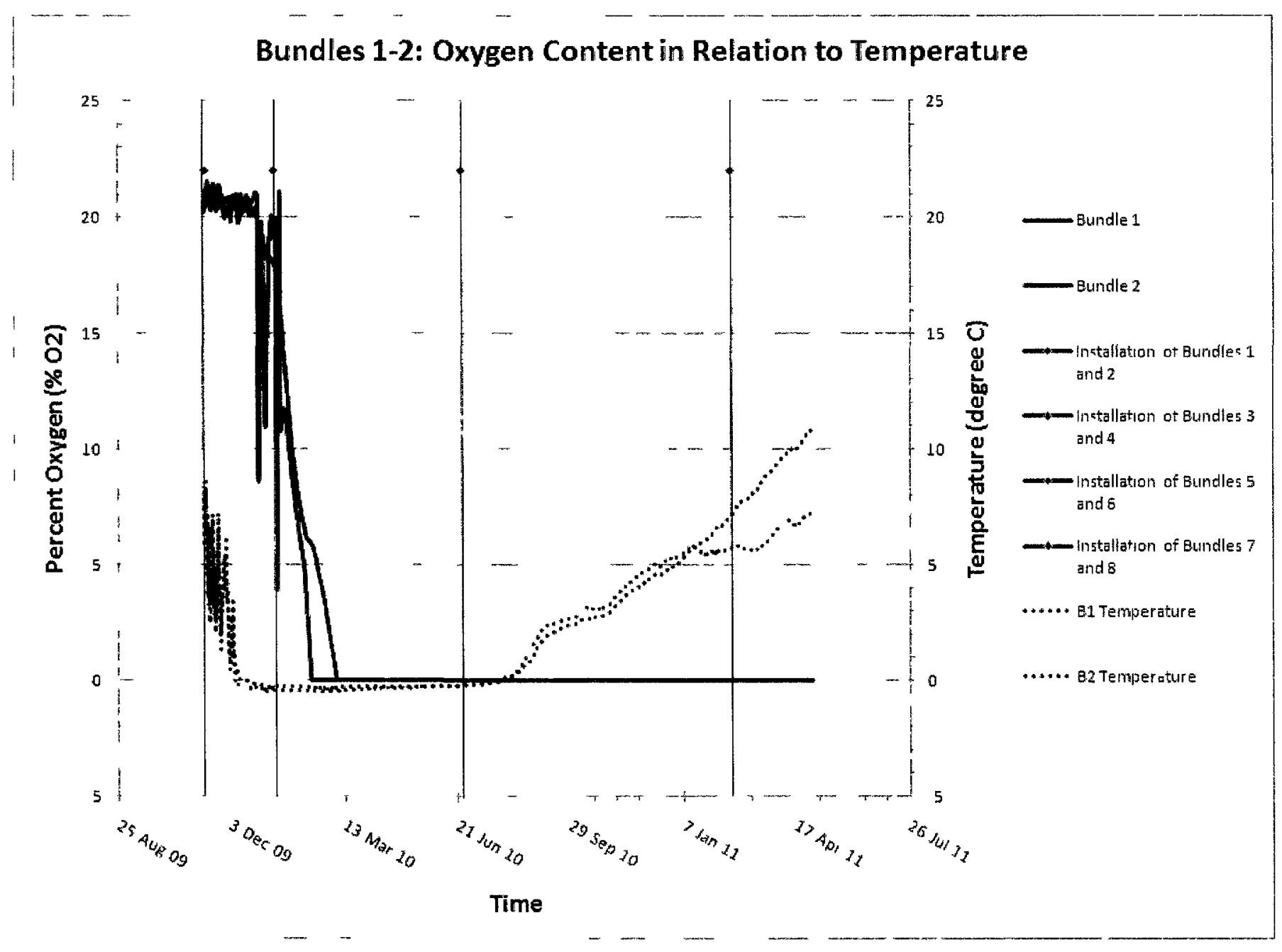

Figure 48: Oxygen Content for Bundles 1-2 in Relation to Temperature. 
Figure 49 shows the oxygen content recorded at Bundles 3 and 4 over the study period compared to the average temperature of the waste. Unfortunately, the declining trend of oxygen content which took place after the installation was not recorded due to faulty wiring of the sensor to the datalogger. The wiring issue was corrected by June 2010 and 0\% oxygen content was measured at both Bundles 3 and 4 approximately 6 months after installation. Testing of the oxygen sensors in Bundles 3 and 4 would be very beneficial to verify the wiring was correct and the sensors are functioning properly. However, similar to Bundles 1 and 2, air was blocked from being pumped through the hollow tubes back to the instrument bundles. This may be caused by ice within the flexible tubes which blocks the flow of air. As such, it may be that air can not be pumped through to Bundles 3 and 4 until the waste thaws with rising waste temperatures allowing the ice within the flexible tubes to melt and be forced out by the pumped air. 


\section{Bundles 3-4: Oxygen Content in Relation to Temperature}

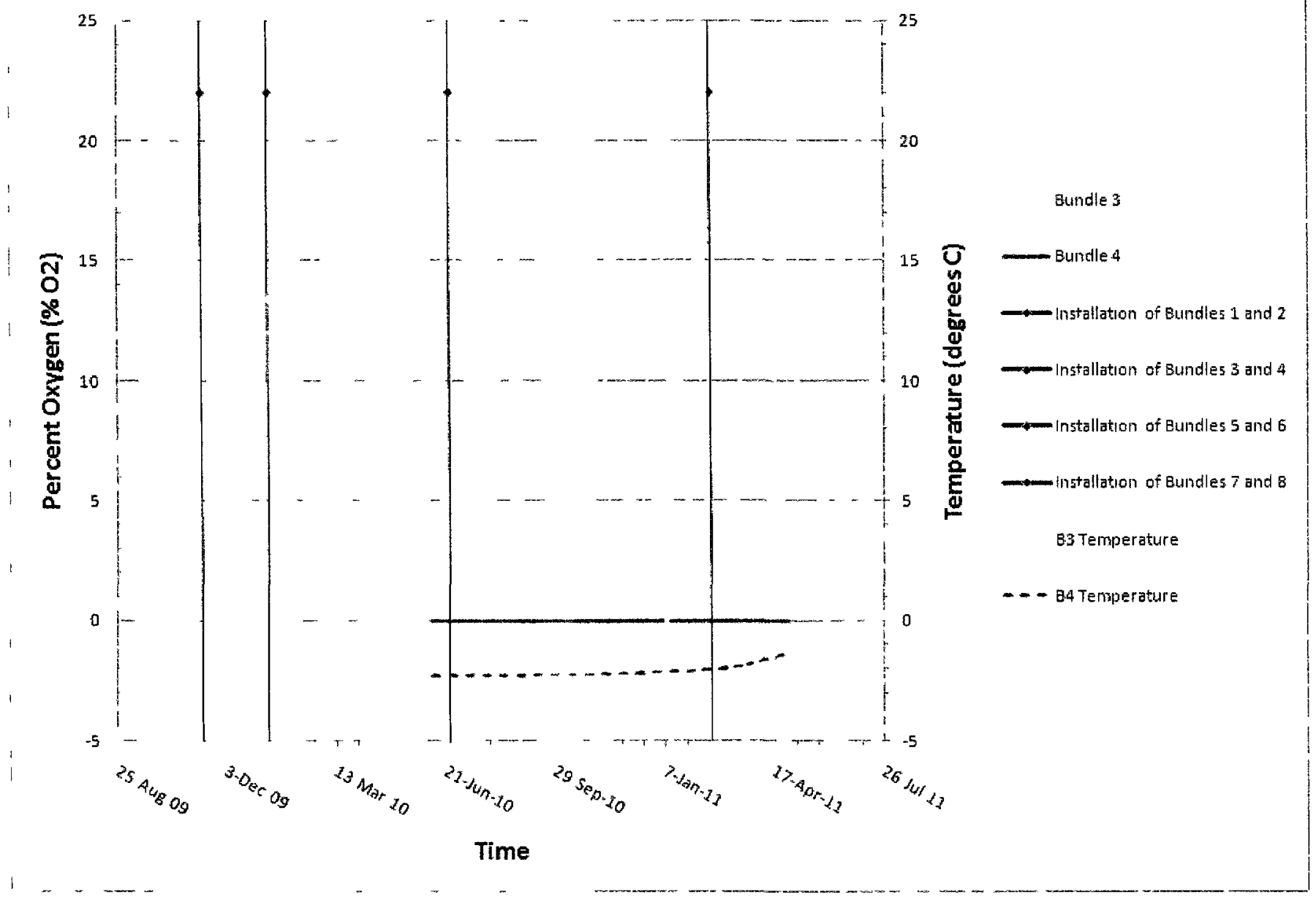

Figure 49: Oxygen Content for Bundles 3-4 in Relation to Temperature. 
Figure 50 shows the oxygen content recorded at Bundles 5 and 6 over the study period compared to the average temperature of the waste. The oxygen levels began at $21 \%$, but declined rapidly to $0 \%$ over the span of approximately 2 days. With waste temperature above $20^{\circ} \mathrm{C}$, this rapid depletion of oxygen indicates that microbial activity is taking place and consuming the available oxygen. The oxygen was depleted much more rapidly at Bundles 5 and 6 than what was observed for Bundles 1 and 2.

The two subsequent peaks in oxygen for Bundle 5 and the one peak for Bundle 6 seen in Figure 50 are the result of oxygen addition to the system to verify the operation of the sensors. Oxygen was added by pumping air through the flexible tubes back towards the instrument bundle via a bike pump (see Figure $\mathrm{H}-1$ ). Initially, water was present in the flexible tubes providing difficulty for pumping. The pumped air was eventually able to push all the water from the flexible tubes clearing the path for pumped air to infiltrate the waste. Even after adding oxygen to Bundles 5 and 6 to confirm that the oxygen sensor is working, the oxygen depleted rapidly over 1-2 days indicating rapid consumption of the oxygen due to biodegradation of the waste, which is expected with the higher temperatures recorded at Bundles 5 and 6. 


\section{Bundles 5-6: Oxygen Content in Relation to Temperature}

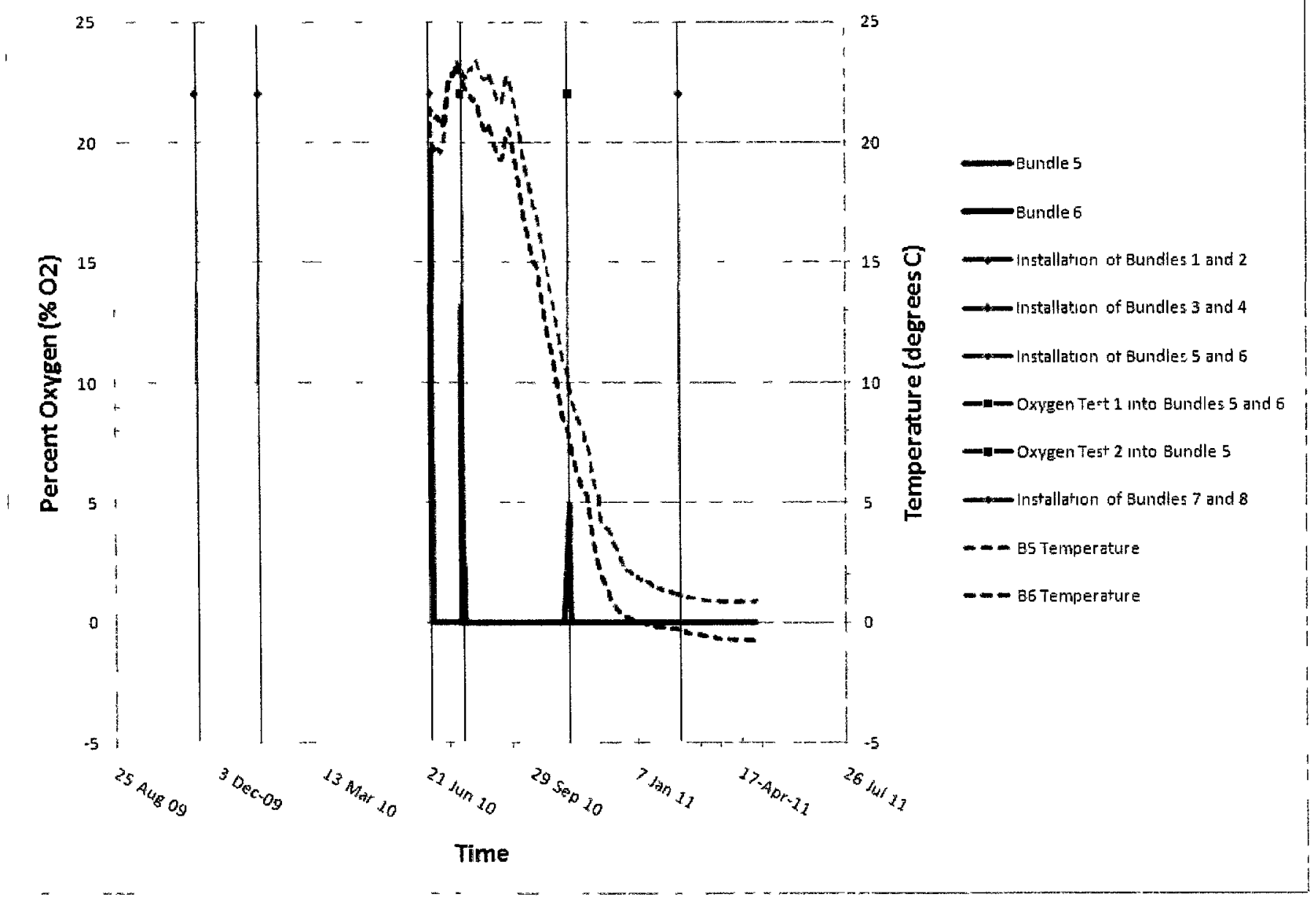

Figure 50: Oxygen Content for Bundles 5-6 in Relation to Temperature. 
Figure 51 shows the oxygen content recorded at Bundles 7 and 8 over the study period compared to the average temperature of the waste. The oxygen levels began at approximately $21 \%$ and began a gradual decline to under $5 \%$ within a few weeks. The excavation of Bundle 8 and the attempted excavation of Bundle 7 caused air to infiltrate the waste and increase the oxygen levels. An oxygen content of just over $10 \%$ was observed for Bundle 7 after the attempted excavation, after which a gradual decline to $0 \%$ occurred over a span of a few weeks. An oxygen content of close to $20 \%$ was observed for Bundle 8 after excavation. The oxygen sensor remained buried under a small amount of sand at the base of the excavation. The excavation over Bundle 8 remained free from waste for the rest of the study period, but was gradually filled by rainfall. A gradual decrease in oxygen content to $0 \%$ occurred for Bundle 8 over a one-month period. The slow decline in oxygen levels in waste which has negative temperatures observed for Bundles 7 and 8 was similar to that of Bundles 1 and 2. As discussed previously, isolated areas where a high concentration of organic waste exists within the waste may experience biodegradation which is causing the slow depletion of oxygen.

In a similar attempt at adding air for Bundles 1-4, no air could be pumped through the hollow tubes via a bike pump back to the Bundles 7 and 8 . This may be because ice has built up within the hollow tubes, blocking the path for the flow of air. As such, warmer waste temperatures are required which may melt the ice present in the hollow tubes, before air can be pumped through to Bundles 7 and 8. 


\section{Bundles 7-8: Oxygen Content in Relation to Temperature}

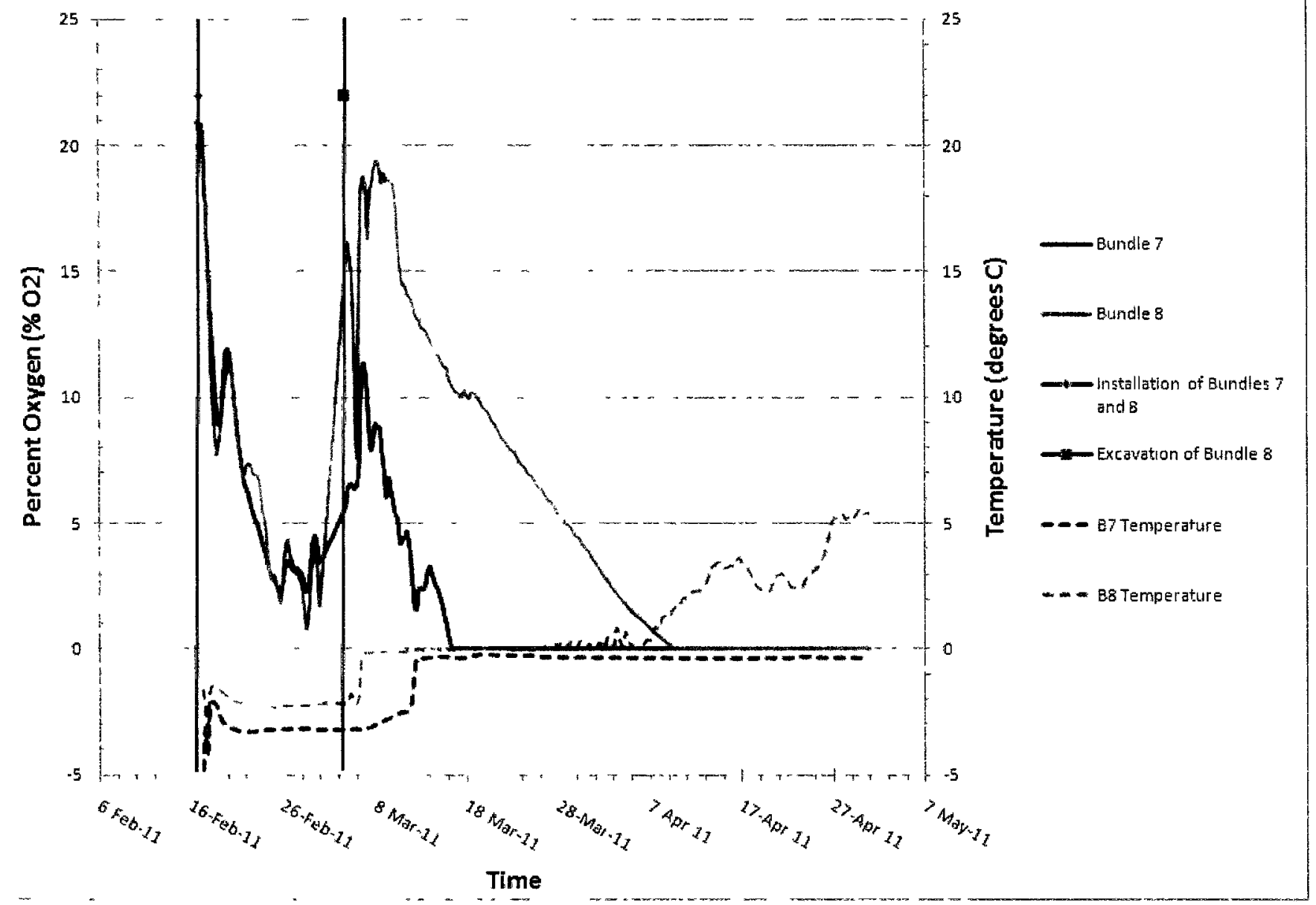

Figure 51: Oxygen Content for Bundles 7-8 in Relation to Temperature. 


\subsubsection{Vibrating Wire Piezometer}

The vibrating wire piezometer produced outputs in $\mathrm{B}$ units $\left(\mathrm{Hz}^{2} \times 10^{-3}\right)$ and temperature readings in degrees Celsius. The raw outputs from the vibrating wire piezometer required corrections for initial installation readings (i.e. zeroing), temperature, and barometric pressure, in order to determine pressure. The pressure was then related to the height of the water column present over the instrument which is responsible for enacting pressure on the piezometer. Appendix I contains all calibration equations, a sample calculation, and calibration records, for the vibrating wire piezometer.

Four piezometers were installed in the Sainte-Sophie bioreactor landfill. Mounding of leachate was not expected to rise above the elevations of Bundles 3 and 4, if at all; therefore, no additional piezometers were deemed necessary. The piezometers were installed with Bundles 1-4 where they were closest to the bottom of the landfill.

Figure 52 shows the corrected piezometer pressures for Bundles 1-4 over the study period. All four instrument bundles indicate a downwards trend in piezometer pressure with negative pressure values, with the values exceeding the accuracy of the piezometers. The accuracies of the piezometers were provided in the calibration sheets in Appendix I, and range from $\pm 0.28 \mathrm{kPa}$ to $\pm 0.53 \mathrm{kPa}$ for Bundles $1-4$. As there is no physical reason for negative pressure readings of this magnitude, this issue is currently being resolved through discussion of the data with the instrument providers. Bundle 4 was the only piezometer which indicated a rise in pressure 
around February 2011. As presented earlier, the estimated VWC at Bundle 4 also rose in February 2011 in response to the placement of the second and third lift of waste. The EC also increased indicating the impacts of leachate. However, there is no evidence or argument for local mounding at Bundle 4. 


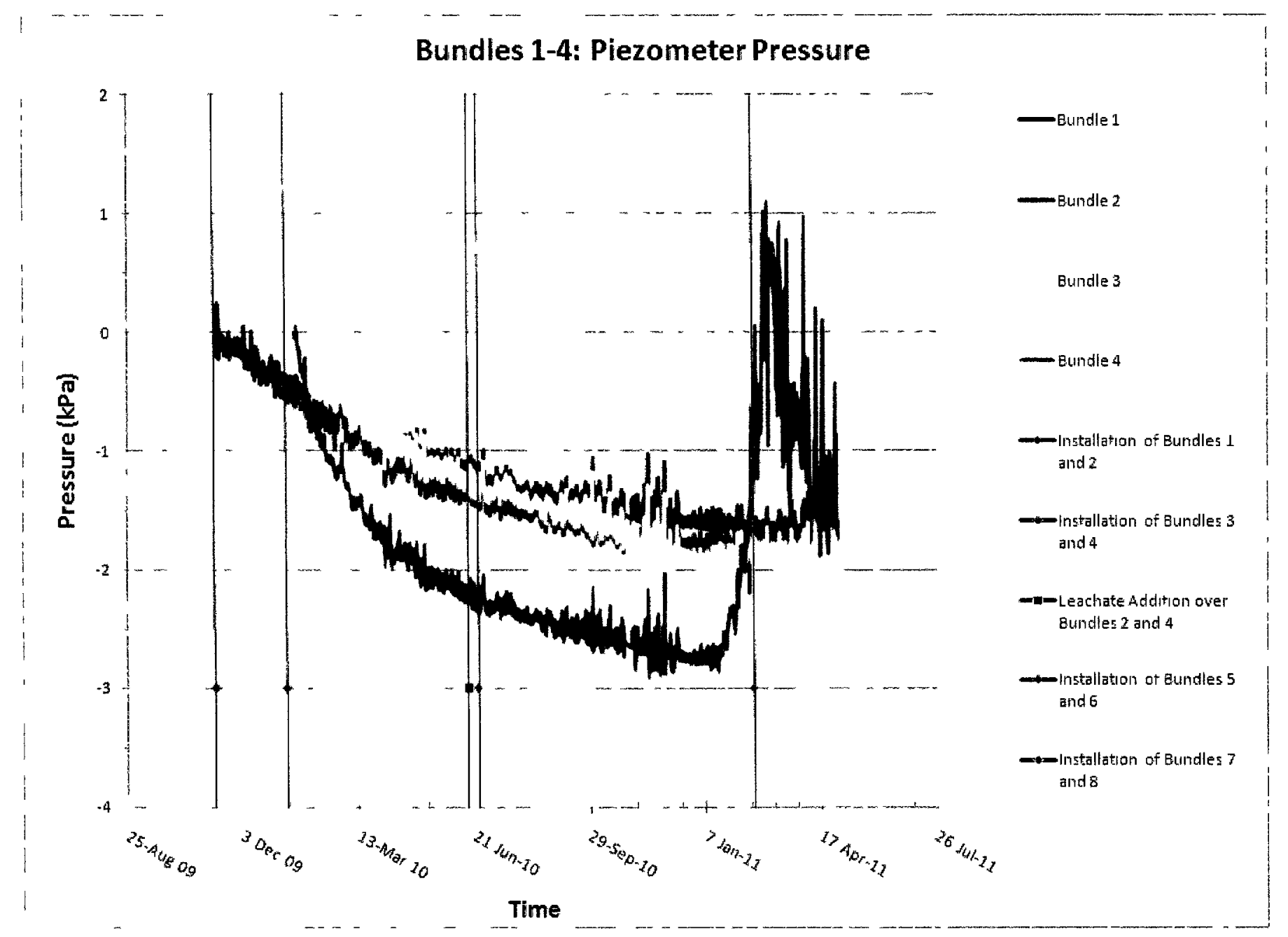

Figure 52: Piezometer pressures for Bundles 1-4. 


\section{Conclusions and Recommendations}

At the time of writing this thesis, eight of the twelve planned instrument bundles were installed within different waste layers in the Sainte-Sophie bioreactor landfill, providing preliminary data about the waste stabilization process in bioreactor landfills operating in northern climates.

The waste demonstrated good insulating properties as limited heat could infiltrate the waste leaving much of the waste to remain frozen throughout the 18 -month study period. The length of time that waste remains frozen is an issue for the feasibility of the bioreactor landfill in northern climates, as positive waste temperatures are required for microbial activity to begin the process of waste stabilization. This research indicated that it is imperative for operators of bioreactor landfills in northern climates to design a waste placement sequence that avoids the consecutive placement of several waste lifts under freezing conditions to ensure that certain waste layers do not remain frozen for extended periods of time. Rather, a sequence that retains heat within the waste lifts will lead to a more uniform waste temperature and stabilization for the bioreactor landfill.

Over the course of this study, the settlement systems measured large amounts of settlement. Bundles located at the centre of the $12 \mathrm{~m}$ waste profile, settled between 1.0 and $1.8 \mathrm{~m}$ over a 10 -month period. However, given the low waste temperatures observed throughout the study, the settlement that did occur was attributed to compaction from the load being applied through overlying layers of waste, rather 
than to biodegradation. This research indicated that settlement and waste stabilization were limited due to the fact that the waste layers in the vicinity of the instrument bundles were all placed in the winter months which delayed biodegradation of the waste.

At bundles where the waste temperature was below zero, the rate of oxygen depletion was very slow; on the order of weeks to months. At bundles where the waste temperature was well above zero, the oxygen depletion was rapid and occurred over a couple of days.

Several discrepancies arose during the measurement of the total load and moisture content. The total earth pressure cell (TEPC), measuring total load, responded positively to the placement of additional waste lifts above the instrument bundles; however, the recorded pressures were considerably higher than the expected pressures due to the height of waste above the bundle. It was hypothesized that the TEPC was susceptible to freezing temperatures causing higher than expected pressures to be measured. Moisture content readings were deemed inaccurate, as the readings by the sensor were impacted by freezing temperatures as well as high electrical conductivity values generated by leachate. However, the electrical conductivity values recorded by the sensor indicated the movement of leachate within the waste. It was hypothesized that the load provided by the additional waste lifts caused the lower waste layers to compact, reducing the void space and increasing the volumetric water content, causing leachate to mobilize. This research indicated that laboratory tests involving freezing temperatures (and increased 
electrical conductivity for the moisture sensor) would be beneficial in understanding the issues these instruments have in field conditions while observing bioreactor landfills in northern climates.

Future work for this research project includes the continual monitoring of the instrument bundle data, especially as waste temperatures rise and biodegradation begins. Four out of twelve instrument bundles remain to be installed. The weather station and GPS system should be operational within the next 6 months, providing more information towards climatic conditions and operating practices at the SainteSophie bioreactor landfill. The GPS data can then be coupled with the instrument bundle data to observe relationships between the two, such that the feasibility and optimization of a bioreactor landfill in a northern climate can be better established. 


\section{References}

Apogee Instruments Instruction Manual (2009) - Oxygen Sensor S0-100 \& 200 Series. Apogee Instruments Inc. Logan, UT.

Benson, C.H., M.A. Barlaz, D.T. Lane, \& J.M. Rowe. (2007) Practice Review of Five Bioreactor/Recirculation Landfills. Waste Management, 27, pp 13-29.

Campbell Scientific Operator's Manual (2006) - CR1000 Measurement and Control System Overview. Revision 11/06. Campbell Scientific, Inc. Logan, UT.

Catley, A., C. Samson, \& P. Van Geel. (2008) Seismic velocity analysis to determine moisture distribution in a bioreactor landfill. Journal of Solid Waste Technology and Management, 34(2): 81-90.

Decagon Devices Operator's Manual (2010) - 5TE Water Content, EC and Temperature Sensors. Version 5. Decagon Devices, Inc. Pullman, WA.

Elagroudy, S.A., M.H. Abdel-Razik, M.A. Warith, \& F.H. Ghobrial. (2008) Waste Settlement in Bioreactor Landfill Models. Waste Management, 28, pp 2366-2374.

El-Rabbany, A. (2006) Introduction to GPS The Global Positioning System. Second Edition. Artech House Publishers, Norwood, MA.

Fickes, M. (2004). Putting Productivity on the Map. Waste Age, Volume 35 Issue 11, pp 36-39.

Gawande, N.A., D.R. Reinhart, P.A. Thomas, P.T. McCreanor, \& T. Townsend. (2003) Municipal Solid Waste In Situ Moisture Content Measurement Using An Electrical Resistance Sensor. Waste Management, 23, pp 667-674.

Genivar. (2008) Figure 4, Configuration du réseau de captage du biogas zone IV. L.E.S. de Sainte-Sophie. Project number Q110532. Prepared for: Waste Management.

Griesbach, B. (2010). Getting Your Bearings: The Stages of Landfill GPS Implementation. Waste Age, Volume 41 Issue 10, pp 18-21.

Grellier, S. H. Robain, G. Bellier, \& N. Skhiri. (2006) Influence of Temperature on the Electrical Conductivity of Leachate from Municipal Solid Waste. Journal of Hazardous Materials, B137, pp 612-617.

Hanson, J.L., N. Yesiller, K.A. Howard, W.-L. Liu, \& S.P. Cooper. (2006) Effects of Placement Conditions on Decomposition of Municipal Solid Wastes in Cold Regions. Current Practices in Cold Regions Engineering. Proceedings of the $13^{\text {th }}$ International Conference on Cold Regions Engineering, Orono, ME. 
Hinkley Center for Solid and Hazardous Waste Management, University of Florida, \& University of Central Florida. (2008) Florida Bioreactor Landfill Demonstration Project: Final Report. Accessed Dec 2010. http://www.bioreactor.org/publications.html

Imhoff, P.T., D.R. Reinhart, M. Englund, R. Guerin, N. Gawande, B. Han, S. Jonnalagadda, T. Townsend, \& R. Yazdani. (2007) Review of State of the Art Methods for Measuring Water in Landfills. Waste Management, 27, pp 729-725.

Jackson, N.M. (2008). Not Your Grandfather's Landfill. Waste Age, Volume 39 Issue 9, pp 52-58.

Kaplan, E.D. \& C.J. Hegarty. (2006) Understanding GPS: Principles and Applications. Second Edition. Artech House, Norwood, MA.

Komilis, D.P., R.K. Ham, \& R. Stegmann. (1999) The Effect of Landfill Design and Operation Practices On Waste Degradation Behaviour: A Review. Waste Management \& Research, 17, pp 20-26.

Kumar, D., S. Jonnalagadda, P. Jain, N.A. Gawande, T. Townsend, \& D.R. Reinhart. (2009) Field Evaluation of Resistivity Sensors for In-Situ Moisture Measurement in a Bioreactor Landfill. Waste Management, 29, pp 1547-1557.

Lefebvre, X., S. Lanini, \& D. Houi. (2000) The Role of Aerobic Activity on refuse Temperature Rise, I. Landfill Experiment Study. Waste Management \& Research, 18, pp 444-452.

MOE. (2010) Landfill Standards: A Guideline on the Regulatory and Approval Requirements for New or Expanding Landfilling Sites. Ontario Ministry of the Environment, 2010, pp 1-108.

NRC. (2007) Canadian Spatial Reference System: GPS Accuracy Levels. National Resources Canada. Last updated: Dec 2007. Accessed: May 2011. http://www.geod.nrcan.gc.ca/edu/geod/gps/gps13 e.php

Pichtel, J. (2005) Waste Management Practices: Municipal, Hazardous, and Industrial. CRC Press Taylor \& Francis Group, Boca Raton, FL.

Rees, J.F. (1980) Optimization of Methane Production and Refuse Decomposition in Landfills by Temperature Control. Journal of Chemical Technology \& Biotechnology, 30 , pp 458-465.

Reinhart, D.R. (1996) Full-scale Experiences with Leachate Recirculating Landfills: Case Studies. Waste Management \& Research, 14, pp 347-365. 
Reinhart, D.R. \& A.B. Al-Yousfi. (1996) The Impact of Leachate Recirculation on Municipal Solid Waste Landfill Operating Characteristics. Waste Management \& Research, 14, pp 337-346.

Reinhart, D.R. \& T.G. Townsend. (1998) Landfill Bioreactor Design and Operation. Lewis Publishers, Boca Raton, FL.

Reinhart, D.R., P.T. McCreanor, \& T. Townsend. (2002) The Bioreactor Landfill: Its Status and Future. Waste Management, 20, pp 172-186.

Rowe, R.K. \& M.Z. Islam. (2009) Impact of Landfill Liner Time-Temperature History on the Service Life of HDPE Geomembranes. Waste Management, 29, 2689-2699.

Rowe, R.K., R.M. Quigley, R.W.I. Brachman, \& J.R. Booker. (2004) Barrier Systems for Waste Disposal Systems. Second Edition. Spon Press, New York, NY.

RST Instruments Instruction Manual (2004) - RST Flexi-Mux (ELM0029A). Revision 1.1. RST Instruments Ltd. Coquitlam, BC.

RST Instruments Instruction Manual (2004) - Total Earth Pressure Cell (LPM0009B). Revision 1.3. RST Instruments Ltd. Coquitlam, BC.

RST Instruments Instruction Manual (2006) - Vibrating Wire Piezometer Model VW2100 (ELM0005I). Revision 1.6. RST Instruments Ltd. Coquitlam, BC.

RST Instruments Instruction Manual (2008) - VW Liquid Settlement System (SSM0018C). Revision 3. RST Instruments Ltd. Coquitlam, BC.

Sharma, H.D. \& K.R. Reddy. (2004) Geoenvironmental Engineering: Site Remediation, Waste Containment, and Emerging Waste Management Technologies. John Wiley \& Sons, Inc., Hoboken, NJ.

Valencia, R., W. van de Zon, H. Woelders, H.J. Lubberding, \& H.J. Gijzen. (2009) The Effect of Hydraulic Conditions on Waste Stabilization in Bioreactor Simulators. Bioresource Technology, 100, pp 1754-1761.

Van Geel, P.J., E. Vingerhoeds, and C. Samson. (2010) Process Optimization at a Bioreactor Landfill in Québec, Canada, Proceedings of WASTECON 2010, Boston, August 15-17, 2010.

Waste Management. (2004) The Bioreactor Landfill: Next Generation Landfill Technology. Waste Management Bioreactor Program. Accessed Dec 2010. http://www.wm.com/sustainability/pdfs/bioreactorbrochure.pdf

Warith, M. (2002) Bioreactor Landfills: Experimental and Field Results. Waste Management, 22, pp 7-17. 
Warith, M., X. Li, \& H. Jin. (2005) Bioreactor Landfills: State-of-the-Art Review. Emirates Journal for Engineering Research, 10(1), pp 1-14.

Yesiller, N., J.L. Hanson, \& W.-L. Liu. (2005) Heat Generation in Municipal Solid Waste Landfills. Journal of Geotechnical and Geoenvironmental Engineering, 131(11), pp 1330-1344.

Zhao, X., R. Musleh, S. Maher, M.V. Khire, T.C. Voice, \& S.A. Hashsham. (2008) Startup Performance of a Full-Scale Bioreactor Landfill Cell Under Cold-Climate Conditions. Waste Management, 28, pp 2633-2634. 


\section{Appendix A - Instrument Specifications}

Additional specifications, for sensors in the instrument bundles, are summarized here.

Settlement System (RST Settlement Manual 2008)

\begin{tabular}{|l|l|}
\hline Manufactured By: & RST Instruments \\
\hline Instrument Name: & Vibrating Wire Liquid Settlement System \\
\hline Model \#: & SS VW $105-170$ \\
\hline Operating Temperature: & $-20^{\circ} \mathrm{C}$ to $+80^{\circ} \mathrm{C}$ \\
\hline Range: & $170 \mathrm{kPa}$ (or $17 \mathrm{~m})$ \\
\hline System Accuracy: & $0.1 \%$ of full-scale (approx.) \\
\hline $\begin{array}{l}\text { Fluid in Liquid Filled } \\
\text { Flexible Tubing: }\end{array}$ & $50 / 50$ mixture of distilled water and ethylene glycol antifreeze \\
\hline Reservoir Type: & $\begin{array}{l}(2 \text { units) } 10 p s i \text { pressure accumulator, } \\
(2 \text { units) weighted accumulator }\end{array}$ \\
\hline Corrections Required: & $\begin{array}{l}\text { Temperature, } \\
\text { Initial Reading at Installation, } \\
\text { Barometric Pressure }\end{array}$ \\
\hline
\end{tabular}


Total Earth Pressure Cell (RST Pressure Manual 2004)

\begin{tabular}{|l|l|}
\hline Manufactured By: & RST Instruments \\
\hline Instrument Name: & Vibrating Wire - Total Earth Pressure Cell \\
\hline Model \#: & LP TPC 12-V-M \\
\hline Operating Temperature: & $-29^{\circ} \mathrm{C}$ to $+65^{\circ} \mathrm{C}$ \\
\hline Range: & $0.5 \mathrm{MPa}$ \\
\hline Accuracy: & $0.1 \%$ of full-scale (approx.) \\
\hline Cell Diameter: & $31.7 \mathrm{~cm}$ \\
\hline Transducer Type: & Vibrating Wire Pressure Transducer \\
\hline Corrections Required: & $\begin{array}{l}\text { Initial Reading at Installation, } \\
\text { Barometric Pressure }\end{array}$ \\
\hline
\end{tabular}

Piezometer (RST Piezometer Manual 2006)

\begin{tabular}{|l|l|}
\hline Manufactured By: & RST Instruments \\
\hline Instrument Name: & Vibrating Wire Piezometer \\
\hline Model \#: & PPA $0094-0.35$ \\
\hline Operating Temperature: & $-20^{\circ} \mathrm{C}$ to $+80^{\circ} \mathrm{C}$ \\
\hline Range: & $350 \mathrm{kPa}$ \\
\hline Accuracy: & $0.1 \%$ of full-scale (approx.) \\
\hline Transducer Type: & Vibrating Wire Pressure Transducer \\
\hline Corrections Required: & $\begin{array}{l}\text { Temperature Correction, } \\
\text { Initial Reading at Installation, } \\
\text { Barometric Pressure }\end{array}$ \\
\hline
\end{tabular}


Oxygen Sensor (Apogee Manual 2009)

\begin{tabular}{|l|l|}
\hline Manufactured By: & Apogee Instruments Inc. \\
\hline Instrument Name: & Oxygen Sensor \\
\hline Model \#: & SO-200 \\
\hline Operating Temperature: & $-20^{\circ} \mathrm{C}$ to $+60^{\circ} \mathrm{C}$ \\
\hline Range: & $0-100 \% \mathrm{O}_{2}$ \\
\hline Accuracy: & $<0.02 \% \mathrm{O}_{2}$ drift per day \\
\hline Sensor: & $\begin{array}{l}\text { Galvanic cell sensor with lead anode, gold cathode, acid } \\
\text { electrolyte, and Teflon membrane. }\end{array}$ \\
\hline Corrections Required: & Zero Offset \\
\hline
\end{tabular}

Moisture Sensor (Decagon Manual 2010)

\begin{tabular}{|l|l|}
\hline Manufactured By: & Decagon Devices \\
\hline Instrument Name: & $5 T E$ Soil Moisture, Temperature, and Electrical Conductivity \\
\hline Model \#: & 40559 \\
\hline Operating Temperature: & $-40^{\circ} \mathrm{C}$ to $+50^{\circ} \mathrm{C}$ \\
\hline Range: & $\begin{array}{l}\text { Volumetric Water Content }(W W C)>>\text { Apparent dielectric } \\
\text { permittivity }\left(\varepsilon_{a}\right): 1 \text { (air) to } 80(\text { water) } \\
\text { Electrical Conductivity }(\mathrm{EC}), \text { bulk: } 0-23 \mathrm{dS} / \mathrm{m}, \\
\text { Temperature: }-40^{\circ} \mathrm{C} \text { to }+50^{\circ} \mathrm{C}\end{array}$ \\
\hline Accuracy: & $\begin{array}{l}\left(\varepsilon_{a}\right): \pm 1 \varepsilon_{\mathrm{a}} \text { (unitless) from } 1-40 \text { (soil range), } \pm 15 \% \text { from } 40-80, \\
\text { VWC: } \pm 3 \% \text { VWC, } \\
\text { EC (bulk): } \pm 10 \% \text { from } 0-7 \mathrm{dS} / \mathrm{m} \\
\text { Temperature: } \pm 1^{\circ} \mathrm{C}\end{array}$ \\
\hline Sensor Type: & $\begin{array}{l}\text { VWC: Frequency domain } \\
\text { EC (bulk): Two-probe design } \\
\text { Temperature: Thermistor }\end{array}$ \\
\hline Corrections Required: & $\begin{array}{l}\text { Temperature Correction, } \\
\text { Initial Reading at Installation, } \\
\text { Barometric Pressure }\end{array}$ \\
\hline
\end{tabular}




\section{Appendix B - Data Acquisition System Specifications and}

\section{Sample Datalogger Program}

Details for the data acquisition system and data collection software are provided here. A sample program from the datalogger for recording data from twelve instrument bundles is also included.

Data Acquisition System and Data Collection Software

\begin{tabular}{|c|c|}
\hline Manufactured By: & RST Instruments \\
\hline Datalogger Model: & (1 unit) CR1000 Datalogger, from flexDAQ Datalogger Series \\
\hline Multiplexer Model: & (12 units) Flexi-Mux \\
\hline Communication: & $\begin{array}{l}\text { Remote accessibility through internet modem, } \\
\text { On-site accessibility through USB connection to a PC }\end{array}$ \\
\hline System Features: & $\begin{array}{l}\text { Battery back-up to maintain memory and system clock, } \\
\text { Time-stamped data, } \\
\text { Real-time access of data }\end{array}$ \\
\hline User Interface Software: & Campbell Scientific LoggerNet 3.4.1 \\
\hline Internet IP Address: & 70.28.241.124:3001 \\
\hline Sampling Frequency: & $\begin{array}{l}30 \mathrm{~min} \text { (also have used } 15 \mathrm{~min}, 3 \mathrm{~min} \text {, and } 1 \mathrm{~min} \text { for more detailed } \\
\text { data analysis) }\end{array}$ \\
\hline
\end{tabular}




\section{Sample Datalogger Program}

'Program name: P:\FILES\CAMPBELL field services\PC208\Hoskins Sci\WM QUEBEC Q012003

'Date written: 19/8/09 DWP, RST Inst'Rev 1

'LANDFILL SETTLEMENT SYSTEM

\section{AngleDegrees}

'READS 6 instrument PLATE each containing, 1 VW Settlement with therm, 1 VW TEPC, 1 VW Piezo with therm (3 CAGES), 1 echo TE water content, 1 02 sensor 'Plus 2 reference sensors for settlement reservoirs.

'logger program will require modifications when additional sensor plates (6) are added

'revision V2, added settle kpa to data table, moved TEout strings to end of data table, changed output calculations by a factor of 1000

'Nov 909 dwp rst V3 changed 02 measurements so that raw V is recorded and individual cal factors can be added in.

'Ver 4 Nov 17 09, dwp, recal 02 sensor f0r 20.95\% today @ 11:15

'Dec 1109 added temp corrections and switched ref trancducer cal factors

'Jan 19, 2010, dwp removed delay in TE sub routine and added error checking in program.

'installed this program with above updates Mar16, 2010

'Jan 2011, dwp RST Inst - added 6 more plates, no additional piezos. Addition TEPC thermistors can be attached to empty piezo thermistor channels

'Feb 152011 add alternate method to read 02 temp sensor

'Feb 16, 2011, dwp add barometric sensor

'V8 FEB 17 - ADDED CAL FACTORS AND CALCS FOR NEW SETTLEMENT REFERENCES

'IIIIIIIIIIIIIIIIIIIIIIIII DECLARATIONS ////////////////////////

Public TECP_Raw(12),TECP_KPa(12)

Public Piezo_Raw(8), Piezo TH(8),P KPa(4)' 4 piezo only, additional 4 are for TECP thermistors if wanted

Public Sett_Raw(12),Sett_TH(12),Settle_kPa(12), Settle_mm(12)

Public Ref_Raw(4),Ref_TH(4),Ref_kPa(4) '2 additional new style are to be added to the original 2

Public Barometer

Public 02_V(12), 02(12), 02Temp(12), oC0(12), 02_T(12), Tc(12) ' $\mathrm{mV}$, intial conversion to 02, sensor temp, intermed temp cal factor, final 02, temp at cal

Public 02_m(12),02TH_Res(12),02TH_V(12) ' individual cal factor for each sensor e.g 20.95\% / (02(i)-2.5) $=0.441 \% 02 / \mathrm{mV}$

Public SH_10k,ratio_10K,DegC_10K,RTH_10K,LnRTH_10K' global vars from Sub SH10K

'Public 02TempM(12)' for testing only

'TE Probes

Const eb0 $=5$

'empirical constant loosely representing the dielectric of dry soil

Public TE,Count

Public TEout(12) As String * 32

Public Pos_RawVWC(12) As Long

Public Pos_RawEC(12) As Long

Public Pos_RawT(12) As Long

Public RawVWC(12) As Float,RawEC(12) As Float,RawT(12) As Float 
Public VWCm(12) As Float',VWCp(TE_Num) as FLOAT 'VWCm for mineral soil, VWCp for potting soil Public Temp(12) As Float

Public eb(12) As Float, ep(12) As Float 'eb is bulk dielectric and ep is the dielectric of the pore water Public ECb(12) As Float ' this is bulk dielectric measured by the TE

Public ECp(12) As Float ' this is the pore water dielectric estimated by

Public Htz(34),Amp(34),S2N(34),NF(34),DR(34),Res(34)

Public VW(6), Result

Public SH,ratio,DegC,RTH,LnRTH ' global vars from Sub SH

Const $\mathrm{C} 0=1.46532 \mathrm{E}-03^{\prime} \log$ poly coefficients 2252

Const $\mathrm{C} 1=2.38716 \mathrm{E}-04$

Const C3 $=9.97189 \mathrm{E}-08$

Public SH3k,DegC3k,RTH3k,LnRTH3k ' global vars from Sub SH3k

Const $\mathrm{k} 3 \mathrm{CO}=1.405027 \mathrm{E}-3$

Const k3C1=2.369386E-4 '3K3A Thermistor

Const k3C3=1.012660E-7

Public Bat V

Public Int_Temp

Public Flag(8) As Boolean

Public i, j

Const oC3 $=-0.000004333$

Const oC2 $=0.001896$

Const oC1 $=-0.03610$

Const COK $10=1.1303 \mathrm{E}-03^{\prime}$ log poly coefficients $10 \mathrm{k}$

Const $\mathrm{C} 1 \mathrm{~K} 10=2.339 \mathrm{E}-04$

Const C3K10 $=8.863 \mathrm{E}-08$

'10000 Ohm @ 25C NTC Thermistor

$$
{ }^{\mathrm{C}} \mathrm{C}=
$$

0.0011303

'C1=

0.0002339

${ }^{\prime} \mathrm{C} 3=0.00000008863$

Const $\mathrm{k}=95.3 \mathrm{kPa}$ to $\mathrm{mm}$ head for $50 / 50 \mathrm{~h} 2 \mathrm{o} / \mathrm{glycol}$

$\begin{array}{llll}\text { Alias } & \text { Settle_mm( } & 1 & \text { ) }=\text { Set_mm1_1 } \\ \text { Alias } & \text { Settle_mm( } & 2 & \text { ) }=\text { Set_mm1_2 } \\ \text { Alias } & \text { Settle_mm( } & 3 & \text { J }=\text { Set_mm2_1 } \\ \text { Alias } & \text { Settle_mm( } & 4 & \text { J }=\text { Set_mm2_2 } \\ \text { Alias } & \text { Settle_mm( } & 5 & \text { J }=\text { Set_mm3_1 } \\ \text { Alias } & \text { Settle_mm( } & 6 & \text { J }=\text { Set_mm3_2 } \\ \text { Alias } & \text { Settle_mm( } & 7 & \text { J }=\text { Set_mm4_1 }\end{array}$




\begin{tabular}{|c|c|c|c|}
\hline Alias & Settle_mm & 8 & J = Set_mm4_2 \\
\hline Alias & Settle_mm & 9 & J = Set_mm5_1 \\
\hline Alias & Settle_mm & 10 & $=$ Set $m m 5$ \\
\hline Alias & Settle_mm & 11 & $\mathrm{~J}=$ Set_mm6_1 \\
\hline Alias & Settle_mm & 12 & $J=$ Set_mm6_2 \\
\hline Alias & $P_{-} \mathrm{KPa}(1$ & \multicolumn{2}{|c|}{ J=Piezo1_1 } \\
\hline Alias & P_KPal 2 & \multicolumn{2}{|c|}{$\mathrm{J}=$ Piezo1_2 } \\
\hline Alias & P_KPa( 3 & \multicolumn{2}{|c|}{$J=$ Piezo2_1 } \\
\hline Alias & P_KPal 4 & \multicolumn{2}{|c|}{$\mathrm{J}=$ Piezo2_2 } \\
\hline Alias & Piezo_TH(1)= & \multicolumn{2}{|c|}{ Piezo_TH1_1 } \\
\hline Alias & Piezo_TH(2)= & \multicolumn{2}{|c|}{ Piezo_TH1_2 } \\
\hline Alias & Piezo_TH(3)= & \multicolumn{2}{|c|}{ Piezo_TH2_1 } \\
\hline Alias & Piezo_TH(4)= & \multicolumn{2}{|c|}{ Piezo_TH2_2 } \\
\hline Alias & TECP_KPa(1)= & \multicolumn{2}{|c|}{ TECP1_1 } \\
\hline Alias & TECP_KPa(2)= & \multicolumn{2}{|c|}{ TECP1_2 } \\
\hline Alias & TECP_KPa(3)= & \multicolumn{2}{|c|}{ TECP2_1 } \\
\hline Alias & $\mathrm{TECP}_{\mathrm{KPa}}(4)=$ & \multicolumn{2}{|c|}{ TECP2_2 } \\
\hline Alias & TECP_KPa(5)= & \multicolumn{2}{|c|}{ TECP3_1 } \\
\hline Alias & TECP_KPa(6)= & \multicolumn{2}{|c|}{ TECP3_2 } \\
\hline Alias & TECP_Kpa(7)= & \multicolumn{2}{|c|}{ TECP4_1 } \\
\hline Alias & TECP_Kpa(8)= & \multicolumn{2}{|c|}{ TECP4_2 } \\
\hline Alias & TECP_Kpa(9)= & \multicolumn{2}{|c|}{ TECP5_1 } \\
\hline Alias & TECP_Kpa $(10)=$ & \multicolumn{2}{|c|}{ TECP5_2 } \\
\hline Alias & TECP_Kpa $(11)=$ & \multicolumn{2}{|c|}{ TECP6_1 } \\
\hline Alias & TECP_Kpa(12) = & \multicolumn{2}{|c|}{ TECP6_2 } \\
\hline
\end{tabular}

"IIIIIIIIIIIIIIIIIIIIIIIIOUTPUT SECTION $/ / / / / / / / / / / / / / / / / / / / / /$

DataTable(Q12003,1,-1)

Sample (12,Sett_Raw0,IEEE4)

Sample (12,Settle kPaO,FP2)

Sample (12,Settle_mm0,FP2)

Sample (12,Sett_TH(),FP2)

Sample (4,Piezo_Raw0,IEEE4)

Sample (4,P_KPaO,FP2)

Sample (8,Piezo_THO,FP2)

Sample (4,Ref_Raw0,IEEE4)

Sample (4,Ref_kPa(O,FP2)

Sample (4,Ref_THO,FP2) 
Sample (12,TECP_Raw0,IEEE4)

Sample (12,TECP_KPa(,FP2)

Sample (1,Barometer,FP2) 'Barometric Pressure kPa

Sample (12,RawVWC0,IEEE4)

Sample (12,RawEC0,IEEE4)

Sample (12,RawT(0,FP2)

Sample (12,VWCm(),FP2)

Sample (12,Temp(),FP2)

Sample $(12, \mathrm{eb} 0, \mathrm{FP} 2)$

Sample $(12, \mathrm{ep} 0, \mathrm{FP} 2)$

Sample (12,ECb0,FP2)

Sample (12,ECp0,FP2)

Sample $\left(12,02 \_V 0, F P 2\right)$

Sample $(12,020, \mathrm{FP} 2)$

Sample (12,02Temp0,FP2)

Sample $\left(12,02 \_T 0, F P 2\right)$

Sample (1,Bat_V,FP2)

Sample (1,Int_Temp,FP2)

Sample (12,02TH_Res(),FP2)

Sample (12,TEout0,String)

EndTable

Sub TE

Delay $(0,10, \mathrm{mSec})$

PortSet $(9,1)$ 'Switch SW12 V port on

Delay $(0,30, \mathrm{mSec})$

SerialFlush(Com4)'Clear com ports of any erroneous characters generated when turning TE on

'Wait for serial data to come into com ports

'Delay $(0,150, \mathrm{mSec})$

Serialln (TEout(i),Com4,150,0,50)

PortSet $(9,0)$ 'Turn off power to switched $12 \mathrm{~V}$ port

EndSub

Sub SH3k(RTH3k,DegC3k)' returns C from RESISTANCE 3K Therm AVW200

If RTH3k $<50$ Then RTH3k $=50$

If RTH3k > 225000 Then RTH3k $=225000$

LnRTH3k=LN(RTH3k)' pre-evaluate

DegC3k=1/(k3C0+k3C1*LnRTH3k+k3C3*LnRTH3k^3)-273.15 
EndSub

'10k thermistor

Sub SH10k(RTH_10K,DegC_10K)' returns C from mV 24.9k completion

'If ratio_10k $<.005$ Then ratio_10K=.005

'If ratio_10k $>.83$ Then ratio_10K $=.83$

'RTH_10K=24900/ratio_10K-24900' $=(2500 \mathrm{mV} / \mathrm{mVTH}) * 24900 \mathrm{ohms}-24900 \mathrm{ohms}$ (calculate resistance)

LnRTH_10K=LN(RTH_10K)' pre-evaluate transcendental for efficiency

DegC_10K=1/(COK10+C1K10*LnRTH_10k+C3k10*LnRTH_10K*LnRTH_10K*LnRTH_10K)-273.15

EndSub

111111111111111111111111111 PROGRAM $/ / / / / / / / / / / / / / / / / / / / / / / / / /$

BeginProg

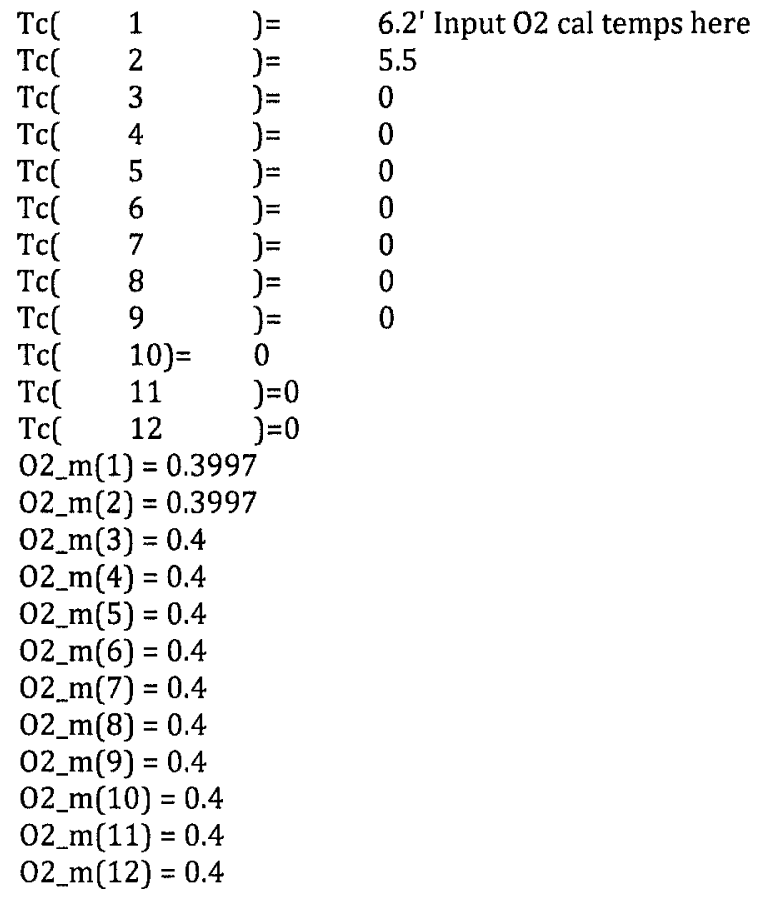

PortSet $(6,1)^{\prime}$ default heaters and modem power on 
SerialOpen (Com1,38400,4,0,10000)'SET UP AVW200 COM

SerialOpen(com4,1200,19,0,10000)'setup for TE probe

$\operatorname{Scan}(30, \mathrm{Min}, 3,0)$

'\#\#\#\#\#\#\#\#\#\#\#\#\#\#\#\#\#\#\#\#\#\#\#\#\#\#\#\#\#\#\#\#\#\#\#\#

Battery(Bat_V)

PanelTemp(Int_Temp, 250)

'Measure Barometer Sensor

PortSet $(6,1)$ 'Power on Barometer

Delay $[0,2, \mathrm{Sec})$ 'two second warmup

VoltSe (Barometer,1,mV2500,4,False,0,60Hz,0.01999,60) ' $\mathrm{KPa}$, Ensure proper offset is inserted for elevation (See Manual)

PortSet $(6,0)$ 'Power off Barometer

If Bat_V $>12.1$ Then 'turn off radio and 02 heaters if battery below 121 volts

PortSet $(6,1)$

Else

PortSet $(6,0)$

Endlf

PortSet $(3,1)$

':ENABLE multiplexer 1 to 7

Delay(0,5,MSEC)

READ Settlement

For $1=1$ To 12

PulsePort $(4,5000) \quad$ 'CLOCK MUX

Delay $(0,5, \mathrm{MSEC})$

'DELAY

AVW200 (Result,Com1,0,200,VW(0,1,1,1,1500,3200,1,60Hz,1,0) '200 is packbus address of AVW200

$\mathrm{Htz}(1)=V W(1)$ 'frequency

Amp(1)=VW(2)'amplitude

$\mathrm{S} 2 \mathrm{~N}(\mathrm{i})=\mathrm{VW}(3)$ 'signal to noise ratıo

$\mathrm{NF}(1)=\mathrm{VW}(4)$ 'noise frquency

$\mathrm{DR}(\mathrm{i})=\mathrm{VW}(5)$ 'decay ratio

$\operatorname{Res}(1)=\mathrm{VW}(6)$ 'thermistor resistsance

If $\mathrm{VW}(2)<.05$ Then $\mathrm{Htz}(1)=0$

Sett_Raw $(1)=\left(\operatorname{Htz}(1)^{\wedge} 2\right) / 1000$

Call SH3k(Res(1),Sett_TH(i))'3k thermistor measured with AVW200 (ohms)- convert therm resistance to deg C Next I 
'Read Piezometers

For $\mathrm{i}=1$ To 8 'only 4 Piezo attached - read TEPC therms on additional empty channels

PulsePort $(4,5000)$

Delay $(0,5, \mathrm{MSEC})$ 'CLOCK MUX

AVW200 (Result,Com1,0,200,VW0,1,1,1,1800,3300,1,_60 Hz,1,0) '200 is packbus address of AVW200

$\mathrm{Htz}(\mathrm{i}+12)=\mathrm{VW}(1)$ 'frequency

$\operatorname{Amp}(i+12)=V W(2)$ 'amplitude

$\mathrm{S} 2 \mathrm{~N}(\mathrm{i}+12)=\mathrm{VW}(3)^{\prime}$ 'signal to noise ratio

$\mathrm{NF}(\mathrm{i}+12)=\mathrm{VW}(4)$ 'noise frquency

$\operatorname{DR}(\mathrm{i}+12)=\mathrm{VW}(5)$ 'decay ratio

$\operatorname{Res}(i+12)=V W(6)^{\prime}$ thermistor resistsance

If $\mathrm{VW}(2)<.05$ Then $\mathrm{Htz}(\mathrm{i}+12)=0$

Piezo_Raw $(\mathrm{i})=\left(\mathrm{Htz}(\mathrm{i}+12)^{\wedge} 2\right) / 1000$

Call SH3k(Res(i+12),Piezo_TH(i))'3k thermistor measured with AVW200 (ohms)- convert therm resistance to deg C Next $\mathrm{i}$

'Read settlement Reference Piezometers

For $\mathrm{i}=1$ To 4

PulsePort $(4,5000) \quad$ 'CLOCK MUX

Delay(0,5,MSEC) 'DELAY

AVW200 (Result,Com1,0,200,VWO,1,1,1,1800,3300,1, 60Hz,1,0) '200 is packbus address of AVW200

$\mathrm{Htz}(\mathrm{i}+20)=V W(1)$ 'frequency

Amp $(i+20)=V W(2)$ 'amplitude

S2N $(i+20)=V W(3)$ 'signal to noise ratio

$\mathrm{NF}(\mathrm{i}+20)=\mathrm{VW}(4)$ 'noise frquency

$\mathrm{DR}(\mathrm{i}+20)=\mathrm{VW}(5)$ 'decay ratio

Res $(i+20)=V W(6)$ 'thermistor resistsance

If $\mathrm{VW}(2)<.05$ Then $\mathrm{Htz}(\mathrm{i}+20)=0$

Ref_Raw(i) $=\left(\operatorname{Htz}(\mathrm{i}+20)^{\wedge} 2\right) / 1000$

Call SH3k(Res(i+20),Ref_TH(i))'3k thermistor measured with AVW200 (ohms)- convert therm resistance to deg C Next $\mathrm{i}$

For $\mathrm{i}=1$ To 1 'skip empty channels

PulsePort $(4,5000) \quad$ 'CLOCK MUX

Delay $(0,25$, MSEC $) \quad$ 'DELAY

Next i 
'Read TECP

For $\mathbf{i}=1$ To 12

PulsePort $(4,5000) \quad$ 'CLOCK MUX

Delay $(0,5, \mathrm{MSEC})$ 'DELAY

AVW200 (Result,Com1,0,200,VW0,1,1,1,1800,3300,1,60Hz,1,0) '200 is packbus address of AVW200

$\mathrm{Htz}(\mathrm{i}+22)=\mathrm{VW}(1)$ 'frequency

Amp $(\mathrm{i}+22)=\mathrm{VW}(2)$ 'amplitude

$\mathrm{S} 2 \mathrm{~N}(\mathrm{i}+22)=\mathrm{VW}(3)$ 'signal to noise ratio

$\mathrm{NF}(\mathrm{i}+22)=\mathrm{VW}(4)$ 'noise frquency

$\mathrm{DR}(\mathrm{i}+22)=\mathrm{VW}(5)$ 'decay ratio

$\operatorname{Res}(\mathrm{i}+22)=V W(6)^{\prime}$ thermistor resistsance

If $\mathrm{VW}(2)<.05$ Then $\mathrm{Htz}(\mathrm{i}+22)=0$

TECP_Raw $(\mathrm{i})=\left(\mathrm{Htz}(\mathrm{i}+22)^{\wedge} 2\right) / 1000$

Next i

PortSet $(3,0)$ ':DISABLE multiplexer 1-7

'Read TE probes

PortSet(5,1) ':ENSABLE multiplexer 8-13

Delay $(0,100, \mathrm{mSec})$

For $\mathrm{i}=1$ To 12

PulsePort(4,5000)'Switch to next Multiplexer channel

Delay $(0,100, \mathrm{mSec})$

Call TE

If TEout $(\mathrm{i})=$ " " AND Count $<4$ Then 'RETRY IF INCORRECT SIGNAL RECEIVED

Count $=$ Count +1

Delay $(0,1500, \mathrm{mSec})$

Call TE

Endlf

Count $=0$

Next i

For $\mathrm{j}=1$ To 12

If TEout(j) <> "' Then

Pos_RawVWC(j) = InStr (1,TEout(j),"String",0)

Pos_RawEC(j) = InStr(Pos_RawVWC(j), TEout (j),CHR(32),2)+1

Pos_RawT(j) $=\operatorname{InStr}($ Pos_RawEC(j),TEout (j),CHR(32),2)+1

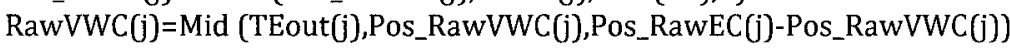

RawEC(j)=Mid (TEout(j),Pos_RawEC(j),Pos_RawT(j)-Pos_RawEC(j)) 
RawT(J)=Mıd (TEout(J),Pos_RawT(J),3)

Temp( $)=(\operatorname{RawT}(\mathrm{J})-400) / 10$

$\mathrm{VWCm(J)=}$ RawVWC(J)*00109 - 629' Use for mineral soll

'VWCp(J)= $000104 *$ RawVWC(J)- $499 \quad$ ' Use for pottıng soll

$\mathrm{ECb}(\mathrm{J})=\operatorname{RawEC}(\mathrm{J}) / 100$

$\mathrm{eb}(\mathrm{J})=764 \mathrm{E}-8 * \operatorname{RawVWC}(\mathrm{J})^{\wedge} 3-885 \mathrm{E}-5 * \operatorname{RawVWC}(\mathrm{J})^{\wedge} 2+485 \mathrm{E}-02 * \operatorname{RawVWC}(\mathrm{J})-10$

$\operatorname{ep}(\mathrm{j})=803-037^{*}(\mathrm{Temp}(\mathrm{J})-20)$

If $V W C m(\mathrm{~J})>010$ Then

$E C p(1)=(\operatorname{ep}(1) * E C b(1)) /(e b(1)-e b 0)$

Else

$\mathrm{ECp}(\mathrm{J})=\mathrm{ECb}(\mathrm{J})$

EndIf

Else

TEout $(\mathrm{J})=$ "No Probe"

RawVWC(J) $=-100$

$\operatorname{RawEC}(1)=-100$

RawT(0) $==100$

Temp() $=-100$

$\mathrm{VWCm}(\mathrm{J})=-100$

$E C b(j)=-100$

$e b(1)=-100$

$\operatorname{ep}(\mathrm{J})=-100$

$\mathrm{ECp}(\mathrm{J})=-100$

Endlf

Next ]

For $1=1$ To 3 'skip expansion and spare channels

PulsePort $(4,5000)$

'CLOCK MUX

Delay $(0,15, \mathrm{MSEC})$

'DELAY

Next 1

'Measure Oxygen sensors on mux 11 - 13

For $1=1$ To 12

PulsePort $(4,5000)$ 'Switch to next Multıplexer channel

Delay $(0,100, \mathrm{mSec})$

'Instruction to measure voltage output of 02 sensor and convert it to $\% 02$

'The multıplier $(0400)$ and offset $(250)$ are examples, the actual values are sensor-specific and determıned via calıbratıon VoltDiff (02_V(1),1,AutoRange,1,True ,0,_60Hz,1,0) 
BrHalf $\left(02 T_{-}\right.$V(i),1,mV2500,3,Vx1,1,2500,False,0,_60 Hz,1,0,0)

02TH_Res(i) $=24.9 / 02 \mathrm{TH} \_\mathrm{V}(\mathrm{i})-24.9$ '02 thermistor resistance

Therm $109(02 \mathrm{Temp}(\mathrm{i}), 1,3, \mathrm{Vx1}, 0,60 \mathrm{~Hz}, 1.0,0)$ 'Instruction to measure internal temperature of 02 sensor

Next i

02TH Res(7) $=(02 \mathrm{TH} \operatorname{Res}(7)-24.9) * 1000$

Call SH10k(O2TH_Res(7),02Temp(7)' this is if 02 therm7 has the extra $24 \mathrm{k} 9$

For $\mathrm{i}=1$ To 12

$02(\mathrm{i})=\left(02 \_\mathrm{V}(\mathrm{i})-2.5\right) * 02 \_\mathrm{m}(\mathrm{i})$

temperature corrections

$\mathrm{oCO}(\mathrm{i})=-\left(\mathrm{oC} 3 * \mathrm{Tc}(\mathrm{i})^{\wedge} 3+\mathrm{oC} 2 * \mathrm{Tc}(\mathrm{i})^{\wedge} 2+\mathrm{oC} 1 * \mathrm{Tc}(\mathrm{i})\right)$

02 T $(\mathrm{i})=02(\mathrm{i})+\left(\mathrm{oC} 3 * 02 \mathrm{Temp}(\mathrm{i})^{\wedge} 3+\mathrm{oC} 2 * 02 \mathrm{Temp}(\mathrm{i})^{\wedge} 2+o \mathrm{C} 1 * 02 \mathrm{Temp}(\mathrm{i})+o \mathrm{CO}(\mathrm{i})\right)$

Next i

PortSet $(5,0)$ 'reset mux 8 - 13

CALCULATIONS

'collected DATA IS NOT CORRECTED FOR DAILY BAROMETRIC CHANGES (NOT COMPENSATED). Correction to be done post processing

\begin{tabular}{|c|c|c|c|}
\hline TECP_KPa(1)=( 8919.1 & -TECP_Raw(1))* & .18070 & TP0995 \\
\hline TECP_KPa(2) $=(8840.9$ & -TECP_Raw(2))* & .18400 & TP0996 \\
\hline TECP_KPa[3) $=(8976.7$ & -TECP_Raw(3))* & .16983 & ТР0997 \\
\hline TECP_KPa(4) $=(8836.1$ & -TECP_Raw(4))* & .18590 & TP0998 \\
\hline TECP_KPa(5) $=(8838.4$ & -TECP_Raw $(5)]^{*}$ & .19203 & TP0999 \\
\hline TECP_KPa(6) $=(8816.1$ & -TECP_Raw(6)]* & .18583 & TP1000 \\
\hline TECP_KPa(7) $=(8006.0$ & -TECP_Raw(7))* & 0.18092 & 'TP1475 Bundle 1 Layer 4 \\
\hline TECP_KPa(8) $=(8079.0$ & -TECP_Raw $(8))^{*}$ & 0.17897 & 'TP1471 Bundle 2 Layer 4 \\
\hline TECP_KPa(9) $=(8226.0$ & -TECP_Raw(9)]* & 0.18266 & 'TP1474 Bundle 1 Layer 5 \\
\hline TECP_KPa $(10)=(8044.0$ & -TECP_Raw $(10))^{*}$ & 0.17307 & 'TP1470 Bundle 2 Layer 5 \\
\hline TECP_KPa(11) $=(8144.0$ & -TECP_Raw(11))* & 0.17680 & 'TP1472 Bundle 1 Layer 6 \\
\hline TECP_KPa(12)=[8088.0 & -TECP_Raw(12))* & 0.17762 & 473 Bundle 2 Lay \\
\hline
\end{tabular}

\begin{tabular}{|c|c|c|c|c|}
\hline P_KPa(1) $=($ & 8971.7 & -Piezo_Raw(1))* & .11890 & VW11919 \\
\hline$P_{-} \mathrm{KPa}(2)=($ & 8889.1 & -Piezo_Raw(2))* & .11496 & VW11920 \\
\hline$P_{-} \mathrm{KPa}(3)=($ & 9009.7 & -Piezo_Raw(3) $)^{*}$ & .11547 & VW11921 \\
\hline$P_{-} \mathrm{KPa}(4)=($ & 8771.3 & -Piezo_Raw(4))* & .12147 & VW11922 \\
\hline & \multicolumn{2}{|c|}{$\mathrm{P}_{-} \mathrm{KPa}(5)=($} & \multicolumn{2}{|c|}{-Piezo_Raw(5) $)^{*}$ 'not installed } \\
\hline & \multicolumn{2}{|c|}{$P_{-} \mathrm{KPa}(6)=($} & -Piezo_F & \\
\hline
\end{tabular}




\begin{tabular}{|c|c|c|c|c|c|c|c|c|c|c|c|}
\hline ' & \multicolumn{2}{|c|}{ 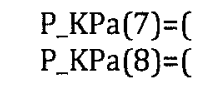 } & & \multicolumn{8}{|l|}{-Piezo_Raw(7))* } \\
\hline Settle_kPaC & 1 & )$=($ & 9832 & -Sett_Raw(1) $)^{*}$ & 0.045846 & $-.03067^{*} C$ & 24.8-Set & $\left.t_{-} \mathrm{TH}(1)\right)$ & , & VS0482 & 'kpa \\
\hline Settle_kPal & 2 & )$=($ & 9633.3 & -Sett_Raw(2))* & 0.046518 & $-.05501 *($ & 24.8-Set & t_TH(2)) & ' & VS0483 & \\
\hline Settle_kPaC & 3 & & 9782.9 & -Sett_Raw(3))* & 0.042113 & $+.04287^{*} \mathrm{C}$ & 25.6-Set & t_TH(3)) & ' & VS0487 & \\
\hline Settle_kPa( & 4 & $j=$ & 9767.2 & -Sett_Raw(4) ${ }^{*}$ & 0.043411 & $+.05245^{*} \mathrm{C}$ & 25.6-Set & t.TH(4)) & ' & VS0485 & \\
\hline Settle_kPaC & 5 & & 9528.5 & -Sett_Raw(5))* & $0.04298+.0348 *(2$ & 25.6-Sett_TH(5)) & 1 & VS0484 & & & \\
\hline Settle_kPa( & 6 & & 9670.4 & -Sett_Raw $(6))^{*}$ & 0.043602 & $+.04835^{*}($ & 25.6-Set & $\left.t_{-} \mathrm{TH}(6)\right)$ & ' & VS0486 & \\
\hline Settle_kPal & 7 & )$=($ & 9857 & -Sett_Raw(7) $)^{*}$ & 0.043228 & $-0.02532 * C$ & 25.6-Set & t_TH(7)) & & 'VS0512 & Bundle 1 Layer 4 \\
\hline Settle_kPaC & 8 & $j=$ & 9651.8 & -Sett_Raw(8))* & 0.041632 & $-0.03601 * c$ & 25.6-Set & t_TH(8)) & & 'VS0515 & Bundle 2 Layer 4 \\
\hline Settle_kPa( & 9 & & 9708.8 & -Sett_Raw(9))* & 0.047208 & +0.04037 & $*($ & 25.6-Set & $\left.t_{-} \mathrm{TH}(9)\right)$ & & 'VS0514 Bundle 1 Layer 5 \\
\hline Settle_kPa( & 10 & & 9440.5 & -Sett_Raw $(10))^{*}$ & 0.045704 & +0.02523 & $* i$ & 25.6-Set & t_TH(10)) & & 'VS0513 Bundle 2 Layer 5 \\
\hline Settle_kPaC & 11 & & 8919 & -Sett_Raw(11))* & 0.044099 & +0.00651 & $* c$ & 25.6-Set & t_TH(11) & & 'VS0516 Bundle 1 Layer 6 \\
\hline Settle_kPa & 12 & & 9743.5 & -Sett_Raw(12)\}* & $0.04793-0.03919 *$ & *( $\quad 25.6-$ Set & $\mathrm{tt} \mathrm{TH}(12)$ & & 'VS0517 & Bundle 2 & 2 Layer 6 \\
\hline - Ref_kPal & 1 & )$=$ & 9811.5 & $\left.-\operatorname{Ref} \_\operatorname{Raw}(1)\right)^{*}$ & $0.04738-.0165 *(2$ & 23.3-Ref_TH(1)) & & VW1188 & 36 res & $\mathrm{kPa}$ & \\
\hline - Ref_kPa( & 2 & & 9612.4 & $\left.-\operatorname{Ref} \_\operatorname{Raw}(2)\right]^{*}$ & $0.04222+0.03442$ & 25.6-Ref & f_TH(2)) & ' & VW1188 & 37 res & \\
\hline Ref_kPaC & 2 & $j=$ & 9811.5 & -Ref_Raw(2))* & $0.04738-0.01650^{*}$ & 23.3-Ref & f_TH(2)) & ' & VW1188 & 36 res & $\mathrm{kPa}$ \\
\hline Ref_kPal & 1 & & 9612.4 & -Ref_Raw $(1))^{*}$ & $0.04222+0.03442$ & 25.6-Ref & f_TH(1)) & ' & VW1188 & 37 res & \\
\hline 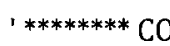 & & & E & & & AREDC & & 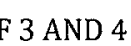 & & & \\
\hline Ref_kPal & 3 & )$=($ & 9911.1 & -Ref_Raw(3))* & $0.043953-0.02712$ & 23.9-Ref & f_TH(3)) & 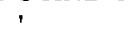 & VW1673 & 32 res & $\mathrm{kPa}$ \\
\hline Ref_kPaC & 4 & & 9486.1 & $-\operatorname{Ref} \_$Raw $\left.(4)\right)^{*}$ & $0.047708-0.05685$ & 23.9-Ref & f_TH(4)) & & VW1673 & 33 res & \\
\hline
\end{tabular}

For $\mathrm{i}=1$ To 3

Settle_mm(i) $=k^{*}($ Ref_kPa(1)-Settle_kPa(i))' calc using reservoir 1

Next i

For $\mathrm{i}=4$ To 6

Settle_mm(i)=k*(Ref_kPa(2)-Settle_kPa(i))' calc using reservoir 2

Next i

For $\mathrm{i}=7$ To 9

Settle_mm(i)=k*(Ref_kPa(3)-Settle_kPa(i))' calc using reservoir $3 \mathrm{VW16732}$ res $\mathrm{kPa}$ Next i 
For $\mathrm{i}=10$ To 12

Settle_mm(i) $=\mathrm{k}^{*}($ Ref_kPa(4)-Settle_kPa(i))' calc using reservoir $4 \mathrm{VW} 16733$

Next i

'SAVE DATA

CallTable Q12003

NextScan

EndProg 


\section{Appendix C - Supplemental Figures from Installation}

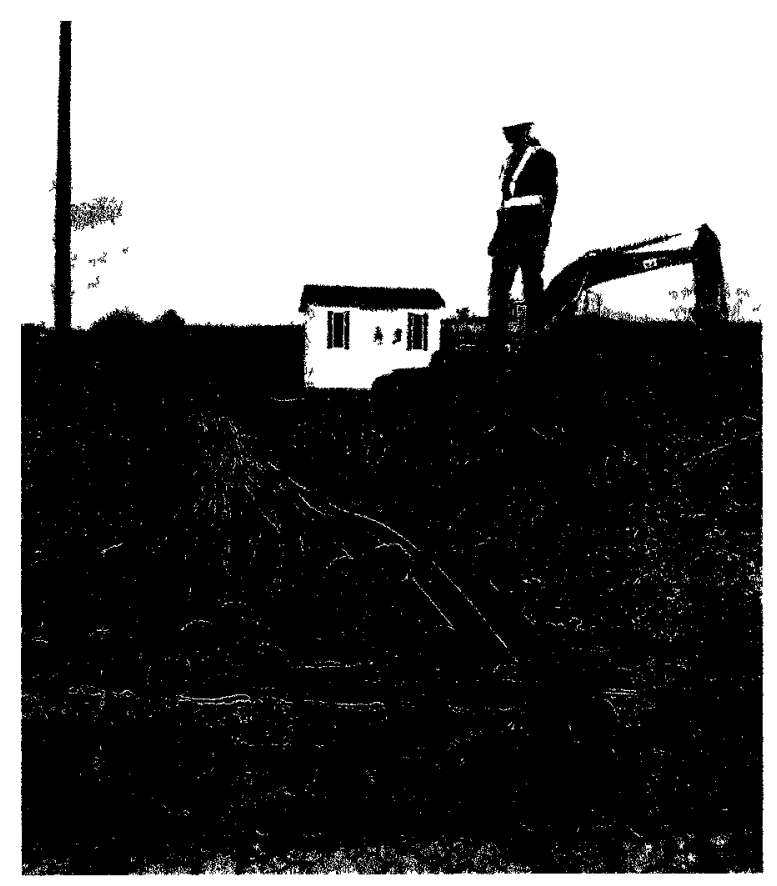

Figure C-1: (Layer 1) PVC pipes under road to bring cables and tubing from instrument bundles to the datalogger in instrument shed.

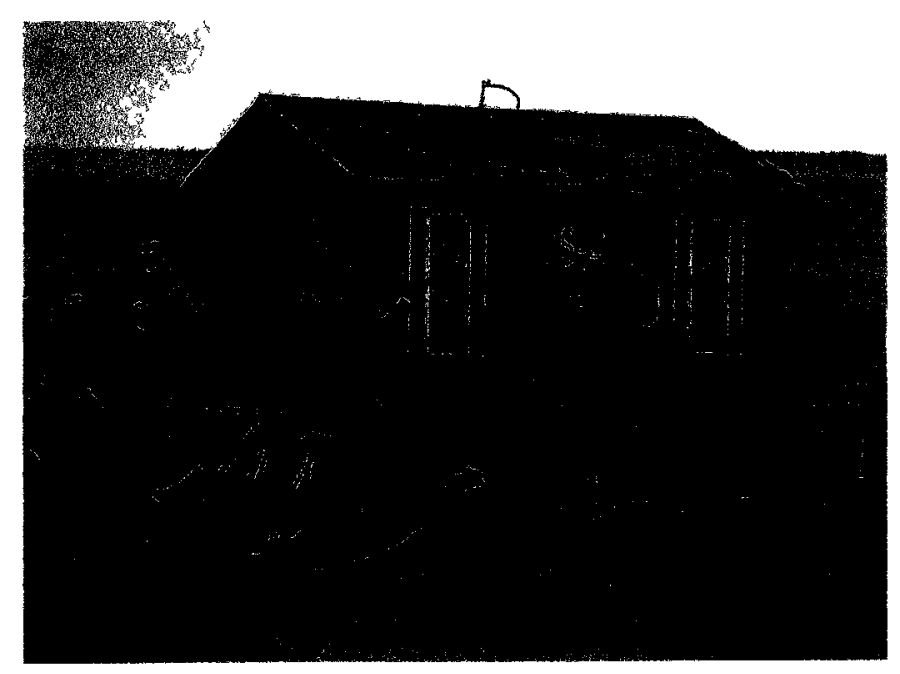

Figure C-2: Instrument Shed 


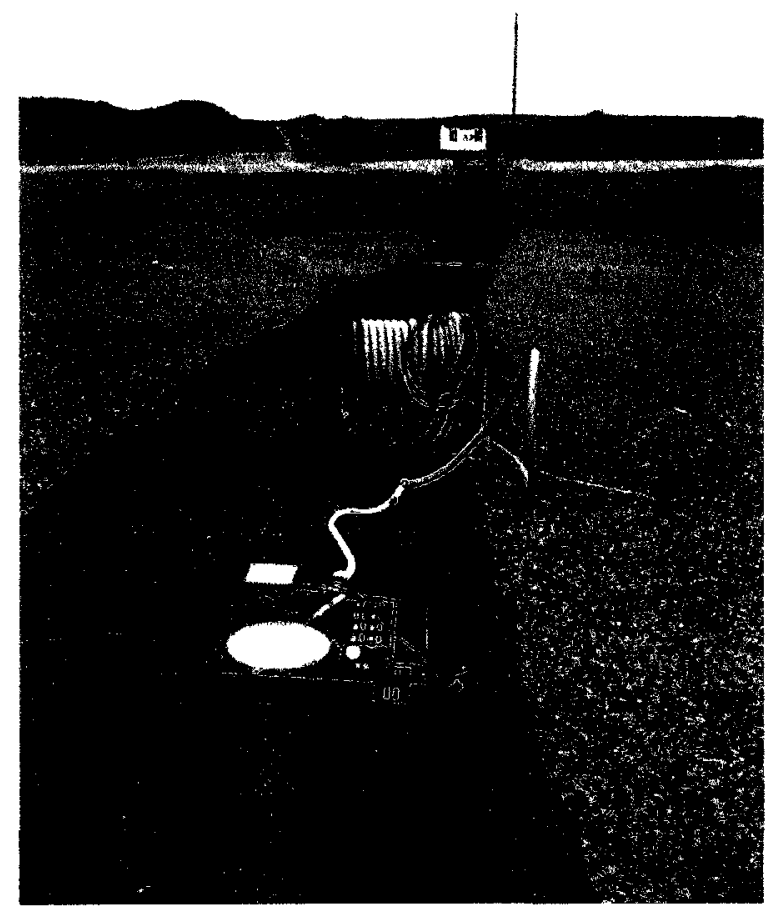

Figure C-3: (Layer 1) Instrument Bundle 1 placed on geotextile in landfill.

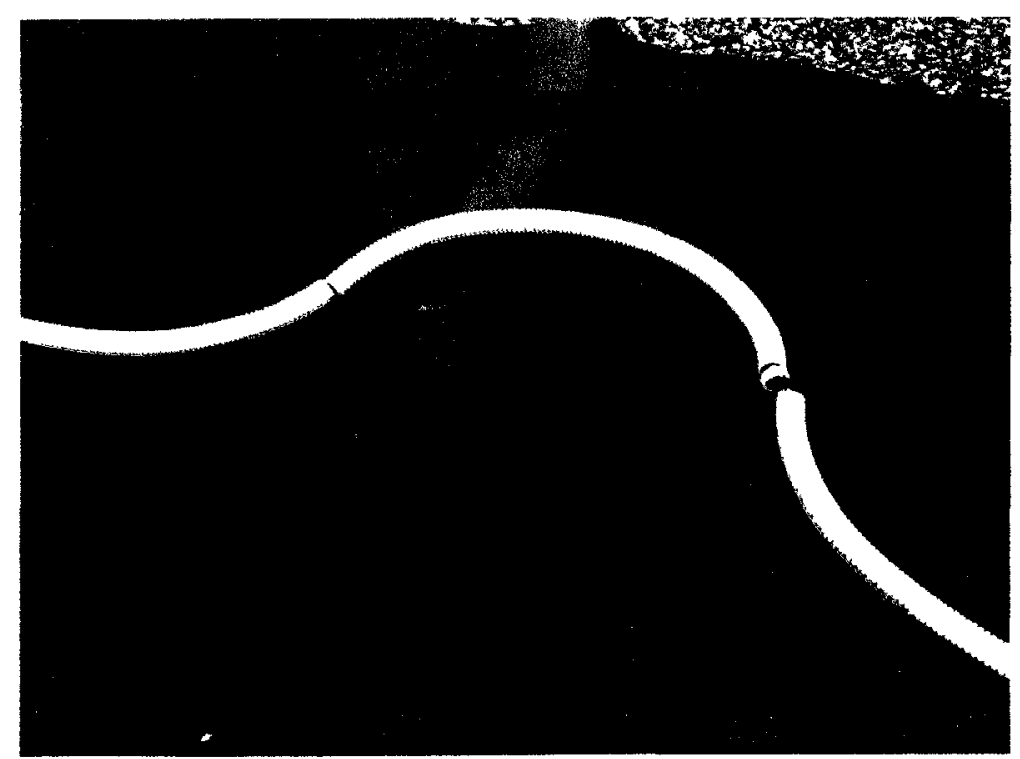

Figure C-4: (Layer 1) Cracking of orange protective casing around cable and tubing. 


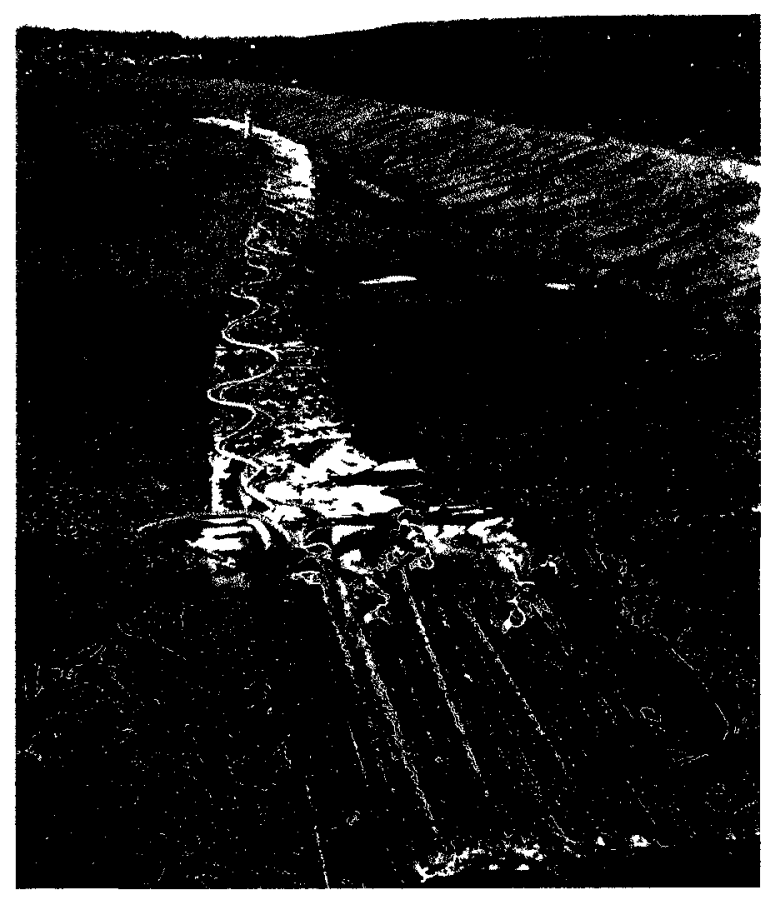

Figure C-5: (Layer 1) Cable snaked to allow for differential settlement.

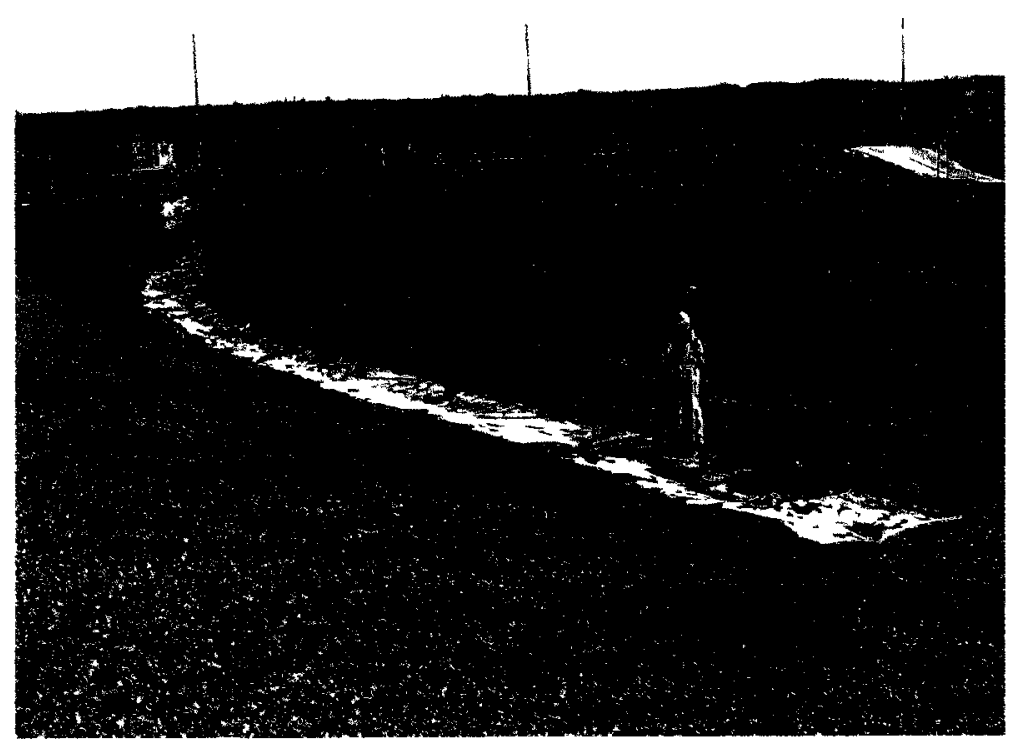

Figure C-6: (Layer 1) Collecting the GPS location of the instrument bundles. 


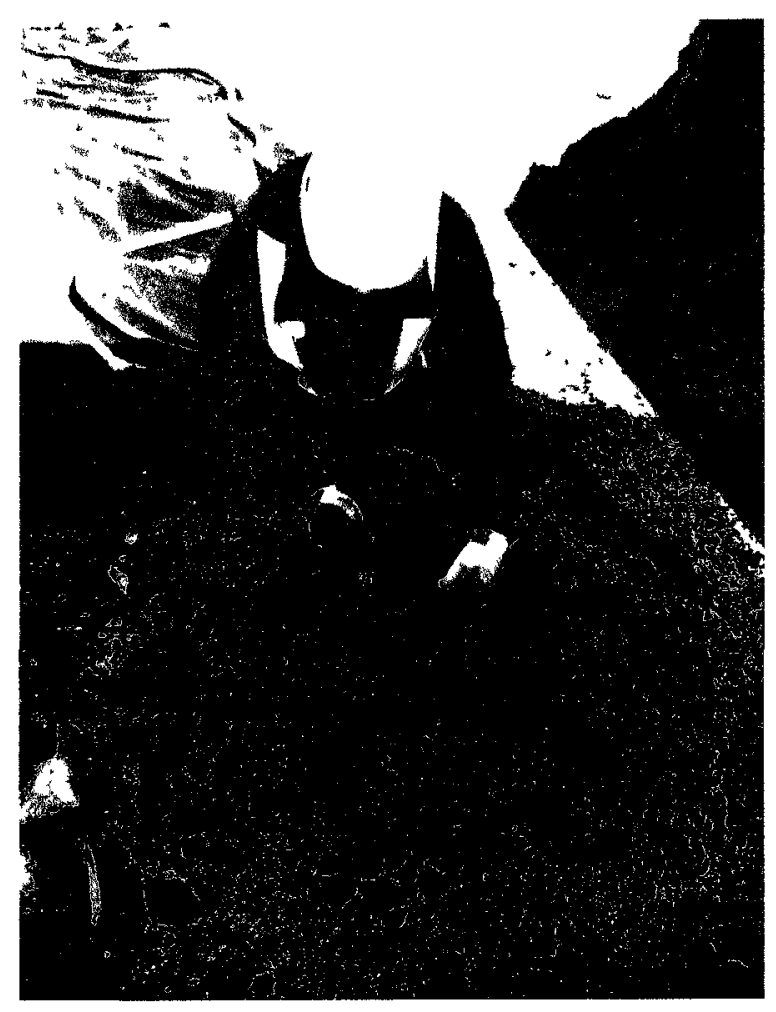

Figure C-7: (Layer 1) Inserting the oxygen sensor and moisture probe into $0.5 \mathrm{~m}$ of sand over the instrument bundle steel plate.

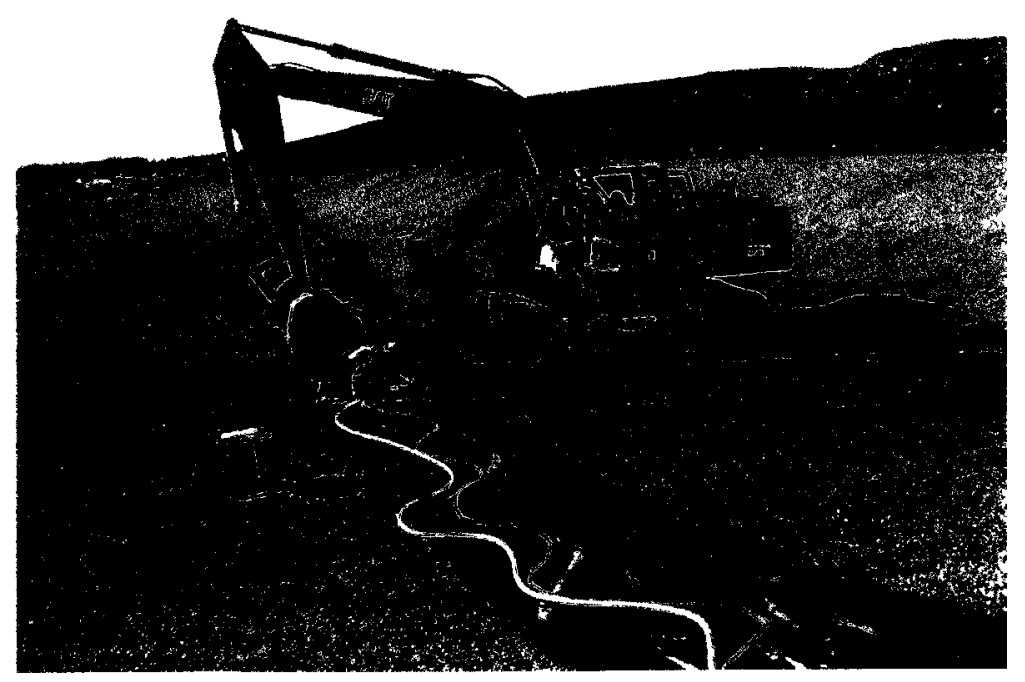

Figure C-8: (Layer 1) Covering the cables and tubing with sand for protection. 


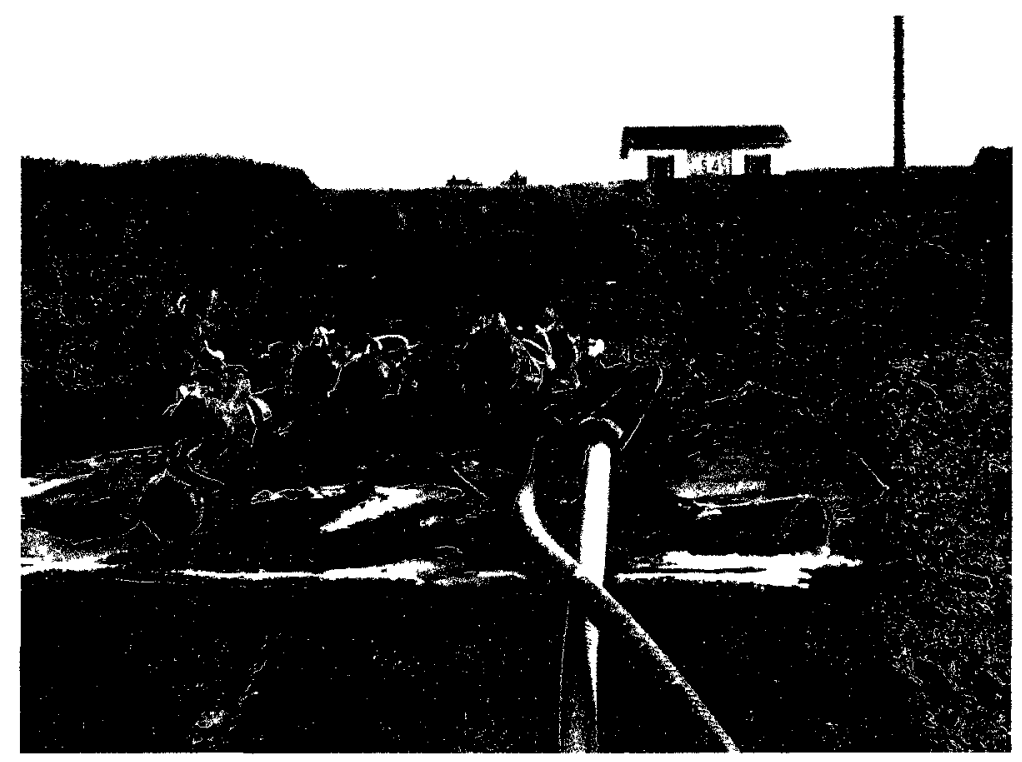

Figure C-9: (Layer 1) and tubing from instrument bundles entering PCV pipes to go under road and enter the instrument shed.

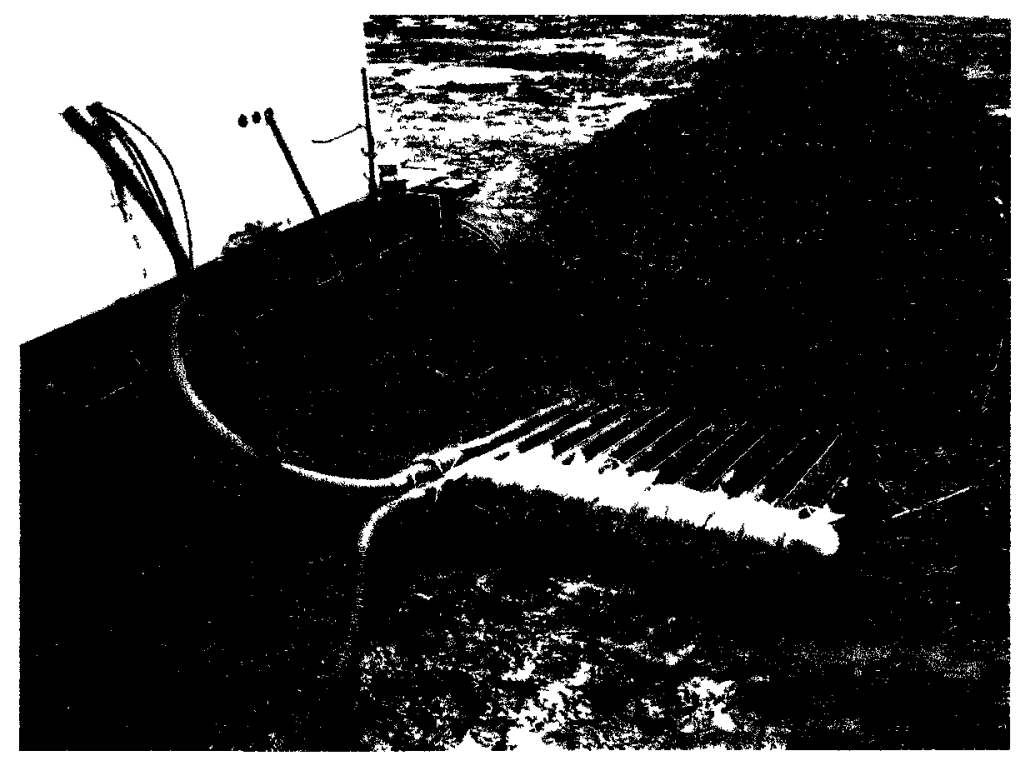

Figure C-10: (Layer 1) Cables and tubing exiting the PVC pipes from under road, and entering the instrument shed. 


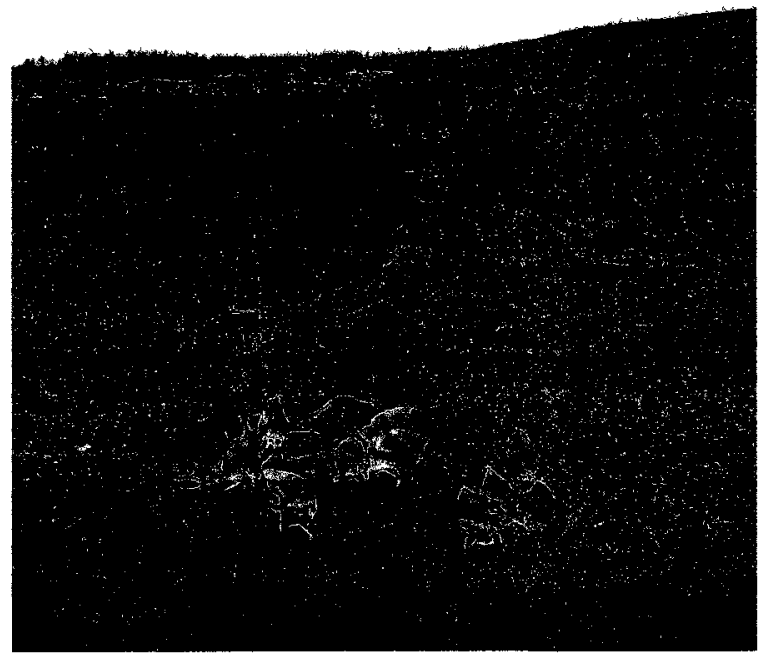

Figure C-11: (Layer 1) Final view of completed installation from road. Cable and tubing covered in sand and wrapped in geotextile for protection.

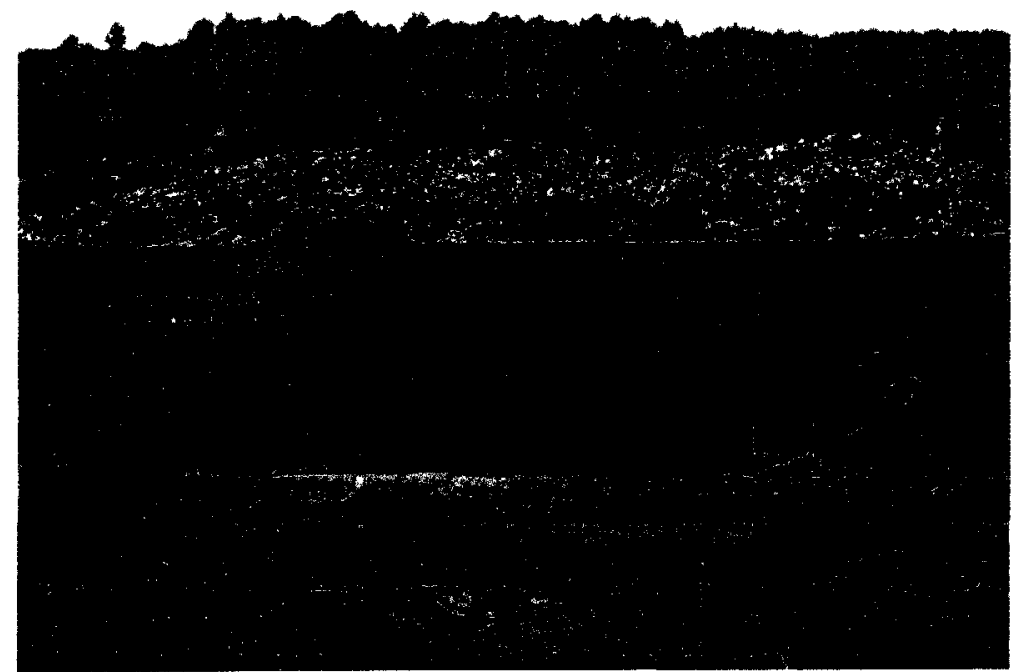

Figure C-12: (Layer 1) View of completed installation of Layer 1 instrument bundles with instrument shed. Waste front is progressing towards instrument bundles. 


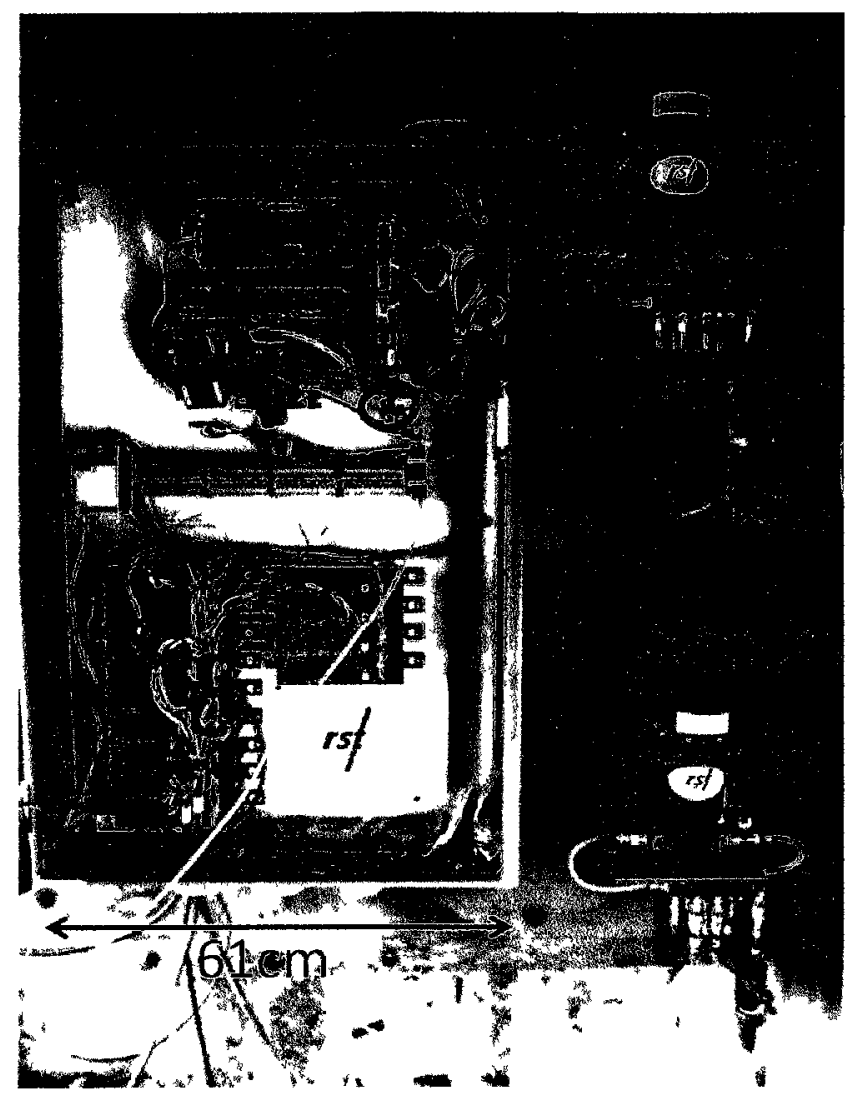

Figure C-13: (Layer 1) Datalogger system and accumulators in the instrument shed.

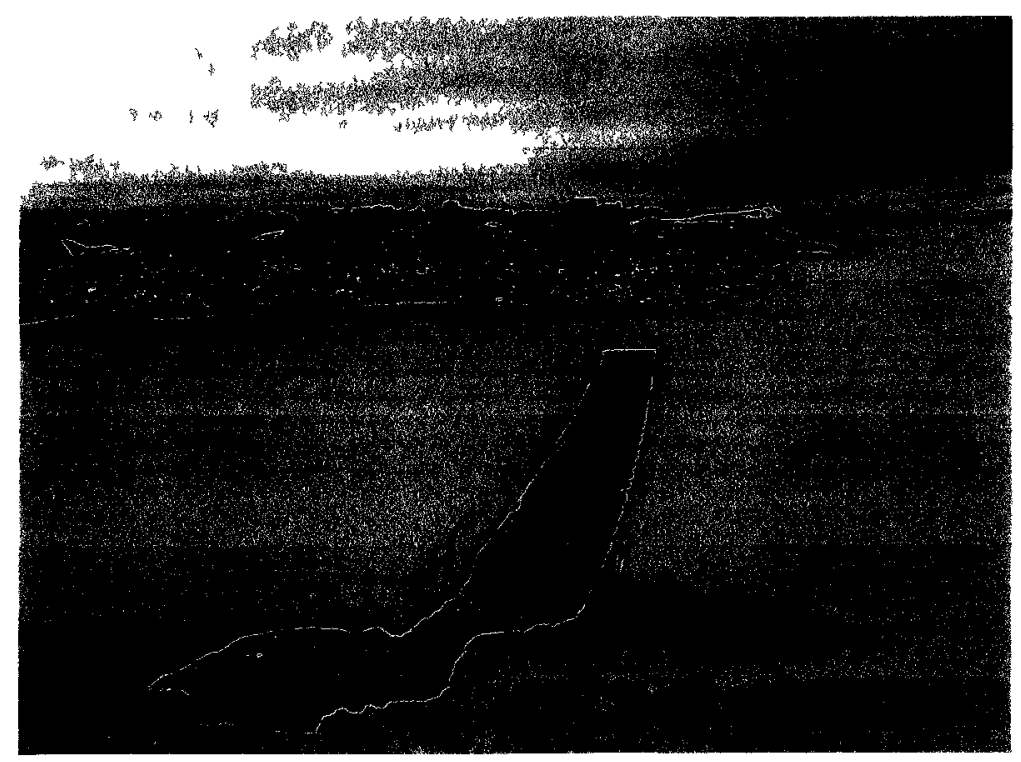

Figure C-14: (Layer 2) Extending the geotextile to the instrument bundle locations. 


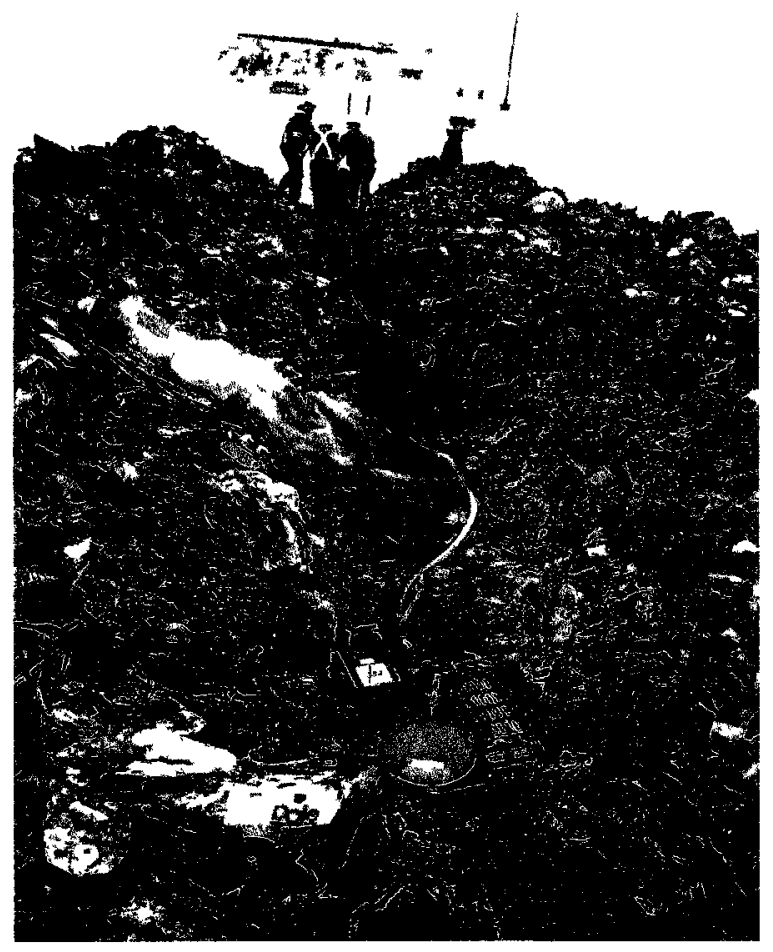

Figure C-15: (Layer 2) Instrument bundle is placed on the waste lift. Cable and tubing is being rolled towards instrument shed.

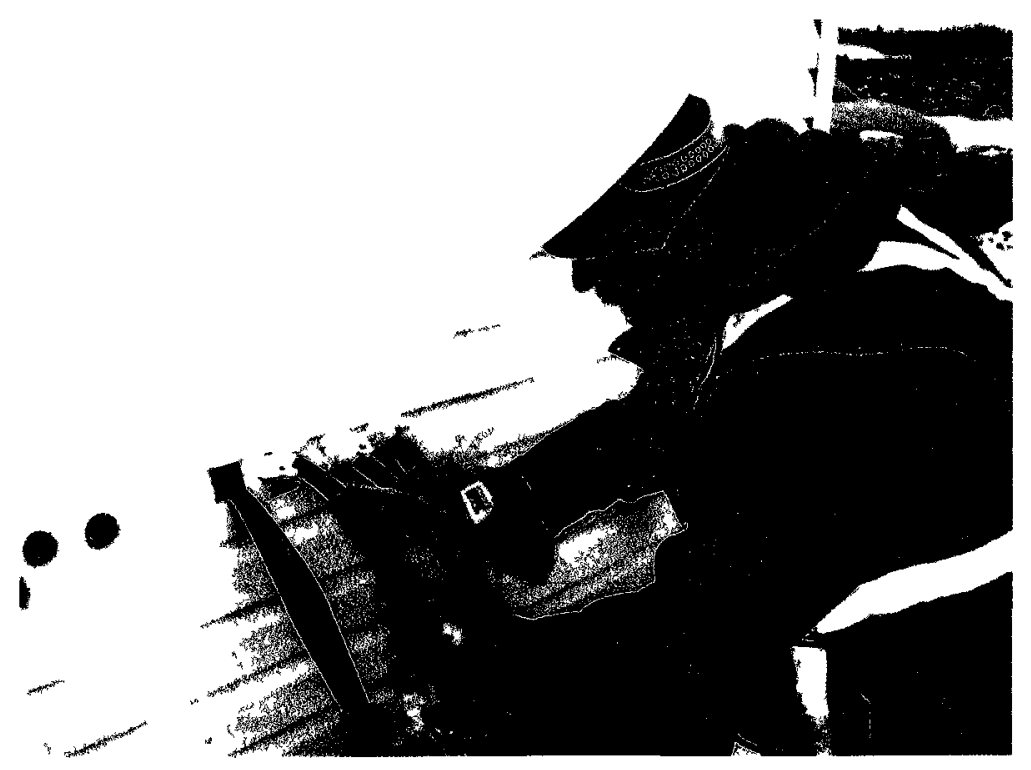

Figure C-16: (Layer 2) Gaps are being caulked to limit flow of landfill gas into instrument shed. 


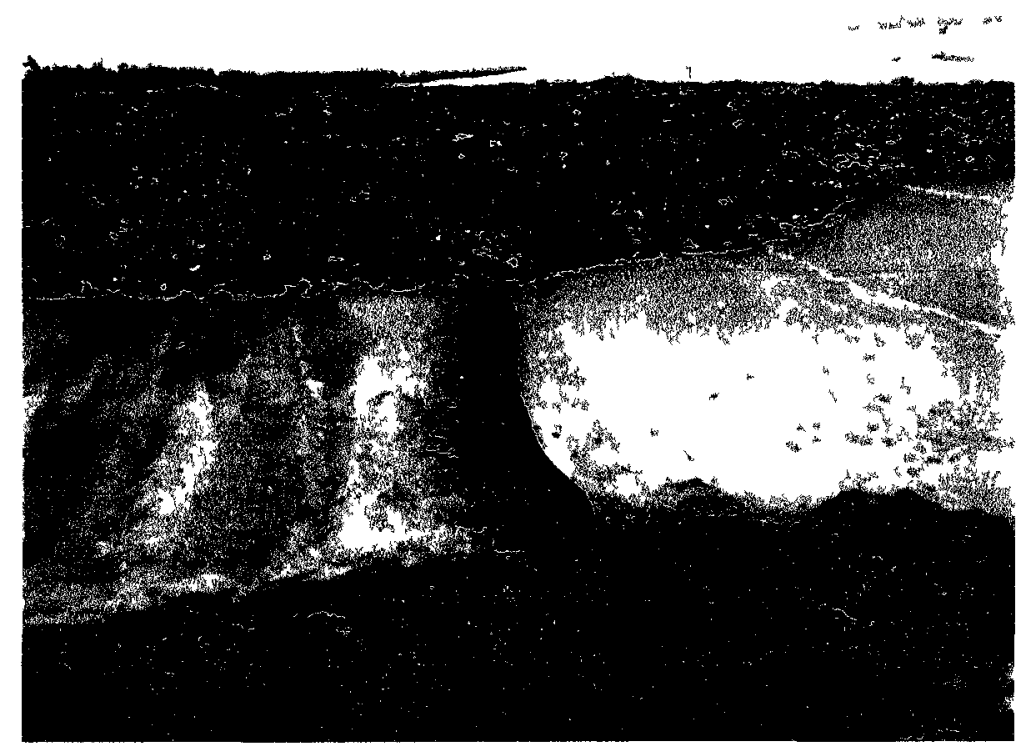

Figure C-17: (Layer 2) Final view of Layer 2 installation from road. Waste has been immediately placed over instrument bundles.

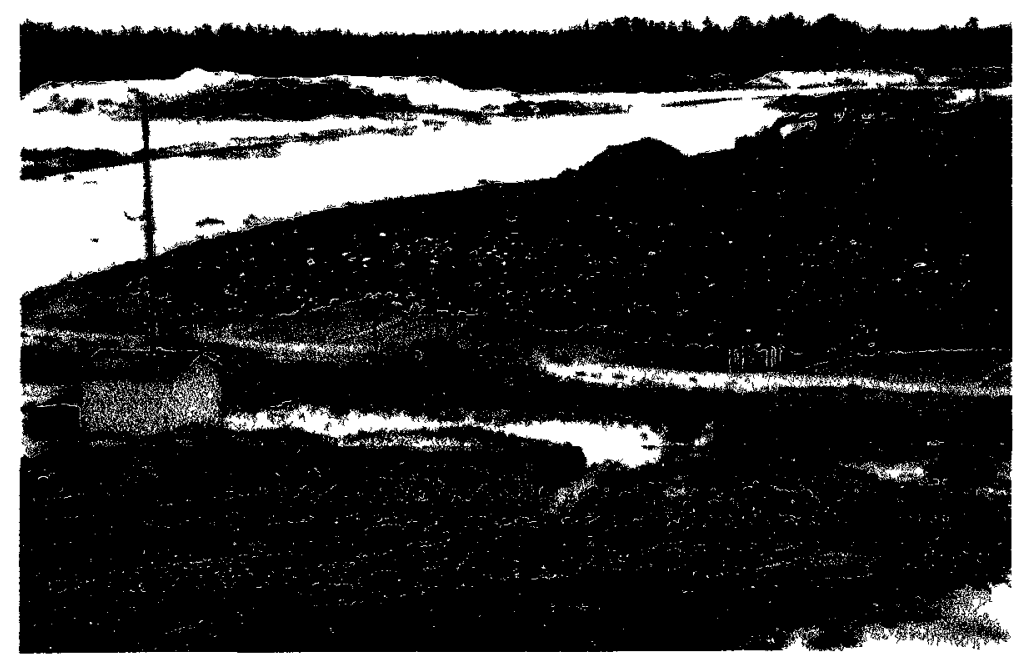

Figure C-18: (Layer 2) View of waste front which has covered instrument bundles in both Layers 1 and 2. 


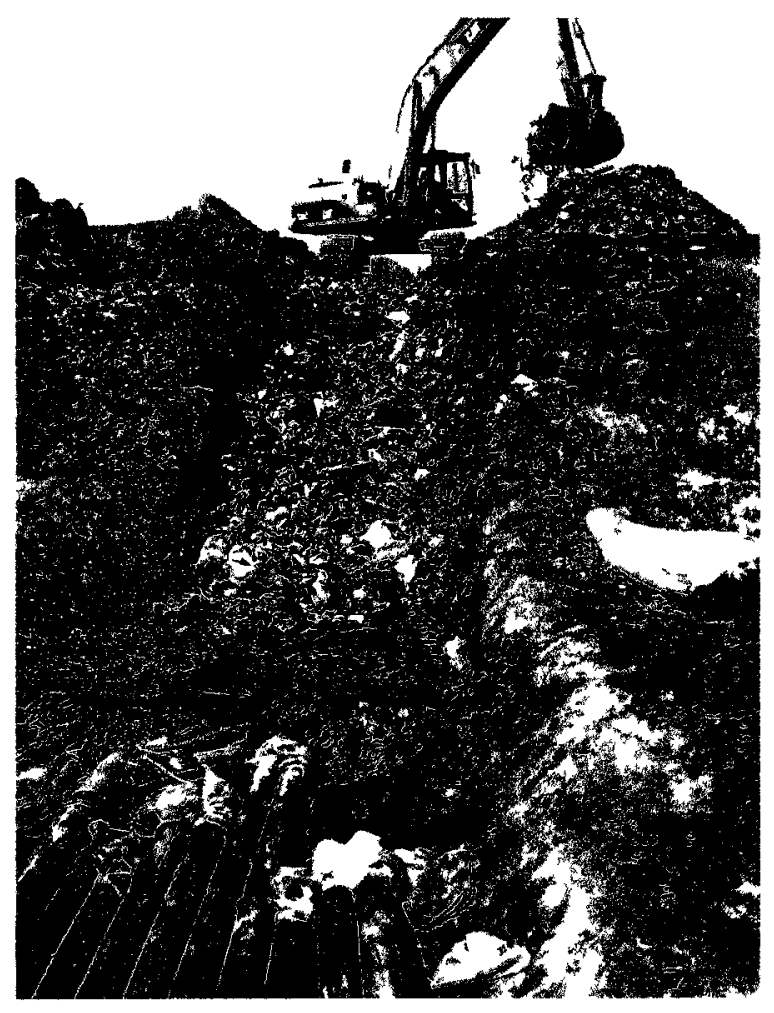

Figure C-19: (Layer 3) Excavating a trench for the bundles.

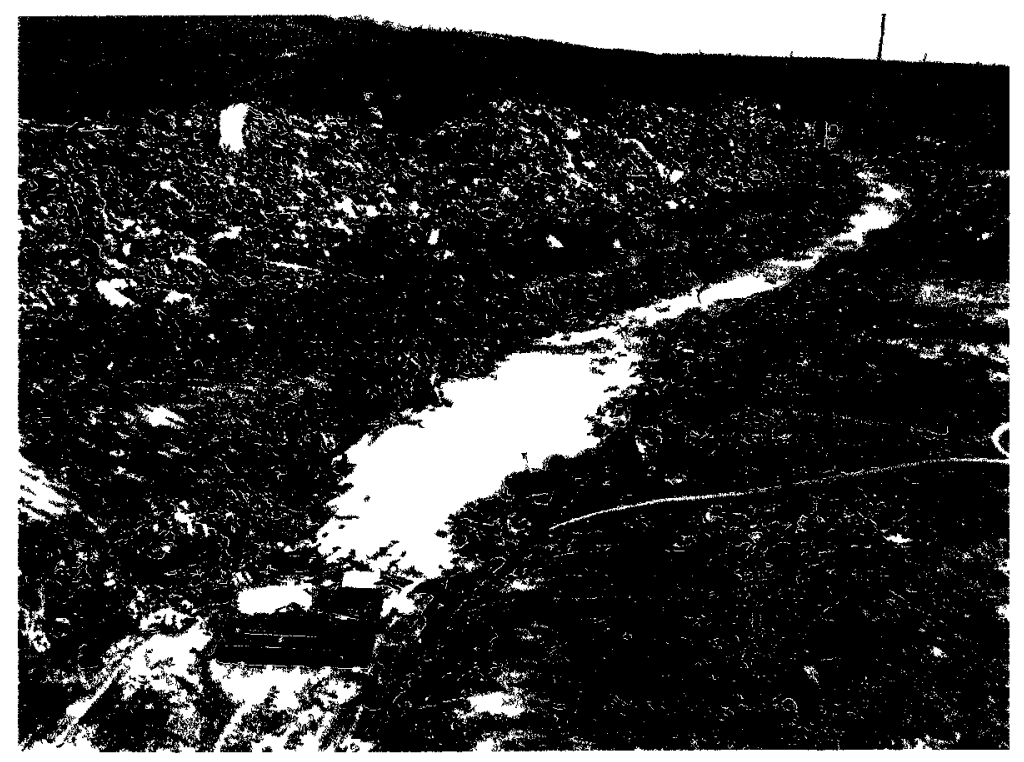

Figure C-20: (Layer 3) Placement of instrument bundle in excavated trench. 


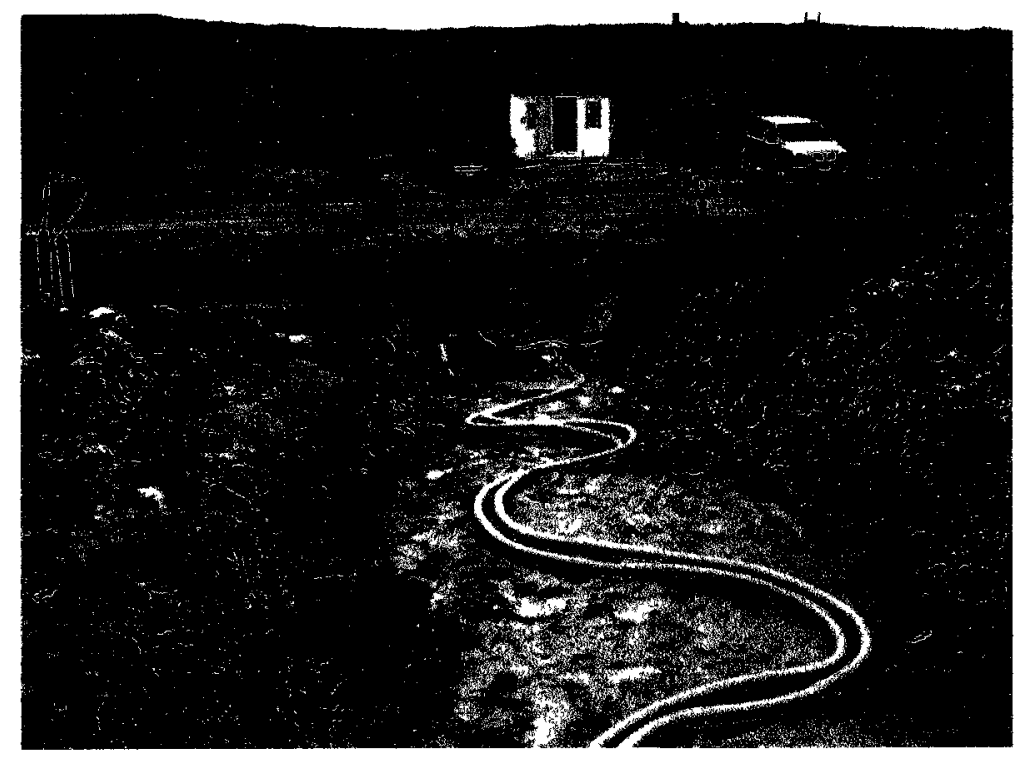

Figure C-21: (Layer 3) Snaked cables and tubing down to road crossing.

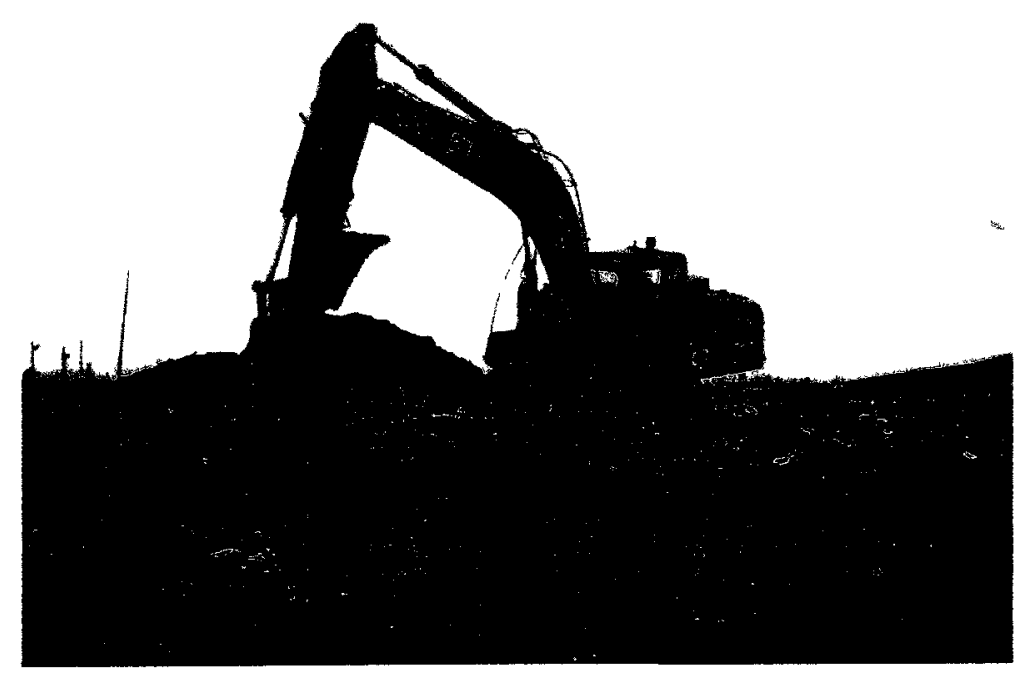

Figure C-22: (Layer 3) Final view of landfill from road after installation. 


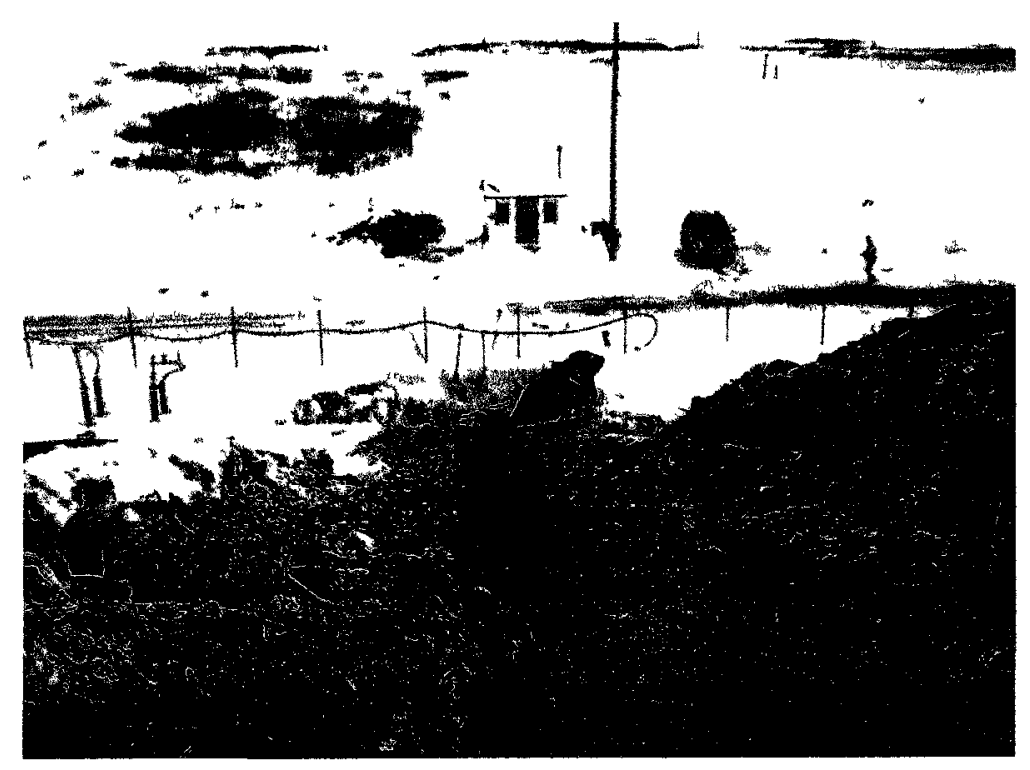

Figure C-23: (Layer 4) Excavation of trench down slope of landfill towards road crossing.

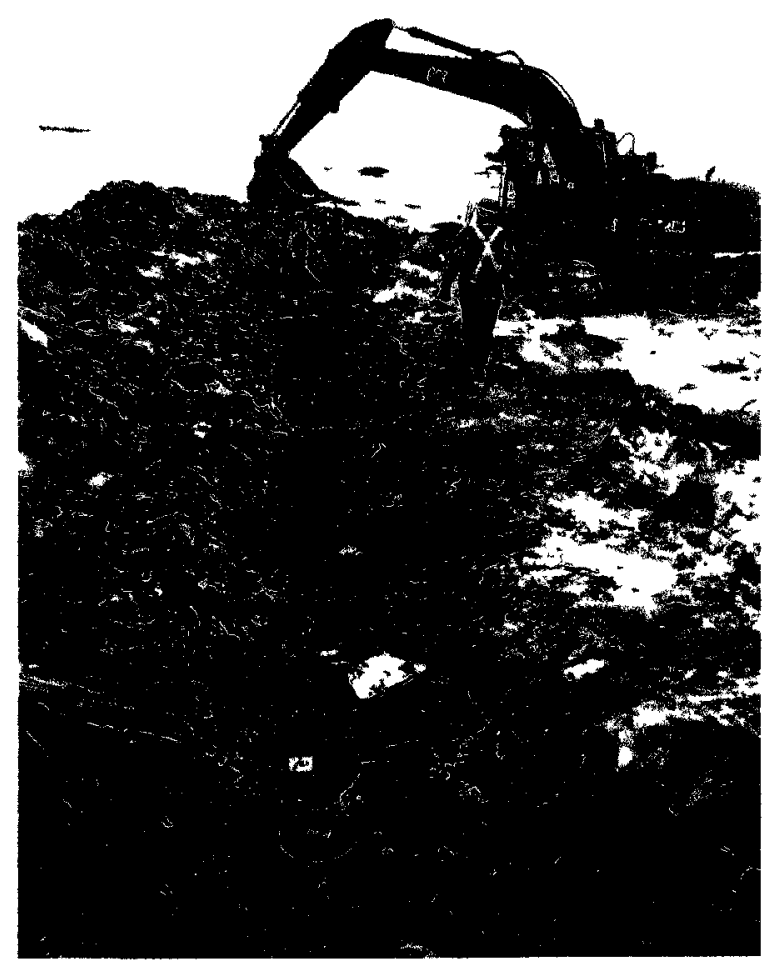

Figure C-24: (Layer 4) Placement of the instrument bundles in the trench. 


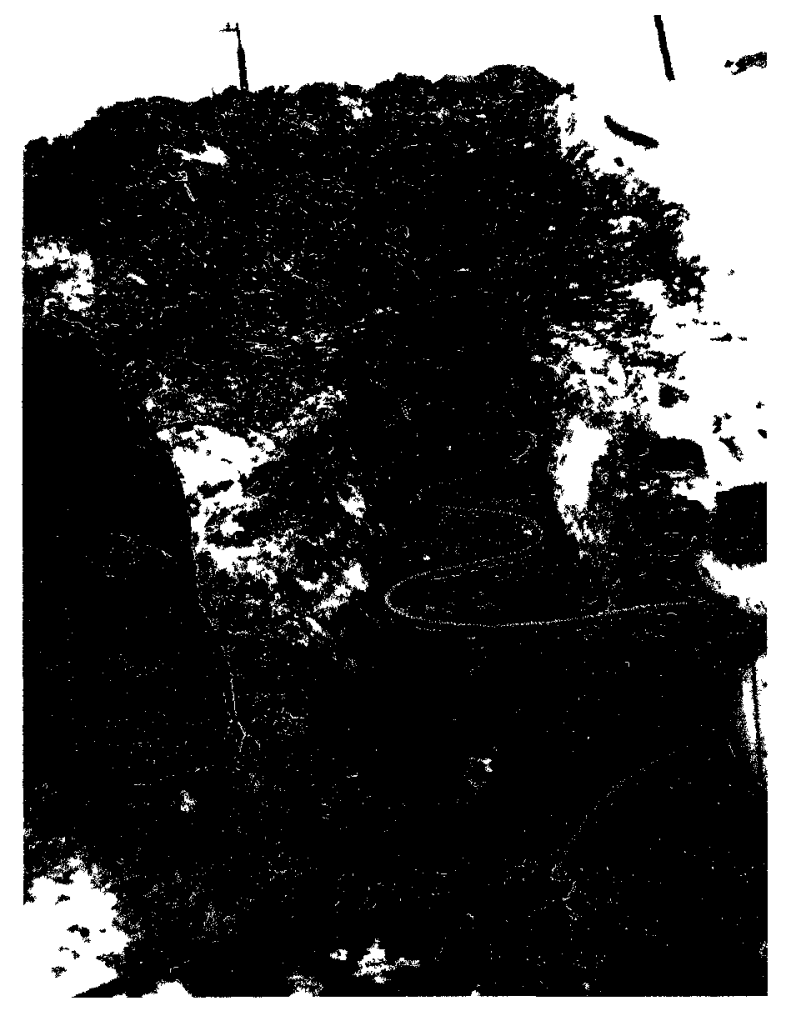

Figure C-25: (Layer 4) Snaking of cable and tubing in trench to PVC pipe under road.

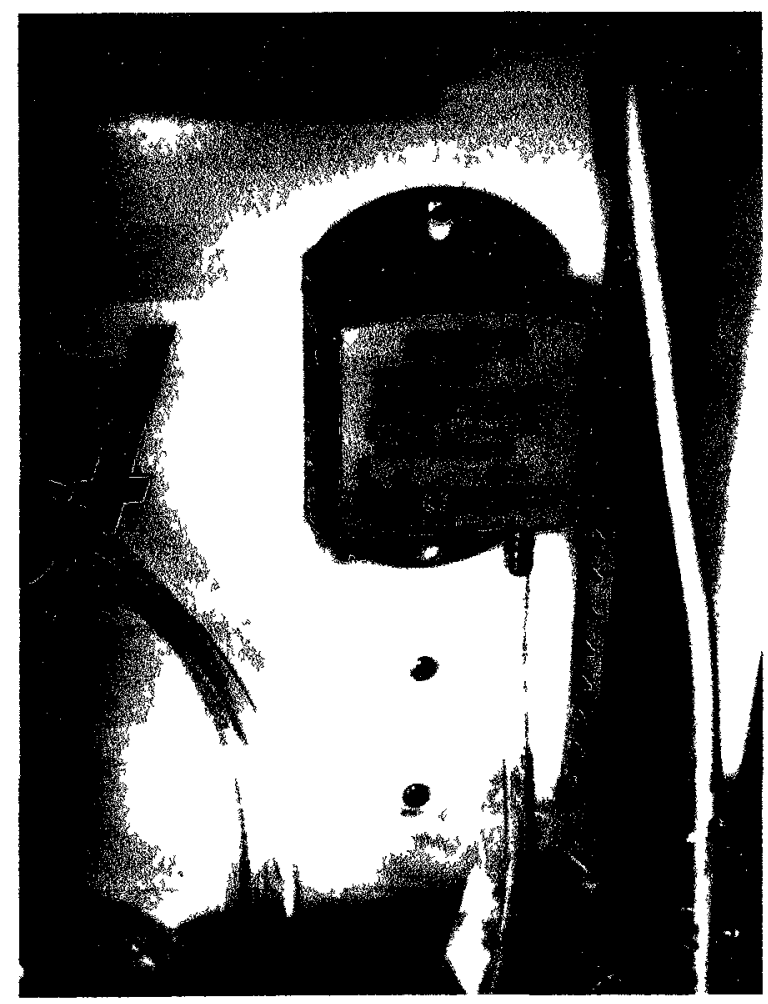

Figure C-26: Barometer $(7.6 \mathrm{~cm}$ high $\times 6.1 \mathrm{~cm}$ wide) installed in instrument shed. 


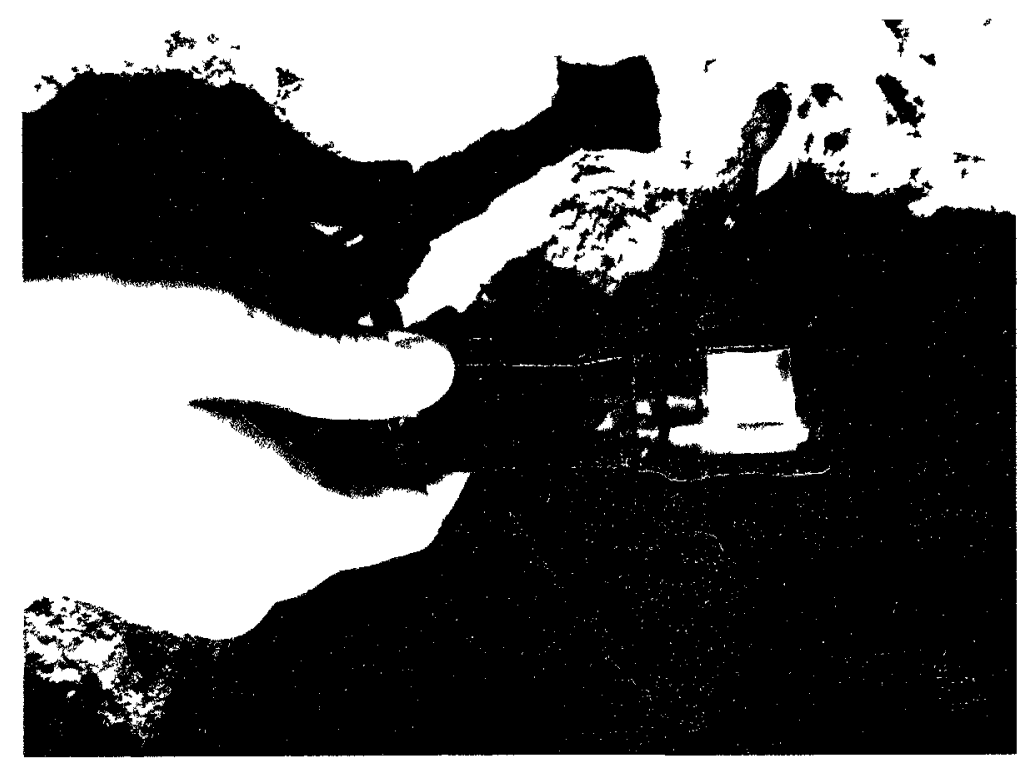

Figure C-27: Damage to oxygen sensor in Bundle 8 after excavation to fix placement.

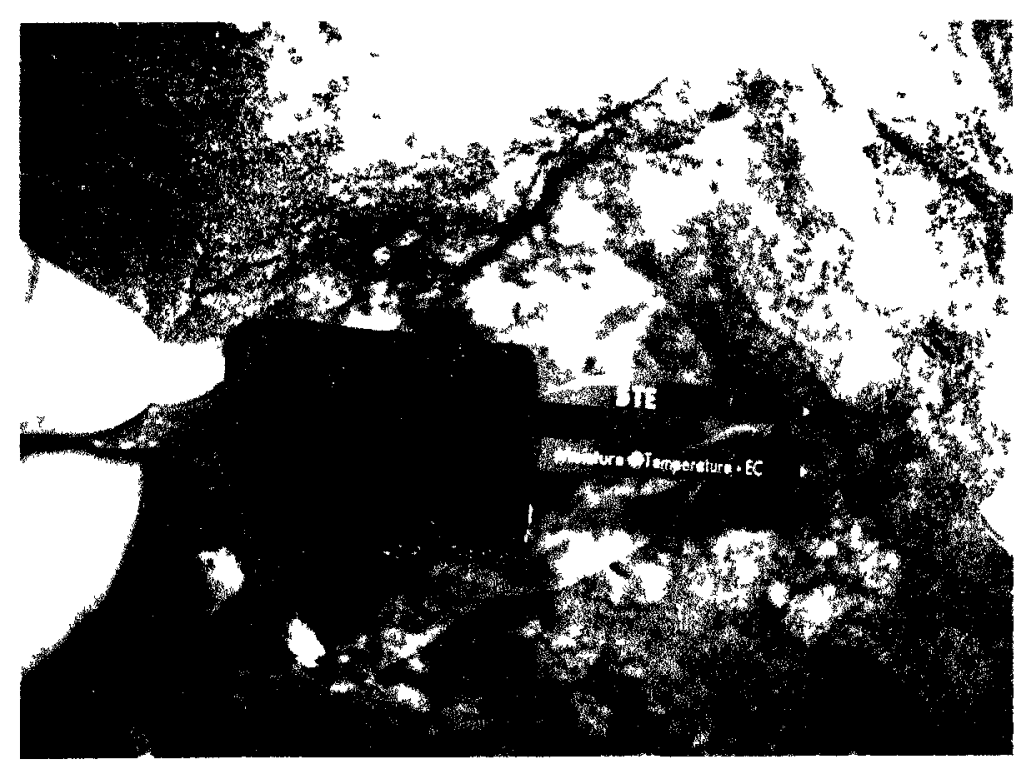

Figure C-28: Damage to moisture probe in Bundle 8 after excavation to fix placement. 


\section{Appendix D - Calibration Details and Example Calculation for Total Earth Pressure Cell}

The total earth pressure cell (TEPC) produced vibrating wire outputs in B units. The

$\mathrm{B}$ unit outputs are related to frequency through the following equation:

$B$ units $=\frac{H Z^{2}}{1000}$

Where:

$\mathrm{Hz}=$ Frequency (hertz)

$B$ units $=$ Raw $B$ scale output from sensor

The raw B unit outputs from the TEPC were converted to pressure with corrections for initial calibration readings and barometric pressure, through the following equation:

$P=C F *(L i-L c)+(B i-B c)$

(Equation D-2)

Where:

$P=$ Pressure $(\mathrm{kPa})$ from linear calibration curve

$C F=$ Linear calibration factor $(\mathrm{kPa} / \mathrm{B}$ Unit $)$

$L i, L C=$ Initial readings from calibration and current reading ( $B$ units)

$B i, B c=$ Initial readings from calibration and current barometric pressure $(\mathrm{kPa})$

Barometric pressures were obtained from obtained from Environment Canada's weather station at the Pierre Elliot Trudeau International Airport, Montreal, Quebec (45.46692N, 73.75020W). In February 2011, a barometer was installed in the instrument shed at the Sainte-Sophie bioreactor landfill. From then on, the 
barometric pressure corrections for the TEPC used the barometer readings from onsite.

The corrected values were calculated; however, the values needed to be zeroed from the time of installation, otherwise the sensors indicate large values even when no load is applied. The zeroing was calculated post-process with the initial installation pressure reading and the current pressure reading through the following equation:

Zeroed $P=$ Pcurrent - Pinitial

Where:

Zeroed $P=$ Pressure zeroed from installation pressure $(\mathrm{kPa})$

Pcurrent $=$ Current pressure $(\mathrm{kPa})$

Pinitial $=$ Initial pressure from installation $(\mathrm{kPa})$

The pressure measured by the TEPC was related to the height of waste which was responsible for enacting this pressure on the instrument bundle. The conversion of pressure to height of waste is displayed in the equation below.

$H W=\frac{\text { Zeroed } P * A}{\rho * A * a} * \frac{1000 P a}{1 k P a}$

(Equation D-4)

Where:

$H w=$ height of waste $(m)$

Zeroed $P=$ Pressure zeroed from installation pressure $(\mathrm{kPa})$

$A=$ area affected by pressure over instrument bundle, assumed as $1 \mathrm{~m}^{2}$

$\rho=$ density of waste, assumed as $1000 \mathrm{~kg} / \mathrm{m}^{3}$

$a=$ acceleration of gravity, $9.81 \mathrm{~m} / \mathrm{s}^{2}$ 


\section{Sample Calculation:}

To calculate the pressure exerted on the instrument bundle, the outputs from the TEPC were required. In addition, barometric pressure was required and obtained from either Environment Canada's weather station, from November 9, 2009 to February 16, 2011, or from the barometer installed in the instrument shed on-site, after February 16, 2011. The following values were recorded for the TEPC at Bundle 2, on April 12011 at the time of 06:00. These values will be used in the following sample calculation.

\begin{tabular}{|c|c|c|}
\hline Timestamp & $\begin{array}{c}\text { Bundle 2 TEPC Output } \\
\text { (B Units) }\end{array}$ & On-site Barometer (kPa) \\
\hline $01 / 04 / 2011$ 6:00:00 AM & 7561.708 & 99.3 \\
\hline
\end{tabular}

Additional information required to complete the calculation is provided below.

\begin{tabular}{|l|l|l|l|l|}
\hline & $\begin{array}{l}\text { CF } \\
(\mathrm{kPa} / \mathrm{B} \\
\text { Unit) }\end{array}$ & $\begin{array}{l}\text { Initial } \\
\text { Reading } \\
\text { (B Units) }\end{array}$ & $\begin{array}{l}\text { Initial } \\
\text { Barometric } \\
\text { Pressure }(\mathrm{kPa})\end{array}$ & $\begin{array}{l}\text { Installation Pressure } \\
\text { Reading for Zeroing } \\
(\mathrm{kPa})\end{array}$ \\
\hline Bundle 2 & $\mathbf{0 . 1 8 4}$ & $\mathbf{8 8 4 1}$ & 101.47 & 10.159 \\
\hline
\end{tabular}

Using Equation D-2, the B unit output from the total earth pressure cells went through corrections for initial calibration readings to calculate a pressure reading.

$P=C F *(L i-L C)+(B i-B c)$

$P_{\text {April 1,2011 06:00 Bundle 2 }}=C F *(L i-L C)+(B i-B C)$

$P_{\text {April 1,2011 06:00 Bundle 2 }}=0.184 *(8841-7561.708)+(101.47-99.3)$

$P_{\text {April 1,2011 06:00 Bundle 2 }}=237.56 \mathrm{kPa}$ 
Equation D-3 was then applied to zero the pressure reading.

Zeroed $P=$ Pcurrent - Pinitial

Zeroed $P=237.56-10.159$

Zeroed $P=227.4 \mathrm{kPa}$

Therefore, these calculations indicate that from the time of connection of Bundle 2 on November 12, 2009 to April 1, 2011, the TEPC has experienced $227.4 \mathrm{kPa}$ of stress enacted upon its surface. Equation D-4 was then used to relate the pressure to an approximate height of waste over the TEPC.

$H=\frac{\text { Zeroed } P * A}{\rho * A * a} * \frac{1000 P a}{1 k P a}$

$H=\frac{237.56 * 1}{1000 * 1 * 9.81} * \frac{1000 P a}{1 k P a}$

$H=24.2 m$

Records of calibration data were provided with each sensor, and include data pertinent to the completion of these calculations. The calibration sheets are provided in subsequent pages. 


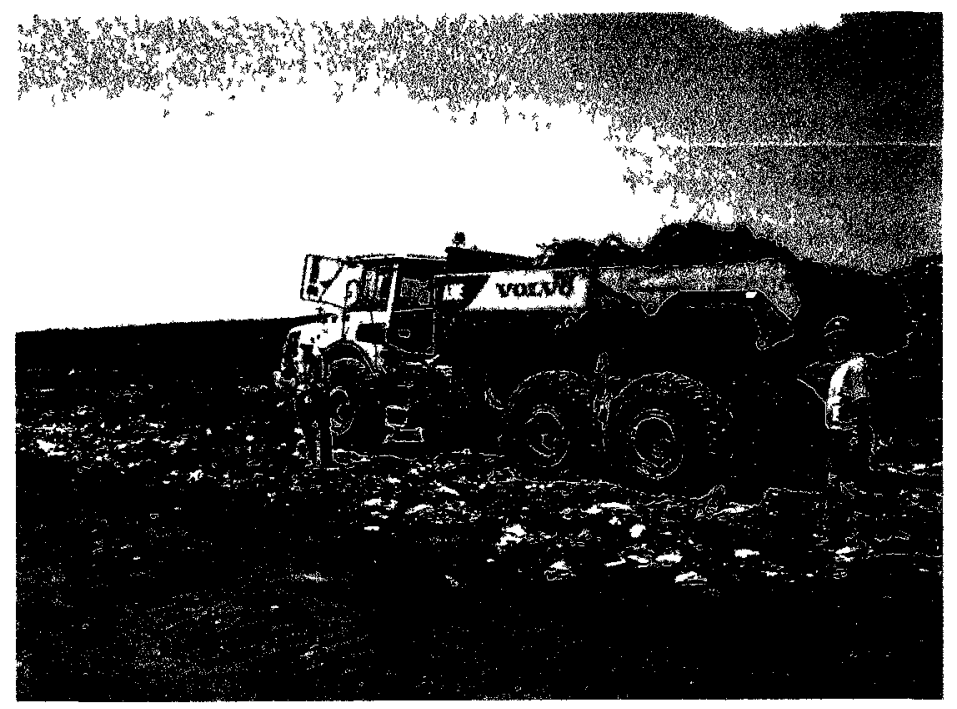

Figure D- 9: Dump truck filled with waste acting as load source for load test 1.

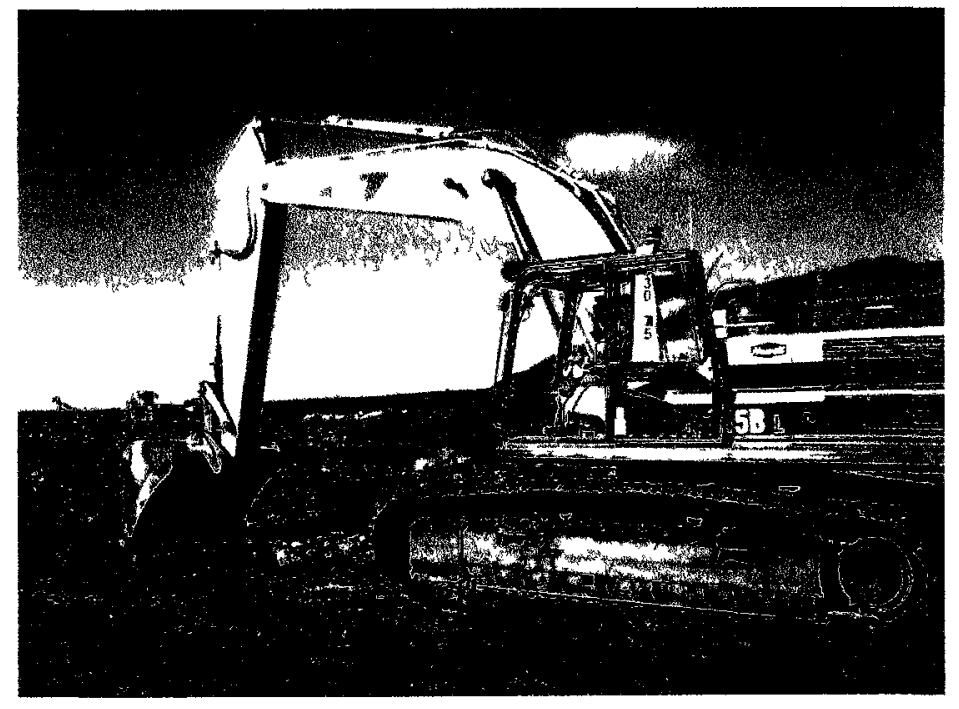

Figure D-10: Excavator acting as load source for load test 2. 


\section{Appendix E - Calibration Details and Example Calculation for Liquid Settlement System}

The liquid settlement sensors and accumulators produced vibrating wire outputs in $\mathrm{B}$ units and temperature readings in degrees Celsius. The B unit outputs are related to frequency from the vibrating wire through Equation D-1.

The B unit outputs from the settlement sensors and accumulators were converted to pressure with corrections for initial installation readings and temperature, through the following equation:

$P=C F *(L i-L c)-[T k-(T i-T c)]$

(Equation E-1)

Where:

$P=$ Pressure $(\mathrm{kPa})$ from linear calibration curve

$C F=$ Linear calibration factor $(\mathrm{kPa} / \mathrm{B}$ Unit $)$

$L i, L C=$ Initial readings from calibration and current reading ( $B$ units)

$\mathrm{Tk}=$ Temperature correction factor $\left(\mathrm{kPa} /{ }^{\circ} \mathrm{C}\right.$ rise $)$

$T i, T c=$ Initial temperature from calibration and current temperature $\left({ }^{\circ} \mathrm{C}\right)$

The change in sensor depth is calculated by subtracting the pressure readings from the settlement sensor and the accumulator, as shown in equation E-2. Barometric pressure corrections are negligible in the calculations, as the same pressure acts on both the settlement sensor and the accumulator.

$\Delta s d=K *(P r-P s)+Z o$

(Equation E-2)

Where:

$\Delta s d=$ Change in sensor depth $(\mathrm{m})$

$K=0.0953$, Conversion for 50/50 mix of ethylene glycol $/$ water $(\mathrm{m} / \mathrm{kPa})$ 
$\operatorname{Pr}=$ Pressure on the accumulator sensor $(\mathrm{kPa})$

$P s=$ Pressure on the settlement sensor $(k P a)$

$Z o=$ Zero offset $(m)$

The final elevation of the sensor plate is calculated with the values of the initial change in sensor depth and the current change in sensor depth, as shown in the following equation.

$C B E=I E B P-\left(\Delta s d_{\text {tnitlal }}-\Delta s d_{\text {current }}\right)$

Where:

$C B E=$ Current bundle elevation $(m)$

$I E P B=$ Initial elevation of bundle at placement $(\mathrm{m})$

$\Delta s d_{\text {intial }}=$ initial change in sensor depth $(\mathrm{m})$

$\Delta s d_{\text {current }}=$ current change in sensor depth $(\mathrm{m})$

Therefore, the amount of settlement that the sensor plate experiences can be calculated through the following equation.

Settlement $=I E B P-C B E$

(Equation E-4)

Where:

Settlement $=$ Depth at which the sensor plate has settled $(m)$

$C B E=$ Current bundle elevation $(m)$

$I E P B=$ Initial elevation of bundle at placement $(\mathrm{m})$

A positive settlement value calculated through Equation E-4 means that the sensor plate has settled to a lower elevation than what it was originally. If a negative settlement value is calculated, this means that there is some rebound of the waste which is causing the sensor plate to rise. 
Sample Calculation:

To calculate amount of settlement experienced by the instrument bundle, the raw vibrating wire outputs and temperatures from both the settlement sensor and corresponding accumulator are required. The following values were recorded for the settlement sensor at Bundle 2 and the Accumulator 2, from April 12011 at a time of 06:00. These values will be used in the following sample calculation.

\begin{tabular}{|c|c|c|c|c|}
\hline Timestamp & $\begin{array}{c}\text { Bundle 2 } \\
\text { Output } \\
\text { (B unit) }\end{array}$ & $\begin{array}{c}\text { Bundle 2 } \\
\text { Temperature } \\
\left({ }^{\circ} \mathrm{C}\right)\end{array}$ & $\begin{array}{c}\text { Accumulator 2 } \\
\text { Output } \\
\text { (B unit) }\end{array}$ & $\begin{array}{c}\text { Accumulator 2 } \\
\text { Temperature } \\
\left({ }^{\circ} \mathrm{C}\right)\end{array}$ \\
\hline $\begin{array}{c}01 / 04 / 2011 \\
6: 00: 00 \mathrm{AM}\end{array}$ & 8002.650 & 6.554 & 9086.938 & 0.993 \\
\hline
\end{tabular}

Additional information required to complete the calculation is provided below.

\begin{tabular}{|l|l|l|l|l|l|l|}
\hline & $\begin{array}{l}\mathrm{CF} \\
(\mathrm{kPa} / \mathrm{B} \\
\text { Unit })\end{array}$ & $\begin{array}{l}\text { Initial } \\
\text { Reading, } \\
(\mathrm{B} \text { units })\end{array}$ & $\begin{array}{l}\mathrm{Tk} \\
\left(\mathrm{kPa} /{ }^{\circ} \mathrm{C}\right. \\
\text { rise })\end{array}$ & $\begin{array}{l}\text { Initial } \\
\text { Temperature } \\
\left({ }^{\circ} \mathrm{C}\right)\end{array}$ & $\begin{array}{l}\mathrm{K} \\
(\mathrm{m} / \mathrm{kPa} \\
)\end{array}$ & $\begin{array}{l}\text { Zo } \\
(\mathrm{m})\end{array}$ \\
\hline Bundle 2 & 0.046518 & 7933.716 & 0.05501 & 6.924 & 0.0953 & 0.577 \\
\hline $\begin{array}{l}\text { Accumulator } \\
2\end{array}$ & 0.042200 & 8318.457 & -0.03442 & 15.890 & N/A & N/A \\
\hline
\end{tabular}

Using Equation E-1, the B unit output from the settlement sensors and accumulators can be converted to a pressure reading with corrections for initial installation readings and temperature.

$P=C F *(L i-L c)-[T k-(T i-T c)]$

$P_{\text {April 1,2011 06:00 Bundle 2 }}=C F *(L i-L c)-[T k-(T i-T c)]$

$P_{\text {April 1,2011 06:00 Bundle } 2}$

$$
=0.046518 *(7933.716-8002.650)-[0.05501 *(6.924-6.554)]
$$

$P_{\text {April 1,2011 06:00 Bundle 2 }}=-3.23 \mathrm{kPa}$ 
Likewise, the pressure reading from Accumulator 2 can be calculated with Equation E-1.

$P=C F *(L i-L c)-[T k-(T i-T c)]$

$P_{\text {April 1,2011 06:00 Accumulator } 2}=C F *(L i-L C)-[T k-(T i-T C)]$

$P_{\text {April 1,2011 06:00 Accumulator } 2}$

$=0.0422 *(8318.457-9086.938)-[-0.03442 *(15.890-0.993)]$

$P_{\text {April 1,2011 06:00 Accumulator } 2}=-3.1 .92 \mathrm{kPa}$

Equation E-2 can now be applied to calculate the change in sensor depth.

$\Delta s d=K *(P r-P s)+Z o$

$\Delta s d_{\text {April 1,2011 06:00 Bundle 2 }}=0.0953 *(-3.1 .92-(-3.23))+0.577$

$\Delta s d_{\text {April 1,2011 06:00 Bundle } 2}=-2.16 \mathrm{~m}$

Upon connection of Bundle 2 on November 12, 2009, the liquid settlement sensor read a change in sensor depth of $-1.929 \mathrm{~m}$. This current reading must be subtracted from the initial reading to give a true representation of the settlement experienced by the bundle. This step is included in Equation E-3, so that the current bundle elevation can be calculated.

$C B E=I E B P-\left(\Delta s d_{\text {initial }}-\Delta s d_{\text {current }}\right)$

$C B E_{\text {April } 1,201106: 00 \text { Bundle } 2}=72.5-(-1.929-(-2.16))$

$C B E_{\text {April 1,2011 06:00 Bundle 2 }}=72.27 \mathrm{~m}$

To see how much the instrument bundle has settled in the waste, in comparison to the initial placement elevation, Equation E-4 can be applied. 
Settlement $=I E B P-C B E$

Settlement $_{\text {April 1,2011 06:00 Bundle 2 }}=72.5-72.27$

Settlement $_{\text {April 1,2011 06:00 Bundle 2 }}=0.23 \mathrm{~m}$

Therefore, these calculations indicate that from the time of connection to the datalogger for Bundle 2 on November 9, 2009 to April 1, 2011, the instrument bundle has settled $0.23 \mathrm{~m}$.

Records of calibration data were provided with each sensor, and include data pertinent to the completion of these calculations. The calibration sheets are provided in subsequent pages. 


\section{Appendix F - Conversion of Raw Counts to Final Values for VWC}

The moisture sensor measured three quantities: raw volumetric water content, raw electrical conductivity and temperature. The datalogger program completed all required conversions and calculations, thereby eliminating the need for postprocessing. The following equations are incorporated directly in the datalogger program. The volumetric water content (VWC) is based on a measurement of dielectric permittivity. Equation F-1 shows how the raw VWC counts output by the moisture sensor are converted to bulk dielectric permittivity.

$\varepsilon_{b}=\frac{R a w_{V W C}}{50}$

(Equation F-1)

Where:

$\varepsilon_{b}=$ Bulk dielectric permittivity (unitless)

Raw $w_{V C}=$ Raw VWC counts as output by the moisture sensor

The actual VWC is determined from the bulk dielectric permittivity through the following equation.

$V W C=\left(4.3 E-6 * \varepsilon_{b}^{3}\right)-\left(5.5 E-4 * \varepsilon_{b}^{2}\right)+\left(2.92 E-2 * \varepsilon_{b}\right)-(5.3 E-2)$

(Equation F-2)

Where:

$V W C=$ Volumetric moisture content $\left(\mathrm{m} 3 / \mathrm{m}^{3}\right)$

$\varepsilon_{b}=$ Bulk dielectric permittivity (unitless)

For the purposes of data analysis for this thesis, Equation F-2 was simplified by substituting $\varepsilon_{\mathrm{b}}$ for Rawvwc from Equation F-1. 


$$
\begin{aligned}
& V W C=\left(4.3 E-6 * \varepsilon_{b}^{3}\right)-\left(5.5 E-4 * \varepsilon_{b}^{2}\right)+\left(2.92 E-2 * \varepsilon_{b}\right)-(5.3 E-2) \\
& V W C= \\
& \left(4.3 E-6 *\left(\frac{R a w_{V W C}}{50}\right)^{3}\right)-\left(5.5 E-4 *\left(\frac{R a w_{V W C}}{50}\right)^{2}\right)+\left(2.92 E-2 *\left(\frac{R a w_{V W C}}{50}\right)\right)- \\
& (5.3 E-2)
\end{aligned}
$$

(Equation F-3)

Where:

VWC $=$ Volumetric moisture content $\left(\mathrm{m} 3 / \mathrm{m}^{3}\right)$

$\varepsilon_{b}=$ Bulk dielectric permittivity (unitless)

RaW $V w C=$ Raw VWC counts as output by the moisture sensor

The raw electrical conductivity counts output by the moisture sensor were converted to actual values of electrical conductivity through the following equation.

$E C_{b}=\frac{R a w_{E C}}{100}$

Where:

$E C_{b}=$ Bulk electrical conductivity $(\mathrm{d} S / \mathrm{m})$

RawEC $=$ Raw EC counts as output by the moisture sensor

The bulk electrical conductivity can be converted to a pore water electrical conductivity, through a linear relationship if the dielectric permittivity is known, as shown in the following equation.

$E C_{p}=\frac{\varepsilon_{p} * E C_{b}}{\varepsilon_{b}-\varepsilon_{d s}}$

(Equation F-4)

Where:

$E C_{p}=$ Pore water electrical conductivity $(\mathrm{d} S / \mathrm{m})$

$E C_{b}=$ Bulk electrical conductivity $(d S / m)$

$\varepsilon_{p}=$ Pore water dielectric permittivity (unitless)

$\varepsilon_{b}=$ Bulk dielectric permittivity (unitless)

$\varepsilon_{d s}=$ Dielectric permittivity of dry soil, approximated as 5 (unitless) 
The pore water dielectric permittivity from Equation F-4 can be calculated through the following equation, dependent on temperature.

$\varepsilon_{p}=80.3-0.37 * T_{\text {soil }}-20$

(Equation F-5)

Where:

$\varepsilon_{p}=$ Pore water dielectric permittivity (unitless)

$T_{\text {soll }}=$ Soil temperature, measured by sensor $\left({ }^{\circ} \mathrm{C}\right)$ 


\section{Appendix G -Moisture Content and Sensor Tests}

Table G-1: Details from Laboratory Analysis of Moisture Content from Bundles 5 and 6 Sand Samples from November 2, 2010.

\begin{tabular}{|l|r|r|r|r|}
\hline \multicolumn{5}{|c|}{ Bundle 5 (Layer 3_Bundle1) } \\
\hline Sample \# & 1 & 2 & 3 & 4 \\
\hline $\begin{array}{l}\text { Sample } \\
\text { Volume } \\
\text { (mL) }\end{array}$ & 2.5 & 2.5 & 2.5 & 2.5 \\
\hline $\begin{array}{l}\text { Weight of } \\
\text { Wet Sand } \\
\text { (g) }\end{array}$ & & & & \\
\hline $\begin{array}{l}\text { Weight of } \\
\text { Dry Sand (g) }\end{array}$ & 2.91 & 2.8 & 2.46 & 3.33 \\
\hline $\begin{array}{l}\text { Volume of } \\
\text { Water (mL) }\end{array}$ & 0.72 & 0.7 & 0.56 & 0.75 \\
\hline $\begin{array}{l}\text { VWC } \\
\text { (=Vw/Vt) }\end{array}$ & 0.29 & 0.28 & 0.22 & 0.3 \\
\hline $\begin{array}{l}\text { Avg VWC } \\
\text { (\%) }\end{array}$ & 27.4 & & & \\
\cline { 1 - 5 }
\end{tabular}

\begin{tabular}{|l|r|r|r|r|}
\hline \multicolumn{5}{|c|}{ Bundle 6 (Layer 3_Bundle2) } \\
\hline $\begin{array}{l}\text { Sample \# } \\
\begin{array}{l}\text { Vample } \\
\text { (mL) }\end{array}\end{array}$ & 1 & 2 & 3 & 4 \\
\hline $\begin{array}{l}\text { Weight of } \\
\text { Wet Sand } \\
\text { (g) }\end{array}$ & 2.5 & 2.5 & 2.5 & 2.5 \\
\hline $\begin{array}{l}\text { Weight of } \\
\text { Dry Sand (g) }\end{array}$ & 2.84 & 3.03 & 3.36 & 3.19 \\
\hline $\begin{array}{l}\text { Volume of } \\
\text { Water (mL) }\end{array}$ & 0.6 & 0.64 & 0.72 & 0.64 \\
\hline $\begin{array}{l}\text { VWC } \\
\text { (=Vw/Vt) }\end{array}$ & 0.24 & 0.26 & 0.29 & 0.26 \\
\hline $\begin{array}{l}\text { Avg VWC } \\
\text { (\%) }\end{array}$ & 26.1 & & & \\
\hline
\end{tabular}


Table G- 2: Summary of Moisture Sensor Testing in Sand with Water

\begin{tabular}{|c|c|c|c|c|c|}
\hline $\begin{array}{c}\text { Volume Soil } \\
(\mathrm{mL})\end{array}$ & $\begin{array}{c}\text { Volume } \\
\text { Water }(\mathrm{mL})\end{array}$ & $\begin{array}{c}\text { Theoretical } \\
\text { VWC }\end{array}$ & $\begin{array}{c}\text { Sensor 1 } \\
\text { VWC }\end{array}$ & $\begin{array}{c}\text { Sensor 2 } \\
\text { VWC }\end{array}$ & $\begin{array}{c}\text { Average } \\
\text { VWC }\end{array}$ \\
\hline 1500 & 0 & 0.00 & 0.06 & 0.06 & 0.060 \\
\hline 1500 & 75 & 0.05 & 0.09 & 0.09 & 0.090 \\
\hline 1500 & 150 & 0.10 & 0.13 & 0.14 & 0.135 \\
\hline 1500 & 225 & 0.15 & 0.16 & 0.17 & 0.165 \\
\hline 1500 & 300 & 0.20 & 0.20 & 0.21 & 0.205 \\
\hline 1500 & 375 & 0.25 & 0.25 & 0.26 & 0.255 \\
\hline 1500 & 450 & 0.30 & 0.27 & 0.27 & 0.270 \\
\hline 1500 & 525 & 0.35 & 0.28 & 0.29 & 0.285 \\
\hline 1500 & 600 & 0.40 & 0.28 & 0.30 & 0.290 \\
\hline
\end{tabular}

Table G- 3: Summary of Moisture Sensor Testing in Sand with Water and Salt

\begin{tabular}{|c|c|c|c|c|c|c|c|c|c|}
\hline $\begin{array}{l}\text { Volume } \\
\text { Soil }(\mathrm{mL})\end{array}$ & $\begin{array}{c}\text { Volume Water } \\
\text { (mL) }\end{array}$ & $\begin{array}{c}\text { Theoretical } \\
\text { VWC }\end{array}$ & $\begin{array}{c}\text { Mass Salt } \\
\text { (g) }\end{array}$ & $\begin{array}{l}\text { Sensor } \\
1 \mathrm{VWC}\end{array}$ & $\begin{array}{c}\text { Sensor } \\
1 \mathrm{EC} \\
(\mathrm{dS} / \mathrm{m})\end{array}$ & $\begin{array}{l}\text { Sensor } \\
2 \text { VWC }\end{array}$ & $\begin{array}{c}\text { Sensor } \\
2 \mathrm{EC} \\
(\mathrm{d} S / \mathrm{m})\end{array}$ & $\begin{array}{c}\text { Average } \\
\text { VWC }\end{array}$ & $\begin{array}{c}\text { Average } \\
\text { EC } \\
\text { (dS/m) }\end{array}$ \\
\hline 600 & 210 & 0.35 & 0.0 & 0.31 & 30 & 0.31 & 31 & 0.310 & 30.5 \\
\hline 600 & 210 & 0.35 & 1.0 & 0.34 & 210 & 0.34 & 211 & 0.340 & 210.5 \\
\hline 600 & 210 & 0.35 & 1.5 & 0.40 & 404 & 0.41 & 246 & 0.405 & 325.0 \\
\hline 600 & 210 & 0.35 & 2.0 & 0.50 & 524 & 0.54 & 482 & 0.520 & 503.0 \\
\hline 600 & 210 & 0.35 & 3.0 & 0.76 & 491 & 0.70 & 452 & 0.730 & 471.5 \\
\hline 600 & 210 & 0.35 & 4.0 & 0.85 & 706 & 0.68 & 472 & 0.765 & 589.0 \\
\hline 600 & 210 & 0.35 & 12.0 & 1.01 & 2417 & 1.01 & 931 & 1.010 & 1674.0 \\
\hline
\end{tabular}




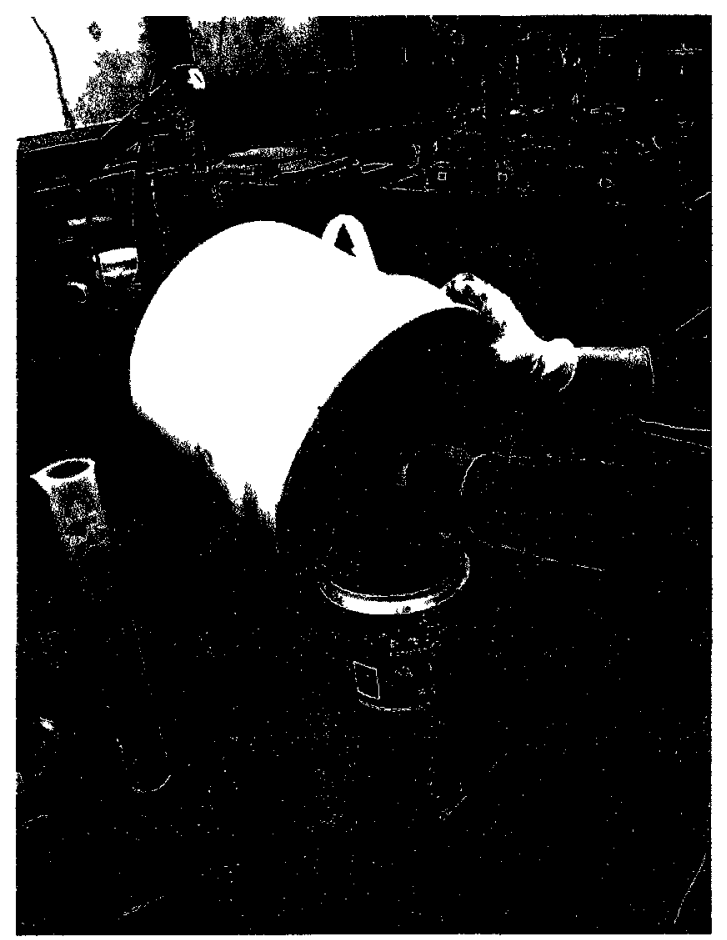

Figure G- 1: Pouring the mixture of sand and water into the bucket which will hold the moisture sensor.

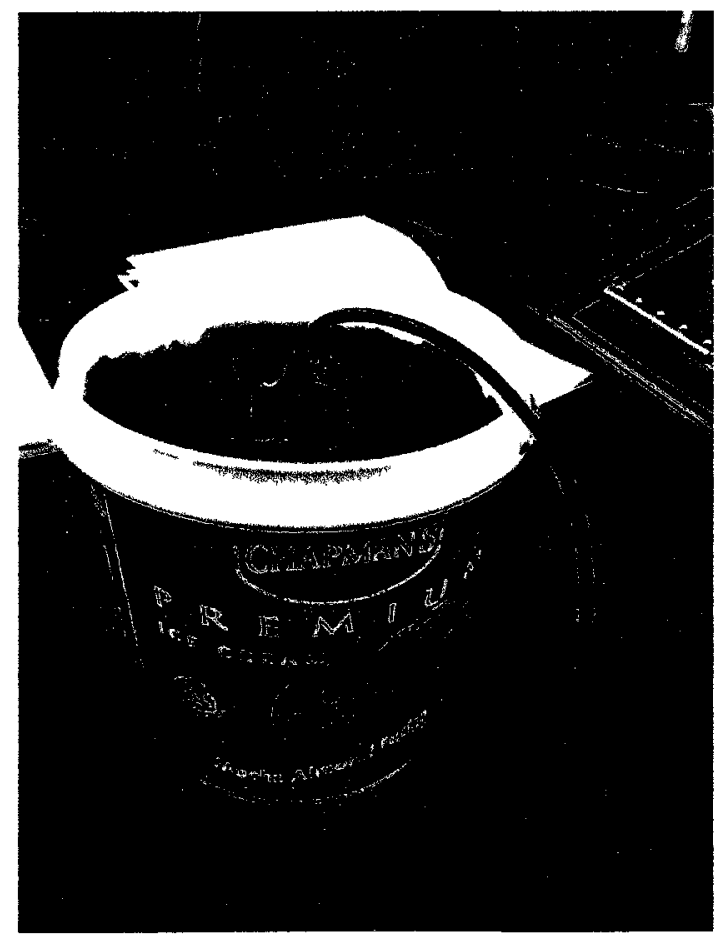

Figure G- 3: Moisture Sensor in sand with minimal moisture. 


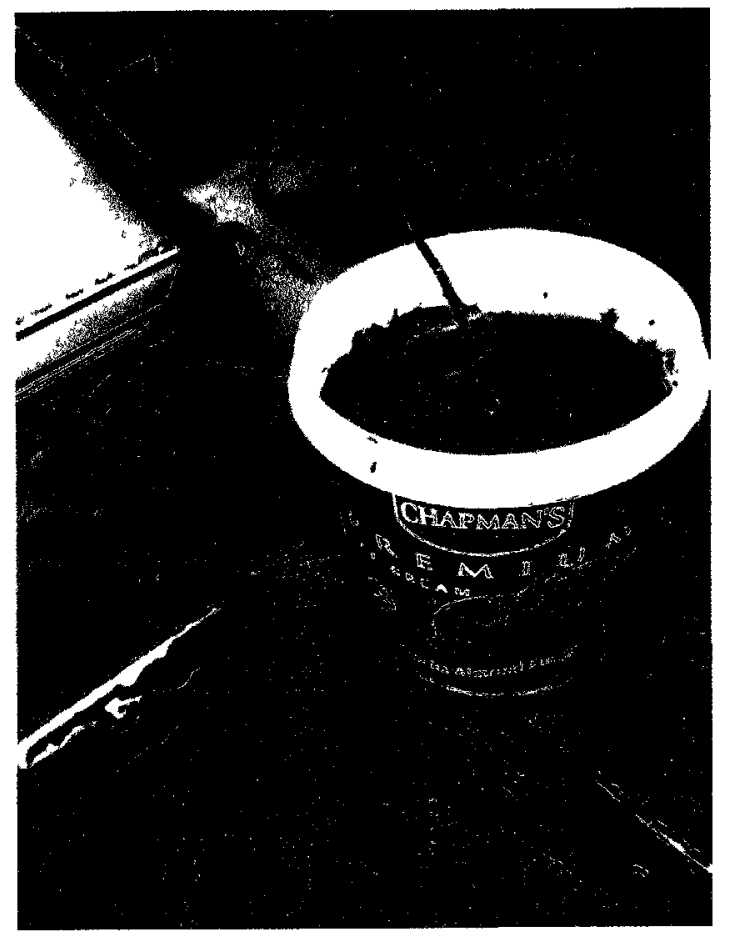

Figure G-3: Moisture Sensor in saturated sand.

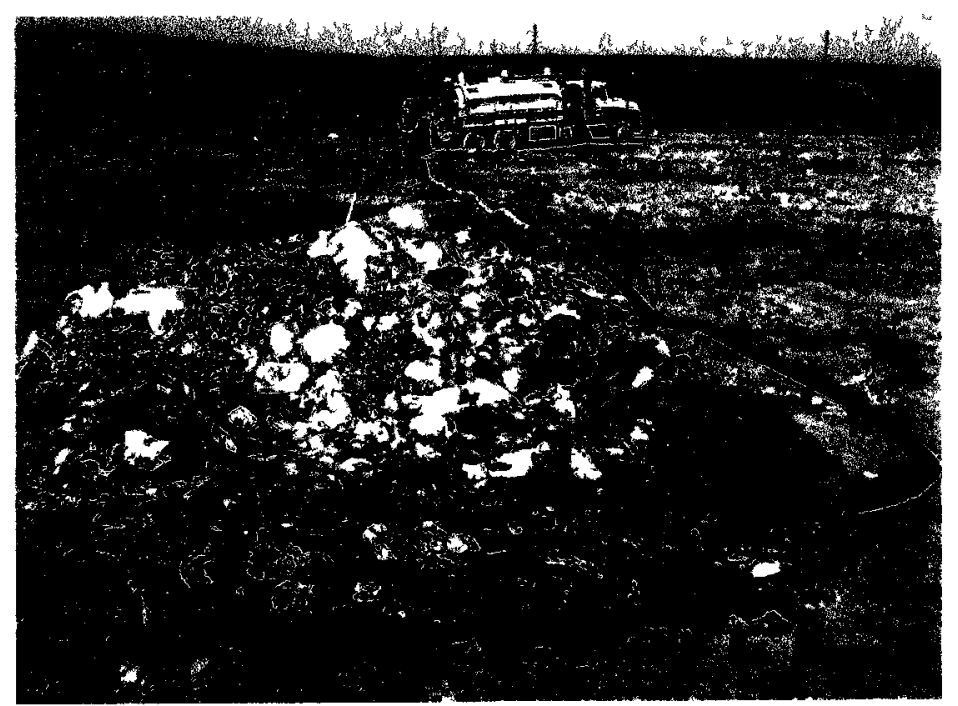

Figure G-4: Leachate addition over Bundles 2 and 4. 


\section{Appendix H - Calibration Details and Example Calculation for Oxygen Sensor}

The oxygen sensor produced a resistance output in $\mathrm{mV}$ and temperature readings in degrees Celsius. The raw $\mathrm{mV}$ outputs from the oxygen sensor required corrections for temperature in order to determine pressure.

The calibration factor multiplier is calculated for each sensor using the initial $\mathrm{mV}$ output at installation, as shown in the following equation.

O2_m $\left(\% \frac{O 2}{m V}\right)=\frac{20.95}{\text { Raw_mV-zero offset }}$

Where:

O2_ $m=$ Calibration factor multiplier for $m V(\% 02 / \mathrm{mV})$

Raw_ $m V=m V$ output from the sensor from installation $(\mathrm{mV})$

Zero Offset = Zero offset from the sensor, approximated as $2.5 \mathrm{mV}(\mathrm{mV})$

The intermediate temperature calibration factor was calculated for each sensor using the initial temperature at installation and three constants given for the soil, as shown in the following equation.

$O C_{-} 0=-\left(O C_{-} 3 * T c^{3}+O C_{-} 2 * T c^{2}+O C_{-} 1 * T c\right)$

(Equation $\mathrm{H}-2$ )

Where:

$O C_{-} 0=$ Intermediate temperature calibration factor

OC_ $3=$ Constant for the soil, $-4.333 E-6$

$O C_{-} 2=$ Constant for the soil, 0.001896

$O C_{-} 1=$ Constant for the soil, -0.03610

Tc = Initial temperature reading at installation $\left({ }^{\circ} \mathrm{C}\right)$ 
An initial conversion of the $\mathrm{mV}$ output to percent oxygen was calculated through the following equation.

$O 2_{\text {tnitıal }}=\left(R a w_{-} m V-\right.$ Zero Offset $) * 02_{-} m$

Where:

$O 2_{\text {mitial }}=$ Initial oxygen content with correction from $m V$ reading (\% O2)

Raw $m V=m V$ output from the sensor $(\mathrm{mV})$

Zero Offset = zero offset from the sensor, approximated as $2.5 \mathrm{mV}(\mathrm{mV})$

O2_ $m=$ Calibration factor multiplier for $\mathrm{mV}(\% 02 / \mathrm{mV})$

The intermediate temperature calibration factor was then included in the following equation with the initial oxygen content, to determine the true percent oxygen.

$O 2_{\text {final }}=$

(Equation $\mathrm{H}-4$ )

$O 2_{\text {lnitıal }}+\left(O C_{-} 3 * O 2_{-} T e m p^{3}+O C_{-} 2 * O 2_{-} T e m p^{2}+O C_{-} 1 * O 2_{-} T e m p+O C_{-} 0\right)$

Where:

$O 2_{\text {final }}=$ Final oxygen content $(\%$ O2)

$O 2_{\text {Inttal }}=$ Initial oxygen content with correction from $\mathrm{mV}$ reading (\% O2)

$O C_{-} O=$ Intermediate temperature calibration factor

$O C_{-} 3=$ Constant for the soil, $-4.333 E-6$

$O C_{-} 2=$ Constant for the soil, 0.001896

$O C_{-} 1=$ Constant for the soil, -0.03610

O2_Temp $=$ Temperature reading from the oxygen sensor $\left({ }^{\circ} \mathrm{C}\right)$ 


\section{Sample Calculation:}

To calculate the percent oxygen within the pore space of the waste in the landfill, the oxygen sensor measured a resistance output in $\mathrm{mV}$ and a temperature in degrees Celsius. The following values were recorded for the oxygen sensor at Bundle 2, from February 12010 at a time of 06:00. These values will be used in the following sample calculation.

\begin{tabular}{|c|c|c|}
\hline Timestamp & $\begin{array}{c}\text { Bundle 2 Oxygen Sensor } \\
\text { Output } \\
(\mathrm{mV})\end{array}$ & $\begin{array}{c}\text { Bundle 2 Oxygen Sensor } \\
\text { Temperature } \\
\left({ }^{\circ} \mathrm{C}\right)\end{array}$ \\
\hline $01 / 02 / 20106: 00: 00 \mathrm{AM}$ & 21.73 & 1.882 \\
\hline
\end{tabular}

Additional information required to complete the calculation is provided below.

\begin{tabular}{|l|l|l|l|l|l|l|}
\hline & $\begin{array}{l}\text { Initial } \\
\text { Reading } \\
\text { at Installation } \\
(\mathrm{mV})\end{array}$ & $\begin{array}{l}\text { Zero } \\
\text { Offset } \\
(\mathrm{mV})\end{array}$ & $\begin{array}{l}\text { Initial } \\
\text { Temperature } \\
\text { at } \\
\text { Installation } \\
\left({ }^{\circ} \mathrm{C}\right)\end{array}$ & $\begin{array}{ll} & \\
\text { OC_3 }\end{array}$ & OC_2 & OC_1 \\
\hline Bundle 2 & 55.19 & 2.5 & 13.09 & $\begin{array}{l}-4.333 \mathrm{E}- \\
6\end{array}$ & 0.001896 & -0.03610 \\
\hline
\end{tabular}

Using Equation $\mathrm{H}-1$, the calibration factor multiplier was calculated for each sensor as shown in the following equation.

$$
\begin{aligned}
& \text { O2_m }=\frac{20.95}{\text { Raw_mV-Zero } \text { Offset }} \\
& O 2 \_m=\frac{20.95}{55.19-2.5} \\
& O 2_{m}=0.3976 \% 02 / \mathrm{mV}
\end{aligned}
$$


The intermediate temperature calibration factor was then calculated using Equation $\mathrm{H}-2$.

$O C_{-} 0=-\left(O C_{-} 3 * T C^{3}+O C_{-} 2 * T c^{2}+O C_{-} 1 * T C\right)$

$\left.O C_{-} 0=-\left(-4.333 E-6 * 13.09^{3}+0.001896 * 13.09^{2}+(-0.03610) * 13.09\right)\right)$

$O C_{-} 0=0.1574$

Equation $\mathrm{H}-3$ was then used for the first correction, of the calibration factor multiplier, to the raw $\mathrm{mV}$ outputs from the oxygen sensor, to establish an initial reading of percent oxygen.

$02_{\text {initial }}=\left(\right.$ Raw $_{m V}-$ Zero Offset $) * O 2_{m}$

$O 2_{\text {initial }}=(21.73-2.5) * 0.3976$

$02_{\text {initial }}=7.6458 \% 02$

Finally, the true value of percent oxygen was calculated as the intermediate temperature calibration factor was then included, with Equation $\mathrm{H}-4$.

$O 2_{\text {final }}=$

$O 2_{\text {initial }}+\left(O C_{-} 3 * O 2_{-} T e m p^{3}+O C_{-} 2 * O 2_{-} T e m p^{2}+O C_{-} 1 * O 2_{-} T e m p+O C_{-} 0\right)$

$O 2_{\text {final }}=$

$7.6458+\left(-4.333 E-6 * 1.882^{3}+0.001896 * 1.882^{2}+(-0.03610) * 1.882+\right.$ $0.1574)$

$O 2_{\text {final }}=7.74 \% O 2$ 
Therefore, the final value of oxygen content in the pore space of the waste on February 1,2010 is $7.74 \%$.

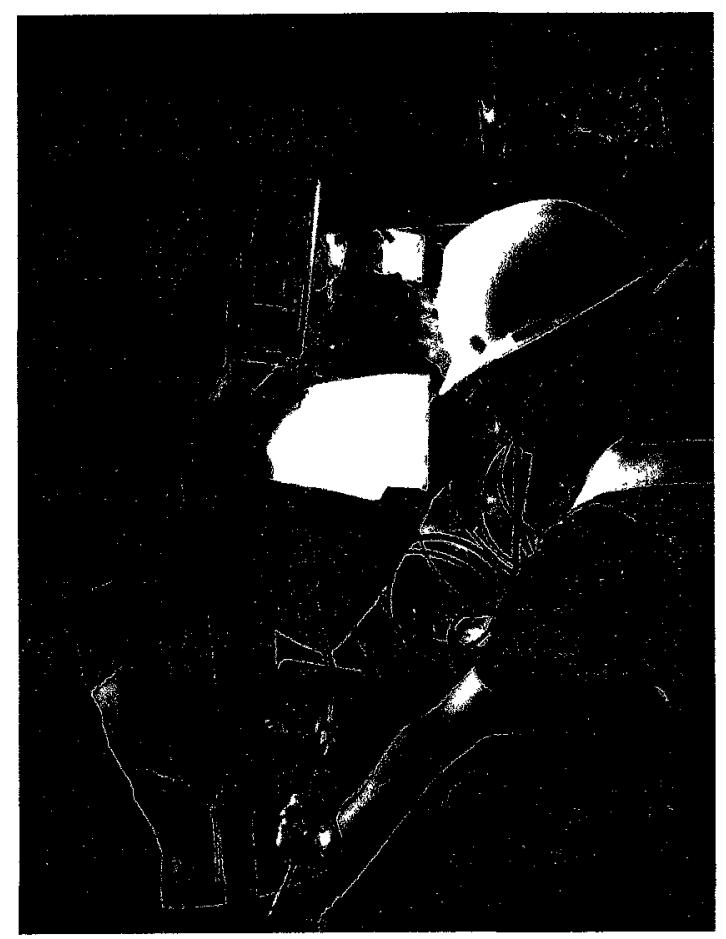

Figure H- 1: Using a bicycle pump to deliver oxygen to Bundle 5 through the empty flexible tubes. 


\section{Appendix I - Calibration Details and Example Calculation for Vibrating Wire Piezometer}

The vibrating wire piezometer produced vibrating wire outputs in B units and temperature readings in degrees Celsius. The $\mathrm{B}$ unit outputs are related to frequency as seen through the Equation D-1.

The raw $B$ unit outputs from the vibrating wire piezometer were converted to pressure with corrections for initial calibration readings, temperature and barometric pressure, through the following equation:

$P=C F *(L i-L c)-[T k *(T i-T c)]+(B i-B c)$

(Equation I-1)

Where:

$P=$ Pressure $(\mathrm{kPa})$ from linear calibration curve

$C F=$ Linear calibration factor $(\mathrm{kPa} / \mathrm{B}$ Unit $)$

$L i, L C=$ Initial readings from calibration and current reading ( $B$ units)

$T k=$ Temperature correction factor $\left(\mathrm{kPa} /{ }^{\circ} \mathrm{C}\right.$ rise $)$

$T i, T c=$ Initial temperature from calibration and current temperature $\left({ }^{\circ} \mathrm{C}\right)$

$B i, B C=$ Initial readings from calibration and current barometric pressure $(\mathrm{kPa})$

Barometric pressures were obtained from obtained from Environment Canada's weather station at the Pierre Elliot Trudeau International Airport, Montreal, Quebec (45.46692N, 73.75020W). In February 2011, a barometer was installed in the instrument shed at the Sainte-Sophie bioreactor landfill. From then on, the barometric pressure corrections for the piezometer used the barometer readings from on-site. 
The pressure measured by the vibrating wire piezometer is related to the height of the water column present over the instrument and which is responsible for enacting pressure on the piezometer. The conversion of pressure to height of water used the approximation that $10.3 \mathrm{~m}$ of water corresponds to $101.1 \mathrm{kPa}$. The conversion is displayed in the equation below.

$H=P * \frac{10.3 m H 20}{101.1 k P a}$

(Equation I-2)

Where:

$H=$ height of water $(m)$

$P=$ Pressure calculated from piezometer $(\mathrm{kPa})$

\section{Sample Calculation:}

To calculate the pressure exerted on the instrument bundle, the raw vibrating wire outputs from the vibrating wire piezometer were required. In addition, barometric pressure was required and obtained from either Environment Canada's weather station, from November 9, 2009 to February 16, 2011, or from the barometer installed in the instrument shed on-site, after February 16, 2011. The following values were recorded for the vibrating wire piezometer at Bundle 4, from March 5 2011 at a time of 6:00. These values will be used in the following sample calculation.

\begin{tabular}{|c|c|c|c|}
\hline Timestamp & $\begin{array}{c}\text { Bundle 4 } \\
\text { Piezometer Output } \\
\text { (B Units) }\end{array}$ & $\begin{array}{c}\text { Bundle 4 } \\
\text { Piezometer } \\
\text { Temperature } \\
\left({ }^{\circ} \mathrm{C}\right)\end{array}$ & $\begin{array}{c}\text { On-site Barometer } \\
\text { (kPa) }\end{array}$ \\
\hline $\begin{array}{c}05 / 03 / 2011 \\
6: 00: 00 \mathrm{PM}\end{array}$ & 8744.123 & -2.007 & 101.13 \\
\hline
\end{tabular}


Additional information required to complete the calculation is provided below.

\begin{tabular}{|l|l|l|l|l|l|}
\hline & $\begin{array}{l}\mathrm{CF} \\
(\mathrm{kPa} / \mathrm{B} \\
\text { Unit })\end{array}$ & $\begin{array}{l}\text { Initial } \\
\text { Reading } \\
(\mathrm{B} \text { Units })\end{array}$ & $\begin{array}{l}\mathrm{Tk} \\
\left({ }^{\circ} \mathrm{C} / \mathrm{B} \text { Unit }\right)\end{array}$ & $\begin{array}{l}\text { Initial } \\
\text { Temperature } \\
\left({ }^{\circ} \mathrm{C}\right)\end{array}$ & $\begin{array}{l}\text { Initial } \\
\text { Barometric } \\
\text { Pressure } \\
(\mathrm{kPa})\end{array}$ \\
\hline $\begin{array}{l}\text { Bundle } \\
4\end{array}$ & 0.12147 & 8748.200 & -0.0730 & -1.871 & 101.37 \\
\hline
\end{tabular}

Using Equation I-1, the B unit output from the vibrating wire piezometer went through corrections for initial installation readings, temperature, and barometric pressure to calculate a pressure reading.

$P=C F *(L i-L c)-[T k *(T i-T c)]+(B i-B c)$

$P_{\text {March 5,2011 18:00 Bundle } 4}$

$$
\begin{aligned}
& =0.12147 *(8748.200-8744.123)-[-0.0730 \\
& *(-1.871-(-2.007))]+(101.37-101.13)
\end{aligned}
$$

$P_{\text {March 5,2011 18:00 Bundle 4 }}=0.495-(-0.009928)+0.24$

$P_{\text {March 5,2011 18:00 Bundle 4 }}=0.74 \mathrm{kPa}$

To convert the pressure measured by the vibrating wire piezometer to the height of water present over the instrument bundle, Equation I-2 was applied.

$$
\begin{aligned}
H & =P * \frac{10.3 \mathrm{mH} 20}{101.1 \mathrm{kPa}} \\
H & =0.74 \mathrm{kPa} * \frac{10.3 \mathrm{~m} \mathrm{H} 20}{101.1 \mathrm{kPa}} \\
H & =0.076 \mathrm{mH} 20
\end{aligned}
$$


The sample calculation shows that a positive pressure acted upon the piezometer at Bundle 4 . The positive pressure was related to $0.076 \mathrm{~m}$, of water accumulated over the instrument bundle. A negative pressure would relate to a height of water of $0 \mathrm{~m}$. Records of calibration data were provided with each sensor, and include data pertinent to the completion of these calculations. The calibration sheets are provided in subsequent pages. 